\title{
1 Policy, Financing and Implementation
}

\section{Coordinating Lead Authors:}

Catherine Mitchell (United Kingdom), Janet L. Sawin (USA), Govind R. Pokharel (Nepal), Daniel Kammen (USA), Zhongying Wang (China)

\section{Lead Authors:}

Solomone Fifita (Fiji/Tonga), Mark Jaccard (Canada), Ole Langniss (Germany), Hugo Lucas (United Arab Emirates/Spain), Alain Nadai (France), Ramiro Trujillo Blanco (Bolivia), Eric Usher (Sweden/Canada), Aviel Verbruggen (Belgium), Rolf Wüstenhagen (Switzerland/Germany), Kaoru Yamaguchi (Japan)

\section{Contributing Authors:}

Douglas Arent (USA), Greg Arrowsmith (Belguim/United Kingdom), Morgan Bazilian (Austria/USA), Lori Bird (USA), Thomas Boermans (Germany), Alex Bowen (United Kingdom), Sylvia Breukers (The Netherlands), Thomas Bruckner (Germany), Sebastian Busch (Austria/Germany), Elisabeth Clemens (Norway), Peter Connor (United Kingdom), Felix Creutzig (Germany), Peter Droege (Liechtenstein/Germany), Karin Ericsson (Sweden), Chris Greacen (USA), Renata Grisoli (Brazil), Erik Haites (Canada),

Kirsty Hamilton (United Kingdom), Jochen Harnisch (Germany),

Cameron Hepburn (United Kingdom), Suzanne Hunt (USA), Matthias Kalkuhl (Germany), Heleen de Koninck (Netherlands), Patrick Lamers (Germany), Birger Madsen (Denmark), Gregory Nemet (USA), Lars J. Nilsson (Sweden), Supachai Panitchpakdi (Switzerland/Thailand), David Popp (USA), Anis Radzi (Liechtenstein/Australia), Gustav Resch (Austria),

Sven Schimschar (Germany), Kristin Seyboth (Germany/USA),

Sergio Trindade (USA/Brazil and USA), Bernhard Truffer (Switzerland), Sarah Truitt (USA), Dan van der Horst (United Kingdom/The Netherlands), Saskia Vermeylen (United Kingdom), Charles Wilson (United Kingdom), Ryan Wiser (USA)

\section{Review Editors:}

David de Jager (The Netherlands), Antonina Ivanova Boncheva (Mexico/Bulgaria)

This chapter should be cited as:

Mitchell, C., J. L. Sawin, G. R. Pokharel, D. Kammen, Z. Wang, S. Fifita, M. Jaccard, O. Langniss, H. Lucas, A. Nadai, R. Trujillo Blanco, E. Usher, A. Verbruggen, R. Wüstenhagen, K. Yamaguchi, 2011: Policy, Financing and Implementation. In IPCC Special Report on Renewable Energy Sources and Climate Change Mitigation [O. Edenhofer, R. Pichs-Madruga, Y. Sokona, K. Seyboth, P. Matschoss, S. Kadner, T. Zwickel, P. Eickemeier, G. Hansen, S. Schlömer, C. von Stechow (eds)], Cambridge University Press, Cambridge, United Kingdom and New York, NY, USA. 


\section{Table of Contents}

11.1 Introduction

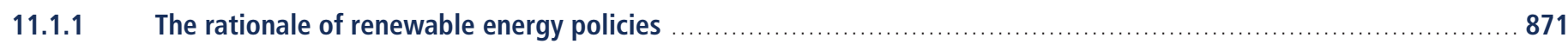

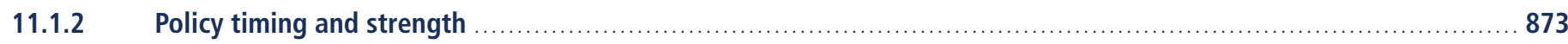

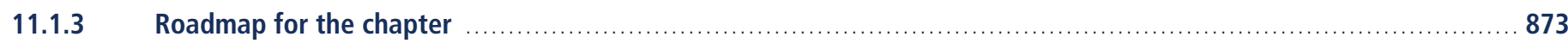

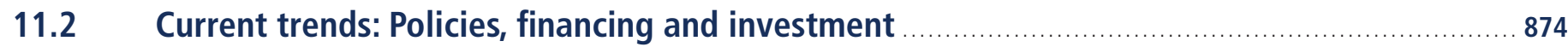

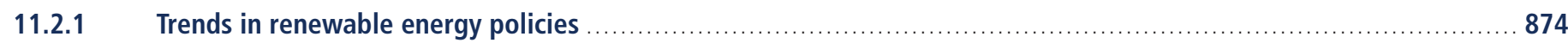

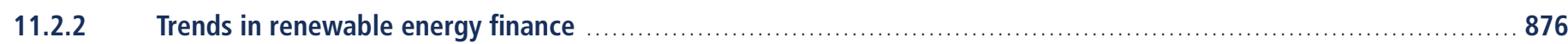

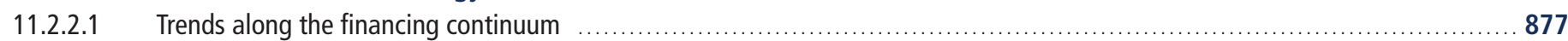

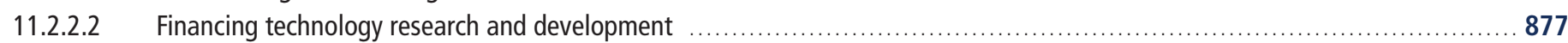

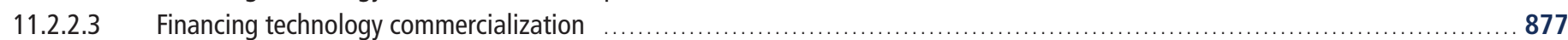

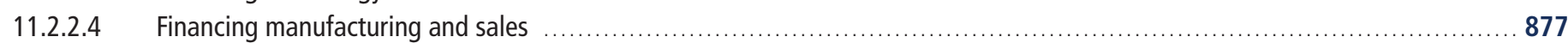

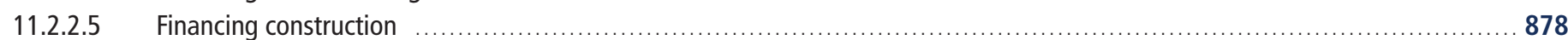

11.2.2.6 Refinancing and sale of companies

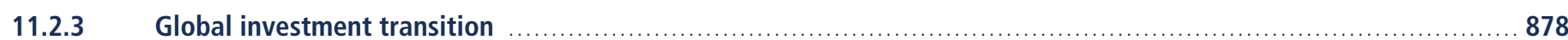

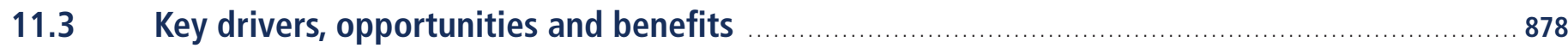

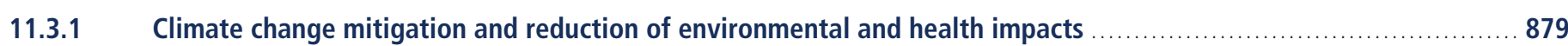

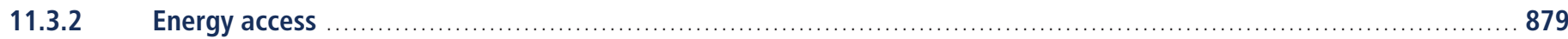

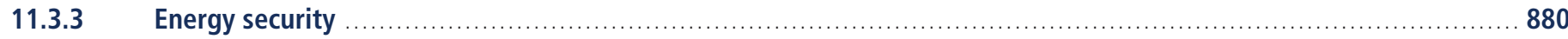

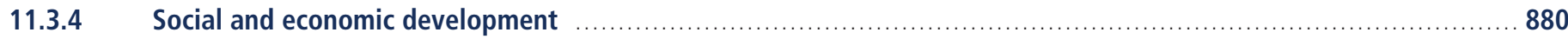

11.4 Barriers to renewable energy policymaking, implementation and financing …...................8 880

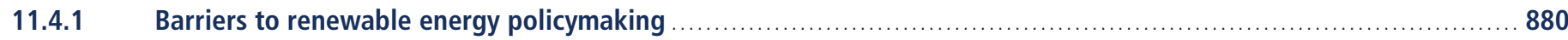

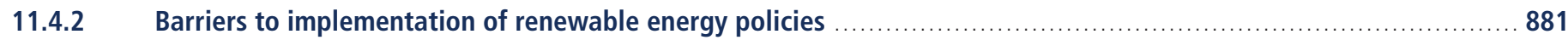

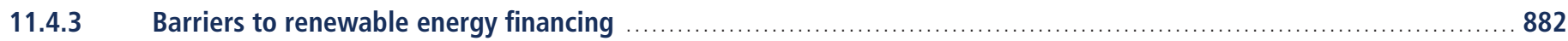




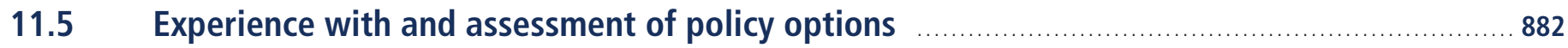

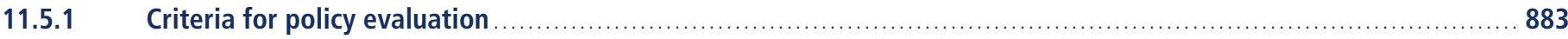

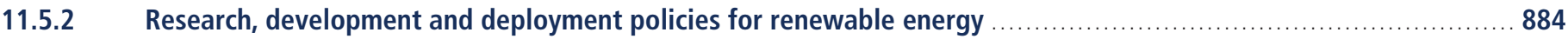

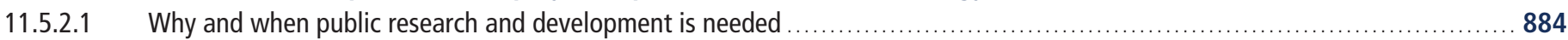

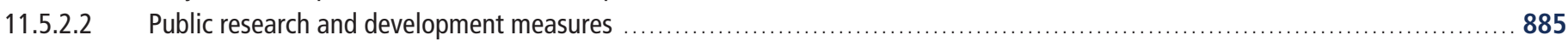

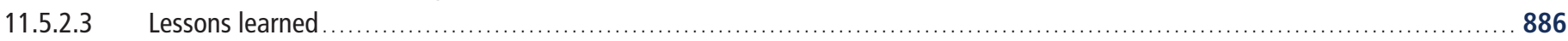

11.5.2.4 Positive feedbacks from combining research and development policies with deployment policies _...........................888

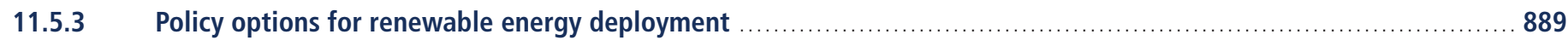

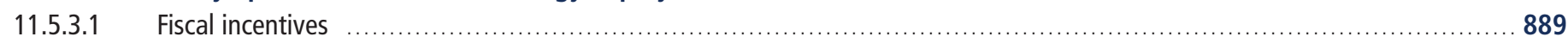

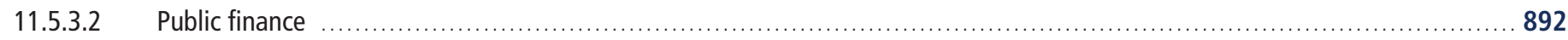

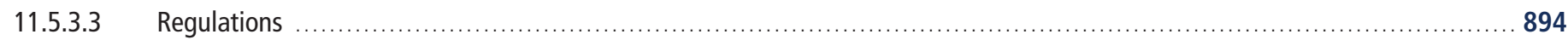

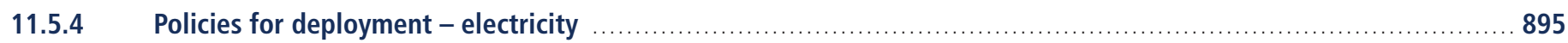

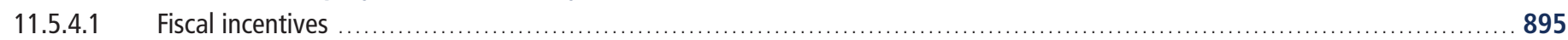

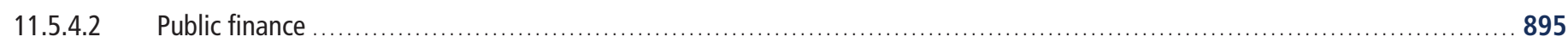

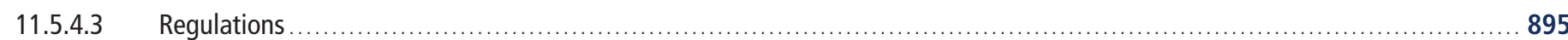

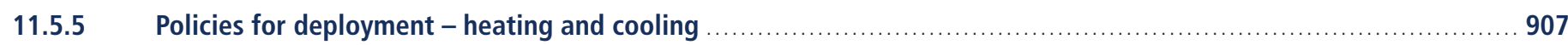

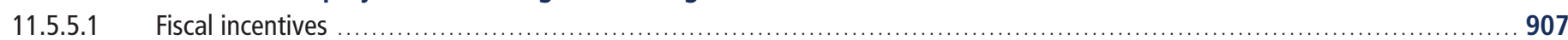

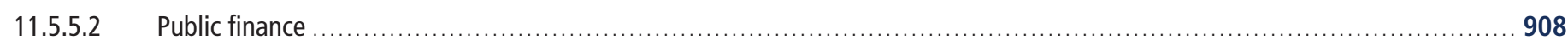

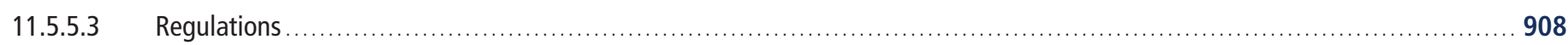

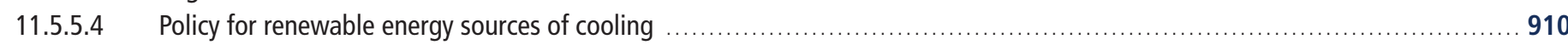

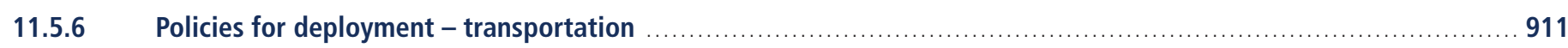

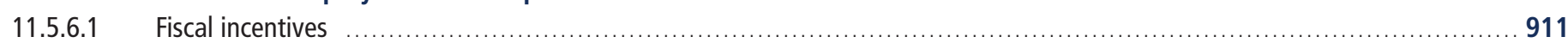

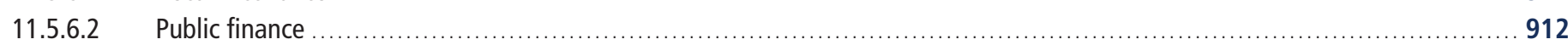

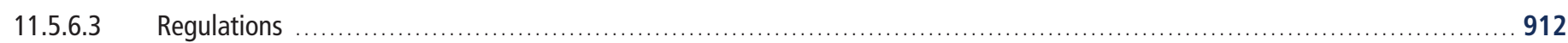

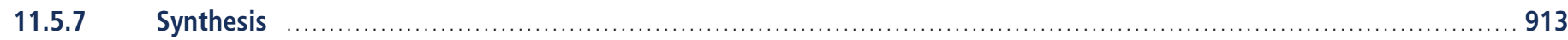

11.5.7.1 Assessment of RE policies . . . .

11.5.7.2 Macroeconomic impacts and cost-benefit analysis . .

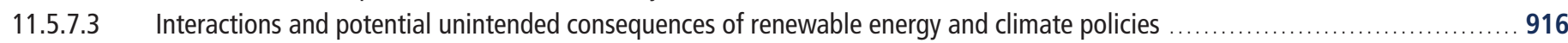

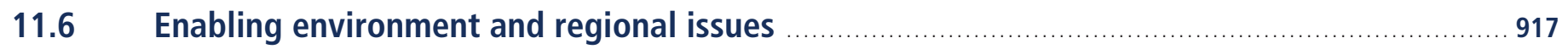

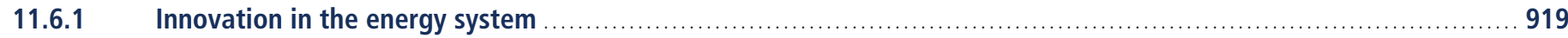

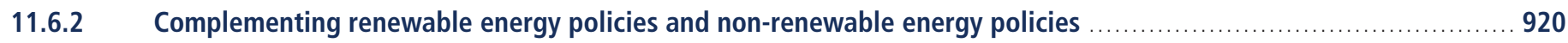

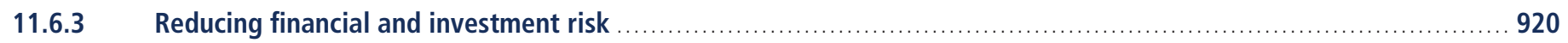




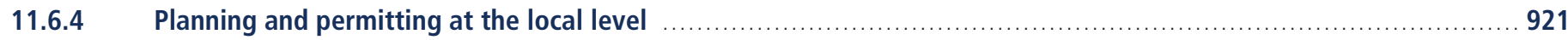

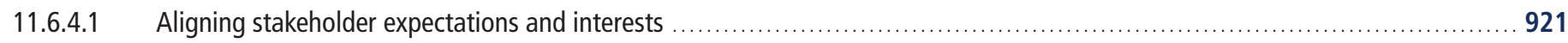

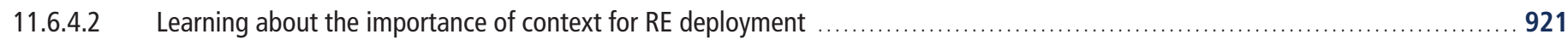

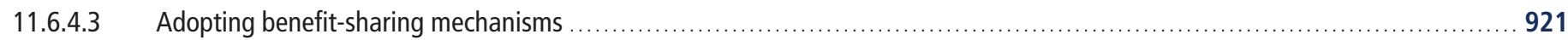

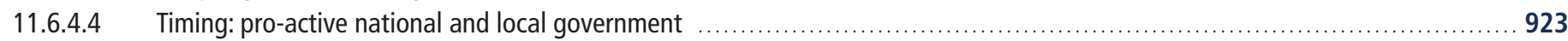

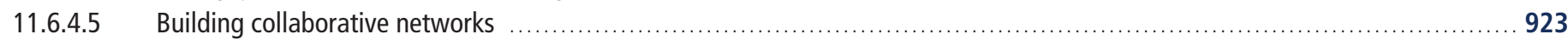

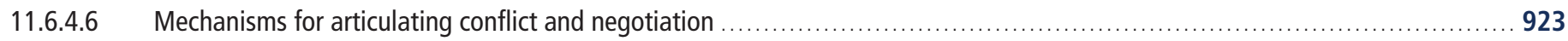

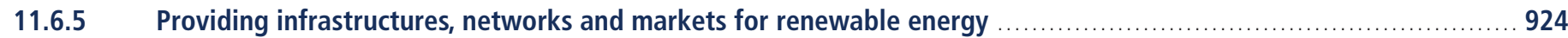

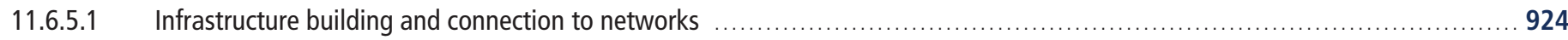

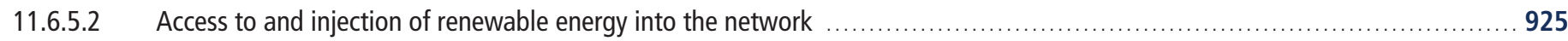

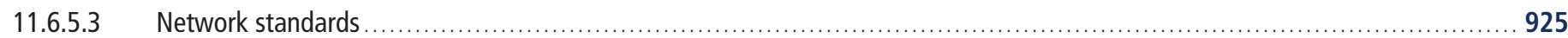

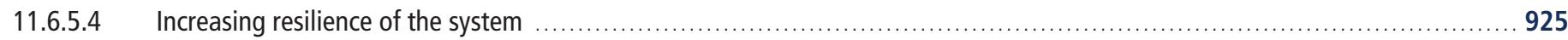

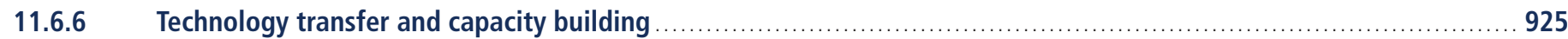

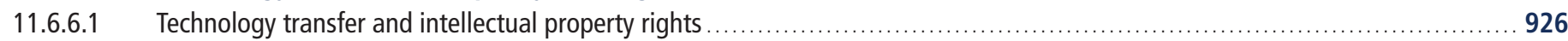

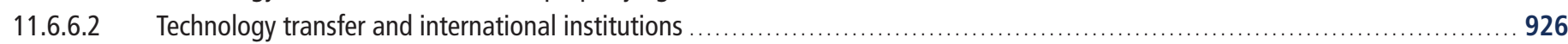

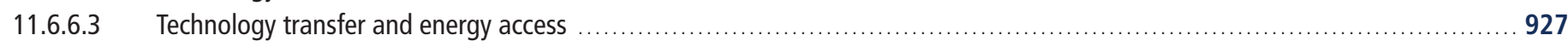

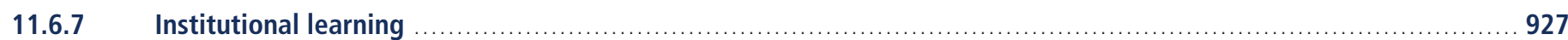

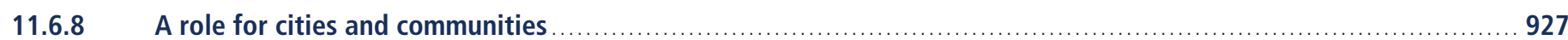

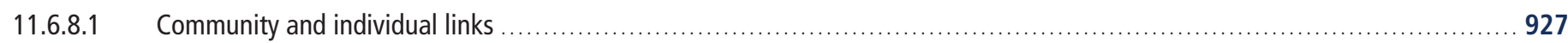

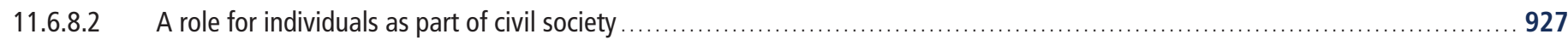

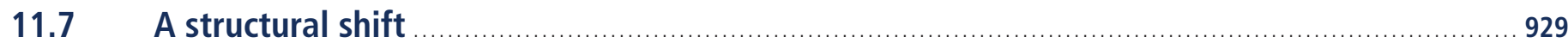

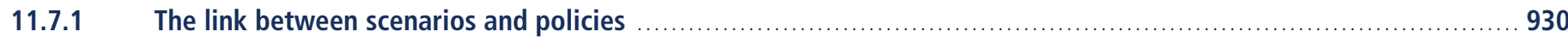

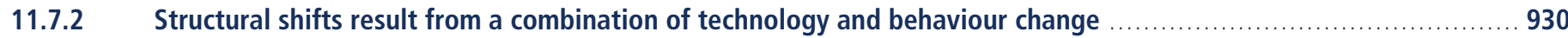

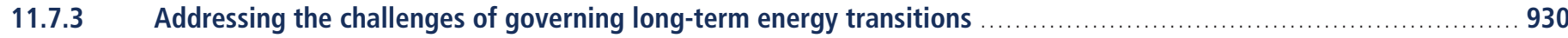

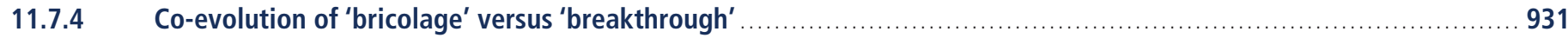

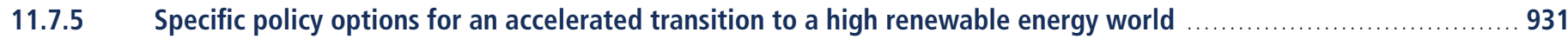

References 


\section{Executive Summary}

Renewable energy can provide a host of benefits to society. In addition to the reduction of carbon dioxide $\left(\mathrm{CO}_{2}\right)$ emissions, governments have enacted renewable energy (RE) policies to meet a number of objectives including the creation of local environmental and health benefits; facilitation of energy access, particularly for rural areas; advancement of energy security goals by diversifying the portfolio of energy technologies and resources; and improving social and economic development through potential employment opportunities. Energy access and social and economic development have been the primary drivers in developing countries whereas ensuring a secure energy supply and environmental concerns have been most important in developed countries.

An increasing number and variety of RE policies-motivated by a variety of factors-have driven substantial growth of RE technologies in recent years. Government policies have played a crucial role in accelerating the deployment of RE technologies. At the same time, not all RE policies have proven effective and efficient in rapidly or substantially increasing RE deployment. The focus of policies is broadening from a concentration almost entirely on RE electricity to include RE heating and cooling and transportation.

RE policies have promoted an increase in RE capacity installations by helping to overcome various barriers. Barriers specific to RE policymaking (e.g., a lack of information and awareness), to implementation (e.g., a lack of an educated and trained workforce to match developing RE technologies) and to financing (e.g., market failures) may further impede deployment of RE. A broad application of RE would require policies to address these barriers, and to help overcome challenges such as the lack of infrastructure necessary for integrating RE into the existing system.

Policy mechanisms enacted specifically to promote RE are varied and can apply to all energy sectors. They include fiscal incentives such as tax credits and rebates; public financing policies such as low-interest loans; regulations such as quantity-driven policies like quotas and price-driven policies including feed-in tariffs for electricity, heat obligations, and biofuels blending requirements. Policies can be sector specific and can be implemented at the local, state/ provincial, national and in some cases regional level and can be complemented by bilateral, regional and international cooperation.

Public research and development (R\&D) investments are most effective when complemented by other policy instruments, particularly RE deployment policies that simultaneously enhance demand for new RE technologies. Together, $R \& D$ and deployment policies create a positive feedback cycle, inducing private sector investment in R\&D. Enacting deployment policies early in the development of a given technology can accelerate learning by inducing private $R \& D$, which in turn further reduces costs and provides additional incentives for using the technology.

Some policy elements have been shown to be more effective and efficient in rapidly increasing RE deployment, but there is no one-size-fits-all policy, and the mix of policies and their design and implementation are also important. Key policy elements for ensuring effectiveness and efficiency can include adequate value to cover costs and account for social benefits, guaranteed access to networks and markets, long-term contracts to reduce risk, inclusiveness and ease of administration.

- Several studies have concluded that some feed-in tariffs have been effective and efficient at promoting RE electricity, mainly due to the combination of long-term fixed price or premium payments, network connections, and guaranteed purchase of all RE electricity generated. Quota policies can be effective and efficient if designed to reduce risk; for example, with long-term contracts.

- An increasing number of governments are adopting fiscal incentives for RE heating and cooling. Obligations to use RE heat are gaining attention for their potential to encourage growth independent of public financial support.

- In the transportation sector, RE fuel mandates or blending requirements are key drivers in the development of most modern biofuel industries. Other policies include direct government payments or tax reductions. Policies have influenced the development of an international biofuel trade. 
The flexibility to adjust as technologies, markets and other factors evolve is important. The details of design and implementation are critical in determining the effectiveness and efficiency of a policy. Policy frameworks that are transparent and sustained can reduce investment risks and facilitate deployment of RE and the evolution of low-cost applications.

A mix of policies is generally needed to address the various barriers to RE. Further, experience shows that different policies or combinations of policies can be more effective and efficient depending on factors such as the level of technological maturity, availability of affordable capital and the local and national RE resource base.

If the goal is to transform the energy sector over the next several decades to one based on low-carbon fuels and technologies, it is important to minimize costs over this entire period, not only in the near term. It is also important to include all costs and benefits to society in that calculation. Conducting an integrated analysis of costs and benefits associated with RE is extremely demanding because so many elements are involved in determining net impacts; thus, such efforts face substantial limitations and uncertainties. Few studies have examined such impacts on national or regional economies; however, those that have been carried out have generally found net positive economic impacts.

Two separate market failures create the rationale for the additional support of innovative RE technologies that have high potential for technological development, even if an emission market (or GHG pricing policy in general) exists. The first market failure refers to the external cost of GHG emissions. The second market failure is in the field of innovation: if firms underestimate the future benefits of investments into learning RE technologies or if they cannot appropriate these benefits, they will invest less than is optimal from a macroeconomic perspective. In addition to GHG pricing policies, RE-specific policies may be appropriate from an economic point of view if the related opportunities for technological development are to be addressed (or if other goals beyond climate mitigation are pursued). Potentially adverse consequences such as lock-in, carbon leakage and rebound effects must be taken into account in the design of a portfolio of policies.

RE technologies can play a greater role in climate change mitigation if they are implemented in conjunction with 'enabling' policies. A favourable, or enabling, environment for RE can be created by encouraging innovation in the energy system; addressing the possible interactions of a given policy with other RE policies as well as with other energy and non-energy policies (e.g., those targeting agriculture, transportation, water management and urban planning); by understanding the ability of RE developers to obtain finance and planning permission to build and site a project; by removing barriers for access to networks and markets for RE installations and output; by enabling technology transfer; and by increasing education and awareness. In turn, existence of an 'enabling' environment can increase the efficiency and effectiveness of policies to promote RE.

The literature indicates that long-term objectives for RE and flexibility to learn from experience would be critical to achieve cost-effective and high penetrations of RE. The energy scenarios analyzed in Chapter 10 show RE penetrations of up to $77 \%$ of primary energy by 2050 , depending on the rate of installation. To achieve GHG concentration stabilization levels with high shares of $\mathrm{RE}$, a structural shift in today's energy systems will be required over the next few decades. Such a transition to low-carbon energy differs from previous ones (e.g., from wood to coal, or coal to oil) because the available time span is restricted to a few decades, and because RE must develop and integrate into a system constructed in the context of an existing energy structure that is very different from what might be required under higher-penetration RE futures.

A structural shift would require systematic development of policy frameworks that reduce risks and enable attractive returns that provide stability over a timeframe relevant to RE and related infrastructure investments. An appropriate and reliable mix of instruments is even more important where energy infrastructure is still developing and energy demand is expected to increase in the future. 


\section{$11.1 \quad$ Introduction}

The potential for RE to play a role in the mitigation of climate change is significant, as discussed in previous chapters. RE capacity is increasing rapidly around the world, and government interest in renewable technologies is driven by a range of factors including climate mitigation, access to energy, secure energy supply, job creation and others. But a number of barriers continue to hold back further RE advances.

The scenarios in Chapter 10 show that the role RE can play in mitigating climate change can range from relatively minor to very significant depending on the rate of RE deployment. This rate, in turn, will depend on choices of societies and governments regarding how best to address climate change, as one among several energy related challenges that also include energy access or security. If $R E$ is to contribute substantially to the mitigation of climate change, and to do so quickly, various forms of economic support policies as well as policies to create an enabling environment are likely to be required.

RE policies can be sector specific and can be implemented at all levels of government-from local to state/provincial to national and international-and can be complemented by bilateral, regional and international cooperation. International agencies such as the International Energy Agency (IEA) are able to advise members about energy sources and policies; some, like the European Commission, can enact Directives while others mainly enhance understanding and awareness and distribute information (e.g., the Renewable Energy Policy Network for the $21^{\text {st }}$ Century (REN21) and the International Renewable Energy Agency (IRENA)). National governments can enact laws, assign different policies, and adapt or create regulations and other enabling environment dimensions. State, provincial or regional, and municipal or local initiatives may provide important support for local policies. In some countries, regulatory agencies and public utilities may be given responsibility for, or on their own initiative, design and implement support mechanisms for RE. The extent to which governments of all levels can 'learn' (Thelen, 1999; Breukers and Wolsink, 2007a)—whether from other governments, institutions, companies, communities and/or individuals_-and are flexible or reflexive to be able to evaluate past policies, to experiment and look for best practice (Smith et al., 2005) is also helpful. This chapter examines the roles of all of these actors, but focuses primarily on national governments and policymakers.

RE policies range from basic R\&D for technology development through to support for deployment of RE systems or the electricity, heat or fuels they produce. Deployment policies include fiscal incentives (tax policies, rebates, grants etc.), public finance mechanisms (loans, guarantees etc.) and regulations (e.g., feed-in tariffs, quotas, building mandates and biofuels blending mandates).

RE projects and production covered by policies can be qualified by RE source (type, location, flow or stock character, variability, density), by technology (type, vintage, maturity, scale of the projects), by ownership (households, cooperatives, independent companies, electric utilities) and other attributes that are in some way measurable (Jacobsson and Lauber, 2006; Mendonça, 2007; Verbruggen and Lauber, 2009). RE may be measured by additional qualifiers such as time and reliability of delivery (availability) and other metrics related to RE's integration into networks (Klessmann et al., 2008; Langniß et al., 2009). There is also much that governments and other actors can do to create an environment conducive for RE deployment. This chapter examines the options available for policymakers and the role of policies in advancing RE. Policies can advance technologies and stimulate markets, but complementary non-RE policies provide comfort for investors, thereby further enabling deployment. Thus, this chapter addresses the role of policies and an enabling environment in making financing available and affordable. It assesses policies based on a number of criteria, including effectiveness, efficiency, equity and institutional feasibility. It provides policymakers with a range of options for achieving the desired level of RE deployment and penetration, and aims to answer the following questions in each of the identified sections:

- Why, and under what conditions, is RE-specific policy support needed (Section 11.1)?

- What are the current trends globally in RE policies, finance and investment (Section 11.2)?

- What are the factors, in addition to climate change mitigation, driving policymakers to enact policies to advance RE? How do these drivers differ between developing and developed countries (Section 11.3)?

- What are the barriers to RE policy making, implementation and finance (Section 11.4), and how can policies help to overcome the various barriers to RE (Sections 11.5, 11.6 and 11.7)?

- What policy options are available to advance RE in different end-use sectors (Section 11.5)?

- What have been the experiences with these policy options to date, and which are most successful and under what conditions (Sections 11.5 and 11.6$)$ ?

- How do RE policies interact with climate policies (Section 11.5) and other types of policies (Section 11.6)?

- What combinations of policy packages can overcome the barriers necessary to achieve varying levels of RE penetration desired for mitigating climate change (Section 11.7)?

The remainder of this section begins to address some of the above questions, starting with a summary of the literature on the conditions that may make RE-specific policies necessary alongside climate policies (carbon pricing) in order to mitigate climate change.

\subsubsection{The rationale of renewable energy policies}

Renewable energies can provide a host of benefits to society. In addition to carbon dioxide emissions reduction, RE technologies are associated with local environmental and health benefits (Sections 11.3.1 and 9.3.4); can facilitate energy access particularly in rural areas (Sections 11.3.2 and 9.3.2); can increase energy security by increasing the portfolio of 
energy technologies and resources (Sections 11.3.3 and 9.3.3); and improve social and economic development (Sections 11.3.4 and 9.3.1) by creating employment opportunities and economic growth.

Some RE technologies are broadly competitive with current market energy prices. Of the other RE technologies that are not yet broadly competitive, many can provide competitive energy services in certain circumstances, for example, in regions with favourable resource conditions or that lack infrastructure for other low-cost energy supplies. In most regions of the world, however, policy measures are still required to facilitate an increasing deployment of RE (Section 10.5).

From a macro-economic perspective, government intervention can be justified where market distortions exist. There are two market failures particularly pertinent to RE:

1. Imperfect appropriability of benefits from innovation: Specifically, research and development $(R \& D)$, innovation, diffusion and adoption of new low-carbon technologies often create wider benefits to society than those captured by the innovator (Jaffe, 1986; Griliches, 1992; Jaffe et al., 2003, 2005; Edenhofer et al., 2005; Popp, 2006b). If firms underestimate the (future) benefits of investments into learning technologies or if they cannot appropriate these benefits, they will invest less than is optimal from a macro-economic perspective. Hence, specific RE policies (e.g., feed-in tariffs or quota systems) can be justified in order to address the market failures associated with technological learning and spill-over effects.

2. External costs of burning fossil fuels: Damages from global warming and local pollution are not usually considered by firms unless the associated external costs are purposefully internalized (Pigou, 1920; Cropper and Oates, 1992). As a consequence, there is an under-investment in energy efficiency improvements as well as in low-carbon technologies including RE. Where implemented, carbon pricing (via carbon taxes, emission trading schemes, or implicitly through regulation) is expected to yield a cost-efficient mix of mitigation measures-provided that no additional market failures introduce further distortions (Stern, 2007).

Where two market failures exist, two types of policies may be required to obtain a socially optimal outcome. With regard to the two market failures that are relevant to $\mathrm{RE}$, carbon pricing and support for research, development and diffusion of new technologies would be required. Otherwise, the two objectives (internalizing the cost of greenhouse gas (GHG) emissions and encouraging innovation and deployment of low-carbon technologies) would have to be traded off against one another-possibly sacrificing one of the objectives to some extent. For instance, carbon pricing on its own is likely to under-deliver investment in R\&D for new low-carbon technologies (Rosendahl, 2004; Rivers and

\footnotetext{
1 Both market failures must be taken into account simultaneously for those RE technologies that are prone to cost reductions via R\&D and technological learning.
}

Jaccard, 2006; Stern, 2007, Ch. 16; Fischer, 2008; Fischer and Newell, 2008; Otto et al., 2008).

There are further barriers that impede RE technologies, including oligopoly and imperfect competition, existing subsidies, network economies, information failures, labour market failures and non-internalized environmental and health effects beyond the impact of climate change (Sorell and Sijm, 2003; Sjögren, 2009; see also Sections 1.4.2, 9.5.1, and 9.5.2.1) Energy utilities whose incumbent technologies may have benefited from economies of scale might resist the entry of low-carbon competitors. Past investments into carbon-intensive infrastructure and engineering knowledge based upon that infrastructure may have created a lock-in into related technologies, impeding innovation and integration of RE (Unruh 2000; Acemoglu et al., 2009).

Transforming the energy system would require substantial investment, potentially binding capital for multiple decades. Hence, for such a target, investors would need clear and stable framing regulatory conditions as well as well-developed capital, insurance and futures markets to diversify investment risks. Information asymmetries (regarding, e.g., the innovation, learning and potential deployment of technologies) on capital markets increase the perceived risks and thus also the cost of investments. This is particularly relevant for some RE technologies, which as capital-intensive technologies suffer from high capital costs (Section 11.4.3).

Since, in practice, governments have not yet implemented 'ideal' carbon pricing or 'ideal' support for low-carbon $R \& D$, there may be a role for additional 'second-best' government intervention, including stronger RE deployment policies to tackle more effectively the climate externality. Carbon prices are often nonexistent or lower than estimated associated social costs (Stern, 2007; Tol, 2009), and have not provided a sufficiently credible basis for a large-scale shift towards low-carbon investment (see, for example, Committee on Climate Change 2010 (CCC, 2010) for the UK). Further, because governments are unable to pre-commit for the long term, there is a general lack of belief in government policies on long-term carbon pricing (Ulph and Ulph, 2009). Uncertainty over future regulation and, thus, over the future role of RE in the energy mix, discourages capital-intensive long-term investments. That is a salutary reminder that policymakers in the real world are subject to lobbying and rent-seeking as well as uncertainty about the costs and benefits of policies, including the costs of public administration of those policies.

The uncertainty of costs and the complex linkage of RE-specific market failures and barriers make it difficult to determine the optimal level of RE deployment for each of the drivers and co-benefits of RE. The remainder of this chapter presumes that decision makers aim to increase RE deployment as a means to achieve any number of social objectivesmitigating climate change is considered as one objective among many. Nonetheless, the complex interplay of RE policies with climate policies is revisited later in the chapter (see Section 11.5.7.3) as an important component for consideration, as the two policies might influence each other and lead to unintended consequences. 


\subsubsection{Policy timing and strength}

The timing, strength and level of coordination of R\&D versus deployment policies have implications for the efficiency and effectiveness of the policies, and for the total cost to society, in three main ways:

1. Whether a country promotes RE immediately or waits until costs have declined further. Although many RE technologies currently are not yet competitive with the energy market prices, the levelized cost of energy generated by RE has declined substantially in the past. As many of these technologies are still in early phases of their respective development chains, further cost reductions are expected in the future, especially if these technologies are appropriately supported by research, development, demonstration and deployment programs (RDD\&D) (IEA, 2008b, 2010a). Chapter 10 concludes that in order to achieve full competitiveness with fossil fuel technologies, significant up-front investments will be required until the break-even point is achieved. When those investments should be made depends on the goal. If the international community aims to stabilize the average global temperature increase at $2^{\circ} \mathrm{C}$, then investments in low-carbon technologies must start almost immediately. If a less stringent level were chosen there would be more time;

2. Once a country has decided to support RE, the timing, strength and coordination of when R\&D policies give way to deployment policies (Nemet, 2006; Junginger et al., 2010), discussed in Section 11.5.2; and

3. The critical debate of the cost and benefit of accelerated versus slower 'market demand' policy implementation. This debate concerns the dual objectives of rapid deployment of clean energy technologies to 'jump start' market growth, generally at higher upfront costs but with significant ability to evolve technologies down the cost curve (Langniß and Neij, 2004) to reduce GHG emissions, versus slower deployment that may not have as rapid a climate benefit, but which comes at a lower up-front capital and political cost.

\subsubsection{Roadmap for the chapter}

An increasing number of governments around the world are investing in RE and enacting RE policies to address climate change and for a variety of other reasons. As described in the introduction, the chapter aims to answer a number of questions about policy needs and experiences to date. The next section (11.2) begins by highlighting recent trends in RE policies to promote deployment, and then discusses trends in financing and research and development funding. Section 11.3 examines various drivers of RE policies, and Section 11.4 briefly reviews the barriers that impede RE policymaking and implementation, and barriers to financing.
Section 11.5 presents the various RE-specific policy options available to advance RE technology development and deployment. Tables 11.1 and 11.2 , found near the beginning of the section, list and define a range of policies currently used specifically to promote RE, and Table 11.2 notes which policies have been applied to which end-use sectors (electricity, heating and cooling, transportation). The section provides some assessment of how various policy options stand up to a range of different criteria, primarily effectiveness and efficiency, and provides a discussion of key elements to consider when selecting and designing RE policies.

In Section 11.6, an enabling environment is defined and explained. An environment that is enabling includes a skilled workforce, capacity for technology transfer, access to affordable financing, access to networks and markets, transparency in the process of obtaining permitting, etc. While it is not a critical prerequisite to have all elements of an enabling environment in place for the successful deployment of RE, the ease with which RE projects interact with these dimensions will match the ease with which RE is deployed.

This chapter concludes with Section 11.7, which focuses on broader considerations and requirements for a structural shift to a sustainable, low-carbon energy economy, particularly one based on RE and energy efficiency.

A number of case studies appear in text boxes in Sections 11.5 and 11.6. These aim to highlight key messages of the chapter and to provide insights into specific policy experiences that offer lessons for other regions or countries.

The issue of finance and RE can be examined in several ways, including: an assessment of the current trends in RE finance (Section 11.2.2); a review of existing barriers to financing of RE (Section 11.4.3); a review of public finance instruments as a policy option available to governments (Section 11.5.3); and a discussion of the relationship between RE project financing and broader financial market conditions that may contribute to the success of a project (Section 11.6.3). Because of the cross-cutting nature of finance, relevant aspects for RE are addressed in most sections of the chapter.

Available RE resources vary from place to place, and maturity levels vary among the different RE technologies; further, political, economic, social, financial, ecological and cultural needs and conditions differ from one city, state, region or country to another, thereby leading to different options and constraints. Thus there is no one-size-fits-all policy package, and the optimal mix of RE policies will differ from one place to the next. Clearly, it is not possible to cover everything in a single chapter. However, there are valuable and transferable lessons to be learned from experiences to date, and this chapter aims to elucidate them.

In general, this chapter does not include technology-specific policy needs and related experiences. 


\subsection{Current trends: Policies, financing and investment}

The number of RE-specific policies enacted and implemented by governments, and the number of countries with RE policies, is increasing rapidly around the globe (Figure 11.1). The focus of RE policies is shifting from a concentration almost entirely on electricity to include the heating/cooling and transportation sectors. These trends are matched by increasing success in the development of a range of RE technologies and their manufacture and implementation (see Chapters 2 through 7), as well as by a rapid increase in annual investment in RE and a diversification of financing institutions. This section describes recent trends in RE policies and in public and private finance and investment, from research and development (R\&D) through to refinancing and the sale of RE companies.

\subsubsection{Trends in renewable energy policies}

While several factors are driving rapid growth in RE markets, government policies have played a crucial role in accelerating the deployment of RE technologies to date (Sawin, 2001, 2004; Meyer, 2003; Renewables 2004, 2004; Rickerson et al., 2007; REN21, 2009b; IEA, 2010d).

Until the early 1990s, few countries had enacted policies to promote RE. Since then, and particularly since the early- to mid-2000s, policies have begun to emerge in a growing number of countries at the municipal, state/provincial, national and international levels (REN21, 2005, 2009b). Initially, most policies adopted were in developed countries, but an increasing number of developing countries have enacted policy frameworks at various levels of government to promote RE since the late 1990s and early 2000s (Wiser and Pickle, 2000; Martinot et al., 2002; REN21, 2010).

According to the Renewable Energy Policy Network for the 21st Century (REN21), which is believed to be the only source that tracks RE policies annually on a global and comprehensive basis, ${ }^{2}$ the number of countries with some kind of RE target and/or deployment policy related to RE almost doubled from an estimated 55 in early 2005 to more than 100 in early 2010 (REN21, 2010). By early 2010, at least 85 countries, including all 27 EU member states, had adopted RE targets at the national level-for specific shares of electricity, or shares of primary or final energy from RE; sub-national targets exist in a number of additional countries (REN21, 2010). This is up from 43 countries with national targets in mid-2005 (plus 2 countries with state/provincial level targets) (REN21, 2006). An estimated 83 countries were known to have RE policies in place by early 2010 .

2 Note that the International Energy Agency database focuses on the Organisation for Economic Cooperation and Development (OECD), BRICS (Brazil, Russia, India, China and South Africa) and other countries that supply information, but is not as comprehensive as REN21 (which relies on the IEA database and other sources).
There is much overlap between these two categories (countries with policies and those with targets); some countries have adopted policies specifically to deliver their targets, while others have enacted policies but do not have official targets at the national level. Further, a significant number of developing countries have adopted targets but have not yet enacted national RE policies. Most countries with RE policies have more than one type of policy in place, and many existing policies and targets have been strengthened over time (REN21, 2010).

Existing RE policies are directed to all end-use sectors-electricity, heating and transportation. (See Section 11.5 and Tables 11.1 and 11.2 for full discussion of RE policy options.) By the date of publication, however, most RE deployment policies focused on the electricity sector. At least 83 countries had adopted some sort of policy to promote RE power generation by early 2010 (IEA, 2010c; REN21, 2010), up from an estimated 48 countries in mid-2005 (REN21, 2006). These policies included fiscal incentives such as investment subsidies and tax credits; government financing such as low-interest loans; and regulations such as feed-in tariffs (FITs), quotas and net metering. Of those countries with RE electricity policies, approximately half were developing countries from every region of the world (REN21, 2010).

Although governments use a variety of policies to promote RE electricity, the most common ones in use as of publication were FITs and quotas or Renewable Portfolio Standards (RPS). By early 2010, at least 45 countries had FITs at the national level (including much of Europe), with a further 4 countries using them at the state/provincial/territorial and/or municipal levels (Mendonça, 2007; Rickerson et al., 2007, 2008; REN21 2010). RPS or quotas are also widely used and, by early 2010 , were in force in an estimated 10 countries at the national level, and at least 4 additional countries at the state, provincial or regional level, including 29 US states, at least 12 Indian states, and some provinces and regions in Canada and Belgium (REN21, 2010).

An increasing number of governments are adopting incentives and mandates to advance renewable transport fuels and renewable heating technologies (IEA, 2007b; Rickerson et al., 2009). For example, in the 12 countries analyzed for the International Energy Agency, the number of policies introduced to support renewable heating either directly or indirectly increased from 5 in 1990 to more than 55 by May 2007 (IEA, 2007b; REN21, 2009b).

By early 2010, at least 41 states/provinces and 24 countries at the national level had adopted mandates for blending biofuels with gasoline or diesel fuel, while others had set production or use targets (REN21, 2009b). Most mandates require blending relatively small (e.g., up to $10 \%)$ percentages of ethanol or biodiesel with petroleum-based fuels for transportation. Brazil has been an exception, with ethanol blending shares required in the 20 to $25 \%$ range, although many vehicles in Brazil operate on $100 \%$ ethanol, which is also readily available (Goldemberg, 2009). Production subsidies and tax exemptions for biofuels have also increased in use in developed and developing countries (REN21, 2010). 


\section{5}
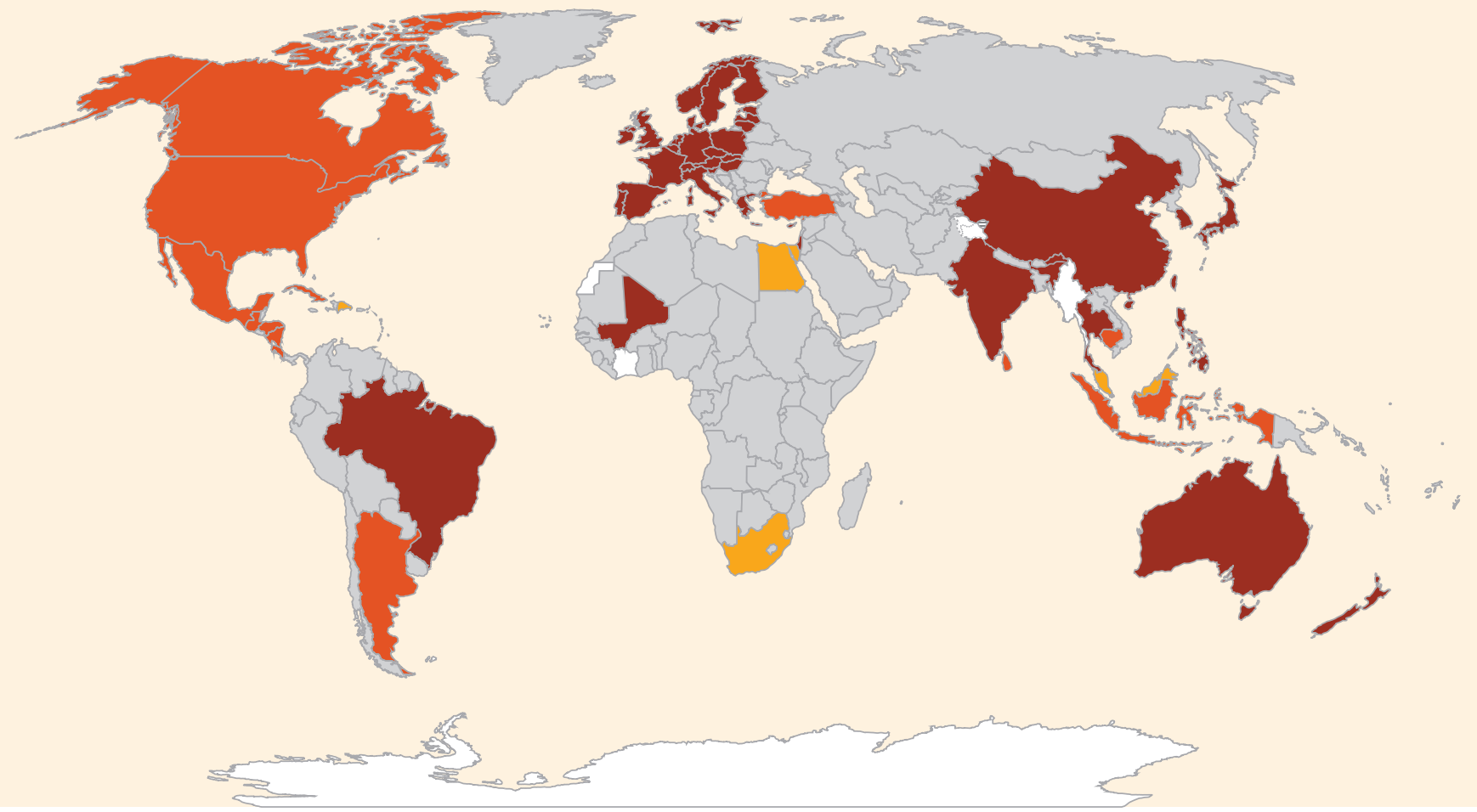

Early 2011
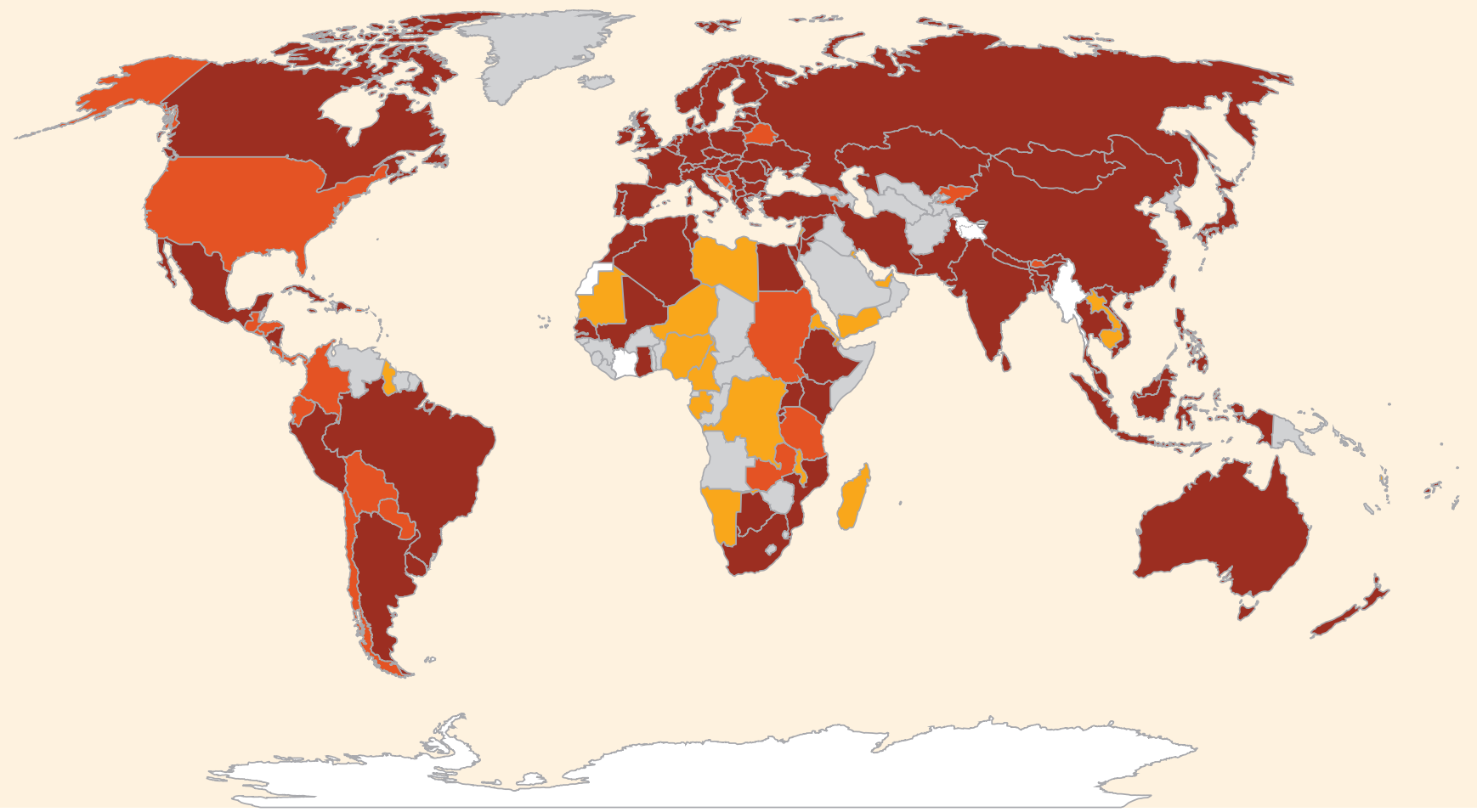

Countries with at least one RE-specific Policy and at least one RE Target

Countries with at least one RE-specific Policy
Countries with at least one RE Target

Countries with neither RE-specific Policies nor RE Targets

Figure 11.1 | Countries with at least one RE-specific deployment target and/or at least one RE-specific deployment policy in mid-2005 and in early 2011. This figure includes only national-level targets and policies (not municipal or state/provincial) and is not necessarily all-inclusive (RECIPES, 2005; REN21, 2005, 2010, 2011; CIPORE, 2011; Austrian Energy Agency, 2011; IEA, 2011; REEGLE, 2011; DSIRE, 2011). 
Another policy trend seen particularly with bioenergy, and biofuels especially, is the adoption of environmental and other sustainability standards, including regulations on associated lifecycle $\mathrm{CO}_{2}$ emissions, such as the U.S. Renewable Fuel Standard and mandatory sustainability standards under the EU Renewable Energy Directive (European Commission, 2009b; USEPA, 2010b). (For more on sustainability standards, see Section 2.4.5.2.)

Beyond national policies, the number of international policies and partnerships is increasing. The EU Renewables Directive entered into force in June 2009, setting a binding target to source $20 \%$ of EU final energy consumption from RE by 2020; all member states have been assigned targets for 2020 that are driving RE policies at the national level (European Commission, 2009a; REN21, 2009b). Another example is the Mediterranean Solar Plan, an agreement among countries in the region for research and deployment of $20 \mathrm{GW}$ of RE by 2020 (Resources and Logistics, 2010).

Several hundred city and local governments around the world have also established goals or enacted renewable deployment policies and other mechanisms to spur local RE development (Droege, 2009; REN21, 2009b). Innovative policies such as Property-Assessed Clean Energy (PACE) have begun to emerge on this level (Fuller et al., 2009a) (see Box 11.3). Indeed, some of the most rapid transformations from fossil fuels to RE-based systems have taken place at the local level, with entire communities and cities-including Samsø in Denmark and Güssing in Austria (see Box 11.14)—devising innovative means to finance RE and making the transition towards 100\% RE systems (Droege, 2009; Sawin and Moomaw, 2009).

The IEA (IEA et al., 2010) estimates that in 2009, governmental RE deployment support-including subsidies, renewable portfolio standards/ quotas, FITs, green certificates and several fiscal incentives (but excluding R\&D support)—totalled USD ${ }_{2005} .49$ billion (USD ${ }_{2009} 57$ billion). This compares with USD ${ }_{2005} 38$ billion (USD ${ }_{2008} 44$ billion) in government support during 2008 and USD 2005 35 billion (USD 2007 billion) in 2007.

The vast majority of capacity or generation for most RE technologies is still in a relatively small number of countries. However, as RE policies are enacted by an increasing number of governments, new countries and regions are emerging as important manufacturers and installers of RE (GWEC, 2008, 2010; REN21, 2010).

\subsubsection{Trends in renewable energy finance}

In response to the increasingly supportive policy environment, the overall RE sector globally has seen a significant rise in the level of investment since 2004-2005. According to UNEP and Bloomberg New Energy Finance (BNEF), USD 2005101.1 billion were newly invested in RE electricity (not including hydropower plants) and biofuels technologies in 2009. This was up from USD ${ }_{2005} 16.9$ billion in 2004 (UNEP and
BNEF, 2010), although down from USD ${ }_{2005} 110.7$ billion in 2008 due to the financial downturn (Figure 11.2). Using a different methodology, ${ }^{3}$ REN21 (2010) identified a total investment figure for 2009 that was significantly higher than the findings of UNEP and BNEF (2010).

Meanwhile, global investment in hydropower facilities increased from approximately USD ${ }_{2005} 6.2$ billion in 2004 to USD ${ }_{2005} 58.5$ billion in 2009 (IJHD, 2009) (Figure 11.3).

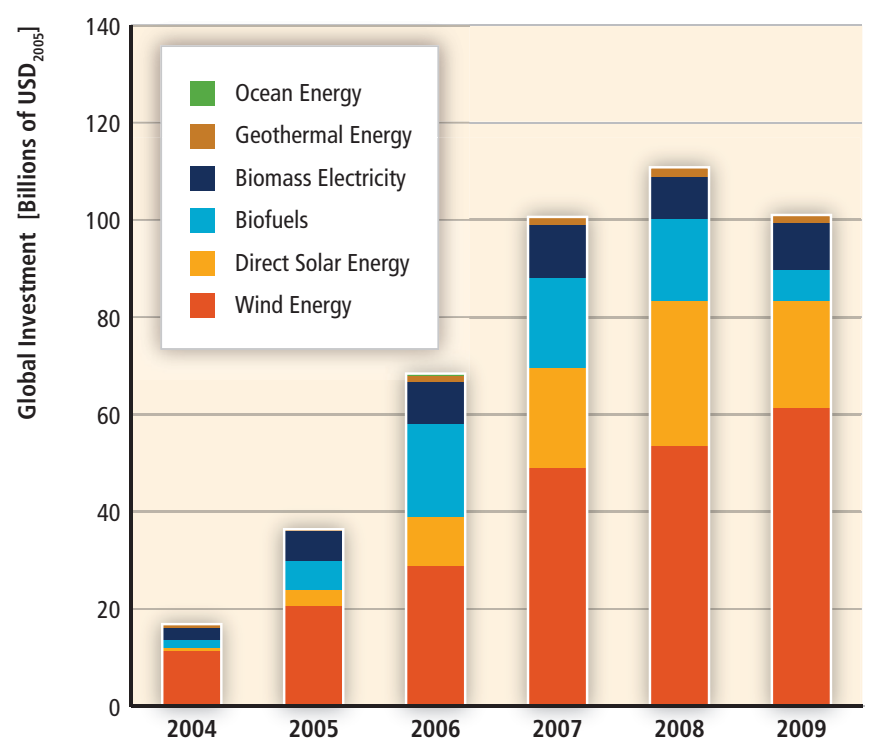

Figure 11.2 | Global investment in RE electricity (excluding hydropower) and biofuels, by technology, 2004 to 2009 (UNEP and NEF, 2009).

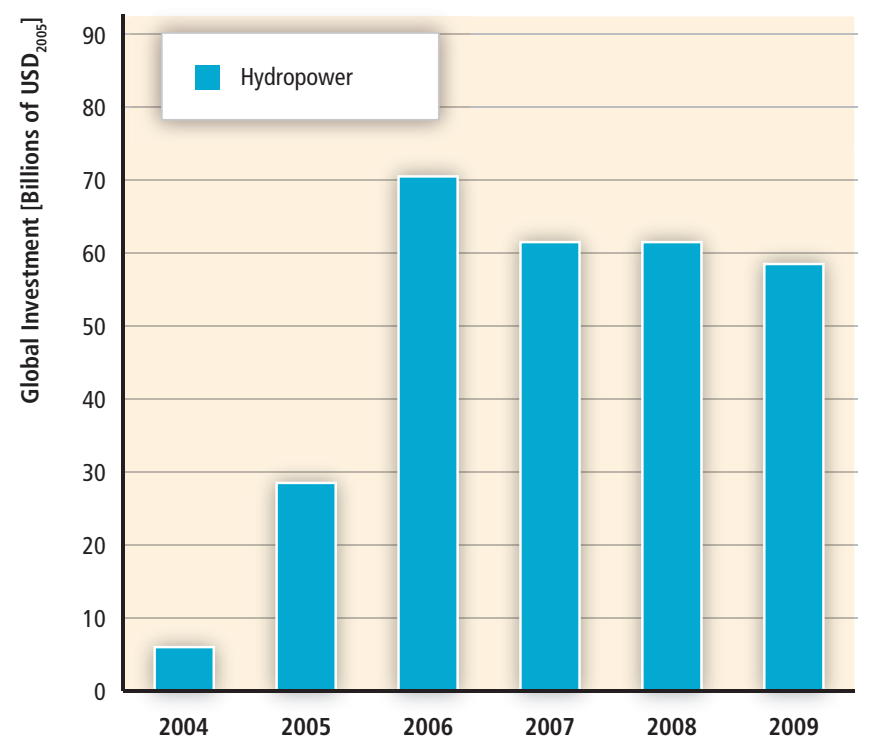

Figure 11.3 | Global investment in hydropower plants, 2004 to 2009 (IJHD, 2009).

3 The REN21 estimates were higher than BNEF/UNEP estimates for two reasons: REN21 data for small-scale projects included (1) global investment in solar hot water (estimated at USD ${ }_{2005} 12$ billion); and (2) balance-of-plant costs for distributed grid-connected solar photovoltaics (PV) $(<200 \mathrm{~kW})$, while BNEF/UNEP included only PV module costs (REN21, 2010). 


\subsubsection{Trends along the financing continuum}

Financing occurs over what is known as the 'continuum' or stages of technology development. The five segments of the continuum are: i) R\&D; ii) technology development and commercialization; iii) equipment manufacture and sales; iv) project construction; and v) the refinancing and sale of companies, largely through mergers and acquisitions. Literature is available that examines financing along this continuum for biofuels and all RE electricity technologies except hydropower. For these technologies, financing has been increasing all along the continuum. These trends represent successive steps in the innovation process and provide indicators of the RE sector's current and expected growth, as follows:

- Trends in (i) R\&D funding and (ii) technology development and commercialization (Sections 11.2.2.2 and 11.2.2.3) are indicators of the long- to mid-term expectations for the sector-investments are being made that will usually only begin to pay off in several years' time, once the technology is fully commercialized.

- Trends in (iii) manufacturing and sales investment (Section 11.2.2.4) are an indicator of near-term expectations for the sector-essentially, that the growth in market demand will continue.

- Trends in (iv) construction investment (Section 11.2.2.5) are an indicator of current sector activity, including the extent to which internalizing costs associated with GHGs can result in new financial flows to RE projects.

- Trends in (v) industry mergers and acquisitions (Section 11.2.2.6) can reflect the overall maturity of the sector, and increasing refinancing activity over time indicates that larger, more conventional investors are entering the sector, buying up successful early investments from first movers.

Each of these trends is discussed in the following sub-sections. The sum of the funds invested in each segment, in biofuels and RE electricity (except hydropower) equals the amount shown for the technologies included in Figure 11.2. In some segments of the continuum, public finance (funds from governments) and regulatory support mechanisms, which provide certainty of revenue, also play an important complementary role, as discussed in Section 11.5 .

Although the concept of a continuum infers a smooth transition among the different types of financing involved, the reality is that financiers each have their own risk and return expectations and have different external drivers that make the various segments of the continuum less or more attractive for commercial investment.

\subsubsection{Financing technology research and development}

Governments fund most of the basic research aimed at increasing the understanding of fundamental principles, often with no direct or immediate commercial benefits. Large corporations fund most of the applied research and development aimed at a specific commercial or client-driven purpose. Worldwide public investment in RE R\&D grew most rapidly from 1974 to 1980 , when it peaked; it then declined throughout the 1980s and remained low in the 1990s. Since 2000, it has steadily risen to close to USD ${ }_{2005} 1.81$ billion (USD ${ }_{2008} 2$ billion) as of 2008 (IEA, 2010b), although that level is below investment in the 1978 to 1982 period. Private sector investment has followed a similar path (Nemet and Kammen, 2007). Another source reports higher levels of government sponsored non-hydro RE R\&D, increasing from USD ${ }_{2005} 0.9$ billion in 2004 to USD ${ }_{2005} 2.3$ billion in 2009, a compound annual growth rate of 19\% (UNEP and BNEF, 2010). (See also Section 10.5.5.)

\subsubsection{Financing technology commercialization}

Venture capital is a type of private equity capital typically provided for high-potential technology companies in the early market deployment phase in the interest of generating a return on investment through a trade sale of the company or an eventual listing on a public stock exchange. Venture capitalists begin to play a role once technologies are ready to move from the lab bench to the early market deployment phase, often working with and through government public-private demonstration and commercialization programmes.

According to Moore and Wüstenhagen, venture capitalists were initially slow to pick up on the emerging opportunities in the energy technology sector (Moore and Wüstenhagen, 2004), with RE accounting for only 1 to $3 \%$ of venture capital investment in most countries in the early 2000s. However, between 2002 and 2009, venture capital investment in RE technology firms increased markedly. Venture capital into RE electricity (excluding hydro) and biofuels companies grew from USD 2005392 million in 2004 to USD $_{2005} 1.41$ billion in 2009 (UNEP and BNEF, 2010), representing a compound annual growth rate of $29 \%$. This growth trend in technology investment now appears to be a leading indicator that the finance community expects continued significant growth in the RE sector. Downturns such as that experienced in 2008/2009 may slow or reverse the trend in the short term (as seen in Figure 11.2), but in the longer term, increased engagement of financial investors is foreseen in RE technology development (UNEP and NEF, 2009).

\subsubsection{Financing manufacturing and sales}

Once a technology has passed the demonstration phase, the capital needed to set up manufacturing and sales facilities usually comes initially from private equity investors (i.e., investors in unlisted companies) and subsequently from public equity investors who buy shares of companies listed on the public stock markets. Private equity investment is capital provided by investors and funds directly into private companies, 
often for setting up a manufacturing operation or other business activity, whereas public equity investment is capital provided by investors into publicly listed companies. These forms of capital are also used to finance some of the working capital requirements of companies, with the rest coming from bank loans.

Private and public equity investment in RE electricity (excluding hydro) and biofuels grew from USD 2005691 million in 2004 to USD $_{2005} 13.5$ billion in 2009, representing a compound annual growth rate of $81 \%$ (UNEP and NEF, 2009). Even with this very fast growth in manufacturing investments, several technologies had supply bottlenecks through early 2008 that delayed sector growth and pushed up prices. In 2008, stock markets in general dropped sharply, but RE shares fared worse due to the energy price collapse and the fact that investors shunned stocks with any sort of technology or execution risk, particularly those with high capital requirements (UNEP and NEF, 2009). Financing for manufacturing facilities has also been negatively affected by some policy-induced boom and bust cycles that have made long-term production planning difficult (see for instance Box 11.5).

\subsubsection{Financing construction}

Financing RE generating facilities involves a mix of equity investment from project owners and loans from banks ('private debt') or capital markets ('public debt' raised through bond offerings). Both types of finance are combined into the term 'asset finance', which represents all forms of financing secured for RE projects (whether from internal funds, debt finance or equity finance). Regulatory RE policies (see Section 11.5), which create a quota for RE or ensure a certain price, may be important and complementary factors.

Asset financing of RE electricity (excluding hydro) and biofuels grew from USD $_{2005} 15.3$ billion in 2004 to USD $_{2005} 88.7$ billion in 2009, representing a compound annual growth rate of $42 \%$ (UNEP and NEF, 2009).

By 2007, the capital flows available to RE projects had become more mainstream and had broadened, meaning that the industry had gained access to a far wider range of financial sources and products than it had around 2004/2005 (UNEP and NEF, 2008). For instance, the largest component of total RE capital flows by 2009 was through project finance investment (DBCCA, 2010), an approach that mobilizes large flows of private sector investment in infrastructure.

Consumer loans, micro-finance and leasing are some of the instruments that banks offer to households and other end users to finance the purchase of small-scale technologies. However most investment in such systems comes from the end user themselves, usually through purchases made on a cash basis. Total global investment in residential RE projects was USD $_{2005} 16.43$ billion in 2009 (UNEP and NEF, 2008), about $14 \%$ of total investment in RE projects. REN21, however, reported a much larger figure of USD ${ }_{2005} 46$ billion in 2009 using a broader methodology that includes balance of systems costs for photovoltaics (PV) and small-scale solar water heating systems (REN21, 2010).

Multilateral and development bank support has increased significantly in recent years, with USD 2005 19.2 billion loaned to RE in 2009, up from USD $_{2005} 6.1$ billion in 2007. According to de Jager et al. (2010), from mid2008 onwards the multilateral banks aimed to fill the void in the project finance market caused by the financial crisis.

\subsubsection{Refinancing and sale of companies}

In 2009, USD ${ }_{2005} 53.1$ billion worth of mergers and acquisitions (M\&A) took place involving the refinancing and sale of RE companies and projects (excluding hydro larger than $50 \mathrm{MW}$ ), up from USD ${ }_{2005} 9.3$ billion in 2004 , or $42 \%$ compound annual growth (UNEP and NEF, 2009). M\&A transactions usually involve the sale of generating assets or project pipelines, or sale of companies that develop or manufacture technologies and services. Increasing M\&A activity in the short term is a sign of industry consolidation, as larger companies buy smaller, less well-capitalized competitors. In the longer term, increasing M\&A activity provides an indication of the increasing mainstreaming of the sector, as larger entrants prefer to buy their way into the industry rather than developing RE businesses from the ground up.

\subsubsection{Global investment transition}

The recent trends in RE policies and finance have been generally positive for the RE sector. Even despite the financial downturn, total investment in 2009 in new RE capacity was greater than investment in new fossil fuel capacity in the electricity sector, for the second year running (UNEP and BNEF, 2010). This trend was driven in large part by that fact that more than half the world's countries had some type of policy target or promotion policy in place for RE (REN21, 2010). These inter-linked trends underline that RE was not a by-product of the ill-fated credit boom, but part of a global investment transition that is likely to strengthen over time (UNEP and BNEF, 2010). The next section examines the drivers, opportunities and benefits associated with this transition.

\subsection{Key drivers, opportunities and benefits}

A number of environmental, economic, social and security opportunities provided by RE are discussed in Chapters 1 and 9 . In the policy context, they are considered as drivers, or factors that drive governments to adopt policies for RE development and deployment.

The motivations of policymakers to promote RE are described with specific examples from selected countries for illustrative reasons. The 
relative importance of the drivers for RE differ from country to country, and may vary over time. Without ranking them, key drivers for policies to advance RE are outlined below.

In general, economic opportunities drive policies in most developing countries, where RE is sometimes the only affordable means for providing energy access (e.g., Bolivia (REN21, 2009b), Bangladesh (Urmee et al., 2009), Brazil (Lucena et al., 2009), China (Standing Committee of the National People's Congress, 2005), India (Hiremath et al., 2009), Pakistan (Government of Pakistan, 2006), Tonga (Government of the Kingdom of Tonga, 2010), South Africa (Department of Minerals and Energy, 2003) and Zambia (Haanyika, 2008)) (Domac et al., 2005). So in terms of the share of global population concerned, this driver has been most important. In most developed countries, the desire to reduce environmental impacts of energy supplies, including climate change mitigation, and to decrease dependence on energy imports have been the primary drivers for RE promotion (for instance Australia, California in the USA, the EU, Quebec in Canada (Domac et al., 2005)). Thus, in terms of RE capacity added globally between 1990 and 2010, these drivers have been most important. In addition, in some countries the possibility of developing a new industry with related jobs is considered an opportunity; such motivations are of increasing importance in many emerging and developing economies as well.

\subsubsection{Climate change mitigation and reduction of environmental and health impacts}

RE can be a major tool for climate change mitigation (Section 9.3.4), although the degree to which RE mitigates climate change depends on many factors (Sections 10.2 and 10.3).

$\mathrm{RE}$ is an integral aspect of government strategies for reducing $\mathrm{CO}_{2}$ (and other) emissions in many countries, including all member states of the EU (e.g., BMU, 2006; European Parliament and of the Council, 2009); and several US states, including California (CEC and CPUC, 2008) and Washington (CTED, 2009). Developing countries are also enacting RE policies in order to address climate change, among other goals. India's National Action Plan on Climate Change, launched in 2008, specifically mentions RE, and the country's National Solar Mission aims to constitute a major contribution by India to the global effort to meet the challenges of climate change (JNNSM, 2009). The 2009 meeting of Leaders of Pacific Island Countries observed that in addition to RE offering the promise of cost-effective, reliable energy services to rural households it will also provide a contribution to global GHG mitigation efforts (PIFS, 2009a).

In numerous cities, from Chicago (Parzen, 2009) and Miami (City of Miami, 2008) in the USA to Rizhao in China and Waitakere in New Zealand (IEA, 2009a), RE is playing an important role in climate mitigation strategies. By March 2010, more than 1,300 European municipalities had joined the Covenant of Mayors, committing to reduce $\mathrm{CO}_{2}$ emissions beyond the $\mathrm{EU}$ objective of $20 \%$ by 2020 with the help of RE deployment, among other tools (European Commission, 2010).

The benefits of RE to the broader environment and human health (Section 9.3.4) are also driving governments to enact RE policies. At the same time, manufacture, construction and disposal of RE systems can have direct non-climate change impacts on the natural environment, including land use and aesthetics, and problems associated with chemicals required for manufacture and others. Policymakers can implement processes to minimize these negative outcomes while benefiting from the opportunities and benefits. Chapter 9 explores these issues in detail, while Chapters 2 through 7 review technology-specific impacts.

In China, for example, a major driver for the promotion of clean energy technologies, including RE, has been the goal of reducing or avoiding negative local and regional environmental impacts associated with energy (Standing Committee of the National People's Congress, 2005; Gan and Yu, 2008). The government of Pakistan intends to develop RE in order to avoid local environmental and health impacts of unsustainable and inefficient traditional biomass fuels and fossil fuel-powered electricity generation (Government of Pakistan, 2006). The South African government recognizes that millions of people are routinely exposed to noxious gases and particulates from the burning of fossil fuels due to inadequate living conditions and a lack of infrastructure in much of the country; the need to improve air quality has been a motivating factor in government plans to deploy RE technologies (Department of Minerals and Energy, 2003). In light of increasing concerns about water scarcity, many governments are turning to RE to reduce water consumption associated with energy production (Inhaber, 2004).

Growing awareness of the potential for RE to avoid some of the harmful impacts of fuel extraction on biodiversity of plant and animal species (IPCC, 2002) has led some governments to establish targets, or to adopt other policies, to increase RE deployment. For example, the Commonwealth of the Bahamas pays special attention to RE technology as a means to sustain vulnerable ecosystem services (National Energy Policy Committee, 2008). In Nepalese villages, modern RE systems have been deployed to mitigate negative impacts on biodiversity and deforestation resulting from the unsustainable use of biomass (Zahnd and Kimber, 2009).

\subsubsection{Energy access}

RE can enhance access to reliable, affordable and clean modern energy services (DBCCA, 2009), it is particularly well-suited for remote rural populations, and in many instances can provide the lowest cost option for energy access (Lucena et al., 2009; Mahapatra et al., 2009; Section 9.3.2). Many developing countries-including Bolivia (REN21, 2009b), Bangladesh (Urmee et al., 2009), Brazil (Lucena et al., 2009), China (Standing Committee of the National People's Congress, 2005), India (Hiremath et al., 2009), Pakistan (Government of Pakistan, 2006), Tonga (Government of the Kingdom of Tonga, 2010), South Africa (Department 
of Minerals and Energy, 2003) and Zambia (Haanyika, 2008)—have adopted RE policies, such as connection targets and subsidies, in order to provide access to energy services in rural areas.

\subsubsection{Energy security}

RE can improve security of energy supply in a variety of ways, including reducing dependence on imported fuels, helping to diversify supply, enhancing the national balance of trade and reducing vulnerability to price fluctuations (Section 9.3.3). These various benefits are driving a number of governments around the world to adopt policies to promote RE.

Since the early 1970s, Brazil has promoted ethanol from sugarcane as an alternative to fossil transport fuels in order to decrease dependency on imported fuels (Pousa et al., 2007; see Box 11.10). China established its 2005 Renewable Energy Law in part to diversify energy supplies and safeguard a secure energy supply (Standing Committee of the National People's Congress, 2005; see Box 11.11), and the Jamaican government aims to diversify its energy portfolio by incorporating RE into the mix, reducing reliance on imported oil (Government of Jamaica, 2006). A number of municipalities and communities from across Canada (St. Denis and Parker, 2009) to Güssing in Austria (see Box 11.14) and elsewhere are adopting RE plans to become more energy self-sufficient. Many governments have regarded RE (particularly biofuels) as a means to enhance their national balance of trade by substituting domestic RE fuels for imported fuels (National Greenhouse Strategy, 1998; Department of Minerals and Energy, 2003; DTI, 2007; Smitherman, 2009).

The relationship between public RE R\&D funding and movements in the price of oil illustrate the significant role that the security of supply consideration has on government decisions to fund research into alternative sources of energy such as RE. Figures collected by the IEA (2008c) show that spending on RE peaked in 1981, and as oil prices dropped in the 1980s, RE R\&D spending declined by more than two thirds, hitting a low in 1989. RE R\&D funding has gradually increased since then, but not to earlier levels, as discussed in Section 11.2.2.2. The IEA (2008a) has argued that governments choose to focus their attention on technologies that can tap into their most abundant domestic natural resources. Non-IEA countries also justify focusing on a particular energy resource by pointing to its relative local abundance, like solar energy in India (JNNSM, 2009) and Singapore (SERIS, 2009). But there are important exceptions. Germany, for instance, spends more on PV R\&D than any other country in Europe (European Commission, 2009a), but with a view to growing a competitive export industry (IEA, 2008c).

\subsubsection{Social and economic development}

Policymakers in many countries are enacting RE policies with the purpose of advancing economic development and/or creating jobs. (See
Section 9.3.1 for a full discussion of RE in relation to social and economic development.) For example, the EU has highlighted the potential of RE to create new jobs, especially in rural and isolated areas (European Parliament and of the Council, 2009). Creating employment opportunities was an important driver in creation of the German Renewable Energy Act in 2000 (Jacobsson and Lauber, 2006), and Germany's fast-growing RE industries have motivated policymakers there to maintain strong promotion policies. A main target of the Greek government's RE promotion policies is to strengthen employment (Tsoutsos et al., 2008).

The development of domestic markets for RE is also seen as a means to attract new industries that may in turn supply international markets, thereby gaining competitive advantages (Lewis, 2007; Lund, 2008). One example is the case of Japan (see Box 11.2) and its PV industry. However, if combined with policies that promote domestic/local content and provide subsidies to protect domestic industries, conflicts can arise over international trade rules (International Center for Trade and Sustainable Development, 2010).

Rural development is often tied to the deployment of RE, whether in developed or developing countries. The biogas program operated by the Nepalese Alternative Energy Promotion Center together with the Netherlands Development Organization (SNV) has linked the deployment of RE with its socioeconomic development program (Mendis and van Nes, 1999). Bangladesh has been exploring the potential for RE to aid in rural development, with public and nongovernmental organizations working together to develop rural RE projects (Mondal et al., 2010). Rural development is also a key driver for RE policies in India, such as the country's support for biofuels (Bansal, 2009).

\subsection{Barriers to renewable energy policymaking, implementation and financing}

While there are a number of drivers, opportunities and benefits associated with $\mathrm{RE}$, there are also a number of barriers to the development and deployment of RE. If RE is to play a significant role in mitigating climate change, it is important to address these barriers. Chapter 1 of this report offers an overview of barriers to RE development and deployment, while Chapters 2 through 7 cover technology-specific challenges, Chapter 8 addresses barriers to integration of RE at high shares, and Chapter 9 discusses barriers to RE in the context of sustainable development. This section summarizes some of the numerous barriers to successful policymaking, implementation and financing, which can also hamper the development and deployment of RE.

\subsubsection{Barriers to renewable energy policymaking}

Barriers to making and enacting policy include a lack of information and awareness about RE resources, technologies and policy options; lack of understanding about 'best' policy design or how to undertake energy 
transitions; difficulties associated with quantifying and internalizing external costs and benefits; and lock-in to existing technologies and policies.

A lack of information and awareness can affect policymaking in the design and enactment stages. Many policymakers lack the required knowledge and experience of RE policies: for example, the available policy options; how they work and should be implemented; how much they cost; what their benefits and difficulties are; and experiences to date in other countries. Best practices for successful RE policy, such as setting clear goals for sustainable technology innovation and communications with stakeholders, may not be effectively conveyed among policymakers, from the local to the international level (IEA, 2006; van den Bergh and Bruinsma, 2008). Further, lack of information about the effectiveness of policies, once implemented, can impede the redesign and improvement of existing policies or design of potential new policies. The failure of past policies can also create resistance to new policies to promote RE (Sawin, 2001).

Added to this, RE technological development is uncertain, dynamic, systemic and cumulative (Grubler, 1998; Fri, 2003; Foxon and Pearson, 2008). RE sources are local and circumstantial, and doing an inventory of resource potential and possibilities for development requires multidisciplinary expertise (Twiddell and Weir, 2006). This means that even if policymakers have a general understanding of $\mathrm{RE}$, time and effort are required to understand local conditions and develop connections to practitioner and scientific communities.

Further, there are a number of technology options available to policymakers wishing to pursue low-carbon energy futures-including $R E$, energy efficiency improvements, fast-track development of carbon capture and storage, or nuclear power-and assessments of the various portfolio options based on transparent sets of criteria are generally lacking (IEA, 2006 , 2008a). Even once a portfolio of options has been selected, many policymakers lack the knowledge and expertise required to design policies that can proactively and effectively integrate RE supplies with other low-carbon options, with other policy goals (such as poverty alleviation, spatial planning), and across different but interconnected sectors (e.g., agriculture, housing, education, health, water and transportation) (Section 11.6.2). There are still differences of opinion about the linkages and interactions between climate policies (i.e., carbon pricing through tax or cap and trade) and RE policies (Section 11.5.7.3).

Although there is some understanding of how energy transitions occurred in the centuries past (R. Fouquet, 2008), there is no clear roadmap to a transition. Nevertheless, there is increasing analysis of how to undertake transitions to RE (e.g., van den Bergh and Bruinsma, 2008). This new generation of governance approaches aims at inducing and navigating the complex processes of socio-technical change by means of deliberation, probing and learning. Some argue that policy design should be longer term and be flexible, adaptive and reflexive (Voß et al., 2009). Others argue that a transformation to a low-carbon energy system can emerge only from interactions among multiple interest groups as well as wider institutional and social constituencies (Smith et al., 2005; Verbong and Geels, 2007).
Any or all of these factors can make policy design difficult; they can also make it difficult to reach a consensus and to enact specific policies (C. Mitchell, 2010). In addition, regulatory authorities and policymakers face an asymmetry of information between established and newer technologies, and they may also be captured by incumbent technology interest groups, leading to decisions on energy policy that do not optimize social welfare (Laffont and Tirole, 1998; Helm, 2010).

There are also economic barriers related to RE costs and externalities associated with energy production and use. Policymakers may not recognize the value of RE due to the higher costs of many RE technologies relative to current energy market prices. Further, although there is growing acceptance that the social costs and risks of energy use should be incorporated into the price of energy (Stern, 2007), it is difficult to quantify and internalize these costs (Stirling, 1994). If societies could reach a policy consensus on how much RE is socially desirable, in terms of how much extra society is prepared to pay, and/or in terms of a specific share of energy to be derived from RE sources, public policies could be implemented to reflect this social consensus. However, it is difficult for societies to make a rational choice about technology without full information.

Further, the existing energy system exerts a strong momentum for its own continuation (Hughes, 1987), which locks existing technologies and policies (mostly fossil fuel-based (IEA, 2009d)) in place and locks out new technologies and ways of doing things (Unruh, 2000). This dampens the drive for new policies while also making it harder for them to be put into practice because implementation occurs within the existing energy system. In addition, incumbents of the existing energy system enjoy greater organizational strength, more influential networks and increased lobbying power over newer RE technologies (Hughes, 1986), and thus have greater potential to influence policy design and enactment.

\subsubsection{Barriers to implementation of renewable energy policies}

Once policies have been enacted, challenges can arise related to implementation. These include conflicts with existing regulations; lack of skilled workers; and/or lack of institutional capacity to implement RE policies.

Regulation of markets and networks, including existing standards and licensing practices that were established to aid and maintain the existing energy system, can erect barriers to RE (Beck and Martinot, 2004; P. Baker et al., 2009; M. Baker, 2010). Existing administrative procedures often make it a lengthy and difficult process to change the scope or applicability of economic regulation to accommodate RE technologies (P. Baker et al., 2009; C. Mitchell, 2010).

In addition, workforce education and training generally reinforce incumbent technologies and lag behind the emergence of new technologies, constraining the rate of RE installation and maintenance. Even when programmes are in place, ramping up skills takes time. This lack of educational and skills base in turn constrains the knowledge about 
emerging options, and it aggravates a low awareness and acceptance by authorities, companies and the public (IEEE PES, 2009; Bird and Institute for Public Policy Research, 2009; Energy Skills Queensland, 2009; MERC Partners, 2009; European Centre for Development of Vocational Training, 2010).

Institutional barriers also hold back RE policymaking and implementation at all levels of government. Planning frameworks and institutional coordination for RE policy are often rudimentary or may not yet exist (ECLAC, 2009). Further, lack of coordination among overlapping national and local authorities, regarding such aspects as spatial planning for accommodation of RE installations, may lead to a long process for obtaining necessary permits (Ragwitz et al., 2007). In addition, in some municipalities, states/provinces or countries, the institutions needed to administer RE policies might not yet be in place (de Jager and Rathmann, 2008).

\subsubsection{Barriers to renewable energy financing}

As discussed in Section 11.2.2, financing is critical in every stage of technology development. Yet there are also many barriers that affect the availability of financing.

First, and most importantly, many RE technologies are not economically competitive with current energy market prices, making them financially unprofitable for investors absent various forms of policy support, and thereby restricting investment capital.

Second is a lack of information. To operate effectively, markets rely on timely, appropriate and truthful information. But energy markets are far from perfect; this is particularly true of markets in technological and structural transition, such as the RE market. As a result of insufficient information, underlying project risk tends to be overrated and transaction costs can increase as compared to conventional fossil fuel technologies (Sonntag-O'Brien and Usher, 2004).

Compounding this lack of information is the issue of financial structure. RE projects typically have higher investment costs and lower operating costs than fossil fuel technologies do. Their financial structure therefore requires a higher level of financing that must be amortized over the life of the project. This makes an RE investment's risk exposure a longer-term challenge than that faced with fossil fuel generating plants, which often have lower investment costs (Sonntag-O'Brien and Usher, 2004).

In addition to higher investment costs, financiers face other issues of concern that are related to RE projects. Besides having more assets at risk and over a longer time period, other aspects of risk also come into play. According to de Jager et al. (2010), private investors lack experience on the technology side (upstream) with new types of sponsors, business models, the markets and/or technologies involved. On the project side (downstream), their concerns often relate to the performance of the installation, the experience and reliability of the developer or owner, and difficulties in obtaining operating licenses, the purchase power agreement (PPA) and other administrative hurdles (de Jager et al., 2010).

The issue of project scale can also act as a barrier to RE financing. Since RE projects are typically smaller than traditional fossil or nuclear projects, the transaction costs are disproportionately higher. Any investment requires initial feasibility and due diligence work, and the costs for this work do not vary significantly with project size. As a result, pre-investment costs, including legal and engineering fees, consultants and permitting costs have a proportionately higher impact on the transaction costs of RE projects. Furthermore, the generally smaller nature of RE projects results in lower gross returns, even though the rate of return may be well within market standards of what is considered an attractive investment (Sonntag-O'Brien and Usher, 2004).

Developers of RE projects are often under-financed and have limited track records. Financiers therefore perceive them as being high risk and are reluctant to provide non-recourse project finance where the financier cannot recover the loan beyond the value of that specific project's assets and revenues. Lenders wish to see experienced construction contractors, suppliers with proven equipment and experienced operators. Additional development costs imposed by financiers on under-capitalized developers during due diligence can significantly jeopardize a project (Sonntag-O'Brien and Usher, 2004).

Further, institutional weakness including imperfect capital markets and insufficient access to affordable financing can inhibit private sector engagement in RE project finance. In many countries, the financial sectors are not developed sufficiently to provide the form of long-term debt that RE and related infrastructure projects require (UNEP, 2008). This is a particular problem in many developing countries. A lack of appropriate financing mechanisms available to end users in developing countries is another significant barrier to RE uptake (Derrick, 1998). Stronger intervention may be necessary to unlock private sector investment in new technologies (UNEP Finance Initiative, 2009), particularly for off-grid and rural markets.

\subsection{Experience with and assessment of policy options}

This section explains the policies currently available and in use around the world to support RE technologies - from their infant stages, to demonstration and pre-commercialization, and through to maturity and wide-scale deployment-in order to address existing barriers outlined in Section 1.4 and many of the barriers in Section 11.4, and to enable $\mathrm{RE}$ to play a significant role in mitigating climate change. These include government R\&D policies (supply-push) for advancing RE technologies, and deployment policies (demand-pull), which aim to create a market for RE technologies. This section focuses on policies directly supporting $\mathrm{RE}$, based on the assumption that policymakers are aiming to increase 
RE levels based on drivers of their choosing. For those policymakers targeting climate change mitigation goals, the interplay between RE and climate policies is discussed in Section 11.5.7.3.

Policies could be categorized in a variety of ways and there exists no globally agreed list of RE policy options or groupings. For the purpose of simplification, this chapter organizes R\&D and deployment policies within the following categories:

- Fiscal incentive: actors (individuals, households, companies) are allowed a reduction of their contribution to the public treasury via income or other taxes or are provided payments from the public treasury in the form of rebates or grants.

- Public finance: public support for which a financial return is expected (loans, equity) or financial liability is incurred (guarantee); and

- Regulation: rule to guide or control conduct of those to whom it applies.

RE policies are often linked to national or regional targets, such as the EU RE Directive, which calls for RE to provide $20 \%$ of energy used in the EU by 2020. Literature is lacking that provides evidence of whether targets, absent obligatory mandates or implementing policies, make RE policies more efficient or effective within the energy system. Although targets are a central component of policies, policies in place may not need specific targets to be successful. Further, targets without policies to deliver them are unlikely to be met, as seen in the Pacific Island States where RE targets and financing without appropriate RE policies have been insufficient to achieve significant progress with RE (See Box 11.1).

After a discussion on policy evaluation criteria (Section 11.5.1), this section first summarizes the policy options for R\&D and the important interactions of R\&D policies with deployment policies (Section 11.5.2). Most of the section then focuses on policies for RE deployment, with a general overview of policy options (Section 11.5.3) and then sectorspecific (electricity, Section 11.5.4; heating and cooling, Section 11.5.5; transportation, Section 11.5.6) assessments and lessons learned based on experiences to date. The section concludes with some general findings, a discussion of the macroeconomic impacts of RE policies, and a review of the possible positive or negative interactions between RE and carbon policies. Only those policies specifically targeting RE advancement are covered in this section; a full discussion of policies required to create an enabling environment for RE is provided in Section 11.6.

\subsubsection{Criteria for policy evaluation}

The success of policy instruments is determined by how well they are able to achieve various objectives or criteria. To the extent that literature is available, this section assesses policies based on a variety of criteria that have been used for evaluating policy instruments (Bohm and Russell,
1985; Hanley et al., 1997; Aldy et al., 2003; Hanley et al., 2004; Huber et al., 2004; Sawin, 2004; Gupta et al., 2007; Bergek and Jacobsson, 2010; European Commission, 2010; Verbruggen, 2010; among others). These criteria include the following:

- Effectiveness: the extent to which intended objectives are met, for instance the actual increase in the amount of RE electricity generated or share of RE in total energy supply within a specified time period. Beyond quantitative targets, factors may include achieved degrees of technological diversity (promotion of different RE technologies), which is considered a crucial factor for dynamic effectiveness (long-term sustained growth that enables innovation and the development of a manufacturing base), or of spatial diversity (geographical distribution of RE supplies).

- Efficiency: the ratio of outcomes to inputs, or RE targets realized on economic resources spent, mostly measured at one point in time (static efficiency); also called cost-effectiveness. Dynamic efficiency adds a future time dimension by including how much technology development and innovation is triggered by the policy instrument. Reducing the risks to investors is crucial for minimizing costs of financing, which in turn reduces project costs.

- Equity: the incidence and distributional consequences of a policy, including dimensions such as fairness, justice and respect for the rights of indigenous peoples. Equity can be assessed, in part, by looking at the distribution of costs and benefits of a policy (e.g., a policy that follows the polluter pays principle is generally considered to be fair (Heyward, 2007)), and/or by evaluating the extent to which it allows the participation of a wide range of different stakeholders (e.g., equal rights to independent power producers and to incumbent utilities). Excess profits, created by suboptimal policy designs, transfer money from rate- or taxpayers to mostly incumbent power producers, undermining equity (Verbruggen, 2009; Bergek and Jacobsson, 2010).

- Institutional feasibility: the extent to which a policy instrument is likely to be viewed as legitimate, gain acceptance, and be adopted and implemented. Institutional feasibility is high when policies are well adapted to existing institutional constraints. Economists traditionally evaluate instruments for environmental policy under ideal theoretical conditions; however, those conditions are rarely met in practice, and instrument design and implementation must take political realities into account. In reality, policy choices must be both acceptable to a wide range of stakeholders and supported by institutions. In market economies, instruments need to be compatible with markets. An important dimension of institutional feasibility addresses the ability to implement policies once they have been designed and adopted.

Other criteria are also examined in the literature, including subcategories of the four set out above. But most literature focuses on effectiveness and efficiency of policies, which are therefore the main criteria that 


\section{Box 11.1 | Lessons from the Pacific Island States: Renewable energy target setting.}

The Pacific Islands, home to more than 1.5 million people, are among the most vulnerable places in the world to the impacts of climate change. Although their contribution to global GHG emissions is negligible, the islands are blessed with significant RE resources and are receiving significant donor assistance that is specific to RE: the Global Environment Facility (GEF) contributed approximately USD 30 million during 2000 through 2009 (SIS, 2009), and development partners have allocated a further estimated USD 300 million in funding for 2010 to 2015 (SPC, 2010). ${ }^{1}$ RE is increasingly viewed as a means for achieving energy security—supporting accessibility, affordability, productivity and clean energy (SPC, 2010).

In response to these factors, the Pacific Island countries have adopted national RE targets and made commitments to pursue a RE development path. For example, Fiji targets at least $90 \%$ of its energy needs to be met with RE by 2011 , Nauru targets $50 \%$ of its energy to be derived from RE by 2015 and Vanuatu's power utility will generate 25\% of its electricity from RE by 2012 (PEMM, 2009). Both Tonga and Tuvalu have incorporated RE targets into their national energy strategies (PIFS, 2009a). Tonga originally set itself a 50\% RE target in three years, but has since redirected its approach by adopting a Tonga Energy Roadmap (TERM) with the objective of finding a least-cost implementation plan that involves energy efficiency improvements and a shift from fossil-based electricity generation to RE (Government of the Kingdom of Tonga, 2010). At their annual meeting in 2010, the Pacific Island Leaders adopted a regional framework for Energy Security in the Pacific which is based on the premise of 'Many Partners One Team One Plan' (PEMM, 2009; PIFS, 2010).

However, the RE target commitments made are ambitious and require a full understanding of RE resource potential, RE investment costs, and their technical and economic viabilities. Thus far the general progress towards the RE target is slow. Experiences imply that setting RE targets and having significant amounts of financing available are both important factors in advancing RE, but they are not sufficientthey need to be backed by appropriate policies and they must be realistic and practical (PIFS, 2009b, 2010).

Note: 1. Conversion to 2005 dollars is not possible given the range of study-specific assumptions.

serve as the basis of some of the discussion in Section 11.5. Ultimately, however, criteria for judging how well policies work will depend on the policy goals of the jurisdiction that enacts and implements those policies.

\subsubsection{Research, development and deployment policies for renewable energy}

\subsubsection{Why and when public research and development} is needed

While private sector engagement in the R\&D process is essential, and ultimately comprises the majority of investment, governments play a crucial role in funding RE R\&D for several reasons. First, it is difficult for private companies to fully appropriate investments in some R\&D activities, especially early stage ones (Nelson, 1959), which reduces incentives to invest (Jaffe et al., 2005). Second, firms may be reluctant to take on the risk associated with investing in a new technology that may not ultimately succeed (Siddiqui et al., 2007; Popp, 2010). Third, the time involved with bringing a technology from the R\&D phase to adoption in the marketplace sufficient to pay back investments may be beyond that required by private investors (Meijer et al., 2007a,b; Kenney, 2010). And fourth, expected future payoffs may not stimulate private sector R\&D because future markets for RE technology may be considered too uncertain, especially because RE markets are typically heavily influenced by policy decisions, which can change and thus make markets volatile and risky (Yang et al., 2008; Blyth et al., 2009; Nemet, 2010b). It is for these reasons that the R\&D and innovation market failure was described earlier as a key factor motivating the need for policy intervention beyond carbon pricing to most efficiently address climate mitigation.

Not all countries can afford to support R\&D with public funds, but in the majority of countries where some level of support is possible, public R\&D for RE enhances the performance of nascent technologies so that they can meet the demands of initial adopters and it improves existing technologies that already function in commercial environments. Investments falling under the rubric of R\&D span a wide variety of activities along the technology development lifecycle, from RE resource mapping to improvements in commercial RE technologies. The magnitudes of investments required in each stage vary substantially; importantly, the costs of progressing from one stage to the next generally increase (NSB, 2010). Several studies claim that current levels of public (and private) investment in RE R\&D are too low to address energy-related concerns including climate change (Schock et al., 1999; Holdren and Baldwin, 2001; Davis and Owens, 2003; Nemet and Kammen, 2007; Weiss and Bonvillian, 2009).

As with any new technology, RE technologies at some point are likely to traverse the point just before a technology has proven itself and is ready for widespread deployment. The so-called 'valley of death' is a particular problem associated with the integration of $R \& D$ and demand side (or 
deployment) policies (Murphy and Edwards, 2003; Weyant, 2010). This stage of development is characterized by a troublesome combination of a substantial increase in the scale of investment required, unproven technical reliability, uncertain market receptiveness and outcomes that are likely to be highly beneficial to companies other than those making an investment. One way of putting it is that social returns to investment at this stage far exceed private returns; a lack of investment by both the public and private sector has been a typical result.

This stage of the technology innovation process is particularly amenable to cost sharing between governments and private firms, and industrial consortia, as with PV in Japan (Watanabe et al., 2004). In the USA and Europe, public-private partnerships for demonstration (where industryled projects demonstrate new technologies with government co-funding) are increasingly viewed as one appropriate vehicle to vault this 'valley' (Strategic Energy Technology Plan, 2007; House of Commons, 2008; US DOE, 2009).

The need for R\&D continues even after technologies reach commercial deployment. Scale economies and learning by doing may dominate innovation at the deployment stage, but codification of experiencederived changes, improvement of manufacturing processes, increasing reliability and the development of supporting innovations may all benefit from sustaining R\&D during deployment. Continuing R\&D support offers many opportunities to accelerate cost reductions and performance improvements (Neuhoff, 2005). Examples of important post-deployment R\&D programs include wind power in Germany and Denmark (Langniß and Neii, 2004) (see Boxes 11.6 and 11.12), concentrating solar thermal electric generation in California in the 1980s (Lotker, 1991; Cohen et al., 1999) and the US PV manufacturing program in the 1990s and 2000s (R. Mitchell et al., 2002; Jayanthi et al., 2009).

While RE R\&D investment is typically associated with the accumulation of new knowledge, technical know-how developed through R\&D can lose its value over time. Knowledge depreciates when employees turn over and tacit knowledge in researchers' heads is lost, and existing knowledge becomes obsolete once it is no longer suitable for application to updated processes and techniques (Argote et al., 1990). Depreciation of $R \& D$ assets may be especially problematic in RE where funding levels are volatile and technological change is rapid, for example in PV (Watanabe et al., 2000). Stable funding levels, retention of personnel, as well as codification of techniques and experimental outcomes, can avoid the waste associated with preventable depreciation of $R \& D$ investments.

An essential element of R\&D projects is the stochastic nature of the results: the outcomes of R\&D investments are inherently unknowable in advance. Moreover, analysis of past energy R\&D investments shows that benefits attributable to a small number of successful projects more than make up for the investments in projects that did not result in commercial applications (NRC, 2001). Further, an important determinant of the social value of RE investments is how quickly they become adopted by the market (Moore et al., 2007). One implication of unknowable ex ante technical and market outcomes is that evaluation of RE R\&D is best suited to considering investments as 'insurance' (Schock et al., 1999), a 'hedge' (E. Baker et al., 2003), and as having 'option value' (Davis and Owens, 2003; Siddiqui et al., 2007). Prospectively, an important way to address inherently uncertain returns on $R \& D$ is to make use of an aggregation of expert opinions on expected future technology outcomes (NRC, 2007). Finally, these features of RE R\&D investments make them particularly amenable to consideration of them as portfolios of investments (Frenken et al., 2004; Richels and Blanford, 2008; Blanford, 2009). Key considerations in portfolio design are: level of tolerance for risk; when to support diversity and when to eliminate options; whether investments are characterized by critical minimal scale or diminishing returns; and how to populate the probabilities of successful outcomes (Nemet, 2009; Sovacool, 2009b).

Critics of public investment in R\&D for RE cite the possibility that public spending crowds out private investment (Goolsbee, 1998; David et al., 2000), the mixed record of success in past investments (Cohen and Noll, 1991), and the tendency to isolate scientific understanding from technical knowledge (Stokes, 1997). However, recent work on RE finds limited evidence of crowding out (Popp and Newell, 2009).

\subsubsection{Public research and development measures}

Table 11.1 presents a list of RE policies for R\&D and their definitions. One general trend is that policy measures in the RD\&D sphere are becoming more collaborative and innovative as governments seek new means of tapping into potential financiers, investors and innovators. Collaboration encourages 'buy-in' from partners as early as possible in the technology development spectrum, and intends to use public money as efficiently and effectively as possible.

Fiscal incentives available to policy makers include the following, and more, as outlined in Table 11.1:

Contingent grants can serve to cover some of the costs during the highest-risk development stages and in some cases increase investor confidence, thereby leveraging highly needed risk capital.

Technology incubators can assist developers in covering operating costs, provide advice on business development and raising capital, help to create and mentor management teams, and provide energyrelated market research. An example is the UK Carbon Trust Incubator Programme, which furnishes an important stepping stone to commercialization for new sustainable energy and 'low carbon' technologies (UNEP, 2005).

Public Research Centres can provide a means for 'open innovation', a way for companies to acquire intellectual property by jointly contracting with one or more public R\&D centres, while endorsing both the costs and benefits associated with the innovation. It is currently developed for silicon PV cells in Belgium and the Indian government wants to explore a similar scheme (IMEC, 2009a,b; JNNSM, 2009). 
Table 11.1 | Definitions of existing R\&D policy mechanisms.

\begin{tabular}{|c|c|}
\hline Policy & Definition \\
\hline \multicolumn{2}{|l|}{ PUBLIC R\&D POLICIES } \\
\hline \multicolumn{2}{|l|}{ FISCAL INCENTIVES } \\
\hline Academic R\&D funding & $\begin{array}{l}\text { Investment monies provided to academics for undertaking creative work to increase stock of knowledge in a particular field and use it to } \\
\text { devise new applications. }\end{array}$ \\
\hline Grant & $\begin{array}{l}\text { Funding for R\&D and demonstration with no repayment requirements. Challenge grants are provided alongside industry commitments, often } \\
\text { targeting product innovations or early manufacturing facilities. Contingent grants are loans that do not require repayment unless and until } \\
\text { technologies and intellectual property have been successfully exploited. }\end{array}$ \\
\hline Incubation support & Assistance to entrepreneurs including business development and raising financing. \\
\hline National/International Public Research Centre & Research facility funded by local, national or international government bodies or publicly funded organizations. \\
\hline Public-private partnership & $\begin{array}{l}\text { Arrangement typified by collaboration between the public and private sectors. Can cover delivery of policies, services, technologies and } \\
\text { infrastructure. }\end{array}$ \\
\hline Prize & Awarded to winning competitors to help finance costs of private R\&D; generally used in innovation stage. \\
\hline Tax credit & Allows investments in RE R\&D to be fully or partially deducted from tax obligations or income. \\
\hline Voucher scheme & Provides companies access to R\&D centres for the purpose of doing research. \\
\hline \multicolumn{2}{|l|}{ PUBLIC FINANCE } \\
\hline Venture capital & Financing aimed at turning promising research into new products and services; invested independently or with matching private investors. \\
\hline Soft/convertible loan & $\begin{array}{l}\text { Financing instrument available at pre-commercial stage to promote and commercialize RE technologies; often loans are repayable only once } \\
\text { technology reaches commercialization. }\end{array}$ \\
\hline
\end{tabular}

Public-private partnerships in research can include co-funded research, which has the benefit of creating direct research networking among different sectors (academy, industry), disciplines or locations. It may enable partners to take bigger risks, move off the beaten track, and to build a supply chain and ultimately realize a product, process or business model. Research networks can draft joint action plans in order to meet short-, medium- and long-term goals for technology performance and cost (IEA, 2008a); governments can then scrutinize and adopt these plans. Road mapping is one example of collaborative R\&D that has been outlined in Japan for PV technology (see Box 11.2), and in the European region (Strategic Energy Technology Plan, 2007; NEDO, 2009).

Prizes are sometimes used to foster technology development. While the $R \& D$ risk lands on the shoulders of the competitors, they have freedom in the way they approach innovation and the competition process is sometimes easier than applying for public grants (contracting, reporting, control) (Peretz and Acs, 2011).

Besides R\&D support, public funding is also needed to help move technology innovations through the product development stages towards commercialization. To convince investors, developers must prove that their technology will be able to perform in real market conditions and be commercially viable (UNEP, 2005). In addition, governments are starting to implement new financing mechanisms that are capitalized by public sources, such as convertible loans and publicly backed venture capital, in order to push technology innovation towards the market and to engage commercial investment in the RE sector (UNEP, 2005).

Various government agencies in the USA, Australia and the UK have been experimenting with venture capital mechanisms as part of their overall industrial and economic development policy aimed at turning promising research into new products and services (SEF Alliance, 2008). More than one mechanism can be used at a time-for example, the US state of Connecticut combines grant support for demonstration projects with a soft loan that is repayable if the technology reaches commercialization.

\subsubsection{Lessons learned}

Successful subsidies lead technology innovators towards commercialization and help attract early and later risk capital investment that otherwise would not be available because investors see high risk and protracted investment horizons. Further, experience has shown that it is important that subsidies for R\&D (and beyond) are designed to have an 'exit strategy' whereby the subsidies are progressively phased out as the technology commercializes, leaving a functioning and sustainable sector in place (ICCEPT, 2003). Subsidy policies can be designed to avoid dependence (i.e., a tendency to keep technologies at the R\&D and first demonstration stages rather than moving them on to deployment) and instead to grow a new technology area while minimizing market distortions. Grant-support models that are linked to performance, for example, can allow developers to build a track record, which is not possible if only traditional up-front grants are used.

Successful outcomes from R\&D programmes are not solely related to the total amount of funding allocated, but are also related to the consistency of funding from year to year. On-off operations in R\&D are detrimental to technical learning, and learning and cost reductions depend on continuity, commitment and organization of effort, and where and how funds are directed, as much as they rely on the scale of effort (Grubler, 1998; Sawin, 2001). Karnoe (1990) compared the early US and Danish wind 


\section{Box 11.2 | Lessons from Japan: Coupling supply-push with demand-pull for PV.}

Japan turned to RE in search of energy security and stable supply after the first oil shock seriously weakened the nation's economy (Sugiyama, 2008). Starting in 1974, MITI (Japan's Ministry of International Trade and Industry) launched the 'Sunshine Project', which aimed to achieve technological progress with new energy technologies, and significant funds were directed to PV R\&D. The principal long-term target has been the development of highly efficient low-cost solar cells (Takahashi, 1989).

MITI worked to link its PV project to Japan's industrial development. Although the primary goal was development of solar energy technologies, MITI expected that technological advances could provide benefits that went well beyond the energy field. It was hoped that the national investment in PV R\&D would lead not only to provision of electric power on a large scale and realization of a domestic supply of energy, but also to new international markets for solar calculators and other appliances (Watanabe et al., 2000).

The investment paid off with the global increase in demand for electronic appliances and the expansion of a semiconductor market for computer 'chips'. By 1990, when MITI established an R\&D consortium for PV development (Photovoltaic Power Generation Technology Research Association), electronic machinery companies like Sanyo and Sharp were the major players. The result was a dramatic decrease in solar cell prices between 1974 and 1994, from 26,120 yen/W (38,580 yen ${ }_{2005}$ W $_{\left(U^{2}\right.}$ USD $\left._{2005} 350\right)$ ) to 650 yen/W (USD 2005 5.4) (Watanabe et al., 2000). Based on this achievement, in 1992 Japan's electric utility companies voluntarily started to purchase surplus PV power, helping to expand the market for grid-connected PV systems and to demonstrate PV's potential to meet domestic power needs.

In 1993, the purpose of RE advancement expanded to encompass sustainable development objectives, including $\mathrm{CO}_{2}$ reductions, and Japan made the transition to the 'New Sunshine Project'. Parallel to its R\&D efforts, Japan established targets for PV deployment and initiated a gradually-declining subsidy for residential rooftop PV systems, in exchange for operational data, with the goal of driving down PV costs through economies of scale and commercial competition among manufacturers. To create market awareness, the government began promoting PV through a variety of avenues, including television and newspapers (IEA, 2003a).

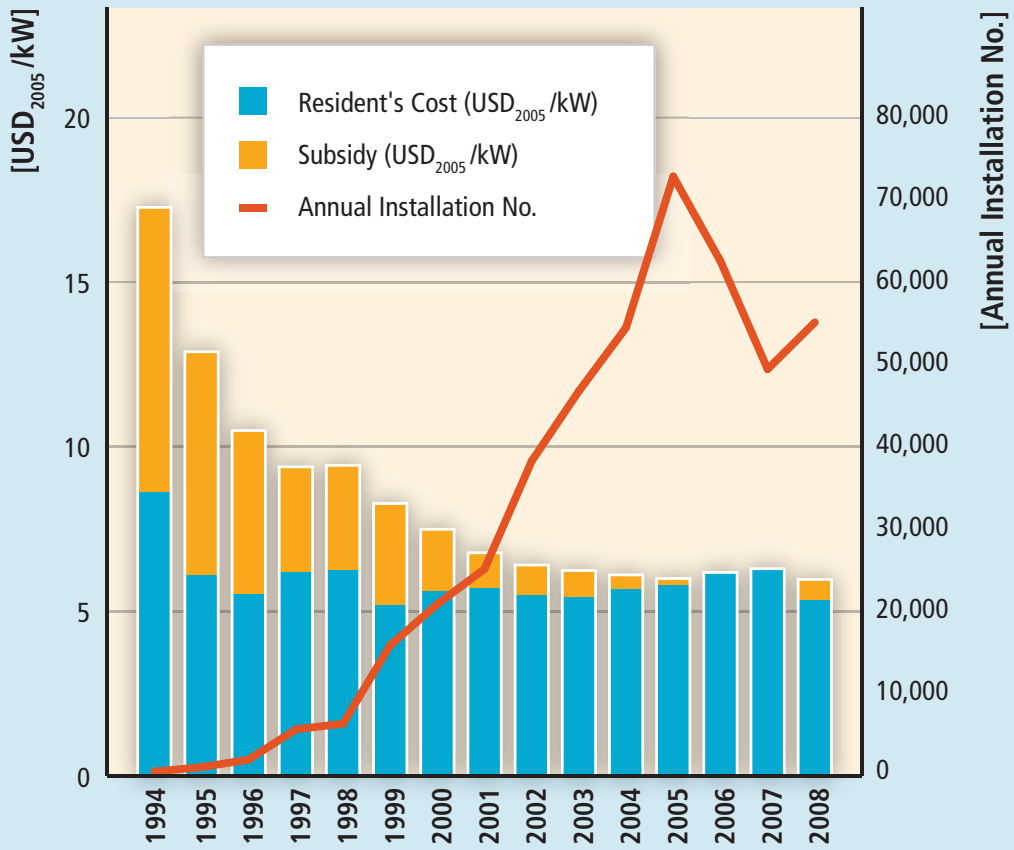

Figure 11.4 | Japan's rooftop PV: annual costs, subsidies and number of systems installed annually, 1994 through 2008 (Ito, 2003; Kobayashi, 2003; NEPC, 2009).

Note: 1. Levelized cost estimates based on the following assumptions: duration 20 years; capacity factor 12\%; and discount/interest $4 \%$. Assumptions are based on the practice of the Government of Japan.
The result was a dramatic increase in installed capacity and accompanying reduction in PV costs. Japan rose from a minor player to become the world's largest PV producer in less than a decade. Over the 1994 to 2004 period, system costs declined by two-thirds, from USD $200518\left(\mathrm{USD}_{2005} 1.2 / \mathrm{kWh}^{1}\right.$ based on $2000 \mathrm{yen} / \mathrm{W})$ in 1994 to $\mathrm{USD}_{2005} 6$ (USD $_{2005}$ $0.4 / \mathrm{kWh}$; based on 660 yen/W) in 2004 (NEDO, 2009), and annual installations increased more than 1,000-fold over this period, from $1.8 \mathrm{MW}$ in 1994 to 2,002 MW in 2004 (Ito, 2003; Kobayashi, 2003; NEPC, 2009). Despite these advances, market growth slowed after the subsidy program ended in 2005 (see Figure 11.4), and Japan's role in global PV manufacturing has subsequently declined in part as a result of the rising dominance of China's solar manufacturing sector.

In 2009, for the purpose of job creation and increased competitiveness in the international marketplace, the government established a buy-back system for residential rooftop PV (residential producers can sell excess power to the utility company at about twice the retail rate). The purpose was to further accelerate the introduction of PV and provide an incentive for customers to minimize their own 
electricity use in order to sell as much as possible to their utility (METI, 2009). In April 2010, a revised subsidy system started again, further boosting the domestic PV market.

For most of the past three decades, Japan has enacted effective and consistent policies to promote PV and has retained them even through major budget crises. Its experience suggests the importance of long-term targets and planning, the potential to link RE development to other applications and industries, as well as the positive feedback of declining costs, technology advances and increasing deployment that result from coupling supply push (R\&D) with policies to create a market.

energy R\&D programmes and found that, while the USA had invested a great deal more in funding, they were less successful in turbine development due to their focus on scale and other factors rather than reliability (Karnoe, 1990; Sawin, 2001). Garud and Karnøe (2003) argue that 'bricolage not breakthrough' —or progress via research aiming at incremental improvements versus radical technological advances - is the more successful approach to R\&D policy. Nemet (2009) also analyzed the value of incremental versus non-incremental approaches (see Section 11.7.4 for a longer discussion). Successful technology development occurring via the incremental approach is supported by detailed studies of RE technology development in Europe (Jacobsson and Johnson, 2000) as well as experiences in Japan and Thailand (see Boxes 11.2 and 11.7). However, others argue that both approaches are required simultaneously (O'Reilly and Tushman, 2004; Hockerts and Wüstenhagen, 2010).

Additionally, several key considerations exist for improving the effectiveness of future RE R\&D investments. Improved measurement and documentation of R\&D investment outcomes continues to be needed and can inform future decisions. Promising approaches to optimize public $R \& D$ investments include those informed by option value, portfolio analysis, and aggregation of expert opinion (NRC, 2007). Evaluation of programs based on the results of the overall portfolio, rather than individual investments, may lead to different incentives than exist today. The results of past investments have the potential to substantially improve the management of and budget allocations for government RE R\&D programs. Still, several types of decisions remain crucial, for example: how much diversification is optimal, given that there may be increasing returns to the scale of R\&D investment; consideration of whether public managers have incentives to take on more early stage technical risk than the private sector is willing to accept; when to patiently continue support and when to terminate programs with low likelihoods of success; and when to switch from emphasizing R\&D to emphasizing demand-side support (Nemet, 2010a).

\subsubsection{Positive feedbacks from combining research and} development policies with deployment policies

The timing of R\&D policies, and their balance with deployment policies, is also important (Langniß and Neij, 2004; Neij, 2008). One of the most robust findings, from both the theoretical literature and technology case studies, is that $R \& D$ investments are most effective when complemented by other policy instruments-particularly, but not limited to, policies that simultaneously enhance demand for new RE technologies. Relatively early deployment policies in a technology's development accelerate learning, whether learning through R\&D or learning through utilization (as a result of manufacture) (Neij, 2008), as seen in Japan and Denmark, for example (see Boxes 11.2 and 11.12). Disentangling the contributions of public R\&D spending and economies of scale to cost reduction is difficult, especially since the commercialization of the technology stimulates private sector investment in R\&D (Schaeffer et al., 2004). Nonetheless, existing literature suggests that R\&D and deployment policies used simultaneously can best induce innovation (Mowery and Rosenberg, 1979; Johnstone et al., 2010). Successful innovations show the ability to connect, or 'couple' a technical opportunity with a market opportunity (Freeman, 1974; Grubb, 2004), while studies of the effectiveness of technology policy for RE support this general consensus that both are needed (Grubler et al., 1999b; Norberg-Bohm, 1999; Requate, 2005; Horbach, 2007).

It is not simply that both factors contribute; they also interact because a positive feedback exists between R\&D and deployment (Watanabe et al., 2000) (see Figure 11.5). This cycle of positive feedback, and its resulting benefits, can also cause a positive feedback to the policy cycles (from agenda and target setting to policy implementation and evaluation), increasing acceptance for (more) ambitious policies. This dynamic mechanism in countries like China and Germany (see Boxes 11.11 and 11.6) has encouraged policymakers to introduce stricter RE targets (Jacobsson and Lauber, 2006; Jänicke, 2010). Real-world deployment experience can also reveal new challenges that require investments in R\&D to overcome them; it can facilitate the incorporation of market feedback about what customers actually want into subsequent R\&D decisions; and commercialization generally increases the ability of firms to profit from their inventions, heightening the incentives for private sector investment in R\&D (Nordhaus, 2010). An important result to consider in allocating between the two is that $R \& D$ typically dominates investment in the early stages of the innovation process, while deployment mechanisms are more important in the later stages (Dosi, 1988; Freeman and Perez, 1988). Moreover, not only are both types of policies needed, many different parties are likely to be needed in the commercialization of R\&D programs (Mowery et al., 2010). 


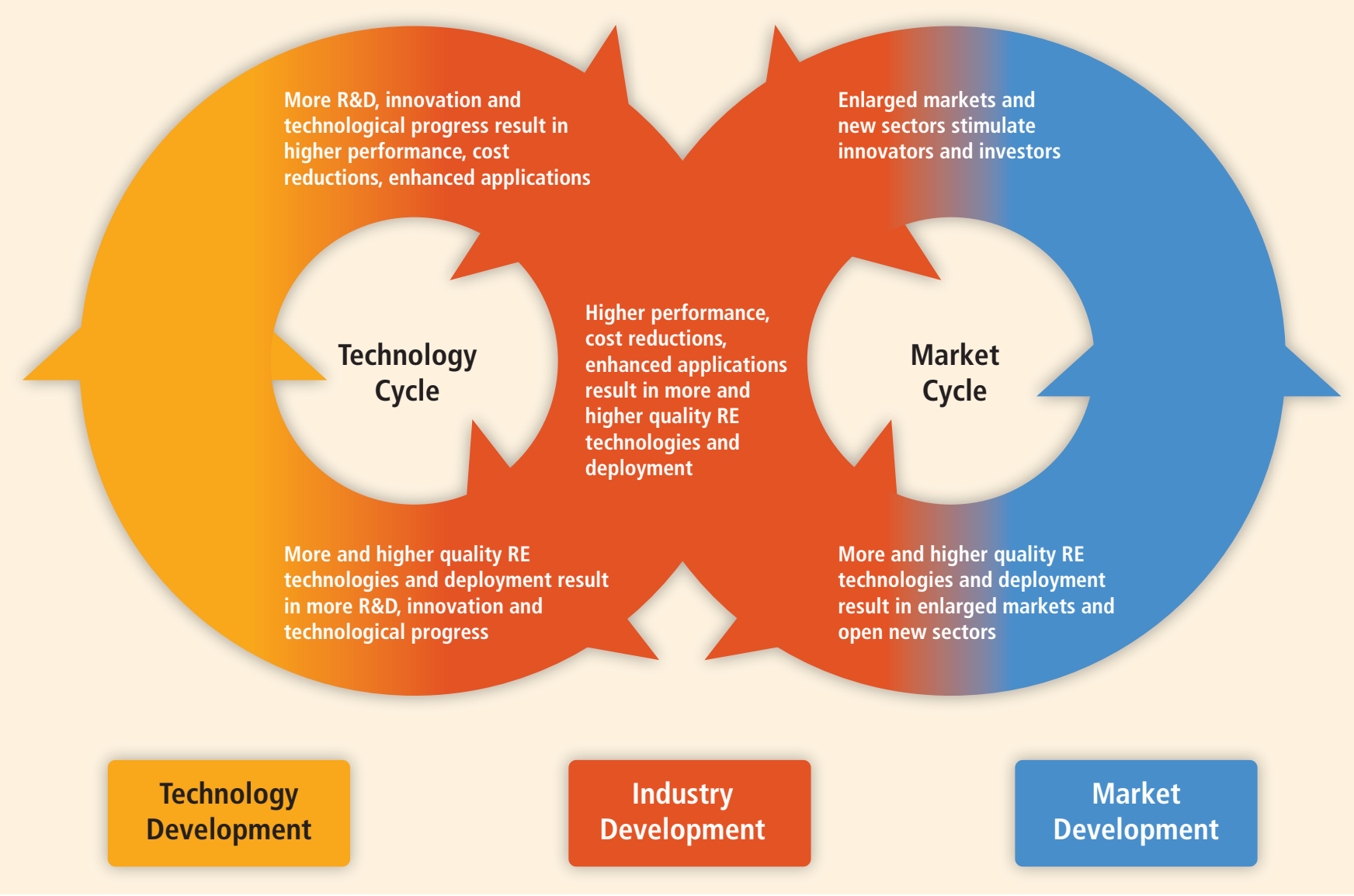

Figure 11.5 | The mutually reinforcing cycles of technology development and market deployment drive down technology costs (Based on IEA, 2003b).

\subsection{3}

\section{Policy options for renewable energy deployment}

This section provides an introduction to the RE-specific policy options for RE deployment-or demand-pull policies—-that create demand for RE technologies in the marketplace, as set out in Table 11.2. This section focuses primarily on fiscal incentives and public financing tools, which apply generally to all end-use sectors, though a brief discussion is also provided on regulatory policies. To the extent possible, analysis of these policy options is provided relative to the assessment criteria set out early in Section 11.5, with a focus primarily on effectiveness and efficiency. Most discussion surrounding regulatory policies along with sector-specific experiences and analysis can be found in the end-use sector-specific Sections 11.5.4 (electricity), 11.5.5 (heat) and 11.5.6 (transportation).

\subsubsection{Fiscal incentives}

Financial incentives of various forms - based on investment or production, and including tax credits, reductions and exemptions; accelerated or variable depreciation of investment expenditure; and rebates and grants (all set out in Table 11.2)—can reduce the costs and risks of investing in RE by lowering the upfront investment costs associated with installation, reducing the cost of production or increasing the payment received for energy generated with renewable sources. Fiscal incentives compensate for the various market failures that leave RE at a competitive disadvantage compared to energy market prices (Section 1.4.2), and help to reduce the financial burden of investing in RE. Setting the correct level of incentive requires care to ensure expansion without an excessive public burden (IEA, 2007a).

\section{Grants and rebates}

Some countries, like Japan and several US states, have promoted RE deployment by subsidizing investment through grants or rebates (Sawin, 2004). Grants consist of money provided up front to help finance an investment, whereas rebates are refunds provided after an investment has been made.

Capital grants and rebates assist directly with reducing the upfront investment cost of a plant, with a government typically providing a certain level of financial support, for example a refund per megawatt of installed capacity or a percentage of total investment, up to a specified limit. They can apply from the small scale, for example, a domestic solar thermal or PV system, through to large-scale generating stations such as biomass combined heat and power (CHP) plants. 
Table 11.2 | Definitions of existing RE-specific deployment policies and their use by sector.

\begin{tabular}{|c|c|c|c|c|}
\hline \multicolumn{5}{|c|}{ Electricity $(\mathrm{E})$, Heating $(\mathrm{H})$ and Transport $(\mathrm{T})$} \\
\hline Policy & Definition & $\mathbf{E}$ & $\mathbf{H}$ & $\mathbf{T}$ \\
\hline \multicolumn{5}{|l|}{ DEPLOYMENT POLICIES } \\
\hline \multicolumn{5}{|l|}{ FISCAL INCENTIVES } \\
\hline Grant & $\begin{array}{l}\text { Monetary assistance that does not have to be repaid and that is bestowed by a government for specified } \\
\text { purposes to an eligible recipient. Usually conditional upon certain qualifications as to the use, maintenance } \\
\text { of specified standards, or a proportional contribution by the grantee or other grantor(s). Grants (and rebates) } \\
\text { help reduce system investment costs associated with preparation, purchase or construction of RE equipment or } \\
\text { related infrastructure. In some cases grants are used to create concessional financing instruments (e.g., allow- } \\
\text { ing banks to offer low-interest loans for RE systems). }\end{array}$ & $x$ & $\mathrm{x}$ & $x$ \\
\hline Energy production payment & Direct payment from the government per unit of renewable energy produced. & $\mathrm{x}$ & $\mathrm{x}$ & $\mathrm{x}$ \\
\hline Rebate & $\begin{array}{l}\text { One-time direct payment from the government to a private party to cover a percentage or specified amount of } \\
\text { the investment cost of a RE system or service. Typically offered automatically to eligible projects after comple- } \\
\text { tion, not requiring detailed application procedures. }\end{array}$ & $x$ & $\mathrm{x}$ & $x$ \\
\hline Tax credit (production or investment) & $\begin{array}{l}\text { Provides the investor or owner of qualifying property with an annual income tax credit based on the amount } \\
\text { of money invested in that facility or the amount of energy that it generates during the relevant year. Allows } \\
\text { investments in RE to be fully or partially deducted from tax obligations or income. }\end{array}$ & $x$ & $x$ & $\mathrm{x}$ \\
\hline Tax reduction/exemption & $\begin{array}{l}\text { Reduction in tax-including but not limited to sales, value-added, energy or carbon tax-applicable to the } \\
\text { purchase (or production) of renewable energy or RE technologies. }\end{array}$ & $\mathrm{x}$ & $x$ & $\mathrm{x}$ \\
\hline Variable or accelerated depreciation & $\begin{array}{l}\text { Allows for reduction in income tax burden in first years of operation of RE equipment. Generally applies to } \\
\text { commercial entities. }\end{array}$ & $\mathrm{x}$ & $x$ & $x$ \\
\hline
\end{tabular}

\section{PUBLIC FINANCE}

Investment

Guarantee

Loan

\begin{tabular}{l|}
\hline Public procurement \\
\hline REGULATIONS \\
\hline Quantity-Driven
\end{tabular}

Renewable Portfolio Standard/ Quota obligation or mandate

\begin{tabular}{l|}
\hline Tendering/ Bidding \\
\hline Price-Driven \\
\hline Fixed payment feed-in tariff (FIT) \\
\hline Premium payment FIT \\
\hline Quality-Driven \\
\hline Green energy purchasing \\
\hline Green labelling
\end{tabular}

\section{Access}

Net metering (also net billing)
Financing provided in return for an equity ownership interest in a RE company or project. Usually delivered as a government-managed fund that directly invests equity in projects and companies, or as a funder of privately managed funds (fund of funds).

Risk-sharing mechanism aimed at mobilizing domestic lending from commercial banks for RE companies and projects that have high perceived credit (i.e., repayment) risk. Typically a guarantee is partial, that is, it covers a portion of the outstanding loan principal with 50 to $80 \%$ being common.

Financing provided to a RE company or project in return for a debt (i.e., repayment) obligation. Provided by government, development bank or investment authority usually on concessional terms (e.g., lower interest rates or with lower security requirements).

Public entities preferentially purchase RE services (such as electricity) and/or RE equipment.

\begin{tabular}{|c|c|c}
\hline$x$ & $x$ & $x$ \\
$x$ & $x$ & $x$ \\
$X$ & $x$ & $x$ \\
\hline$x$ & $x$ & $x$ \\
\hline
\end{tabular}

Obligates designated parties (generators, suppliers, consumers) to meet minimum (often gradually increasing) RE targets, generally expressed as percentages of total supplies or as an amount of RE capacity, with costs borne by consumers. Building codes or obligations requiring installation of RE heat or power technologies, often combined with efficiency investments. RE heating purchase mandates. Mandates for blending biofuels into total transportation fuel in percent or specific quantity.

Public authorities organize tenders for given quota of RE supplies or supply capacities, and remunerate winning bids at prices mostly above standard market levels.

\begin{tabular}{|l|l|l} 
& & \\
$\mathrm{X}$ & $\mathrm{X}$ & $\mathrm{X}$ \\
$\mathrm{x}$ & & \\
\hline
\end{tabular}

Guarantees RE supplies with priority access and dispatch, and sets a fixed price varying by technology per unit delivered during a specified number of years.

Guarantees RE supplies an additional payment on top of their energy market price or end-use value.

\begin{tabular}{|c|c|c}
\hline$x$ & $x$ & \\
\hline$x$ & $x$ & \\
\hline
\end{tabular}

Regulates the supply of voluntary RE purchases by consumers, beyond existing RE obligations.

Government-sponsored labelling (there are also some private sector labels) that guarantees that energy products meet certain sustainability criteria to facilitate voluntary green energy purchasing. Some governments require labelling on consumer bills, with full disclosure of the energy mix (or share of RE).

\begin{tabular}{|c|c|c|}
\hline$x$ & $x$ & $x$ \\
\hline$x$ & $x$ & $x$ \\
\hline
\end{tabular}

Allows a two-way flow of electricity between the electricity distribution grid and customers with their own generation. The meter flows backwards when power is fed into the grid, with power compensated at the retail rate during the 'netting' cycle regardless of whether instantaneous customer generation exceeds customer demand. 


\begin{tabular}{l|l|c|c}
\hline Electricity (E), Heating (H) and Transport (T) & E & H & T \\
\hline Policy & Definition & $X$ & $X$ \\
\hline $\begin{array}{l}\text { Priority or guaranteed access to } \\
\text { network }\end{array}$ & Provides RE supplies with unhindered access to established energy networks. & $X$ & $X$ \\
\hline Priority dispatch & Mandates that RE supplies are integrated into energy systems before supplies from other sources. & $\mathrm{X}$ \\
\hline
\end{tabular}

Notes: Assumes that transport is only liquid fuel-based and heat is only non-electric; electric-based transport or heat are covered under the electricity category.

Grants and rebates do not require a long-term policy and financial commitment to each specific project, and they can play a significant role in increasing deployment of small, customer-sited projects particularly for emerging renewable technologies (Wiser and Pickle, 1997). However, they have often failed to provide the stable conditions required to promote market growth and thus may not be effective at driving broad adoption of RE (Lantz and Doris, 2009). This is in part because they can be vulnerable to fluctuations in budgets to the detriment of stable demand growth, as with the German Market Incentive Program (Nast et al., 2007) and the UK's Low Carbon Building Programme (BERR, 2008).

Rebate programs function well when the rebate amount is tailored to existing market and policy conditions, when they are matched with a clear set of goals, and when used to advance technologies from the prototype stage to mass production (Lantz and Doris, 2009). Automatic rebates for eligible projects may be especially valuable for smaller-scale RE facilities that face investment cost barriers and where competitively awarded grants or other policy approaches may be less suitable due to the transaction costs of incentive administration.

Capital grants have both advantages and disadvantages (DEFRA/BERR, 2007; Connor et al., 2009). From the point of view of the recipient, they are very low risk, in the sense that payment is not subject to the vicissitudes of future policy. From the point of view of the payer, the value of the grant is known and does not create, at least in principle, any future liabilities. But while a grant may help get a facility built, without post-installation follow up it does not ensure that a project will operate or operate efficiently. Grants generally require oversight to ensure that certain preconditions are met, that the quality of new generating capacity meets at least a minimum standard, and that effective operation of installed systems is achieved. This implies additional administrative costs (DEFRA/BERR, 2007; Connor et al., 2009).

If the project fails, either under construction or subsequently, the grantor generally has little recourse. Grants are therefore most attractive for facilities that have significant investment costs, but relatively low operating costs. There is an argument that they are best suited to less mature technologies. Grants provide a straightforward way to stimulate investment and, potentially, to draw new investors. Grantors can increase the efficiency of grants through competitive awards, though this can increase administration costs and may be more effective for larger-scale developments due to the relevance of experience in preparing bids (van Dijk et al., 2003; Bürger et al., 2008; Connor et al., 2009).
The volume of funding and the continuous availability of grants or rebates can significantly influence their effectiveness in driving RE deployment. For example, there is some evidence that if funding runs out early in a program, consumers might delay an investment that they would have made without the grant, thus potentially reducing investment and the economic efficiency of applying public funds. Early exhaustion of funds also tends to indicate that the grant or rebate levels may have been set too high, since it implies that some projects not at the margin have received funding (van Dijk et al., 2003; Bürger et al., 2008; Connor et al., 2009).

\section{Tax Policies}

Tax credits, reductions or exemptions amount to tax-deductible sums that involve foregone government revenue and that are calculated as predefined fixed amounts or a percentage of total investment in an installation or on the basis of energy delivered. In theory at least, tax incentives are flexible tools that can be gradually increased or decreased as technologies and supply chains develop and as markets evolve. They can be targeted to specific technologies and/or selected markets, or applied more broadly (de Jager et al., 2010).

Tax policies can influence supply and demand sides. For example, production tax credits encourage an increase in production, whereas tax credits or exemptions for the use of RE electricity, heat or fuels affect the demand side. Investment tax credits focus on initial investment costs, whereas production tax credits address operating production costs. Tax reductions and exemptions may also cover property, sales, energy, carbon and value-added tax and act directly on the total payable tax, thereby reducing its magnitude and thus the total cost associated with development (Connor et al., 2009).

A study for the IEA Renewable Energy Technology Deployment implementing agreement determined that the effectiveness of fiscal incentives such as tax reductions or exemptions (e.g., from energy, carbon or other taxes) depends on the applicable tax rate (de Jager and Rathmann, 2008). In the Nordic countries, which apply relatively high energy tax rates, such tax exemptions can be sufficient to stimulate the use of renewable electricity; however, in countries with relatively low energy tax rates, they must be combined with other measures (European Commission, 2005). The current US federal investment and production tax credits (which provide a credit against income tax for each kWh or MJ of electricity produced) have created strong growth in the nation's wind and solar markets, but only when the credits have been in place 
for multiple years, allowing enough time from project planning through to completion (Sawin, 2004; Wiser et al., 2007).

Accelerated or variable depreciation that can be used as a means of reducing taxable income in the early years of an investment and therefore improving the economics of that investment, has been successful in encouraging small-scale wind development in Sweden and Denmark, in particular. In Denmark, this policy contributed to a significant increase in farmer-owned wind turbines during the mid-1990s (Buen, 2005; Barry and Chapman, 2009). Accelerated depreciation has also been extensively used in the USA for most RE technologies and in India for wind energy. Policies such as the Netherlands Willekeurige Afschrijving Milieu-Investeringen (VAMIL) programme, Canada's Accelerated Capital Cost Allowance and the UK's Enhanced Capital Allowance Scheme are examples of programmes that have been successful in the RE heating sector (Worrell and Graus, 2005; IEA, 2007b).

\section{Assessment of fiscal incentives}

The impacts of production and investment support instruments like investment grants, rebates and tax policies are difficult to measure as they are generally used as supplementary policy tools (European Commission, 2005; Klein et al., 2008a). In the EU, for example, only Finland and Malta used tax incentives and investment grants as their main support schemes as of 2008 (Klein et al., 2008a). Fiscal incentives have also been used as the primary means of support at the national level in the USA, although most US states have additional RE incentives or mandates in place (DSIRE, 2011).

Despite the difficulties in measuring their impact, some studies have found that financial incentives tend to be most effective when combined with other policy mechanisms (IEA, 2008a). Japan's solar roofs program of the 1990s and early 2000s combined rebates that declined over time with net metering, low interest loans and public education. This expanded capacity, which helped to drive down system costs, made Japan the world's leading manufacturer of solar PV, at least temporarily (Watanabe et al., 2000) (see Box 11.2).

In general, those countries that have relied heavily on tax-based incentives have often struggled with unstable or insufficient markets for wind power or biogas, for example (Lewis and Wiser, 2005). In the USA, this is due in part to the frequent expiration of the available tax credits, as seen in Box 11.5. It could also result from the fact that only a small number of players have enough tax liability to take direct advantage of the tax credits, meaning the value of the credit varies according to legal standing, income level or tax rate (Metcalf, 2008). This challenge can be addressed by making tax policies more inclusive or finding other policies that encourage broader participation (Mendonça et al., 2009). Generally, tax credits work best in countries where there are numerous profitable, tax-paying private sector firms that are in a position to take advantage of them.

Experience with wind energy policies suggests that cash payments may be preferable to tax credits because the benefits of payments and rebates are equal for people of all income levels and thus promote broader investment and use. Also, because they are generally provided at or near the time of purchase or production, they result in more even growth over time (rather than the tendency to invest in most capacity toward the end of a tax period) (Sawin, 2001). According to a 2009 UN Environment Programme report, the global economic slow-down of 2008-2009 made clear that markets driven by tax credits are generally not effective in a downturn (UNEP and NEF, 2009). Responding to the inability of investors to take advantage of federal tax credits during the economic crisis, the US government temporarily offered cash grants in their stead (Wiser and Bolinger, 2010) (see Box 11.5).

Incentives that subsidize production are generally preferable to investment subsidies because they promote the desired outcome-energy generation (Sawin, 2001); they encourage market deployment while also promoting increases in efficiency (Neuhoff, 2004). However, policies must be tailored to particular technologies and stages of maturation, and investment subsidies can be helpful when a technology is still relatively expensive or when the technology is applied on a small scale (e.g., small rooftop solar systems), particularly if they are paired with technology standards and certification to ensure a minimum quality of systems and installation (Sawin, 2001). Many have argued, for example, that wind power never would have taken off in California in the 1980s without investment credits because the risks and investment costs were high. Alternatively, production incentives can be paired with other policies that help to reduce the cost of financing (Sawin, 2001).

\subsubsection{Public finance}

The provision of public finance can also be of great importance for supporting RE uptake. RE projects generally operate with the same financing structures that apply to conventional fossil-fuelled energy projects. The main forms of capital involved include equity investment from the owners of the project, loans from banks, insurance to cover some of the risks, and possibly other forms of financing, depending on the specific project needs.

For many RE projects the availability of commercial financing is still limited, particularly in developing countries, where the elevated risks and weaker institutional capacities frequently inhibit private sector engagement. Often the gaps can be filled only with financial products created through the help of public finance mechanisms, which help commercial financiers act within a national policy framework, filling gaps and sharing risks where the private sector is initially unwilling or unable to act on its own (UNEP, 2008).

Public finance mechanisms have a twofold objective: to directly mobilize or leverage commercial investment into RE projects, and to indirectly create scaled up and commercially sustainable markets for these technologies. It is important to design policies such that their direct short-term benefits do not create market distortions that indirectly hinder the growth of sustainable, long-term markets (UNEP and BNEF, 2010). 


\section{Investments}

Public finance mechanisms can take the form of government funds set up to invest equity in private transactions, termed private equity. A public institution's role in the operation of private equity funds can be either as the fund manager, directly investing in projects or companies, or as a fund of funds, whereby they pool their monies alongside other investors in a private sector managed fund. Either way, the funds can be structured to provide a range of financial products, from venture capital for new technology developments, to early stage equity for project development activities, to late stage equity for projects that are already fully permitted and ready for construction (UNEP, 2008).

\section{Guarantees}

Guarantees can mobilize domestic lending by sharing credit risk, thereby reducing what local banks might perceive as a high credit risk (i.e., repayment risk) associated with some RE projects. Guarantees help banks to gain experience managing portfolios of RE loans, putting them in a better position to evaluate true project risks and thus addressing perceptions of elevated risk associated with RE projects (UNEP, 2008), as discussed in Section 11.4.3.

\section{Loans}

Loans (debt financing) account for the bulk of the financing needed for RE projects (London School of Economics, 2009). The challenges for mobilizing this debt relate to access and risk. As mentioned in Section 11.4.3, the financial sectors in many countries are not developed sufficiently to provide long-term debt required for RE and related infrastructure projects. Public finance mechanisms can be used to provide financing directly to projects or as credit lines that deliver financing through locally based commercial financial institutions.

Credit lines are generally preferable because they help build local capacity for RE financing (UNEP, 2008). For example, credit lines from the World Bank, Kreditanstalt für Wiederaufbau (KfW, Reconstruction Credit Institute) and the Asian Development Bank (ADB) helped the Indian Renewable Energy Development Agency (IREDA) become an important lender to India's RE sector, and key to its success. Incorporated in 1987, IREDA invests mainly as a senior lender and provides debt financing that covers up to $80 \%$ of project investment costs for terms up to 10 years. About one-third of its capital is now raised domestically, through bank borrowing and the issuance of tax-free bonds. IREDA is now working with state governments in India to replicate its capability through state energy conservation funds (UNEP, 2008).

Public loans are usually offered at concessional rates, or 'softened', and are relatively easy to administer (IEA, 2007b). Soft loans have long been a feature of German efforts in support of RE technologies; Norway and Spain also have loan programs relating to RE heat, and Japan and Sweden have employed soft loans for RE in the past (IEA, 2007b). Alternatively, approaches such as subordinated loans, which take a higher risk position in the financial structure (i.e., they get paid out only after the senior lenders are paid), can leverage higher levels of commercial financing (London School of Economics, 2009).
Public funds can also be used to buy down the interest rate, while a commercial finance institution provides the bulk of the financing. This reduces the interest rate seen by borrowers, effectively reducing the cost of financing. This approach has been applied successfully in India for domestic solar thermal and solar PV systems, in Tunisia for solar thermal and in Germany for a range of RE technologies (UNEP, 2008).

Other innovative lending mechanisms are arising at various levels of government, including the municipal level. For example, Property Assessed Clean Energy (PACE), which first emerged in the USA, has the potential to provide access to affordable financing while also helping to overcome the market failure of split incentives (see Section 1.4.2 and Box 11.3) With such mechanisms even small investors, such as home owners, are able to repay loans over the lifetime of their systems, with repayment essentially matched by energy savings (Fuller et al., 2009a).

\section{Public procurement}

Public procurement of RE technologies and energy supplies is a frequently cited but not often utilized mechanism to stimulate the market for RE. Governments can support RE development by making commitments to purchase RE for their own facilities or encouraging clean energy options for consumers. The potential of this mechanism is significant: in many nations, state and national energy purchases are the largest components of public expenditures, and also in many nations the state is the largest consumer of energy (IEA, 2009c).

\section{Assessment of public finance}

Public finance is most commonly employed today in developing countries where the commercial financial sector is usually less mature and therefore unable to provide RE companies and projects with the many types of financing they require (UNEP, 2008). In the developing world, development agencies and financing institutions partner with governments and the private sector to develop frameworks conducive for RE investments; they demonstrate innovative technologies, provide soft loans for sector investment plans and pave the road for market introduction. And they promote technology deployment by means of international carbon finance, in part by stimulating the use of the Kyoto Protocol's Clean Development Mechanism (CDM). Their work builds institutional capacities and is important for reducing financial and investment risk.

Development agencies and financing institutions include multilateral development banks, such as the World Bank and international development banks, and bilateral development banks that are supervised by individual developed countries. These two groups have been major drivers of RE deployment in some developing countries (SEI, 2009). International development finance institutions frequently work closely with national development banks in developing countries. Government development agencies and international environment programmes have also played an important role in disseminating best practices, supporting strategy and policy development, setting up training programmes for decision makers and strengthening institutions like Designated National Authorities under the CDM (UNEP, 2008). 


\section{Box 11.3 | Innovative financing: Berkeley Sustainable Energy Financing District.}

In 2007, the US city of Berkeley, California, established a Sustainable Energy Financing District (or Property Assessed Clean Energy, PACE) for which it issued bonds and used the proceeds to provide loans to property owners for energy efficiency improvements and/or the installation of solar PV systems. The loans to property owners typically have 20-year terms, allowing repayment to be matched with energy savings; thus, costs are not front-loaded but paid for during the period of use, and purchase decisions do not depend on the need for a quick payback. In existing and proposed programmes, the structure has allowed for locally appropriate and cost-effective technology choices (Fuller et al., 2009a). The city bears the credit risk of the loans but collects loan payments on the property tax bill. The tax assessment belongs to the property, rather than the individual end user, even when the property is sold, protecting the purchaser of the RE system from loss if they sell their home before their investment has been paid back in the form of energy savings.

Several other U S cities and counties have implemented PACE districts and more than 20 US states have enacted enabling legislation to launch PACE programmes; efforts are also underway in Germany, Italy and Portugal (Fuller et al., 2009b).

By late 2010, PACE programs across the USA were on hold, however, due to the severe US recession, which produced a record number of property foreclosures. As a result, the Treasury Department ruled that any policy increasing the debt burden was to be avoided, at least temporarily, and it was required that all PACE loans be paid off in full before the sale or refinancing of properties. Aside from the current US situation, PACE programmes are considered a positive force when economies are stable or growing (Kammen, 2009).

Coordination of public finance mechanisms is increasingly important as the number of funding initiatives increase and because there is a multitude of decentralized activities. The Paris Declaration and Accra Agenda for Action $(O E C D, 2008)$ have both formalized and helped to implement principles to improve the effectiveness of international development cooperation, leading to better coordination of international development cooperation in the climate change field, among others. However, financing RE projects and developing national frameworks through international donor coordination and alignment remain challenges. Decentralized and centralized models (e.g., Reed et al., 2009; Müller, 2010) are thus under discussion at the level of international climate negotiations in order to make best use of the capacity and experience of existing development and financing institutions in full alignment with newly created institutions.

A subject of growing research interest is the leveraging of private international investment flows by means of public funding that is delivered via development finance institutions (UNEP, 2008). Results and leverage factors are specific to the technologies, country conditions and the instruments applied (UNEP, 2008).

\subsubsection{Regulations}

As set out in Table 11.2, regulatory policies include quantity- and pricedriven policies including quotas and feed-in tariffs, quality aspects and incentives, and access instruments such as net metering. Below are short descriptions of each policy type. Details are provided here only for quality incentives, which are not discussed in Sections 11.5.4 through 11.5.6.

\section{Quantity- and price-driven policies}

Quantity-driven policies set the quantity to be achieved and allow the market to determine the price, whereas price-driven policies set the price and allow the market to determine quantity. Quantity-driven policies can be used in all three end-use sectors in the form of obligations or mandates. The best examples of price-driven policies to date are feed-in tariffs (FITs). Sections 11.5.4, 11.5.5 and 11.5.6 discuss these options in detail.

\section{Quality incentives}

Quality incentives include green energy purchasing and green labelling programs (occasionally mandated by governments, but not always), which provide information to consumers about the quality of energy products to enable consumers to make voluntary decisions and drive demand for RE.

In the USA, some states have required utilities to provide consumers with green energy options (in many places such options are also voluntary on the part of utilities), which enable consumers and institutions to procure RE for a portion or all of their energy needs. To date, most such programs have been in the electricity sector. Green energy can typically be purchased from utilities, retail suppliers in markets with retail competition, or in the form of RE certificates (RECS) that are sold separate from electricity (or heat/fuels). Retail premiums for green power products vary, but have generally declined in recent years (Bird and Sumner, 2010).

While voluntary commitments to purchase RE can help provide support for and awareness of the importance of RE, they may not be as 
effective as direct financial incentives or regulatory policies in driving new RE development because they rely on voluntary, often short-term commitments by purchasing entities (Gillenwater, 2008). However, voluntary markets may provide additional revenue streams and alternative markets for output that reduce risks for developers (Bird and Lokey, 2007). The impact on new development also depends on whether or not purchases are additional to regulatory requirements, such as quota obligations.

Green labelling of products is another example of quality incentives or regulations. For instance, the EU Guarantee of Origin (GO) is an electronic document with the sole function of providing proof to a final customer that a given share or quantity of energy was produced from renewable sources. GOs are used for green electricity products and quality labels, as these are systems based on voluntary participation. However, because these labels and products are based on demand for RE over and above that already being generated, they are likely to require implementation of a fully consistent and transparent system that can be audited to demonstrate additionality (Vrolijk et al., 2004).

\section{Access policies}

RE projects need to connect to networks in order to sell their electricity, heat, or fuels for heating, cooking and transportation. The ease and cost of doing this is also central to the ability of project developers to raise finance. Once connected, the generation has to be sold or 'taken' by the network. Connection and then sale of generation are two different requirements and it is important to overcome barriers to both. Access to markets-both physical connection and sale of energy or fuels produced-is provided via different policy mechanisms in each of the end-use sectors (i.e., access rules for electricity (Section 11.5.4), third party access (TPA) for heating (Section 11.5.5), blending mandates for biofuels (Section 11.5.6)).

\subsubsection{Policies for deployment - electricity}

To date, far more policies have been enacted to promote RE for electricity generation than for heating and cooling or for transport, and this is reflected in the vast literature available regarding RE electricity policies. It is important to note, however, that much of the literature describing and comparing these instruments, including their costs, is European, and grey, stimulated largely by the need of EU countries to fulfil their RE Directive requirements by 2020 (e.g., Haas et al., 2011).

After a short discussion of fiscal incentives and public finance, this section describes quantity-driven regulatory instruments, including quota obligations and tendering/bidding regulations, as well as price-driven regulatory policies. It then assesses these regulatory options relative to the criteria set out at the beginning of Section 11.5, particularly effectiveness and efficiency. The section concludes with a brief discussion of access policies.

\subsubsection{Fiscal incentives}

The range of fiscal incentives set out in Table 11.2 has been used to promote RE in the electricity sector. Assessment of policy options and impacts is found in Section 11.5.3.1.

\subsubsection{Public finance}

Loans and other public finance policies have been used to advance deployment of RE electricity technologies, for PV in Spain, for example (see Box 11.8), and innovative financing in many municipalities, as described in Section 11.5.3. Concessionary loans, guarantees and even equity investments have been used frequently in other contexts as well, including in developing countries. Government procurement is also an option that is of increasing significance in some countries, including the USA. For example, the US Energy Policy Act of 2005 requires federal agencies to obtain $7.5 \%$ of their electricity needs from renewable sources by 2013 and thereafter (US DOE, 2008b). In addition, many US state and local governments have made voluntary commitments to purchase renewable electricity for government facilities (USEPA, 2010a).

\subsubsection{Regulations}

\section{Quantity-based policy}

Quota obligations. Quota obligations are also known as Renewable Portfolio Standards (RPS) (among others) in the USA, Renewable Electricity Standards (RES) in India, Renewables Obligations (RO) in the UK, and Renewable Energy Targets in Australia (Lewis and Wiser, 2005). By early 2010, quotas were in place in 56 states, provinces or countries, including more than half of the US states (REN21, 2009b).

Under quota systems, governments typically mandate a minimum amount or share of capacity, generation or sales to come from renewable sources. Quotas tend to be placed on a purchasing authority, with any additional costs of RE generally borne by electricity consumers. There are significant variations of design from one scheme to the next (e.g., Verbruggen, 2009; Bergek and Jacobsson, 2010), even among various state-level policies in the USA (Wiser et al., 2007) and India (MNRE, 2010).

Quotas can be linked to certificate trading, for example 'tradable green certificates' (TGCS) in Europe, or 'renewable energy credits/certificates' (RECS) in the USA (Sawin, 2004; C. Mitchell et al., 2006; Ford et al., 2007; Fouquet and Johansson, 2008). Generally, certificates are awarded to producers for the renewable electricity they generate, and add flexibility by enabling actors with quota obligations to trade, sell or buy credits to meet their obligations-provided there is sufficient liquidity in the marketplace (Sawin, 2004). Electricity suppliers, or other agents in the power sector, 'prove' they have met their obligations by showing the 
regulator (or other executive body) the number of certificates equal to their obligation. Most quotas have built-in penalties for actors who do not comply with the quota (C. Mitchell, 2008).

One of the intrinsic effects of uniform RE quotas, for example in Sweden, is that only lowest-cost RE options achieve notable levels of deployment. This is because such policies fail "to trigger immediate deployment, enhancements and cost reduction of (RE) technologies which are currently still more expensive" (Resch et al., 2009). To overcome this drawback, technology-specific support can be introduced either via a banding approach (e.g., UK and Italy) or via 'carve-outs', which are subquotas reserved for specific technologies (popular in many U.S. states).

Quota schemes with banding enable less mature/more expensive RE technologies to receive a greater number of certificates per MWh generation (i.e., two ROCs/MWh in the UK rather than one ROC/MWh received for wind generation), which increases the value of the RE to the generator (ASIF, 2009). In a quota with carve-outs, a prescribed part of the overall target can be met by only a particular type, or types, of RE. In practice, this leads to a market separation and narrows the tradable volume within each sub-quota.

Experiences in Sweden (see Box 11.4), the USA (see Box 11.5) and Australia demonstrate that the effectiveness of quota schemes can be high and compliance levels achieved if RE certificates are delivered under well-designed policies with long-term contracts that mute (if not eliminate) price volatility and reduce risk (Lauber, 2004; van der Linden et al., 2005; Agnolucci, 2007; Rickerson et al., 2007; Toke, 2007; Wiser et al., 2007). More than $50 \%$ of total US wind power capacity additions between 2001 and 2006 were driven at least in part by state RPS laws (Wiser et al., 2007). As discussed in Box 11.5, the US experience has also shown the benefits of longer-term certainty provided by RPS laws in combination with stable and consistent fiscal incentives to address various barriers to RE deployment.

In some instances-including some US states (Wiser et al., 2007) and the UK - targets under quota schemes have not been achieved. For example, under the UK Renewables Obligation, eligible sources rose from $4.0 \%$ of electricity generation in 2005 to $5.4 \%$ in 2008, rather than the obligated increase from 5.5 to $9.1 \%$. Between 2005 and 2008, only 59 to $73 \%$ of each annual obligation was met, with an annual average of $65 \%$ (DUKES, 2009). In the USA, experiences in meeting set-asides (or carve-outs) have also been mixed, with only three of nine states with solar or distributed generation set-aside obligations in 2008 achieving their targets. One reason is caps set on the costs that utilities may bear, which have sometimes been set below the amount required to achieve existing targets. Despite such challenges, state RPS programs resulted in more than $250 \mathrm{MW}$ of new solar capacity through the end of 2009 (Wiser et al., 2010).

Electricity policy in the Canadian province of British Columbia provides evidence that it is possible for a quota system to achieve a very high rate of RE investment if the quota is high enough and backed by credible policy and legal requirements (Jaccard et al., 2011). In 2007, the province implemented a $93 \%$ clean energy requirement that is now backed by legislation (GBC, 2010). This step resulted in the cancellation of two proposed coal-fired plants (BC Hydro, 2006-2008) and accelerated RE deployment. As of late 2010, all new electricity investment $(2,260 \mathrm{MW})$ had been in RE capacity (BC Hydro, 2007-2010), acquired at the lowest possible cost because of the confidential, closed-envelope bidding system and the freedom of $B C$ Hydro to pick the lowest bids (Jaccard et al., 2011).

RE tendering or bidding. An alternative to the quota or price-driven mechanisms are bidding schemes, for example, the Non Fossil Fuel Obligation (NFFO) that was in place in the UK from 1990 to 1998 (C. Mitchell, 1995, 2000). Under the NFFO, a generator put in a bid to produce a specific amount of electricity from a particular technology at a certain price. The government accepted the cheapest bids up to a maximum, predetermined level. Generators had five years to install approved projects before forfeiting their contract. An NFFO contract provided generators with a fixed price for a certain number of years and a guaranteed a purchase contract for all generation (rather like a FIT), which could be used as the basis of financing. Problems with the NFFO included intense competition resulting from limited available funds (unlike a FIT), and a lack of penalties for failing to implement a contract, which led to bids at unattainably low prices. As a result, the NFFO did not deliver much deployment (C. Mitchell, 2000).

Bidding procedures for large onshore wind power plants and, later, wind turbines and offshore wind power plants, have also been common in China as one of two key policies driving growth in wind power plant installations since 2003 (the other being regionally differentiated FIT prices; see Yu et al. (2009); Liu and Kokko (2010); and Box 11.11). As in the UK, wind power plant bidding for both on- and offshore wind energy has led to concerns about price competition and the resulting low profitability of plant ownership (Han et al., 2009; Yu et al., 2009; Liao et al., 2010). A large number of wind power plants have come online as a result of the program, however, and bidding has also led to some level of price transparency that has been used in establishing FIT prices (Yu et al., 2009; Wang et al., 2010). More recently, somewhat similar bidding procedures have been extended to solar plants in China, for both PV and concentrating solar power (CSP).

Lessons learned. The most effective and efficient quantity-based mechanisms have included most if not all of the following elements, particularly those that minimize risk (Sawin, 2004; van der Linden et al., 2005; Wiser et al., 2005):

- Application to a large segment of the market (quota only);

- Clearly defined eligibility rules including eligible resources and actors (applies to quotas and tendering/bidding);

- Well-balanced supply-demand conditions with a clear focus on new capacities-quotas should exceed existing supply but be achievable at reasonable cost (quota only); 
- Long-term contracts/specific purchase obligations and end dates, and no time gaps between one quota and the next (quota only);

- Adequate penalties for non-compliance, and adequate enforcement (applies to quotas and tendering/bidding);
- Long-term targets, of at least 10 years (quota only);

- Technology-specific bands or carve-outs to provide differentiated support (applies to quotas and tendering/bidding); and

- Minimum payments to enable adequate return and financing (applies to quotas and tendering/bidding).

\section{Box 11.4 | Lessons from Sweden: Success with tradable renewable electricity certificates and bio- energy.}

The Swedish quota obligation scheme with tradable renewable electricity certificates (TRECs) went into force in May 2003. Its aim was to increase RE electricity generation 10 TWh (36 PJ) above 2002 levels by 2010. The scheme has subsequently been revised and extended several times, with the growth target raised in 2009 to 25 TWh (90 PJ) above 2002 levels by 2020. Electricity production eligible for TRECs includes all RE except hydropower greater than 1.5 MW and, since 2004, peat used in CHP production. Plants that were commissioned before introduction of the policy are entitled to certificates through 2012, while others can receive TRECs for 15 years, or until the end of 2035 , whichever is earlier.

RE electricity is sold at the market electricity price. However, in addition to income from the sale of electricity, RE producers receive income from the sale of TRECs, which are traded separately. Electricity suppliers are obliged to purchase TRECs corresponding to a certain proportion (legislated quota) of the electricity they sell. Only electricity used in manufacturing processes in electricity-intensive industries is excluded from the required quota. Suppliers annually submit the required amount of TRECs to the Swedish Energy Agency, one of the two authorities responsible for the scheme. The other authority, Svenska Kraftnät, is the state-owned company that administers and runs the national electrical grid. In case of non-compliance, a supplier must pay a penalty fee of $150 \%$ of the average annual price of TRECs.

The TREC scheme more than doubled eligible RE electricity production over a seven-year period, from 6.5 TWh (24.3 PJ) in 2002 to 14.7 TWh (52.9 PJ) in 2009_ or 15.6 TWh (56.2 PJ) in 2009 including peat (Swedish Energy Agency, 2010a). Biomass-based electricity production in CHP plants has experienced steady growth under the scheme, accounting for $63 \%$ of the TRECs in 2009. About half of the biomass CHP electricity is produced in district heating systems (see Box 11.9) and the other half in the pulp and paper industry.

Investments in wind power were initially restricted by the short time frame of the scheme, but conditions improved in 2006 after the scheme was extended and a 15-year support period was established. Wind power investments took off after that but have been slowed down by permitting and planning procedures. The permitting procedure for wind power was simplified in 2009, when two parallel processes were replaced by one. At the same time, however, local governments were given the legal right to veto wind power investments in their municipality, something that has become an important obstacle to wind power investments. In 2009, wind power producers received $16 \%$ of the TRECs (Swedish Energy Agency, 2010a).

The annual average price of TRECs has varied between USD $_{2005} 22$ and 41/MWh (approximately USD $\left._{2005} 6.1-11.4 / G J\right)$. In 2009, the scheme generated USD ${ }_{2005} 573$ million in income for RE electricity producers, while it increased the average cost of electricity to consumers by USD $_{2005}$ 6.6/MWh (approximately USD $\left.{ }_{2005} 1.83 / G J\right)$ (Swedish Energy Agency, 2010a).

Since 2006, the TREC scheme has fulfilled RE electricity targets by providing stable investment conditions. However, the scheme has been criticized for overcompensating biomass CHP, a fairly mature technology, and not driving technology development, requiring additional support for nascent technologies (Bergek and Jacobsson, 2010). So far the price of TRECs has been too low to generate investments in more expensive RE technologies; for example, solar electricity has received a negligible amount of TRECS.

Sweden's experiences with the TREC scheme show that this instrument, if appropriately designed (i.e., long time frame), can provide stable investment conditions and fulfil RE electricity targets. The scheme stimulates investments in the least expensive RE technology, and thus does not drive technology development unless specifically designed to do so. The experience with wind power shows that additional policies addressing non-economic barriers, such as the adoption of clearer permitting procedures, are also important for the diffusion of RE technologies. 


\section{Box 11.5 | Lessons from the USA: Mix of stable and consistent policies for wind power develop- ment.}

In the USA, installed wind energy capacity grew from 2.6 GW in 2000 to more than 40 GW in 2010 (Wiser and Bolinger, 2010; AWEA, 2011). Federal tax incentives, state RPS, other RE incentives and the improving economics of wind drove this development, most of which occurred towards the end of the decade (Menz and Vachon, 2006; Wiser et al., 2007; Adelaja et al., 2010).

From 1999 to 2004, failure to consistently renew the federal production tax credit (PTC), which provides approximately two cents per kilowatt-hour for the production from wind facilities for the first 10 years of operation, created a boom and bust cycle for wind development (Bird et al., 2005). Figure 11.6 shows the impact of allowing the PTC to expire at the end of 1999, 2001, and 2003, as installations peaked before the expiration and fell in subsequent years.

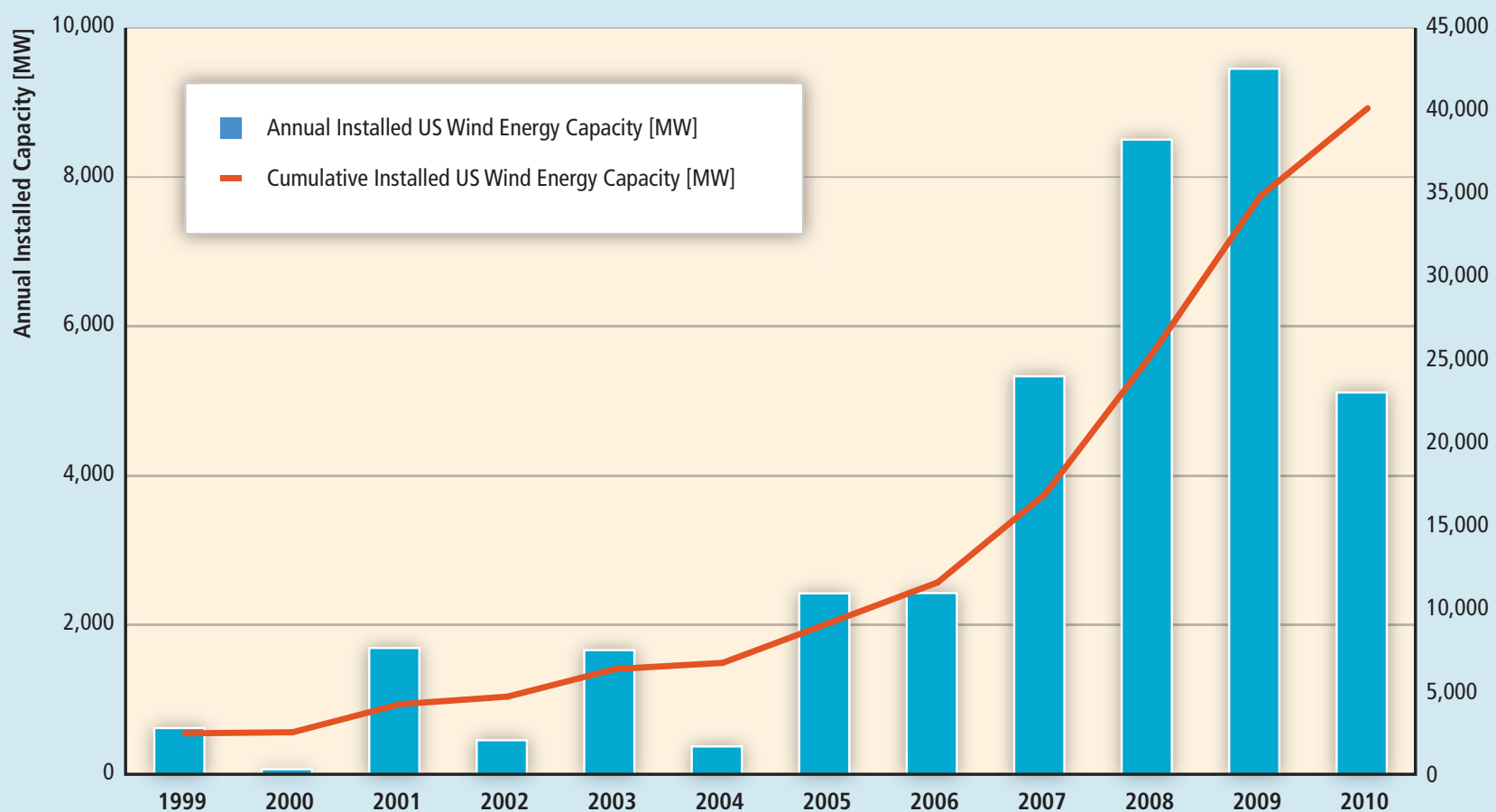

Figure 11.6 | US wind power annual installations and cumulative capacity, 1999 to 2010 (Wiser and Bolinger, 2010; AWEA, 2011).

However, between 2005 and 2009, the rate of annual installations climbed steadily, as federal tax credits were re-authorized before expiring, more states adopted RPS laws and many states strengthened pre-existing RPS targets. As of June 2010, 29 states had adopted an RPS and another 7 had established nonbinding renewable energy goals. Many states require electricity providers to obtain $20 \%$ or more of the power needed to serve their loads from RE sources by 2020. Collectively, these state RPS policies call for more than 65 GW of new RE by 2020 (Wiser and Barbose, 2008).

Some states have seen rapid RE growth through these policies, and Texas achieved its 2015 RPS target of 5 GW of installed renewable capacity six years early (ERCOT, 2010). However, the socio-political context and siting barriers have impeded development in other states (Fischlein et al., 2010), demonstrating the need to address barriers, such as siting and transmission, in addition to establishing targets and financial incentives.

Collectively, the combination of policies establishing binding, long-term state RE mandates and federal and state financial incentives, and efforts to address siting and financing barriers, have created greater market certainty and reduced regulatory risk, which in turn have contributed to investments in manufacturing capacity. Companies have also sought local manufacturing to reduce transportation costs and currency risks (Wiser and Bolinger, 2009, 2010). Between 2004 and 2009, US domestic manufacturing of wind turbines and their components increased 12-fold and, as of 2009, 16 turbine manufacturers had opened or announced plans for factories in the USA, up from only 1 turbine manufacturer in 2004 (AWEA, 2010). 
Starting in 2008, the federal government provided RE support as part of its effort to help fuel economic recovery. In response to the inability of investors to utilize tax incentives during the recession, the government provided project developers with the short-term option to receive cash grants in lieu of the federal tax credits and extended the tax credits for wind through 2012. This policy, which provided an important response to financial barriers to wind development, contributed to a record number of new wind power installations in 2009 (Wiser and Bolinger, 2010). However, installations slowed considerably in 2010 (AWEA, 2011). The slowdown resulted from a drop in wholesale power market prices driven by lower natural gas prices, and by reduced demand for RE because of a slowing in electricity consumption and the large amount of wind that came online the previous year, putting some states temporarily ahead of their RPS targets (Wiser and Bolinger, 2010).

Overall, the US wind industry experience over the last decade indicates the importance of a mix of stable, consistent and responsive long-term policies that address economic and other barriers to create investor and developer confidence and lead to a robust market and steady growth in manufacturing for renewable energy. State RPS requirements have provided greater market certainty and have influenced the location of development, while federal tax incentives have helped improve the cost-effectiveness of wind and other renewable technologies.

\section{Price-driven policies}

Price-driven policies set a price for RE electricity and let the market determine the quantity supplied (except for those systems with capacity caps, such as Spain with PV). They have been called feed-in tariffs (FITs), premium payments, standard offer contracts, minimum price payments, renewable energy payments, and advanced renewable tariffs (Couture and Gagnon, 2009; Couture et al., 2010). Price-driven instruments generally guarantee connection and access to the network, but not always. They have different impacts on investor certainty and payment, ratepayer payments, the speed of deployment, and transparency and complexity of the system, depending on details of their design (Couture, 2009).

The most important distinction is between FITs that set a fixed price that is independent of electricity market prices (e.g., used in Germany (see Box 11.6) and Greece), and those with premium payments (e.g., Denmark, the Netherlands and Thailand (see Box 11.7)), which provide fixed premiums on top of market prices for electricity. The four main approaches used to set FIT payments are levelized costs of RE generation, value of RE generation, simple fixed-price incentives based on neither generation costs nor notion of value, and auction-based mechanisms (Couture et al., 2010).

The fixed-price FIT typically also ensures connection to the network at a pre-agreed price and guarantees the purchase of all generation, sometimes with limited exceptions. These three factors (a set price independent of the electricity price, network connection, and guaranteed purchase) lead to an almost risk-free contract from the point of view of generators (Couture et al., 2010). European FIT policies generally extend eligibility to anyone who is able to invest (Couture et al., 2010). Rules concerning the costs of connection differ amongst different FIT schemes (for example, in Denmark, Germany and Spain these costs are capped) as does whether the generation has guaranteed purchase.

Premium payment systems have gained some ground in recent years. In some countries they are the primary form of support, whereas in others (e.g., Spain and the Czech Republic) they operate in parallel with fixedprice FITs. Premiums can be linked to electricity price developments (e.g., limited by a floor price or cap), or set adders; the former provides higher certainty and less risk of overcompensation. These systems provide a secure additional return for producers but, compared to fixed-price FITs, they provide less certainty for investors because producers are exposed to electricity price risk. This, in turn, implies higher risk premiums and a higher cost of capital. The advantage of premiums is that they encourage producers to adjust generation in response to market price signals (de Jager et al., 2010).

FITs can be very simple and available for one technology only, such as wind power, or they can be quite complex. For example, fixed payments can vary by technology according to state of development and/or generating costs. FITs are suited to incremental adjustments and payments can be increased or decreased as necessary to meet policy goals or to account for technology advances or changes in the marketplace. The costs of FITs can be covered by energy taxes, supplementary means such as auction of carbon allowances or, more frequently, by an additional per-kilowatt hour charge spread across electricity consumers, sometimes with exemptions, for example major electricity users in Germany (BMU, 2010).

To limit FIT-related expenditures and/or provide support where the benefit is greatest, tariffs can be 'stepped' so that payment levels are linked to available resource, location or time of day generated (Mendonça, 2007; Couture and Gagnon, 2009; BMU, 2010; Couture et al., 2010). Most price-driven policies include a regularly scheduled tariff degression (i.e., reduction in the tariff as applied to new eligible RE plants).

It is important to set the right price to avoid overpayment and overstimulation of the market, as well as high costs that might result from supporting significant installation of more expensive RE technologies. To this end, some countries (e.g., Spain) have established caps on annual payments or set limits on capacity that can qualify for payment. The 


\section{Box 11.6 | Lessons from Germany: From a single policy to a comprehensive approach.}

Germany has devoted significant resources to RE technology development and market deployment since the 1970s, driven by the oil crises and the anti-nuclear movement (Jacobsson and Lauber, 2006). As a result of public R\&D efforts, by the mid-1980s many technologies were ready for deployment even though they were not yet cost-competitive (IEA, 2004a). But in the 1980s and beyond, RE faced a largely hostile political-economic structure in Germany. Declining oil prices and surplus electric capacity in the late 1980s made it difficult for RE to compete in the market, while the electricity supply system was dominated by large utilities that opposed all small and decentralized forms of generation as uneconomic and foreign to the system (Jacobsson and Lauber, 2006).

In 1989, the government established a subsidy (€0.031/kWh, USD ${ }_{2005} 0.053 / \mathrm{kWh}$ or approximately $€ 8.6 / \mathrm{GJ}, \mathrm{USD}_{2005} 14.7 / \mathrm{GJ}$ ) for the first $100 \mathrm{MW}$ of wind power installed in Germany. Beneficiaries were obliged to report on performance so that a common knowledge base was established. In 1990, Germany's first FIT law was enacted, requiring utilities to connect RE power plants to the grid, purchase the generated power and buy the electricity at a specified percentage of the retail rate: for wind and solar energy, this amounted to $90 \%$ of the average tariff for final customers (Lauber and Mez, 2004).

The FIT was revised and broadened into the Renewable Energy Sources Act (Erneuerbare Energien Gesetz - EEG) in 2000, adding geothermal and large biomass power plants and introducing cost-based tariffs that are guaranteed to all RE generators for at least 20 years (Lipp, 2007). The remuneration decreases for new plants at a predetermined annual rate (Langniß et al., 2009). It obligates grid operators and electricity suppliers to purchase RE electricity (Langniß et al., 2009).

The EEG sets a target for 30\% of Germany's power to come from RE by 2020 (Büsgen and Dürrschmidt, 2009). It has been amended twice, reflecting progress in technology development and stringent requirements for RE integration (Büsgen and Dürrschmidt, 2009).

As installations increase, particularly for more expensive PV, the extra burden to consumers of financing the EEG has been discussed more widely. The total additional cost from PV support alone, granted through the EEG during 2000 through 2008, was an estimated $\epsilon_{2007} 35$ billion (USD 2005 41.6 billion) (Frondel et al., 2010); in 2007, the additional annual cost amounted to $€ 4.3$ billion (USD 2005 5.12 billion) (Büsgen and Dürrschmidt, 2009). Benefits include avoided $\mathrm{CO}_{2}$ emissions, saved fossil fuels, employment (Lehr et al., 2008) and merit-order effects (Sensfuß et al., 2008).

Several other policies have been used to promote deployment of RE electricity, to support further R\&D and to level the playing field (Laird and Stefes, 2009). Federal banks offered low-interest loans with favourable payment conditions, easing access to capital. Changes to German building codes granted RE the same legal status as other power generation technologies, and municipalities were required to allocate potential sites to wind power facilities in their land development plans (IEA, 2004b).

As a result, Germany has seen rapid growth of electricity generation from RE. Germany's share of electricity from RE rose from 3.1\% in 1991 to $7.8 \%$ in 2002, and more than doubled again by the end of 2009 to $16.9 \%$ (Wüstenhagen and Bilharz, 2006; BMU, 2009). Wind energy has experienced the greatest increase, but bioenergy and solar PV have grown substantially under this policy as well. (Note that wind-generated electricity declined towards the end of this period due to below average annual winds, but installed capacity continued to increase (BWE, 2011).) (See Figure 11.7.)

Since 2000, the focus of Germany's RE promotion policies has broadened to include heat and transport fuel markets. A comprehensive 'market acceleration programme' introduced to award investment grants and soft loans for RE heat systems was supplemented in 2009 with a mandate requiring a minimum share of RE heating/cooling in new buildings. Initially promoted through tax exemptions (Bomb et al., 2007), RE transport fuels are now mandated through a blending quota for fuel suppliers.

The government's overarching frame for RE development has been creation of ambitious targets for the use of RE in individual sectors and for the economy as a whole. The share of RE in total primary energy supply increased steadily from $1.3 \%$ in 1990 to $8.9 \%$ in 2009 (BMU, 2010; BWE, 2011).

Note: 1 . Note that the BMU reports data based on statistics that rely on the physical content method for primary energy conversion, whereas this report uses the direct equivalent method. 
The German example shows how rapidly RE can advance when supported by ambitious policies that convey clear and consistent signals and that adapt to technical and market changes. RE deployment policies can start with simple incentives, evolving towards stable and predictable policies and frameworks to address the long-term nature of developing and integrating RE into existing energy systems. However, integration of RE remains a constant challenge as indicated by recent limitations of the German electricity network to absorb rising shares of RE, and the cost implications of Germany's program have also begun to attract concern.

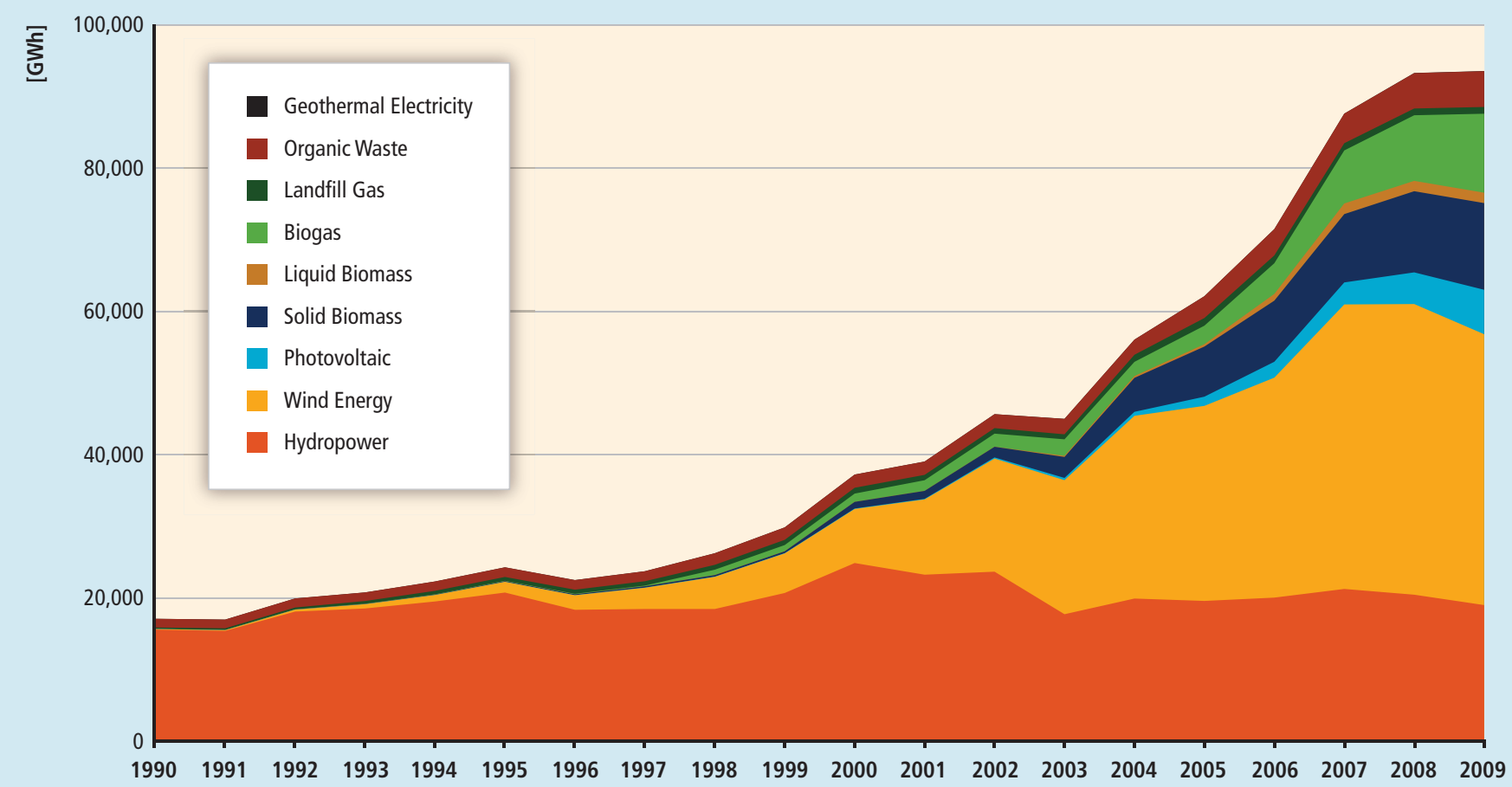

Figure 11.7 | Germany's electricity generation from RE, 1990 to 2009 (BMU, 2010).

downside of caps is that they reduce investment stability and cause frequent stop-and-go in the market. Thus, some countries (e.g., Germany for PV) have established 'growth corridors' with continuous automatic adjustments of tariffs (BMU, 2010). Market growth above the corridor results in a stepped-up tariff degression; if growth is lower than desired, the rate of tariff degression is decreased. The higher the frequency of adjustments (e.g., quarterly instead of annually) and the higher the degression rate in case of overshoot, the greater the control of support cost but the lower the stability for investors. Although this option preserves investment stability to a higher degree than a cap does, it may be less effective in limiting the increase in support expenditures (de Jager et al., 2010).

An advantage of the FIT with a fixed price is the long-term certainty of receiving a fixed payment, which lowers investment risk. Guaranteed network connection and priority access further reduce investor risk because investors are assured a market for the electricity they produce. An advantage of the premium payment is that RE generators participate to a greater degree in the electricity market and, if they have fuel costs, they can be given incentives to produce electricity when the market needs it most.
Although they have not succeeded in every country that has enacted them, price-driven policies have resulted in rapid renewable electric capacity growth and strong domestic industries in several countriesmost notably Germany (See Box 11.6) and Spain (See Box 11.8) but more recently in China and other countries as well-and have spread rapidly across Europe and around the world (REN21, 2006, 2009b; Mendonça, 2007; Rickerson et al., 2007; Girardet and Mendonca, 2009). (See Boxes 11.7, 11.11 and 11.12.)

The success of FIT policies depends on the details. The most effective and efficient policies have included most or all of the following elements (Sawin, 2004; Mendonça, 2007; Klein et al., 2008a; Couture, 2009):

- Utility purchase obligation;

- Priority access and dispatch;

- Tariffs based on cost of generation and differentiated by technology type and project size, with carefully calculated starting values;

- Regular long-term design evaluations and short-term payment level adjustments, with incremental adjustments built into law in order to reflect changes in technologies and the marketplace, to encourage innovation and technological change, and to control costs; 


\section{Box 11.7 | Lessons from Thailand: Gradual expansion of RE policies.}

Decentralized, grid-connected RE has made a substantial and rapidly increasing contribution to Thailand's electricity supply. As of March 2010, 1,364 MW of private sector RE was online and an additional 4,104 MW with signed power purchase agreements (PPAs) were in the pipeline. Biomass makes up the bulk of this capacity with 1,292 MW (online) and 2,119 MW (PPA only). Solar electricity is second but rapidly catching up, with $78 \mathrm{MW}$ online and signed PPAs for an additional 1,759 MW (EPPO, 2010b,c). Strong market growth has been due to plentiful agricultural residues and a comprehensive set of policies including streamlined grid interconnection access, a FIT based on premium payments, tax breaks and low-cost financing (Amranand, 2009; Fox, 2010).

Policies to accommodate grid interconnection of customer-owned RE started in 1992 with the Small Power Producer (SPP) program, which included standardized interconnection and PPAs for generators up to 90 MW (Greacen and Greacen, 2004). By 2007 the program had saturated at 53 RE generators (mostly bagasse cogeneration) with combined nameplate capacity of 967 MW (EPPO, 2007b).

In 2002, Thailand adopted Very Small Power Producer (VSPP) regulations, modelled on US net metering legislation, further streamlining utility interconnection requirements for generators up to $1 \mathrm{MW}$ (Greacen et al., 2003). This and other policies helped to foster the development of integrated biorefineries for sugarcane and rice, enabling simultaneous production of food, ethanol, heat and electric power, and the recovery of some of the fertilizer value. By 2008, for electricity production sold to the grid, there were 42 biomass-based VSPP projects using a variety of biomass residues and 31 biomass-based SPPs, for example, from bagasse and rice husks. The generating capacity of these projects totalled 1,689 MW; about half of this produced power for the grid (Amranand, 2009; Jenvanitpanjakul and Bhandhubanyong, 2009).

In 2006, the Thai government enacted a FIT premium payment that provides an adder paid on top of utility avoided costs, differentiated by technology type and generator size, and guaranteed for 7 to 10 years. Additional per-kilowatt hour subsidies are provided for projects that offset diesel use in remote areas (on mini-grid systems), and utilities are provided further incentives to accommodate VSPPs. Incremental costs are passed through to consumers; however, electricity is subsidized for small consumers ( $<150 \mathrm{kWh} / \mathrm{month}$ or $<540 \mathrm{MJ} /$ month) such that they pay less than marginal cost and are not negatively affected by the FIT (Amranand, 2008). In 2010, the additional burden associated with the FIT was USD ${ }_{2005}{ }^{1} 0.001 / \mathrm{kWh}$ or approximately USD 2.78/GJ) (ERC, 2010); the Thai government expects that by 2022 the FIT adder will be about double that amount. In response to the FIT adder, RE online capacity increased sharply, from $992 \mathrm{MW}$ in February 2007 to 1,364 MW by March 2010 (EPPO, 2007a, 2010c).

The government's decision to adopt a FIT premium payment was driven by concerns about increasing reliance on imported fossil fuels; difficulty siting new coal and natural gas plants; interest in reducing GHG emissions; encouragement from the Thai RE industry; and a national target of 8\% RE by 2011 (Prommin Lertsuriyadej, 2003; Thai Ministry of Energy, 2003; Amranand, 2008). Other important incentives for RE include an eight-year corporate tax holiday; reduction or exemption of import duties; technical assistance; and low-interest loans and government equity financing (Yoohoon, 2009).

Further, the government has worked to address challenges as they have arisen. For example, in response to companies that applied for PPAs only to sell them to developers, the government requires a reimbursable bid bond for projects over $100 \mathrm{~kW}$, and projects must produce power within one year of the scheduled date of commissioning to receive subsidies (Tongsopit, 2010). The variability of RE and small size of individual generators has been difficult to accommodate using traditional planning methods (Greacen, 2007). This was acknowledged and partially addressed in the 2010 revision of the Power Development Plan (EPPO, 2010a).

Thailand's experience demonstrates that well-designed and effectively implemented policies can lead to substantial deployment of RE in developing countries. The FIT adder has been instrumental in increasing RE capacity and encouraging a diversity of RE sources. Explicit financial incentives for Thai utilities to purchase VSPP power helps overcome their reluctance to accommodate interconnection, grid operations and billing challenges that can accompany distributed generation. The sequence of regulation, starting with interconnection policies and later adoption of FITs, has allowed utilities to 'learn by doing' as they ramp up programs to accommodate distributed RE.

Note: 1. The 2010 monetary figure has been deflated to USD $_{2005}$ for the years 2009 to 2005, as the 2010 data was not yet available. Thus, the given number is only an approximation. 
- Tariffs for all potential generators, including utilities;

- Tariffs guaranteed for a long enough time period to ensure adequate rate of return;

- Integration of costs into the rate base and shared equally across country or region;

- Clear connection standards and procedures to allocate costs for transmission and distribution;

- Streamlined administrative and application processes; and

- Attention to preferred exempted groups, for example, major users on competitiveness grounds or low-income and other vulnerable customers.

\section{Assessment of quantity- and price-based policies}

This section reviews the literature assessing quantity- and price-based policies, with a focus on quotas and FITs. More than 100 countries, states, and provinces, and even some municipalities around the world have had experience with one or both of these mechanisms (REN21, 2010). For several years, particularly in Europe and to a lesser extent in the USA, there has been debate regarding the efficiency and effectiveness of FITs versus quota systems (Rickerson et al., 2007; Commission of the European Communities, 2008; Cory et al., 2009). As a result, there is a wealth of literature assessing these policy options, with most analysis focused on effectiveness and efficiency.

\section{Effectiveness}

As defined above, effectiveness is the extent to which intended policy objectives are met, and can include the amount or share of RE generation and/or degrees of technological and/or geographical diversity of installed capacity.

Many US states have successfully achieved their targets with RPS, although others have not due to overly aggressive targets, insufficient enforcement and/or lack of long-term contracting (van der Linden et al., 2005; Wiser et al., 2007). Ragwitz et al. (2009) and Resch et al. (2009), in reviews of European policies, found that countries with FITs were typically more effective at generally moderate support levels, with the exception of France, where rapid wind development was found to be prevented by administrative barriers.

The IEA argues that the key for countries like Germany, Spain and Denmark has been high investment security coupled with low administrative and regulatory barriers (IEA, 2008c). The IPCC's Fourth Assessment Report, in comparing quantity-based mechanisms and FITs, noted that: "In theory, this difference should not exist as bidding prices that are set at the same level as feed-in tariffs should logically give rise to comparable capacities being installed. The discrepancy can be explained by the higher certainty of current feed-in tariff schemes and the stronger incentive effect of guaranteed prices." (Sims et al., 2007). Likewise, Stern (2007) concluded that "feed-in mechanisms achieve larger [RE] deployment at lower cost. Central to this is the assurance of long-term price guarantees [that come with FITs].... Uncertainty discourages investment and increases the cost of capital as the risks associated with the uncertain rewards require greater rewards.". Bürer and Wüstenhagen (2009) found that, because
FITs effectively reduce risk, venture capital and private equity investors perceive FITs to be the most effective policy to stimulate investment in RE technologies (Bürer and Wüstenhagen, 2009).

With regard to technological diversity, quantity-based systems have been found to benefit the most mature, least-cost technologies (Espey, 2001; Sawin, 2004; Jacobsson et al., 2009), although quantity-based mechanisms can address this if they distinguish among RE options or are paired with other incentives (de Jager et al., 2010). In Sweden (as seen in Box 11.4), the UK and Flanders, TGC systems have advanced mainly biomass generation and some wind power, but have done little to advance other RE (Jacobsson et al., 2009). In the USA, between 1998 and $2007,93 \%$ of non-hydropower additions under state RPS laws came from wind power, $4 \%$ from biomass, with only $2 \%$ from solar and $1 \%$ from geothermal (Wiser and Barbose, 2008). As a result, a large number of states have created set-asides of various forms to encourage diversity (DSIRE, 2011. FITs have encouraged both technological (Huber et al., 2004) and geographic diversity (Sawin, 2004), and have been found to be more suitable for promoting projects of varying sizes (Mitchell and Connor, 2004; van Alphen et al., 2008).

\section{Efficiency}

As noted early in Section 11.5, static efficiency can be measured as cost-effectiveness or a comparison of total support received relative to generation costs, and dynamic efficiency accounts for future technology development that is triggered by a policy.

A number of studies have concluded that FITs have consistently delivered new supply, from a variety of technologies, more effectively and at lower cost than alternative mechanisms, including quotas, although they have not succeeded in every country that has enacted them (Ragwitz et al., 2005; Stern, 2007; de Jager and Rathmann, 2008).

Recent studies (Resch et al., 2009; de Jager et al., 2010) of quota systems in Europe found that Italy, the UK, Poland and Belgium had experienced high producer profits resulting from high investment risks and low growth rates. Other studies have reached similar conclusions (D. Fouquet et al., 2005; New Energy Finance Limited, 2007; Jacobsson et al., 2009; Verbruggen and Lauber, 2009). Such profits primarily benefit incumbent actors and relatively mature, low-cost technologies, and can be costly for consumers (Jacobsson et al., 2009). The exception among European countries using a quota obligation is Sweden, which has experienced a high rate of $\mathrm{RE}$ growth coupled with relatively low producer profits. This was because quota systems tend to favour least-cost RE and Sweden has an abundance of biomass (see Box 11.4).

The higher risk under quota systems includes price risk (fluctuating power and certificate prices), volume risk (no purchase guarantee), and balancing risk; all three risks increase the cost of capital (C. Mitchell et al., 2006). While quota and tendering systems theoretically make optimum use of market forces, government tendering systems in particular have often had a stop-and-go nature that has not been conducive to 


\section{Box 11.8 | Lessons from Spain: Policy issues for PV deployment.}

To provide a predictable and transparent framework to attract private investments, the Spanish government enacted a FIT in 1998 and published indicative 2010 targets for installed capacity in the Plan to Promote Renewable Energies 2000-2010 (MlyE, 1998; IDAE, 2009).

Due to the immaturity of the market, initially the FIT was not enough to develop the PV sector despite Spain's significant solar resource and, in 2001, a combination of investment subsidies and low-interest loans was established. They remained in place until 2005, and total direct subsidies to PVs during the period amounted to USD ${ }_{2005} 64.6$ million (IDAE, 2009).

The FIT was revised in April 2004 (Ministerio de Economía, 2004) and again in May 2007 (MITyC, 2007). In addition to raising the tariff for PV, both acts increased the maximum capacity of projects that could receive the high tariff (from a maximum of $100 \mathrm{~kW}$ to $10 \mathrm{MW}$ starting in May 2007), and made projects of up to $50 \mathrm{MW}$ eligible to receive 25-year fixed price contracts. Cost benefits associated with the economies of scale of larger projects combined with the 2007 policy changes to encourage development of several new ground-mounted projects of 10 MW. Newly installed capacity increased from 21 MW in 2005 to 107 MW in 2006 and 555 MW in 2007 (IDAE, 2008).

In September 2007, 85\% of Spain's RE target had been achieved, setting off a one-year deadline for the government to publish new targets and tariffs, and for developers to complete projects under the existing scheme. This period was fine for most RE projects already under development, with relatively long lead times; but PV projects can be developed quite quickly. The one-year notice set off a mad rush to install PV systems before the existing system expired. As a result, 2,575 MW of PV were added in 2008, breaking all past records and making Spain the world leader for PV installations that year (IDAE, 2009; MITyC, 2009).

Because the country's 2010 targets had been exceeded, in September 2008 the government established a new economic regime for future installations (MITyC, 2008). For the first time, a differentiated tariff was adopted for building-integrated PV (BIPV). In addition, annual caps were set for new capacity, with separate caps for ground-mounted (up to $10 \mathrm{MW}$ ) and rooftop (under $20 \mathrm{~kW}$; and $20 \mathrm{~kW}$ to $2 \mathrm{MW}$ ) PV projects. The caps adjust automatically depending on the previous year's installations, while the tariff for ground-mounted projects continues to decrease over time. The new scheme aimed to: provide long-term predictability; better control the cost of the FIT; guarantee profits more appropriate for a regulated market; encourage declining investment costs; increase competitiveness; and encourage distributed generation through BIPV. The policy change resulted in a significant increase in distributed rooftop projects (IDAE, 2010).

At the same time, uncertainty about the design of the new framework scheduled for adoption in late 2008 , the reduction in market size due to the cap on ground-mounted systems, and lack of experience with the new administrative procedures led to a significant reduction in new capacity installations (MITyC, 2008) (see Figure 11.8).

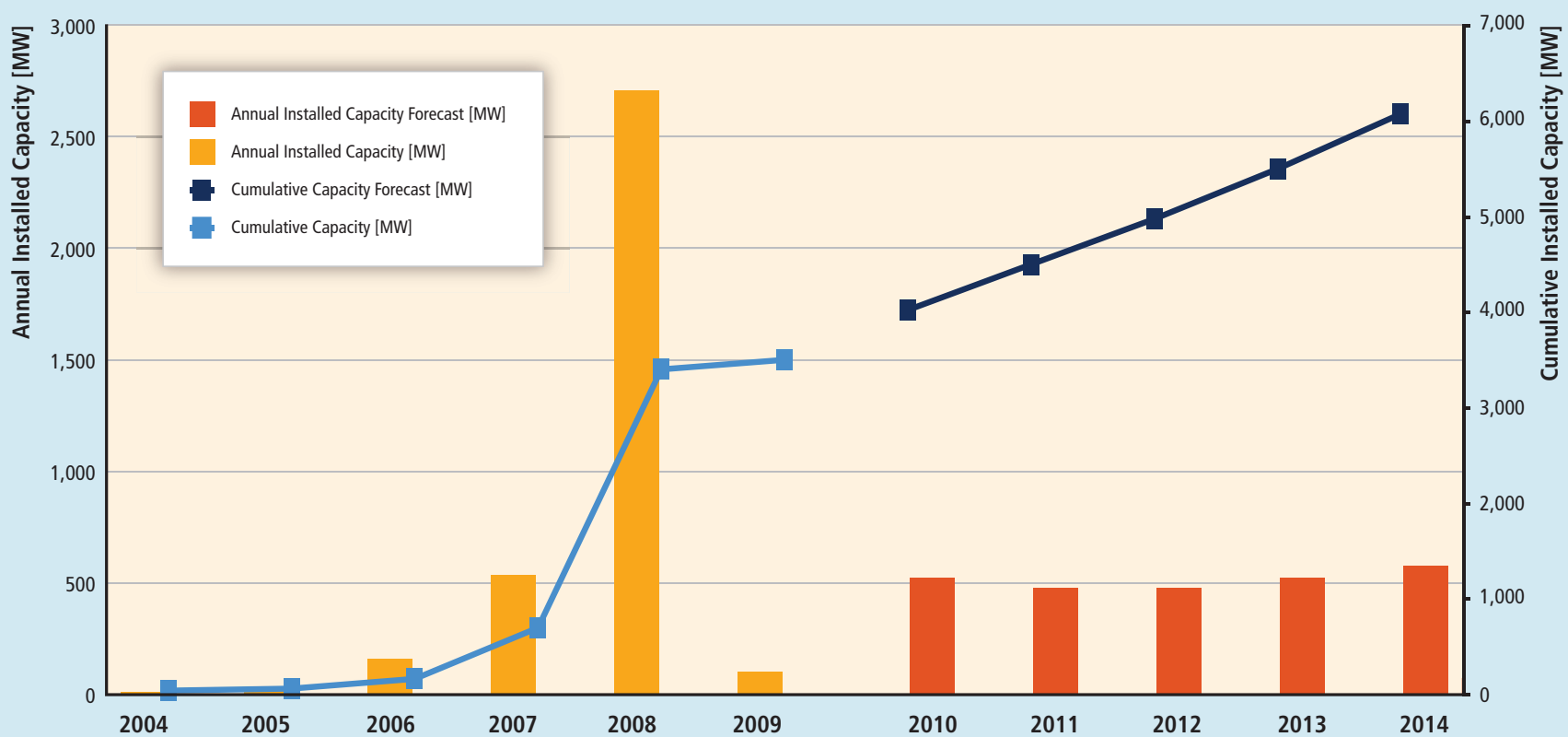

Figure 11.8 | Spanish PV annual installations and cumulative capacity, actual (2004 to 2009) and projected (2010 to 2014) (IDAE, 2010). 
Spain's story highlights the importance of learning from experience and of building forward-looking flexibility into policy to avoid the need for frequent regulatory changes. Overall, lessons from Spain's experience include: a combination of support schemes can be important for advancing RE technologies, particularly when the market is immature; ambitious long-term targets are critical as are stable, predictable policies; and transitional incentives that decrease over time internalizing technology development and therefore keeping constant a reasonable internal rate of return for each new project, can foster technological innovation and control total costs.

stable investment conditions. In addition to private investment-related risks, there is also the risk that low-bid projects may not be implemented (European Commission, 2005).

However, experience in the USA demonstrates that the effectiveness and efficiency of quota schemes can be high and compliance levels achieved at reasonable cost and with lower producer profits if RE certificates are delivered under well-designed policies with long-term contracts that mute (if not eliminate) price volatility and reduce risk (Lauber, 2004; van der Linden et al., 2005; Agnolucci, 2007; Rickerson et al., 2007; Toke, 2007; Wiser et al., 2007). Others have concluded that more challenging targets and better enforcement could improve the results of TGC systems (Mitchell and Connor, 2004; C. Mitchell et al., 2006; Fouquet and Johansson, 2008), and that quota systems in many states and countries are still quite new and thus in a transitional phase (Wiser et al., 2007; Commission of the European Communities, 2008).

While Spain has been very successful in terms of deployment, recent experiences there demonstrate that even FITs can bring uncertainty and temporarily high per unit costs with frequent and unpredictable policy adjustments (see Box 11.8) that have increased political risk for all FITs (CITI, 2010) while having a significant short-term impact on the solar industry.

In the USA, there is little evidence of a sizable impact on electricity costs associated with quotas, but cost impacts have varied from state to state and significant REC price fluctuations are possible, impeding development (Wiser et al., 2007). Toke (2007) notes that success of the US RPS in states like Texas, and their ability to achieve targets cost-effectively, is greatly due to the federal production tax credit (Toke, 2007) (see Box 11.5).

With respect to competitiveness, another element of efficiency, a 2008 analysis found that market competition (number of players) was stronger among wind turbine producers and constructors under the German FIT than under the quota scheme used in the UK (Butler and Neuhoff, 2008). Except in the case of Spain, where the premium option attracts mostly incumbent power generators, FITs have been more successful at bringing new players into the market (Verbruggen and Lauber, 2009). FITs encourage competition among manufacturers rather than investors (Held et al., 2007). FITs have been found to encourage development of domestic manufacturing industries, which leads to a large number of companies and thereby creates competition (Sawin, 2004). FITs shift competition from electricity price to equipment price, which some analysts have argued is more appropriate competition for capital-intensive RE technologies (Wagner, 1999; Hvelplund, 2001).

Verbruggen and Lauber (2009) demonstrate that well-designed FITs provide dynamic incentives to reduce long-run marginal costs of a variety of RE technologies because investment money is assigned to investors accordingly; more efficient producers obtain greater rents by lowering costs, and the FIT payment rates are regularly adjusted to avoid excessive rents.

\section{Equity}

Concerns about distributional impacts of RE policies on poorer consumers (see Section 11.5.7.2) arise most frequently in countries where FITs have led to significant increases in RE capacity, particularly for relatively high-cost technologies such as PVs, because of resulting increases in total electricity costs. This becomes a greater problem as the total costs of the RE policy increase (Frondel et al., 2010). There are ways to address such impacts, as seen in Thailand where small electricity consumers receive subsidized electricity and are unaffected by the national Premium Payment FIT (see Box 11.7).

Concerns have been raised about electric rate impacts of quota systems as well, especially among sensitive industrial customers in US states with RPS requirements, despite the fact that RPS requirements are typically predicted to have a modest impact on average retail electricity rates. As a result, several state RPS programs have specifically exempted certain industrial loads from the RPS, or have established low caps on the extra costs that may be imposed on these customers (van der Linden et al., 2005). Such exemptions in the USA and Sweden, for example, might also be cause for equity concerns, but have generally been required to gain acceptance of quota regulations (van der Linden et al., 2005).

Another equity-related concern is related to participation. In the USA, for example, publicly owned utilities are sometimes exempt from RPS requirements, leading to equity concerns among other providers (van der Linden et al., 2005). At the same time, detailed analysis of which companies gain from quota systems suggest that it is primarily incumbent actors that continue to benefit from the new market (Girardet and Mendonca, 2009; Jacobsson et al., 2009; Verbruggen and Lauber, 2009). The transaction and administrative costs of a TGC system are higher than with FIT, making participation of small-scale new entrants cumbersome, and therefore limited (C. Mitchell et al., 2006). 
In contrast, FITs tend to favour ease of entry, local ownership and control of RE systems (Sawin, 2004; Lipp, 2007; Farrell, 2009), and thus can result in wider public support for RE (Damborg and Krohn, 1998; Sawin, 2001, 2004; Hvelplund, 2006; Mendonça et al., 2009). Such ease of entry has also proved a powerful means for unleashing capital towards the deployment of RE projects (Couture et al., 2010). Mendonça et al. (2009) found that steady, sustainable growth of RE would require policies that ensure diverse ownership structures and broad support for RE, and they propose that local acceptance will become increasingly important as RE technologies continue to grow in both size and number (Mendonça et al., 2009). This is supported by studies in New Zealand and elsewhere (Barry and Chapman, 2009).

\section{Institutional feasibility}

FITs generally have lower administrative costs than quota policies (Haas et al., 2011) and are considered easier to implement (van der Linden et al., 2005), though tariff setting can be challenging, particularly if there are very dynamic cost developments (as with PV in recent years). Quotas, particularly those operating with tradable certificates, appear to be more complex because of the need to set both penalty prices and quantities. Transaction costs are also generally higher for such quota systems. Complexities also arise from the need for trading platforms under quotas with tradable certificates, and tendering schemes require administrative capacity to deal with the bidding process (Sawin, 2004; de Jager et al., 2010).

With regard to market compatibility, the policies are quite different. Under a FIT with fixed payment or tariff, a single buyer sells all generated electricity into the power market; with all other systems (including premium payments under FITs), generators must sell into the power markets. Because electricity market prices do not influence the remuneration of generators in fixed-payment FIT systems, there is generally no incentive to produce power according to market demand and/or to react to price signals (de Jager et al., 2010).

In summary, a number of historical studies, including those carried out for the European Commission, have concluded that well-designed and wellimplemented FITs are the most efficient (defined as comparison of total support received and generation cost) and effective (ability to deliver increase in the share of RE electricity consumed) support policies for promoting RE electricity (Ragwitz et al, 2005; de Jager et al, 2010; Sawin, 2004; European Commission, 2005; Stern, 2007; Mendonça, 2007; Ernst \& Young, 2008; Klein et al., 2008b; Couture and Gagnon, 2009; Held et al, 2010; Ragwitz et al, 2011). It is important to note that there are FITs that have been very effective and efficient and FITs that have not; quotas that have been effective and efficient, and some that have not (Sawin, 2004). Policy design and implementation play an important role in determining how well these policy options measure up against the various criteria, and governments are continuing to adjust details and to learn how these policy options might meet changing needs.

\section{Access instruments}

Net Metering. Net metering, or net billing, enables small producers to 'sell' into the grid, at the retail rate, any renewable electricity that they generate in excess of their total demand in real time as long as that excess generation is compensated for by excess customer load at other times during the designated netting period. It is essentially a means for customers to use their own generation to offset consumption (through inter-temporal shifting) over a netting period by allowing their electric meter to spin backwards at times when generation exceeds demand. In general, customers have either two unidirectional meters spinning in opposite directions, or one bi-directional meter that can spin in both directions so that net metering customers pay only for their net electricity draw from the grid over the entire netting period (Klein et al., 2008a). Any net export over a specified period (typically a month or a year) is typically compensated at below the retail rate, if at all (DSIRE, 2011).

Net metering is most commonly used as a policy in the USA, where it has been enacted in most states (DSIRE, 2011), but the mechanism is also used in some countries in Europe and elsewhere around the world (Klein et al., 2008b; REN21, 2010).

Net metering is considered an easily administered tool for motivating customers to invest in small-scale, distributed power and to feed it into the grid, while also benefiting providers by improving load factor if RE electricity is produced during peak demand periods (US DOE, 2008a). It has been introduced in some countries (e.g., Italy) with the aim to decrease the grid load and to limit support expenditures (Ragwitz et al., 2010). According to Rose et al. (2008), the best results are achieved when net metering laws do not limit system size or overall capacity, allow credit for excess electricity (meaning that if generation is greater than use in any particular month, the excess generation is credited to the next month), allow customers to keep their RE credits, permit all renewable technologies and customer classes to participate, and protect customers from unnecessary red tape (Rose et al., 2008). In addition, it is important that net metering policies evolve as markets expand and change (IREC, 2010).

However, Klein et al. (2010) found that, at least in the USA, the remuneration is generally insufficient to stimulate substantial growth of less competitive technologies like PV, since generation costs are significantly higher than retail prices (Klein et al., 2010). Instead, distributed PV has been encouraged in the USA by a combination of federal tax policy, state rebates and performance incentives, state RPS programs and net metering (Sherwood, 2010). Based on impacts seen on small wind systems in the USA, Forsyth et al. (2002) concluded that net metering alone provides only minimal incentives for consumers to invest in RE systems, particularly where people must deal with cumbersome zoning and interconnection issues. However, when combined with public education and/ or other financial incentives, net metering might encourage greater participation (Forsyth et al., 2002). 
Priority access to network and priority dispatch. In the EU, the Directive 2001/77/EC on the promotion of electricity produced from renewable energy sources states that EU member states must ensure that transmission and distribution system operators 'guarantee grid access for electricity generated by RE' (European Parliament and of the Council, 2009). This is for both connection to the network and offtake (i.e., injection into the grid). As a result of the EU Directive, some European countries, particularly those that have FITs, have implemented connection regulations that guarantee access to the network. 'Priority' grid access in these countries means that electricity generated by RE projects is given priority access to the network and all is taken into the grid.

However, from a power integration point of view, priority access is different from dispatch. Generation may have access to the network, but it does not necessarily mean that it is dispatched; and whether the RE generator receives remuneration for the dispatched or non-dispatched generation will depend on the policy, network or market rules in place. The Spanish FIT does provide for priority dispatch in the event of a constraint, providing security and quality of the supply is guaranteed. Priority access and dispatch are considered in more detail in Section 11.6.5 (see also Section 8.2.1).

\subsubsection{Policies for deployment - heating and cooling}

In 2008, traditional biomass, modern biomass, solar thermal and geothermal together met $27 \%$ of the total global demand for heat (the majority from traditional biomass) (IEA, 2010d), while RE cooling technologies provided a much smaller share of global cooling demand. For modern RE to meet a growing share of total demand, political support will be needed to overcome barriers (e.g., the initial capital barrier to system purchase) to RE heating and cooling (RE H/C).

Support for RE H/C presents policymakers with a unique challenge due to the often distributed nature of heating and cooling technologies. Heating and cooling services can be provided via small- to mediumscale installations that service a single dwelling, or can be used in large-scale applications to provide district heating ${ }^{4}(\mathrm{DH}) /$ cooling (IEA RETD, 2010). Policy instruments for both RE heating (RE-H) and cooling (RE-C) need to specifically address the more heterogeneous characteristics of resources, including their wide range in scale, varying ability to deliver different levels of temperature, widely distributed demand, relationship to heat load, variability of use and the absence of a central delivery or trading mechanism (IEA, 2007b; Seyboth et al., 2008; Connor et al., 2009).

4 District heating is the distribution of heat generated at one or a few centralized production units through a network of pipelines to residential and commercial buildings that use the heat for space heating and water heating (see Section 8.2.2). DH networks vary in scale from single multi-occupier buildings to city-wide installations.
Similar to RE electricity and RE transport, RE H/C policies will be better suited to particular circumstances/locations if, in their design, the state of maturity of the particular technology, of the existing markets and of the existing supply chains are taken into consideration (Haas et al., 2004). RE-H/C technologies vary in maturity (see Table 1.2), and the maturity of the markets and infrastructure for a given technology may vary by region (e.g., some solar water heating systems are closer to being competitive in China or Israel than in Europe (Xiao et al., 2004)) and in terms of supply chains (manufacturing, integration, infrastructure, maintenance). Though in some regions the infrastructure to support development and installation of RE H/C technologies may not yet exist at all, in others it is well developed. Examples of welldeveloped RE-H infrastructure include solar water heating in China and geothermal energy in Iceland, where geothermal energy for space heating on a commercial scale began in 1930, and in 2005 supplied $89 \%$ of space heat (Lund and Freeston, 2001; IEA, 2007b).

The number of policies to support RE sources of heating and cooling has increased in recent years, resulting in increasing generation of RE H/C (IEA, 2007b). However, a majority of support mechanisms have been focused on RE-H. Policies in place to promote RE-H include fiscal incentives such as rebates and grants, tax reductions and tax credits (Section 11.5.5.1); public finance policies like loans (Section 11.5.5.2); regulations such as use obligations (Section 11.5.5.3); and educational efforts (Section 11.6). To date, fiscal incentives have been the prevalent policy in use (DEFRA/BERR, 2007; Bürger et al., 2008; Seyboth et al., 2008; Connor et al., 2009), though there is increasing interest in regulatory mechanisms.

This section describes the aforementioned policies strictly as they relate to RE H/C. A more general description of the mechanisms themselves can be found in Section 11.5.3. The section concludes with a brief discussion of issues relevant only to RE-C.

\subsubsection{Fiscal incentives}

\section{Grants, rebates, and production incentives}

Rebates and grants are the most commonly applied policy for RE-H (and RE-C to a lesser extent), with various applications in multiple countries and regions including Austria, Canada, Greece, Germany, Ireland, Japan, the Netherlands, Poland and the UK (IEA, 2007b; Bürger et al., 2008; Connor et al., 2009). Production-based incentives could also be used to support the production of RE H/C. For $H / C$, however, productionbased incentives are often complicated by the distributed nature of the heat supply where there are few cost-effective metering or monitoring procedures (IEA, 2007b). Production incentives may therefore be most effective for larger $\mathrm{H} / \mathrm{C}$ systems, such as district heating grids.

Cash incentives, however designed, will have implications for the public budget, which must be carefully considered. Fluctuations, or 
stop-and-go funding, have been shown to have a direct impact on the resulting deployment of RE H/C technologies (IEA, 2007b; IEA RETD, 2010). For example, the German Market Incentive Program (MAP), while successful in increasing the deployment of solar thermal technologies in Germany, experienced complications when demand for the incentive exceeded availability, and as funding fluctuated annually.

\section{Tax policies}

Tax incentives have often been implemented in support of RE-H alongside support for RE electricity technologies (IEA, 2007b). Indirect support for RE $H / C$, such as exemptions from eco-taxes, carbon and energy charges levied on fossil fuels used for heating, has also been successful in the promotion of RE-H, for example, in Sweden (see Box 11.9).

For RE-H/C, both investment and production tax credits are possible. As production tax credits provide incentive for the amount of RE H/C actually produced, they may be advantageous in assuring the generation of RE H/C as well as the increased quality of installation (IEA, 2007b). Similar to cash incentives, however, the application of production tax credits for distributed heat generation is complicated due to the lack of cost-effective metering or monitoring procedures.

Tax credits available after the installation of a RE-H system (i.e., ex-post) may be logistically advantageous compared with grants, for example, which require pre-approval before installation. For instance, in France, the 2005 Finance Law included a tax rebate system that allowed owners to recover costs via an income tax declaration, suggesting an easy-toadminister, simple and straightforward promotion system (IEA, 2007b; Roulleau and Lloyd, 2008; Walker, 2008; Gillingham, 2009). This law effectively shifted the French system — previously largely based on direct investment incentives (e.g., grants) - to a tax rebate system. After this shift, substantial growth occurred in the solar thermal market, likely the result of simplified procedures (IEA, 2007b).

\subsubsection{Public finance}

Public finance policies such as guarantees, loans and public procurement to promote RE-H are much less common than the aforementioned fiscal incentives, though have in some cases been implemented. For example, the Crediting System in Favour of Energy Management (FOGIME) in France began a guarantee of up to $70 \%$ of the total investment on bank loans requested for RE (including RE-H) and energy efficiency projects (IEA, 2007b). Various types of public finance programs have also been used in less developed countries to support the use of modern biomass, residential solar heating and other modern RE technologies.

\subsubsection{Regulations}

Though most support policies for RE H/C technologies to date have been fiscal incentives, regulatory policies like use obligations and quotas have attracted increased interest for their potential to encourage growth of RE H/C independent of public budgets (Bürger et al., 2008; Seyboth et al., 2008).

\section{Use obligation}

A use obligation, or building regulation, requires the installation of RE systems in new construction or buildings undergoing substantial renovation. Use obligations are advantageous in that they support the installation of RE heating technologies and related infrastructure at the time of construction, when installation is most cost-effective. They also address the market failure of split incentives (Section 1.4.2), which might otherwise discourage builders or owners from RE-H investments if they won't be paying to heat a building (CCC, 2009).

Initially adopted in various municipalities in Spain, Germany (Nast, 2010), Italy, Ireland, Portugal and the UK, use obligations are now employed at the national level in Spain and Germany. Variations exist regarding eligible technologies and whether the energy has to be onsite or can be located elsewhere (Bürger et al., 2008; Puig, 2008). Use obligations can be applied at different levels of governance and for DH as well as household systems.

However, there are a number of problems associated with this policy. For example, a gradual increase in the obligation level implies that a building stock compliant with the early use obligation may need to be retrofitted later to meet a more stringent future use obligation. It also imposes costs unequally across society because early obligated parties pay relatively higher costs, while later obligated parties may benefit from cost reductions resulting from volume demand and greater skill capacity. There is also the potential for the policy to motivate a delay in replacement of inefficient technologies as building owners wait for the obligation to come into effect and the requirements to become more clear (Connor et al., 2009), or to delay substantial retrofits to avoid the extra cost of compliance.

Ideally, compulsory refurbishment would also include protection for the economically vulnerable (Bürger et al., 2008; Connor et al., 2009). One simple and less onerous application is to mandate the inclusion of basic connection technologies in new buildings to allow for later integration of RE H/C. Integration of the technology for later connection to district heating or cooling is one potential application that might have a good fit with later investment (Connor et al., 2009).

The application of a system of standards to ensure a minimum quality of hardware, installation and design planning when implementing use obligations for RE-H is likely to be essential to ensuring proper compliance; a monitoring system including periodic examinations of installations and/or minimum quality standards is advisable, though this will increase administrative costs (Connor et al., 2009). A high level of compliance is fundamental to the success of the use obligation (Bürger et al., 2008). 


\section{Box 11.9 | Further lessons from Sweden: Biomass district heat and value of infrastructure}

Sweden's experience with DH illustrates how fiscal incentives for $\mathrm{RE}-\mathrm{H}$ and the existence of an enabling infrastructure can support a shift to RE sources for heating. Between 1980 and 2007, the biomass share in DH production increased from zero to $44 \%$ (90 PJ) (IEA, 2009b).

Sweden's shift to a large share of biomass-based heat was facilitated by the existence of two infrastructure systems (IEA, 2007b). First is Sweden's rich biomass resource (about $52 \%$ of the total land area is productive forest) and its forestry industry, which has a long history and a well-established infrastructure (IEA, 2007b). Second is the country's DH system, which as of 2008 accounted for $56 \%$ of heating in the residential and service sectors (Swedish Energy Agency, 2009a).

The main expansion of the system occurred during the period 1965 to 1985, when municipal administrations and companies built, owned and operated Sweden's DH system. The shift was driven in the 1980s by high oil prices and taxes on oil products; opportunities for combined heat and power (CHP) production, fuel flexibility, economic efficiency, and better pollution control compared to individual boilers also motivated development of DH infrastructure. Expansion was also facilitated by strong local planning powers and high acceptance for solutions driven by the public sector (Ericsson and Svenningsson, 2009).

In 1991, the Swedish government implemented a carbon tax at USD ${ }_{2005} 41$ per tonne of $\mathrm{CO}_{2}$ (this tax gradually increased and reached USD $_{2005} 130$ per tonne in 2007). Biomass was exempt from the tax, making it the least expensive fuel for DH systems. As a result, the use of biomass expanded rapidly as seen in Figure 11.9, from 14 PJ in 1990 to 60 PJ in 1996 (Ericsson and Svenningsson, 2009). Sweden's carbon tax also accelerated the phase-out of oil for heating of individual buildings, to the benefit of DH, ground-source heat pumps and wood pellets (Ericsson and Svenningsson, 2009).

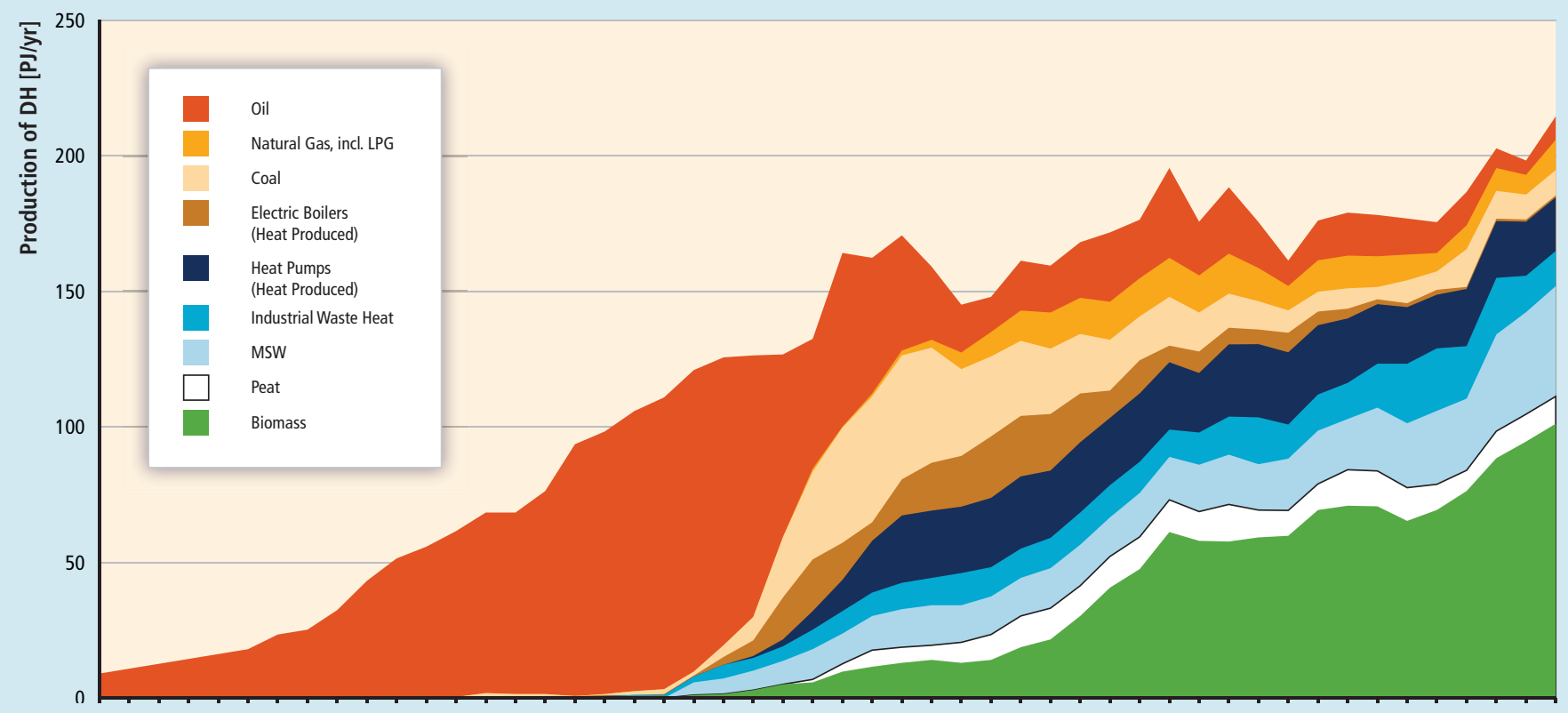

Figure 11.9 | Sweden's district heat production, by fuels and energy sources, 1960 to 2009.

Note: Curves are not corrected for outdoor temperature variations (Swedish District Heating Association, 2001; Ericsson and Svenningsson, 2009; Swedish Energy Agency, 2009b, 2010b).

In addition to the tax exemptions for biomass, investment subsidies were made available for biomass-based CHP from 1991 to 2002 , further helping to fuel growth. In 2003, largely driven by the desire to replace nuclear power, the government introduced an electricity quota obligation combined with a green certificates scheme. This led to a further significant increase in heat (and electricity) generation from biomass-based CHP. In response to these policies, district heat from CHP increased from 22 PJ in 1990 to 71 PJ in 2007 (SCB, 2009$)$, and electricity from CHP increased from about 2 TWh (7.2 PJ) in 1990 to 7.5 TWh (27 PJ) in 2007; of this, 41\% was from biomass (IEA, 2009b; Bergek and Jacobsson, 2010) (see Box 11.4). 


\section{Bonus mechanisms}

The bonus mechanism legislates a fixed payment for each unit of heat generated, with potential for setting different levels of payment according to technology (Bürger et al., 2008). Payments can be given as a result of either metered output or some form of estimation of output. They can be capped for a fixed period or for a fixed output, and they can be designed to vary with technology and/or building size to complement energy conservation efforts. Degression can be applied annually to reduce impacts on government budgets.

Bonus mechanisms are similar to price-driven instruments for electricity such as FITs (see Section 11.5.4.3), and differ primarily in two ways: potential scope (many more RE heat than electricity generators might be expected to result), and the likelihood that heat will be used where it is generated. These factors have the potential to make a bonus programme relatively complex and costly, due to the scale of metering and administration required. Consolidation offers a potential solution; for example, a third party organization could aggregate and distribute the benefits of the bonus payments to a large number of its members, reducing the burden of utility or government administration. Further, bonus funds could be paid on a limited number of occasions, perhaps two to three over the lifetime of an installed technology (Bürger et al., 2008), thereby minimizing administrative costs.

There has been little experience with bonus mechanisms to date. However, because of the limited impact on the public budget if payments are made by utilities suppliers (rather than government), it has received increased interest. For example, the UK adopted legislation for a RE-H bonus mechanism with a projected April 2011 adoption, selected largely on the grounds that it would have lower impact on the public budget than other policy options (BERR/NERA, 2008; DECC, 2009).

\section{Quota obligations}

Quota obligations, also known as RPS, have largely been deployed in support of RE electricity (see Section 11.5.4.3). In some such cases (e.g., in Australia's Mandatory RE Target (Buckman and Diesendorf, 2010), in Japan's Law on Special Measure for the Utilization of New Energy (IEA, 2007b) and in some US states (DSIRE, 2011), the eligibility of RE technologies has included RE-H technologies such as solar hot water heaters.

Although they have been discussed in Germany and the UK, for example, there is very little experience with quota obligations specifically targeting RE-H (IEA, 2007b). Quota obligations for electricity often include a system of tradable certificates, awarded to producers for the renewable energy they generate. Because of the distributed nature of heat generation and use (except in the case of $\mathrm{DH} / \mathrm{C}$ systems), such certificate systems for $\mathrm{RE}-\mathrm{H}$ introduce additional challenges, though in theory RE-H users, their designated agents, or companies in the RE heat supply chain would be eligible to receive tradable certificates if they produced evidence of RE heat use. Market participants could sell certificates to suppliers to earn revenues to offset their costs (Radov et al., 2008).

\section{Network access for district heating}

Third party access (TPA) to DH systems can allow greater levels of competition to drive down costs, and provide increased access to a market (Section 8.2.2). There is little experience with TPA for DH systems to date, but some countries (e.g., Sweden (Ericsson and Svenningsson, 2009)) have considered their implementation. However there is some concern that widening TPA might increase costs for DH providers as a result of both increased administration costs and increased price uncertainty and volatility (SOU, 2005; Wårell and Sundqvist, 2009).

Wårell and Sundqvist (2009) identify three possible forms of TPA in DH: 1) regulated TPA generally means new companies can access the grid if they meet certain conditions, a stipulation that is typical in the electricity sector; 2) negotiated TPA comprises ex-post agreement between the network owner and heat provider; and 3) the single buyer model, under which a single consolidator negotiates with all suppliers and sells to all consumers on a regulated basis; rates account for system costs and a certain permitted rate of return.

Variable local conditions will determine the most appropriate form of TPA regulation; these include:

- Scale of heating networks and their potential for expansion. Lithuania, for example, regulates systems that supply above $10 \mathrm{GWh}$ (36 TJ) per year (Gatautis et al., 2009);

- Availability of different heat sources;

- Potential administrative costs; and

- Political and/or public perspectives regarding the opening of markets.

\subsubsection{Policy for renewable energy sources of cooling}

RE-C can include passive cooling measures, solar-assisted, CSP or shallow geothermal technologies driving active cooling systems (e.g., via absorption cooling), biomass adsorption or absorption cooling (though still at early stages of development), or active compression cooling and refrigeration powered by RE electricity (DG TREN, 2007; IEA, 2007b).

Though there are some examples of policies supporting RE-C technologies, in general policy aiming to drive deployment of RE-C solely is considerably less well-developed than that for RE-H. Many of the mechanisms described in the sections above could also be applied to $\mathrm{RE}-\mathrm{C}$, generally with similar advantages and disadvantages. Most policy support for RE-C to date has been integrated into programs supporting other RE technologies, including RE-H (IEA, 2007b). Such examples have almost exclusively been fiscal incentives. Spain offered grants directly 
for solar cooling installations as part of its Renewable Energy Plan for 2005-2010 (IDAE, 2006). Similarly, in Germany, the Solarthermie 2000 Plus program provides grants for solar air-conditioning installations as well as for solar thermal and solar-assisted DH installations (IEA, 2007b).

The lack of experience with deployment policies for RE-C is likely linked to the early levels of technological development of many RE-C technologies. R\&D support as well as policy support to develop the early market and supply chains may be of particular importance for increasing the deployment of RE-C technologies in the near future.

\subsubsection{Policies for deployment - transportation}

A range of policies has been implemented to support the deployment of $\mathrm{RE}$ for transport around the world. Because the vast majority of these policies have related to biofuels, this section focuses primarily on biofuel policies. Even for biofuel policies, many of which have been put in place only over the last three to four years, the literature has gaps in assessing effectiveness, efficiency, equity and institutional feasibility.

An increasing number of countries have implemented national biofuel strategies in recent years-for example, Argentina, EU member countries, India, Indonesia, Mexico, Thailand and the USA (Altenburg et al., 2008; Felix-Saul, 2008). Many countries, in particular across South America, with favourable climatic conditions for sugar cane-including Peru (USDA/FAS, 2009b) and Guatemala (USDA/FAS, 2009a) —aim to follow what is seen as Brazil's successful experience with fuel ethanol (see Box 11.10).

Biofuel support policies aim to promote domestic consumption via fiscal incentives (e.g., tax exemptions for biofuel at the pump) or regulations (e.g., blending mandates), or to promote domestic production via public finance (e.g., loans) for production facilities, via feedstock support or via tax incentives (e.g., excise tax exemptions). In addition, trade related measures can be applied to either shield local production through protective measures (e.g., import tariffs, standards) or prevent exports by installing export tariffs (Junginger et al., 2011; Lamers et al., 2011). (See 2.4.4 and 2.4.6 for more information on trade issues.)

\subsubsection{Fiscal incentives}

\section{Tax policies}

Tax incentives are commonly used to support biofuels and act to change the cost-competitiveness of biofuels relative to fossil fuels. They can be instituted along the whole biofuel value chain, but are most commonly provided to either biofuel producers (e.g., excise tax exemptions/credits) and/or to end consumers (e.g., tax reductions for biofuels at the pump).

For example, in the USA, Volumetric Excise Tax Credits for the blending of fuel ethanol and biodiesel have been provided to biofuel producers under the American Jobs Creation Act (US Congress, 2004) since 2004. In the EU, the Energy Taxation Directive permits exemptions or reductions from energy taxation for biofuels (Directive 2003/96/EC). Currently, all but two EU member states (Finland and the Netherlands) provide some sort of tax exemption or deduction; the majority are aimed at final consumption (see e.g., European Commission (2011)). Partial or total tax exemptions for biofuels have proven to be critical for the promotion of biofuels across the EU in the past (Wiesenthal et al., 2009). Because the tax exemption given to biofuels must not exceed the level of the fossil fuel tax, the instrument has proven most successful in those EU member states with fossil fuel tax levels high enough to compensate for the additional production costs of biofuels as compared to their fossil fuel alternative (Wiesenthal et al., 2009).

Experiences in Germany and the UK demonstrate that excise duty exemptions can stimulate investments in biofuels, particularly in the early stages of a biofuel market development (Bomb et al., 2007). However, removal of tax breaks can have unintended consequences, as seen in Germany. Prior to August 2006, biodiesel (including pure vegetable oil) was exempt from excise taxes in Germany and the industry flourished, selling 520,000 tonnes of biodiesel in 2005 (Hogan, 2007). By 2006, Germany was the single largest global producer and consumer of biodiesel (REN21, 2007; Eurostat, 2010). However, that year the German government began to gradually phase out tax exemptions for biodiesel and introduced a biofuel mandate as of 2007. This led to a sharp decline in biodiesel consumption (in particular pure vegetable oil). By late 2009, German biodiesel sales had dropped to an estimated 200,000 tonnes (Hogan, 2009). It is estimated that this policy shift reduced biofuels' share of total national fuel consumption from $7.2 \%$ in 2007 to $5.9 \%$ in 2009 (BMU, 2009).

Several other European and G8+5 countries have begun gradually shifting from the use of tax breaks for biofuels to blending mandates (FAO/ GBEP, 2007). This shift has been driven by the potential advantages of mandates as well as disadvantages associated with the use of tax policy (see Section 11.5.3.1).

Fiscal incentives and public finance (see below) have also helped to trigger private sector investments in biofuel production facilities. At the same time, fiscal incentives that are designed cautiously and adapted on a regular basis regarding fossil fuel and biofuel production cost developments are more apt to create market stimuli while avoiding over-compensation.

It is important to note that the introduction of absolute mandates in combination with existing tax credits-as has occurred, for example, in the USA - could have detrimental effects, such as an increased consumption of petrol at the expense of ethanol, Under a mandate, the blenders' ethanol input prices and the ethanol production level will most likely not decline; however, blenders could increase profits by lowering the retail price of fuel and gaining market share, thus reducing the implicit price paid by consumers for the blended fuel (de Gorter and Just, 2010). This could lead to an increase of total fuel consumption while ethanol consumption remains constant under an 


\section{Box 11.10 | Lessons from Brazil: Gradual expansion of policies to deliver a competitive RE fuel source.}

Brazil was hit hard by the first world oil crisis in the mid-1970s. In 1975, taking advantage of its position as a leading sugar producer, the government established the Brazilian Alcohol Program (PROALCOOL) to promote sugarcane ethanol as a gasoline alternative through production targets and producer subsidies (Goldemberg, 2009).

As part of this policy, Brazil's government mandated that ethanol be blended with gasoline in proportions from $20-25 \%$. Production was supported by subsidies, low-interest loans and guaranteed purchase by the state-owned petroleum company (Petrobras), with parallel research to develop engines that could run on pure ethanol (Dias de Moraes and Rodrigues, 2006).

Responding to government pressure due to concerns about fluctuating ethanol supply and prices that began in the mid-1980s, auto manufacturers introduced flex-fuel motors in 2003 (Goldemberg, 2009). Other early challenges included the need for a network for production and use, which was initially addressed through government activities and eventually turned over to the private sector (Goldemberg, 2006; Walter, 2006). (See Section 8.2.4.6 for more on integration.)

To address social and environmental sustainability concerns that have arisen with an increase in ethanol production, several measures have been enacted at the federal and state levels. These include ecological (AgroEcological Zoning for sugarcane or seed oil plants; see Section 2.2.3) and economic zoning laws that dictate where sugarcane and ethanol production can occur and regulations governing water usage (Goldemberg et al., 2008).

Bagasse (fibrous residue from sugarcane) is used for heat and power generation in the sugarcane refining process to ethanol and sugar, lowering associated carbon emissions, and improving the economics of production (Cerri et al., 2007). The mills meet their own energy needs and sell excess electricity to the grid, which provides another source of income (Section 2.2.3). Early production was stimulated through incentives; today, mill owners sell directly into the grid through contracts or auctions, although lack of access to grid connections is still a barrier for some (Azevedo and Galiana, 2009).

Although ethanol production was initiated as a highly subsidized program, improvements in sugarcane and ethanol production technologies and economies of scale drove down production costs (Section 2.7.2). Ethanol subsidies were removed in the 1990s, and by 2004 ethanol in Brazil was economically competitive with gasoline without subsidies (Goldemberg et al., 2004). The only related incentives by 2010 were reduced taxes for flex-fuel cars. Studies have found that the economic costs of Brazil's ethanol policies over the years were more than outweighed by avoided expenditures associated with imported oil (Moreira and Goldemberg, 1999; Goldemberg et al., 2004). By 2010, Brazil was the world's second largest producer of ethanol, after the USA (Section 2.4.4; REN21, 2010; UNICA, 2010).

Brazil's experience suggests the importance of blending mandates for biofuels in combination with other policies to address economic and other barriers.

absolute mandate (de Gorter and Just, 2010). Partial solutions could be tax structures that self-adjust depending on market developments in the price of oil and in biofuel production. So-called price collars establish lower and upper limits on the price of an RE fuel to address the impacts of market price volatility of competing petroleum fuels and give some assurance to both suppliers and consumers.

\subsubsection{Public finance}

A number of countries, including China (IISD, 2008) and Indonesia (Dillon et al., 2008), provide direct support for biofuels via public finance. Direct financial supports have the advantage of providing easily quantified results, but their outcomes tend to be limited to individual projects.
These supports are generally paid for directly out of government budgets (FAO/GBEP, 2007).

As in the electricity sector, public procurement is an option for driving market growth. The government of Thailand, for example, requires all of its fleets to be fuelled with gasohol (gasoline blended with up to $20 \%$ ethanol) (Milbrandt and Overend, 2008).

\subsubsection{Regulations}

\section{Renewable fuel mandates and targets}

Renewable fuel mandates are key drivers in the development and growth of most modern biofuels industries. Such mandates have been enacted in 
at least 41 states/provinces and 24 countries at the national level (REN21, 2010); Russia is the only G8+5 country that has not created a transport biofuel target (FAO/GBEP, 2007; REN21, 2010). Brazil first mandated ethanol blending with gasoline starting in the 1970s, but most countries started blending renewable fuel with voluntary targets. However, mandatory blending mandates, enforceable via legal mechanisms, are becoming increasingly utilized and with greater effect, notably in the EU and in the USA (Canadian Food Grains Bank, 2008).

The distinction between voluntary and mandatory is critical because voluntary targets can be influential but do not have the impact of legally binding mandates. The original EU biofuel strategy (in Directive 2003/30) posed indicative, not mandatory, targets for all member states. The voluntary targets were not influential for most EU countries-only three members (Germany, Austria and Sweden) met the 2005 target (FAO/GBEP, 2007). Under the current EU Fuel Quality Directive (FQD), all member states are required to ensure a $10 \%$ share of $\mathrm{RE}$ in final energy demand in the transport sector by 2020 (European Commission, 2009a). Each member state of the European Union has its own blending mandates for ethanol and biodiesel, and most mandates allow for flexibility in how to meet the mandate (Flach et al., 2009). Generally, blending mandates are able to provide the desired market signals without the need for government funding.

As the recent biofuel policy development in the EU shows, those countries with the highest shares of biofuels in transport fuel consumption have had hybrid systems that combine mandates (including penalties) with fiscal incentives (foremost tax exemptions). However, it is difficult to assess the level of support under biofuel mandates because prices implied by these obligations are generally not public (in contrast to the electricity sector, for example) (Held et al., 2010).

While mandates have proven to be an effective instrument for the promotion of biofuels in general, they are found to be less appropriate for the promotion of specific biofuel types because fuel suppliers tend to blend low-cost biofuels (Wiesenthal et al. 2009). In the European context, this has led to the abolishment of small-scale, distributed regional biofuel production facilities for large-scale production centres in harbours or along strategic inland waterways, which enjoy a greater access to (cheaper) international (feedstock) imports (Lamers et al., 2011). Further, mandates have been criticized for inducing global food insecurity (Pimentel et al., 2009), indirect land use effects such as market-induced deforestation and associated ineffectiveness in reducing GHG emissions (Searchinger et al., 2008; Creutzig and Kammen, 2009; Hertel et al., 2010; Lapola et al., 2010), and negative impacts on water quality (Vitousek et al., 1997) (Section 2.5.3).

Such impacts can be reduced or avoided if additional criteria are mandated. For example, the US Renewable Fuels Standard 2 indicates maximum GHG emission thresholds for different biofuels (USEPA, 2010b). The EU FQD and RED set minimum requirements for GHG savings for biofuels and outline sustainability standards (Section 2.5.7.1). All policies also define specific lifecycle accounting methodologies, assumptions and default values because, as discussed in Chapter 2,
GHG emission estimates for biofuels are hugely varying, especially if indirect land use change is taken into account (Plevin et al., 2010).

Biofuel production and/or blending mandates (of energy or volume content) have proven to be effective in rapidly increasing domestic biofuel production and consumption (Wiesenthal et al., 2009; European Commission, 2011). They are the most important policy option evaluated in terms of effectiveness and institutional feasibility. By nature, however, they need to be carefully designed and accompanied by further requirements in order to reach a broader level of distributional equity. This is particularly the case for biofuels in terms of sustainability criteria such as GHG emission reductions (Section 2.5.4) or land use (Sections 2.5.3 and 2.5.7).

As in the electricity and heating/cooling sectors, governments generally enact a combination of policy options. As noted above, Brazil is a case in point, with a mandate as well as subsidies that were in place for many years, and the USA has had mandates alongside tax credits and other policies. Another example is Thailand, where the government has provided incentives for various ethanol blends through excise tax waivers and fuel price incentives, is building a distribution infrastructure, provides soft loans to farmers growing palm crops and supports R\&D of new crops like jatropha (Johansson et al., 2004; Milbrandt and Overend, 2008; Nilkuha, 2009).

\subsubsection{Synthesis}

\subsubsection{Assessment of RE policies}

Policy mechanisms enacted specifically to promote RE are varied and can apply to all energy sectors. They include fiscal incentives such as tax credits, grants and rebates; government finance policies such as guarantees and loans; and regulations such as quantity-driven policies like quotas and price-driven policies like FITs for electricity, mandates for heating and biofuels blending requirements. Policies can be enacted by local, state/provincial, national and international authorities.

RE R\&D and deployment policies have promoted an increase in RE shares by helping to overcome various barriers that impede technology development and deployment of RE. Table 11.3 lists some possible policy options for addressing the various barriers to RE set out in Chapter 1.

Experience shows that public R\&D investments are most effective when complemented by other policy instruments, particularly RE deployment policies that simultaneously enhance demand for new RE technologies and create a steadily increasing market. Together, R\&D and deployment policies create a positive feedback cycle, inducing private sector investment in R\&D. Enacting deployment policies early in the development of a given technology can accelerate learning by inducing private $R \& D$, which in turn further reduces costs and provides additional incentives for using the technology, as seen in Japan with PV and Denmark with wind power. 
Table 11.3 | Barriers to RE deployment and policies to address them.

\begin{tabular}{|c|c|}
\hline Type of barrier & Potential policy instruments include \\
\hline $\begin{array}{l}\text { Market failures and economic barriers (Section 1.4.2.1) } \\
\text { - Cost barriers } \\
\text { - Financial risk } \\
\text { - Allocation of government financial support } \\
\text { - Trade barriers }\end{array}$ & $\begin{array}{l}\text { Public support for RE R\&D; deployment policies that support private investment, including fiscal incentives, public } \\
\text { finance, and regulatory mechanisms (e.g., FITs, quotas, use standards) }\end{array}$ \\
\hline $\begin{array}{l}\text { Information and awareness barriers (Section 1.4.2.2) } \\
\text { - Deficient data about natural resources } \\
\text { - Skilled human resources (capacity) } \\
\text { - Public and institutional awareness }\end{array}$ & $\begin{array}{l}\text { Resource assessments; energy standards; green labelling; public procurement; information campaigns; education, train- } \\
\text { ing and capacity building }\end{array}$ \\
\hline $\begin{array}{l}\text { Institutional and policy barriers (Section 1.4.2.3) } \\
\text { - Existing infrastructure and energy market regulation } \\
\text { - Intellectual property } \\
\text { - Industry structure }\end{array}$ & $\begin{array}{l}\text { Enabling environment for innovation; economic regulation to enable access to networks and markets and investment } \\
\text { in infrastructure; revised technical regulations; international support for technology transfer (e.g., under UNFCCC); } \\
\text { microfinance; technical training }\end{array}$ \\
\hline $\begin{array}{l}\text { Issues relevant to policy (Section 1.4.3) } \\
\text { - Social acceptance }\end{array}$ & $\begin{array}{l}\text { Information campaigns; community projects; public procurement; governmental (national and local) policy cooperation; } \\
\text { improved processes for land use planning }\end{array}$ \\
\hline
\end{tabular}

Some policy elements have been shown to be more effective and efficient than others for rapidly increasing RE deployment and enabling government/society to achieve specific targets. Institutional feasibility and equity are also important, but these criteria have not been analyzed as fully. Synthesizing the previous sections, key elements of policies that make them most likely to meet these criteria include:

- Adequate value derived from subsidies, FITs etc. to cover costs such that investors are able to recover their investment at a rate of return that matches their risk;

- Guaranteed access to networks and markets or at a minimum clearly defined exceptions to that guaranteed access; and

- Long-term contracts to reduce risk and thereby reduce financing costs.

Note: the three preceding bullets are all important for reducing key risks and encouraging greater levels of private investment. Reducing risk helps to improve access to and lower the cost of financing (because profitability expected is lower (Haas et al., 2011)), which can reduce project costs as well as end costs of delivered energy paid by consumers.

- Provisions that account for diversity of technologies and applications. RE technologies are at varying levels of maturity and with different characteristics, often facing very different barriers. Multiple RE sources and technologies may be needed to mitigate climate change, and some that are currently less mature and/or more costly than others could play a significant role in the future in meeting energy needs and reducing GHG emissions.

- Incentives that decline predictably over time as technologies and/or markets advance, such as the declining grant for wind in Denmark (see Box 11.12), or degressive tariffs in Germany (see Box 11.6).
- Policy that is transparent and easily accessible so that actors can understand the policy and how it works, as well as what is required to enter the market and/or to be in compliance. Also includes longerterm transparency of policy goals, such as medium- and long-term policy targets.

- Inclusive, meaning that potential for participation is as broad as possible on both 1) the supply side (traditional producers, distributors of technologies or energy supplies, whether electricity, heat or fuel), and 2) the demand side (businesses, households etc.), which can 'self-generate' with distributed RE, enabling broader participation that unleashes more capital for investment, helps to build broader public support for RE (as in Denmark and Germany) and creates greater competition.

- Attention to preferred exempted groups, for example, major users on competitiveness grounds or low-income and vulnerable customers on equity and distributional grounds.

It is also important to recognize that there is no one-size-fits-all policy, and policymakers can benefit from the ability to learn from experience and adjust programs as necessary. Policies need to respond to local political, economic, social, ecological, cultural and financial needs and conditions, as well as factors such as the level of technological maturity, availability of affordable capital, and the local and national RE resource base. In addition, a mix of policies is generally needed to address the various barriers to RE, as highlighted by China's experience (see Box 11.11). As seen in the case studies in this and the following sections, more than one policy has been utilized to advance RE-for example, FITs and low-interest loans, grants, or tax credits in combination with quota obligations.

Finally, transparent, sustained, consistent signals-from predictability of a specific policy, to pricing of carbon and other externalities, to 


\section{Box 11.11 | Lessons from China: Mixed policy approach to energy access and large-scale RE.}

China has relied increasingly on RE to help meet its rising energy demand, improve its energy structure, reduce environmental pollution, stimulate economic growth and create jobs (Zhang et al., 2009). China installed more wind power capacity during 2009 than any other country and, by the end of the year, ranked first globally for total RE electricity generation capacity and third for non-hydro RE capacity (REN21, 2010). China is, by far, the leading global market for solar hot water systems and, in 2009, was the third largest producer of ethanol (REN21, 2010). In addition, a strong domestic manufacturing industry for wind power, PV and solar thermal collectors has emerged, triggered in part by policies that have encouraged industry development along with technology deployment (Han et al., 2010; Liu et al., 2010; Q. Wang, 2010).

The Chinese government has devoted significant attention to RE development in recent decades, both for rural energy access and largescale grid-connected projects. China began developing wind power in the early 1970s for the primary purpose of supplying power to remote areas (Changliang and Zhanfeng, 2009). Grid-connected wind power started in the 1980s with small-scale demonstration projects and evolved to a main source of power supply by 2003, when the Wind Farm Concession Program was established through which bidding procedures were used to develop larger wind power plants (Q. Wang, 2010). Solar water heaters have been applied since the 1970s (Han et al., 2010), and biogas digesters have been promoted since the 1980s (Peidong et al., 2009).

Under the Township Electrification Programme, more than 1,000 townships in nine western provinces were electrified in just 20 months, bringing power to almost one million rural Chinese (NREL, 2004). Important to the success of China's rural electrification efforts have been education of local and national decision makers, training and capacity building, technical and implementation standards and community access to revolving credit (Wallace et al., 1998; NREL, 2004; Ku et al., 2005).

For grid-connected RE, China's national Renewable Energy Law took effect in 2006, creating a national framework to support RE and to institutionalize several support policies, including mandatory grid connection standards, RE planning, and promotion funding (Zhang et al., 2009). The law has been followed by a large number of specific regulations and measures to support the development of wind, solar and biomass sources. For example, the Medium and Long-term Renewable Energy Development Plan, released in 2007, set a national target for RE to meet $10 \%$ of total energy consumption by 2010 and $15 \%$ by 2020 (the latter $15 \%$ target was later revised to refer to all nonfossil energy sources) (Q. Wang, 2010), while also establishing RE technology-specific targets. The $30 \mathrm{GW}$ wind power target for 2020, as specified by The 11th Five Year Plan for Renewable Energy in 2008, was achieved a decade ahead of schedule (B. Wang, 2010).

Under the Renewable Energy Law and its implementing regulations, a wide variety of promotional policies have been employed to support the continued growth of renewable electricity (e.g., Yu et al., 2009; Liao et al., 2010; Wang et al., 2010; Zhao et al., 2011). Feed-in tariffs have been established for wind and biomass power plants, while bidding procedures have been used for offshore wind power plants, for wind turbine purchases to serve China's seven planned large-scale wind bases, and increasingly for solar power plants. Grid-connected (and off-grid) PV systems have also benefited from grants. Funding for many of these programs has come from a national electricity surcharge and resulting RE fund, while the Kyoto Protocol's Clean Development Mechanism (CDM) has also played a role in improving project profitability (Lewis, 2010).

In addition to these policies and the national RE targets, the country's largest generating companies have been called upon to expand their renewable power capacity to $3 \%$ of their total capacity by 2010 , and at least $8 \%$ by 2020 . China provides a clear example of a country that has relied upon a diversity of mechanisms to achieve policy goals.

China continues to address challenges as they arise by developing and revising RE policies and measures, including enhancing technical skills; establishing institutions to support R\&D development and a national RE research institute; extending electricity transmission to ensure that new RE capacity can be effectively brought online; creating a domestic market to stimulate demand and avoid over-reliance on overseas markets; and establishing a national RE industry association to coordinate development and formally bridge the industry and policymaking processes (Martinot and Junfeng, 2007; REN21, 2009a). By addressing the wide variety of RE technologies and applications in a coherent long-term manner and with a sizable mix of policies, China has been able to establish RE as a significant bulk energy carrier. This creates good prospects for further growth in deployment and manufacturing of RE technologies. 
long-term targets for RE- have been found to be crucial for reducing the risk of investment sufficiently to enable appropriate rates of deployment and the evolution of low-cost applications.

\subsubsection{Macroeconomic impacts and cost-benefit analysis}

Payment for supply-push, or R\&D, type support tends to come from public budgets (multinational, national, local) and therefore taxpayers, whereas the cost of demand-pull, or deployment, policies often lands on the end users of energy. For example, if a fiscal incentive is added to electricity, the additional cost of this incentive is borne by consumers, although exemptions or re-allocations can reduce costs for industrial or vulnerable customers where necessary, or for equity or other reasons (Jacobsson et al., 2009).

If the goal is to transform the energy sector over the next several decades, then it is important to minimize costs over this entire period, not only in the near term; it is also important to include all costs and benefits to society in that calculation. Moreover, as mentioned above, the timing, strength and level of coordination of $R \& D$ versus deployment policies will affect this calculation.

Conducting an integrated analysis of costs and benefits associated with $\mathrm{RE}$ is extremely demanding because so many elements are involved in determining net impacts. Concepts that try, at least partly, to balance costs and benefits (as the concept of external costs tries to do in terms of environmental aspects) face substantial limitations and are confronted with significant uncertainties (see Section 10.6). Breitschopf et al. (2010, in German only with translation from the German Environmental Ministry (BMU (2010)) conclude that effects fall under three categories, including direct and indirect costs of the system as well as benefits of RE expansion; distributional effects (which economic actors or groups enjoy benefits of, or suffer burdens from, RE support); and macroeconomic aspects such as impacts on the gross domestic product or employment. For example, potential economic growth and job creation are key drivers for RE policies (see Section 11.3.4), but measuring net effects is complex and uncertain because the additional costs of RE support create distribution and budget effects on the economy.

Because of this complexity, there are few studies that examine the economic impacts in this way on a country's or region's economy. Ragwitz et al. (2009) analyzed these effects for the EU, accounting for positive and negative impacts for two possible scenarios: business-as-usual, leading to a $14 \%$ RE share in final energy consumption by 2020; and an 'accelerated deployment policies' scenario, achieving the EU $20 \%$ target by 2020 . They found that RE support policies have a slight positive impact on gross domestic product (GDP) and employment, and that benefits are greater for the higher RE share. Houser et al. (2010) analyzed the potential impacts of Proposed American Power Act on the USA from the perspective of energy security, environmental impact and employment effects, all of which were net positive while the macroeconomic perspective of GDP was broadly neutral. It is important to note that these studies focus on specific geographical areas and that findings could differ for other regions and varying conditions. Most such studies focus on analysing the net effects of RE policy on one economic sector. For example, Lehr et al. (2008) focused on Germany and net employment, and also found positive economic impacts.

These macroeconomic studies are important for gaining an understanding of the distributional impacts across society. While the costs of subsidies are often spread broadly through an economy, the economic benefits tend to be more concentrated (IPCC, 2007). As such, support mechanisms can shift economic wealth from some groups in society to others. Such impacts may simultaneously meet effectiveness, efficiency and equity concerns, or they may cause conflicts among these concerns. Providing energy access, for example, is generally expected to increase equity (Casillas and Kammen, 2010). (See Section 11.5.1 for more on effectiveness, efficiency and equity.)

Distributional impacts are less clear if the cost of a RE policy is assessed relative to an alternative use by government of the same funds or in foregone spending by individuals (Frondel et al., 2010), or in relation to the effects of that policy on different segments of society (Bergek and Jacobsson, 2010). If the costs of a policy are spread across all consumers, poorer people pay a relatively larger share of their income to support RE than do others, unless there are policies in place to mitigate such impacts (Boardman, 2009).

\subsubsection{Interactions and potential unintended consequences of renewable energy and climate policies}

If each externality and each market failure of RE deployment were addressed by the 'ideal' first-best instrument-for example, a carbon price for the climate externality, R\&D and deployment subsidies for innovation spillovers, and financial instruments to reduce inappropriate investment risks - the result would be an economically optimal deployment of low-carbon technologies. In reality, however, due to overlapping drivers and rationales for RE deployment (Section 11.3) and overlapping jurisdictions (local versus national versus international level) there may be substantial interplay among policies at times and with unintended consequences. Due to the barriers to policy development discussed in part in Section 11.4 (e.g., informational and political constraints (Bennear and Stavins, 2007)), policymakers often do not implement policies that address market failures in an 'ideal' way. A clear understanding of the interplay among policies and the cumulative effects of multiple policies is crucial in order to address counterintuitive or unintended consequences. This section addresses the interplay between climate change policies, such as carbon pricing, and RE policies. A discussion of the interplay between RE policies and non-RE policies that goes beyond climate change policies (e.g., agricultural policies) can be found in Section 11.6.2.

Firstly, in order to be effective and efficient, both carbon pricing and RE- specific policies must apply over long time periods. Therefore a careful consideration of dynamic incentive effects is required -in 
particular with respect to the supply of fossil fuel resources. If not applied globally and comprehensively, both carbon pricing and RE policies create risks of 'carbon leakage': RE policies in one jurisdiction or sector reduce the demand for fossil fuel energy in that jurisdiction or sector, which ceteris paribus reduces fossil fuel prices globally and hence increases demand for fossil energy in other jurisdictions or sectors. Similarly, climate change policies in one jurisdiction increase the relative cost of emitting in that jurisdiction, providing firms with an incentive to shift production from plants facing carbon prices or regulation to plants in countries with weaker climate change policy (Ritz, 2009). Hence, the impact of carbon pricing and RE policies on emission reduction could potentially become small or even zero. The scope of offset provisions within a carbon cap-and-trade system (the Kyoto Protocol's Clean Development Mechanism or Joint Implementation, for example) can also affect the RE objective by giving firms an alternative to domestic emissions reductions, thereby reducing the incentive to deploy RE technologies in the country to which the policy applies (del Río González et al., 2005).

Even if implemented globally, suboptimal carbon prices and RE policies could potentially lead to higher carbon emissions (Sinn, 2008; Gerlagh, 2010; Grafton et al., 2010; Van der Ploeg and Withagen, 2010). For example, there is a potential danger that as soon as RE policies start to allow RE to compete with fossil fuel technologies in the market place, fossil fuel prices could fall, discouraging further RE deployment and thereby restoring the competitiveness of fossil fuels. If fossil fuel resource owners fear more supportive RE deployment policies in the long term, they could increase resource extraction as long as RE support is moderate. Similarly, the prospect of future carbon price increases may encourage owners of oil and gas wells to extract resources more rapidly, while carbon taxes are lower, undermining policymakers' objectives for both the climate and the spread of RE technology. The conditions of such a 'green paradox' are rather specific: carbon pricing would have to begin at low levels and increase quickly (Sinn, 2008; Hoel, 2010; Edenhofer and Kalkuhl, 2011). Simultaneously, subsidized RE would have to remain more expensive than fossil fuel-based technologies (Van der Ploeg and Withagen, 2010). If carbon prices and RE subsidies begin at high levels from the beginning, such green paradoxes become unlikely. Moreover, quantity instruments like emissions trading schemes and green quotas (if globally applied) eliminate the risk of green paradoxes altogether.

Secondly, carbon pricing and RE policies administered at the same time create complex changes in the incentives for the deployment of energy technologies (de Miera et al., 2008; de Jonghe et al., 2009; Fischer and Preonas, 2010). The cumulative effect of combining policies that set fixed carbon prices, like carbon taxes, with RE subsidies is largely additive: in other words, extending a carbon tax with RE subsidies decreases emissions and increases the deployment of RE.

However, the effect on the energy system of combining endogenous price policies, like emissions trading and/or RE quota obligations, is usually not as straightforward. This is because several feedback mechanisms have an effect on the resulting price signals for fossil and low-carbon technologies. Adding RE policies on top of an emissions trading scheme usually reduces carbon prices (Amundsen and Mortensen, 2001; Fankhauser et al., 2010), which, in turn, makes carbon-intensive (e.g., coal-based) technologies more attractive compared to other non-RE abatement options such as natural gas, nuclear energy and/or energy efficiency improvements (Blyth et al., 2009; Böhringer and Rosendahl, 2010; Fischer and Preonas, 2010). In such cases, although overall emissions remain fixed by the cap, RE policies reduce the costs of compliance and/or improve social welfare only if $\mathrm{RE}$ technologies experience specific externalities and market barriers to a greater extent than other energy technologies. If that is not the case, the RE support cannot be economically justified on climate policy grounds alone.

However, if an emissions cap were chosen in anticipation of the contribution from well-designed RE deployment policies-whether FITs, fiscal incentives or other policies-that were targeted at RE-specific market failures, RE support can play a role a role in removing those market failures (Fischer and Preonas, 2010). Further, a quantity-based instrument like a quota obligation could become non-binding (implying zero prices) if other instruments are very stringent. For example, $\mathrm{CO}_{2}$ allowance prices within an emissions trading scheme could fall to zero if a strong RE policy (in terms of high RE quotas or subsidies) is in place. Equally, the price of tradable RE certificates could fall to zero if carbon prices are very high due to ambitious emissions caps or high carbon taxes (Unger and Ahlgren, 2005; de Jonghe et al., 2009).

Finally, RE policies alone (i.e., without carbon pricing) are not necessarily an efficient instrument to reduce carbon emissions because they do not provide enough incentives to use all available least-cost mitigation options including non-RE low-carbon technologies and energy efficiency improvements (Fischer and Newell, 2008). The implementation of an appropriate carbon pricing scheme remains crucial if the goal of policymakers is to efficiently reduce carbon emissions (Stern 2007, p. xviii, Ch. 14; IPCC 2007, p. 19).

In conclusion, the combination of carbon pricing and RE policies is most efficient in reaching climate change mitigation goals if RE policies address RE-specific market failures and carbon pricing policies address the climate externality. Carbon pricing is expected by many to be the most important policy to reduce carbon emissions. Poorly designed RE policies, in particular in cases without carbon pricing policies, may increase mitigation costs or can, in extreme cases, even increase carbon emissions. At the same time, if carefully designed, RE policies can be a useful supplement to carbon pricing, removing associated market failures and decreasing mitigation costs.

\subsection{Enabling environment and regional issues}

An environment that is 'enabling' of RE-specific policies is made up of cross-cutting domains as presented in Table 11.4. An enabling environment encompasses different factors such as institutions, 
Table 11.4 | Factors and participants contributing to a successful RE governance regime.

\begin{tabular}{|c|c|c|c|c|c|c|}
\hline $\begin{array}{l}\text { Dimensions of } \\
\text { an Enabling } \\
\text { Environment }>> \\
\text { Factors and actors } \\
\text { contributing to the } \\
\text { success of RE policy } \\
\text { V } \\
\text { V }\end{array}$ & $\begin{array}{c}11.6 .2 \\
\text { Integrating } \\
\text { policies } \\
\text { (national/ } \\
\text { supranational } \\
\text { policies) }\end{array}$ & $\begin{array}{c}11.6 .3 \\
\text { Reducing financial } \\
\text { and investment } \\
\text { risk }\end{array}$ & $\begin{array}{c}11.6 .4 \\
\text { Planning and } \\
\text { permitting at the } \\
\text { local level }\end{array}$ & $\begin{array}{c}11.6 .5 \\
\text { Providing } \\
\text { infrastructures, } \\
\text { networks and } \\
\text { markets for RE } \\
\text { technology }\end{array}$ & $\begin{array}{c}11.6 .6 \\
\text { Technology } \\
\text { transfer and } \\
\text { capacity building }\end{array}$ & $\begin{array}{l}11.6 .7-8 \\
\text { Learning from actors } \\
\text { beyond government }\end{array}$ \\
\hline Institutions & $\begin{array}{l}\text { Integrating RE policies } \\
\text { with other policies } \\
\text { at the design level } \\
\text { reduces potential for } \\
\text { conflict among govern- } \\
\text { ment policies }\end{array}$ & $\begin{array}{l}\text { Development of } \\
\text { financing institutions } \\
\text { and agencies can aid } \\
\text { cooperation between } \\
\text { countries, provide soft } \\
\text { loans or international } \\
\text { carbon finance (CDM). } \\
\text { Long-term commitment } \\
\text { can reduce the percep- } \\
\text { tion of risk }\end{array}$ & $\begin{array}{l}\text { Planning and permitting } \\
\text { processes enable RE } \\
\text { policy to be integrated } \\
\text { with non-RE policies at the } \\
\text { local level }\end{array}$ & $\begin{array}{l}\text { Policymakers and regula- } \\
\text { tors can enact incentives } \\
\text { and rules for networks } \\
\text { and markets, such as } \\
\text { security standards and } \\
\text { access rules }\end{array}$ & $\begin{array}{l}\text { Reliability of RE } \\
\text { technologies can } \\
\text { be ensured through } \\
\text { certification } \\
\text { Institutional agree- } \\
\text { ments enable technol- } \\
\text { ogy transfer }\end{array}$ & $\begin{array}{l}\text { Openness to learning from } \\
\text { other actors can comple- } \\
\text { ment design of policies and } \\
\text { enhance their effectiveness } \\
\text { by working within existing } \\
\text { social conditions }\end{array}$ \\
\hline $\begin{array}{l}\text { Civil society } \\
\text { (individuals, } \\
\text { households, } \\
\text { nongovernment } \\
\text { organizations, } \\
\text { unions etc.) }\end{array}$ & $\begin{array}{l}\text { Municipalities or cities } \\
\text { can play a decisive role } \\
\text { in integrating state } \\
\text { policies at the local } \\
\text { level }\end{array}$ & $\begin{array}{l}\text { Community investment } \\
\text { can share and reduce } \\
\text { investment risk } \\
\text { Public-private partner- } \\
\text { ships in investment and } \\
\text { project development } \\
\text { can contribute to re- } \\
\text { ducing risks associated } \\
\text { with policy instruments } \\
\text { Appropriate interna- } \\
\text { tional institutions can } \\
\text { enable an equitable } \\
\text { distribution of funds }\end{array}$ & $\begin{array}{l}\text { Participation of civil } \\
\text { society in local planning } \\
\text { and permitting processes } \\
\text { might allow for selection } \\
\text { of the most socially } \\
\text { relevant RE projects }\end{array}$ & $\begin{array}{l}\text { Civil society can become } \\
\text { part of supply networks } \\
\text { through co-production of } \\
\text { energy and new decen- } \\
\text { tralized models. }\end{array}$ & $\begin{array}{l}\text { Local actors and } \\
\text { NGOs can be involved } \\
\text { in technology transfer } \\
\text { through new business } \\
\text { models bringing to- } \\
\text { gether multi-national } \\
\text { companies / NGOs } \\
\text { / small and medium } \\
\text { enterprises (SMEs) }\end{array}$ & $\begin{array}{l}\text { Civil society participation in } \\
\text { open policy processes can } \\
\text { generate new knowledge } \\
\text { and induce institutional } \\
\text { change } \\
\text { Municipalities or cities } \\
\text { may develop solutions } \\
\text { to make RE technology } \\
\text { development possible at } \\
\text { the local level } \\
\text { People (individually or col- } \\
\text { lectively) have a potential } \\
\text { for advancing energy-relat- } \\
\text { ed behaviours when policy } \\
\text { signals and contextual } \\
\text { constraints are coherent }\end{array}$ \\
\hline $\begin{array}{l}\text { Finance and business } \\
\text { communities }\end{array}$ & & $\begin{array}{l}\text { Public private partner- } \\
\text { ships in investment and } \\
\text { project development } \\
\text { can contribute to re- } \\
\text { ducing risks associated } \\
\text { with policy instruments }\end{array}$ & $\begin{array}{l}\text { RE project developers } \\
\text { can offer know-how and } \\
\text { professional networks in : } \\
\text { i) aligning project develop- } \\
\text { ment with planning and } \\
\text { permitting requirements ; } \\
\text { and ii) adapting planning } \\
\text { and permitting processes } \\
\text { to local needs and condi- } \\
\text { tions } \\
\text { Businesses can be active } \\
\text { in lobbying for coherent } \\
\text { and integrated policies }\end{array}$ & $\begin{array}{l}\text { Clarity of network and } \\
\text { market rules improves } \\
\text { investor confidence }\end{array}$ & $\begin{array}{l}\text { Financing institutions } \\
\text { and agencies can } \\
\text { partner with national } \\
\text { governments, provide } \\
\text { soft loans or interna- } \\
\text { tional carbon finance } \\
\text { (CDM). }\end{array}$ & $\begin{array}{l}\text { Multi-national companies } \\
\text { can involve local NGOs or } \\
\text { SMEs as partners in new } \\
\text { technology development } \\
\text { (new business models) } \\
\text { Development of corpora- } \\
\text { tions and international } \\
\text { institutions reduces risk of } \\
\text { investment }\end{array}$ \\
\hline Infrastructures & $\begin{array}{l}\text { Policy integration with } \\
\text { network and market } \\
\text { rules can enable } \\
\text { development of infra- } \\
\text { structure suitable for a } \\
\text { low-carbon economy }\end{array}$ & $\begin{array}{l}\text { Clarity of network and } \\
\text { market rules reduces } \\
\text { risk of investment } \\
\text { and improves investor } \\
\text { confidence }\end{array}$ & & $\begin{array}{l}\text { Clear and transparent } \\
\text { network and market } \\
\text { rules are more likely to } \\
\text { lead to infrastructures } \\
\text { complementary to a low- } \\
\text { carbon future }\end{array}$ & & $\begin{array}{l}\text { City and community } \\
\text { level frameworks for the } \\
\text { development of long- } \\
\text { term infrastructure and } \\
\text { networks can sustain the } \\
\text { involvement of local actors } \\
\text { in policy development }\end{array}$ \\
\hline
\end{tabular}




\begin{tabular}{|c|c|c|c|c|c|c|}
\hline $\begin{array}{l}\text { Dimensions of } \\
\text { an Enabling } \\
\text { Environment >> } \\
\text { Factors and actors } \\
\text { contributing to the } \\
\text { success of RE policy } \\
\text { V } \\
\text { V }\end{array}$ & $\begin{array}{c}11.6 .2 \\
\text { Integrating } \\
\text { policies } \\
\text { (national/ } \\
\text { supranational } \\
\text { policies) }\end{array}$ & $\begin{array}{c}11.6 .3 \\
\text { Reducing financial } \\
\text { and investment } \\
\text { risk }\end{array}$ & $\begin{array}{c}11.6 .4 \\
\text { Planning and } \\
\text { permitting at the } \\
\text { local level }\end{array}$ & $\begin{array}{c}11.6 .5 \\
\text { Providing } \\
\text { infrastructures, } \\
\text { networks and } \\
\text { markets for RE } \\
\text { technology }\end{array}$ & $\begin{array}{c}11.6 .6 \\
\text { Technology } \\
\text { transfer and } \\
\text { capacity building }\end{array}$ & $\begin{array}{l}11.6 .7-8 \\
\text { Learning from actors } \\
\text { beyond government }\end{array}$ \\
\hline $\begin{array}{l}\text { Politics } \\
\text { (international } \\
\text { agreements / } \\
\text { cooperation, climate } \\
\text { change strategy, } \\
\text { technology transfer } \\
\text { etc.) }\end{array}$ & $\begin{array}{l}\text { Supra-national } \\
\text { guidelines (e.g., EU on } \\
\text { 'streamlining', ocean } \\
\text { planning, impact study) } \\
\text { may contribute to } \\
\text { integrating RE policy } \\
\text { with other policies }\end{array}$ & $\begin{array}{l}\text { Long-term political } \\
\text { commitment to RE } \\
\text { policy reduces investors } \\
\text { risk in RE projects }\end{array}$ & $\begin{array}{l}\text { Supra-national guidelines } \\
\text { may contribute to evolving } \\
\text { planning and permitting } \\
\text { processes }\end{array}$ & $\begin{array}{l}\text { Development cooperation } \\
\text { helps sustain infrastruc- } \\
\text { ture development and } \\
\text { allows easier access to } \\
\text { low-carbon technologies }\end{array}$ & $\begin{array}{l}\text { CDM, Intellectual } \\
\text { property rights and } \\
\text { patent agreements } \\
\text { can contribute to } \\
\text { technology transfer }\end{array}$ & $\begin{array}{l}\text { Appropriate input from } \\
\text { non-government institu- } \\
\text { tions stimulates more } \\
\text { agreements that are } \\
\text { socially connected } \\
\\
\text { UNFCCC process mecha- } \\
\text { nisms such as Expert Group } \\
\text { on Technology Transfer, } \\
\text { the Global Environment } \\
\text { Facility, and the Clean } \\
\text { Development Mechanism } \\
\text { and Joint Implementation } \\
\text { may provide guidelines to } \\
\text { facilitate the involvement } \\
\text { of non-state actors in RE } \\
\text { policy development }\end{array}$ \\
\hline
\end{tabular}

infrastructures (e.g., networks) and political outcomes (e.g., international agreements/cooperation, climate change strategy) and different actors or participants (e.g., the finance community, business community, civil society, government), each of which influences the success of RE-specific policies while interacting in different configurations. For example, these factors can influence how change may occur within a country; how risky investment in RE may be; how economic regulation encourages (or not) RE deployment; and how communities react to $R E$. These various configurations present different challenges to RE deployment, depending on the countries and their states of development, and local needs and conditions. This section highlights the potential contribution of these individual factors and participants to a governance of RE that can strengthen, and goes beyond, government action.

\subsubsection{Innovation in the energy system}

If RE is to play a major role in climate change mitigation, then an overarching and parallel step is to implement policies that enable change to occur in the energy system. A number of studies have reconstructed the historical emergence and formation of socio-technical systems that are taken for granted today (e.g., transition from horses to the internal combustion engine (Geels, 2005); transition from cesspool to sewer systems in urban hygiene (Geels, 2004)). A widely accepted conclusion is that established socio-technical systems tend to narrow the diversity of innovations because the prevailing technologies develop a fitting institutional environment (David, 1985). This environment supports these technologies by making it easier and cheaper to develop and deploy them, or to develop technologies that do not require a profound transformation of the energy system (Grubler et al., 1999a; Unruh, 2000). Actors, institutions and even the very structure of the economy evolve to depend, to some degree, on the existing sociotechnical systems. This may give rise to strong path dependencies and exclude (or lock out) rivalling and potentially better-performing alternatives (Nelson and Winter, 1982).

For these reasons, socio-technical system change takes time, and it involves change that is systemic rather than linear. Recent studies have focused on ongoing innovation processes in order to understand the preconditions under which radical transformations of sociotechnical systems could occur (Carlsson et al., 2002; Jacobsson and Bergek, 2004; Hekkert et al., 2007; Markard and Truffer, 2008). These studies emphasized that the interplay between existing institutional contexts and technology development was important for explaining the effectiveness (or failure) of specific promotional policies, such as RE policies.

RE technologies are being integrated into an energy system that, in much of the world, was constructed to benefit the existing energy supply mix. As a result, infrastructure favours the currently dominant fuels, and there are existing lobbies and interests that all need to be taken into account (e.g., Verbong and Geels, 2007). In light of this situation, RE deployment policies can be more efficient and effective if the environment around them becomes more conducive to change.

Due to the intricacies of technological change, it is important that all levels of government (from local through to international) encourage RE development through policies, and that nongovernmental actors also be involved in policy formulation and implementation. In recent years, 
public-private partnerships, civil society and business actors have played increasingly influential roles in the formulation and implementation of policies (Rotmans et al., 2001; van den Bergh and Bruinsma, 2008). In response, the focus of political science literature is shifting from "government" to "governance" related research (Rosenau and Czempiel, 1992; Rhodes, 1996; Newig and Fritsch, 2009), focusing increasingly on understanding the interplay between governments and other societal actors and the implications for the success of policy implementation. Some argue that policy action is more effective and efficient when it includes non-state actors, networks and coalitions in building guiding visions, and formulating and implementing public policy (Rotmans et al., 2001; van den Bergh and Bruinsma, 2008).

\subsubsection{Complementing renewable energy policies and non-renewable energy policies}

Government policies are more likely to be effective and efficient if they complement one another (Peters, 1998). Further, the design of individual RE policies will also affect their coordination with other policies (both other RE-specific policies and policies targeting other sectors). Although such coordination has been described as a lynchpin for implementation or realization of sustainable development (Jordan and Lenschow, 2000; Lenschow, 2002), it remains a rather elusive principle that is open to divergent interpretations (Jordan and Lenschow, 2000; Persson, 2004). There is a clear need for strong central coordination to eliminate contradictions and conflicts among sectoral policies and to simultaneously coordinate action at more than one level of governance (Jordan and Lenschow, 2000). However, there are few 'best practices' for coordination that can be shared easily at the international level (Jordan and Lenschow, 2000).

Attempting to actively promote the complementarity of policies (for example, agricultural and energy policies) while also considering the independent objectives of each, is not an easy task and may create win-lose and/or win-win situations, with possible tradeoffs (e.g., economic versus environmental, long- versus short-term) (Lenschow, 2002; Resch et al., 2009), as seen in relation to RE transportation, to take one example.

A number of policies that are not directly aimed at promoting RE in the transport sector can have an influence on the effectiveness and efficiency of RE-specific policies. On the 'negative' side, because nearly all liquid biofuels for transport are currently produced from conventional agricultural crops, the removal of agricultural crop subsidies may have a direct impact on the development of liquid biofuels for transportation (see Sections 11.5.5, 2.4.5, 2.5.7 and 2.8.4). In contrast, urban transport policies that aim to regulate transport demand through price signals (e.g., parking fees and congestion charges) can also induce a shift to alternative fuel vehicles through fee exemptions and thereby facilitate deployment of RE transportation (Prud'homme and Bocajero, 2005; Creutzig and He, 2009). Further, carbon-intensity fuel standards—such as the California Low Carbon Fuels Standard-and the EU Emissions Trading Scheme can provide incentives for low-carbon RE transport fuels by helping to level the playing field (Sperling and Yeh, 2009; Creutzig et al., 2010).

RE policies and demand-side measures can complement each other by taking advantage of synergies between RE and energy efficiency, as discussed in Sections 1.2.5 and 11.7. For example, the use of smart meters, time-differentiated pricing and responsive demand can enable a shift in demand load that can both benefit system operation and match demand to RE supply (Sioshansi and Short, 2010; Sections 11.6.5 and 8.2.1).

\subsubsection{Reducing financial and investment risk}

A broader enabling environment includes a financial sector that can offer access to financing on terms that reflect the specific risk/reward profile of a RE technology or project. The cost of financing and access to it depends on the broader financial market conditions prevalent at the time of investment, and on the specific risks of a project, technology and actors involved. Beyond RE-specific policies, broader conditions can include political and currency risks, and energy-related issues such as competition for investment from other parts of the energy sector, and the state of energy sector regulations or reform (ADB, 2007)The fundamental principle of modern global capital markets is that private capital will flow to those countries, or markets, where regulatory frameworks and policies governing investment are transparent, well-considered and consistent, providing confidence to investors over a time period that is appropriate to the life cycle of their investment (ADB, 2007).

Improving access to finance is necessary but not always sufficient to promote RE project deployment, particularly in developing countries. Successful public finance mechanisms typically combine access to finance with technical assistance programmes that are designed to help prepare projects for investment and to build the capacity of the various actors involved. There are numerous examples of finance facilities that were created but that never disbursed funds because they failed to find and generate sufficient demand for the financing (UNEP, 2008). As seen in the Pacific Islands, access to financing and even targets are not necessarily enough; it is also necessary to have specific policies in support of RE (see Box 11.1).

Government RE policies can play an important role in creating an environment conducive to investment. Long-term commitment contributes to the effectiveness and efficiency of RE policy because it reduces uncertainty about expected returns from investing in RE projects, as described in Section 11.5. However, linking RE policies to permitting policies for RE projects (Section 11.6.4), to the economic regulation of networks and markets (Section 11.6.5), to policies to encourage and enable technology transfer (Section 11.6.6) and to attitudes towards RE beyond government (Section 11.6.7) reduces investor attitudes to risk, thereby freeing up more investment. One specific example can be seen on the 
ground in Nepal, where it has been shown that development of local capacity can play a major role in attracting private financing in developing countries (UNDP and AEPC, 2010; see Box 11.13).

\subsubsection{Planning and permitting at the local level}

Deployment of RE technologies has the potential to interfere with existing and traditional resource uses, conservation values or commercial interests. Rules are needed to integrate RE policy with other (e.g., environmental, landscape, agriculture) policies, to resolve potential conflicts at the local level, and to ensure sustainable deployment of RE technologies (see Chapter 9 for a full discussion). This section addresses the challenges of balancing planning regulation that supports RE deployment while also ensuring public oversight and environmental protection, and it provides some general lessons from experiences to date. Technology-specific planning issues are covered in the relevant technology chapters.

Spatial planning (land/sea space, landscape) processes are social processes (Ellis et al., 2009). It is often in the process of preparing, designing, planning, deciding and implementing a specific project, whether RE or otherwise, that differences in perspectives, expectations and interests become manifest. The system of spatial planning provides for a framework - a set of legal, formal rules and procedures-to address and mediate conflicting interests and values (Owens and Driffill, 2008; Ellis et al., 2009). An appropriate planning framework can reduce hurdles at the project level, making it easier for RE developers, communities or households to access the RE resource and succeed with their projects. It can also provide protection against developments that may not be beneficial to the local community or local environment.

This framework needs to be in line with the national or local political culture and reflects historically evolved 'ways of doing' - for example, traditions of administrative coordination between levels of government, with more or less autonomy for local governments in making decisions on local land use (e.g., Kahn, 2003; Söderholm et al., 2007; Bergek and Jacobsson, 2010).

Whether conflict related to project siting is likely to occur depends greatly on the specific context and on the type of project under consideration. For instance, potential wind energy projects might face significant barriers in locations where landscape amenity is a cultural-historical value (Cowell, 2010; Nadaï and Labussière, 2010), but have less trouble gaining acceptance where this is not the case (Toke et al., 2008).

The successful deployment of RE technologies to date has depended on a combination of favourable procedures at both national and local levels. Universal procedural fixes, such as 'streamlining' of permitting applications, are unlikely to resolve conflicts among stakeholders at the level of project deployment because they would ignore place- and scale-specific conditions (Breukers and Wolsink, 2007b; Agterbosch et al., 2009; Ellis et al., 2009). Recent evidence in the siting and planning of RE points to the need for systems that are pro-active, positive and place- and scale-sensitive. Following are elements that such planning systems might include.

\subsubsection{Aligning stakeholder expectations and interests}

Several case studies in RE planning processes have shown the importance of aligning interests among various stakeholders (Devine-Wright, 2005; Warren and McFadyen, 2010). This can be done in a variety ways, including adopting procedures for project development that are judged fair by the different parties (Gross, 2007), or identifying (creating, negotiating) during the 'pre-application process' multiple benefits that a RE project may bring for different stakeholders (Heiskanen et al., 2008a; Ellis et al., 2009).

\subsubsection{Learning about the importance of context for RE deployment}

Those who object to projects are often very knowledgeable (Ellis et al., 2007) and cannot be dismissed as simply ignorant or misinformed. Understanding the local societal context of RE could help RE planning processes overcome the hurdles they face (Breukers and Wolsink, 2007a; Raven et al., 2008).

\subsubsection{Adopting benefit-sharing mechanisms}

Benefits associated with RE projects (for example, social, environmental, or financial/economic (Madlener, 2007; J. Rogers et al., 2008; Walker, 2008)) accrue mostly to the project developer and to broader society (beyond the area directly affected by a specific project) (e.g., D. Bell et al., 2005).

An acknowledgement that benefits, costs and risks are unequally distributed, followed by efforts to arrive at a more equitable benefit sharing, is helpful. Participation of local communities in the benefits generated by development of a specific project, may include co-ownership (Deepchand, 2002; Meyer, 2007; Walker, 2008; Warren and McFadyen, 2010), as seen in Denmark (see Box 11.12); local employment by making use of/setting up local contractors and services (Faulin et al., 2006; Agterbosch and Breukers, 2008; Heiskanen et al., 2008a); direct reinvestment by developers into infrastructures of the local community (Upreti and Van Der Horst, 2004; Aitken, 2010); transfer of benefits through lump sum or business tax to local communities (Faulin et al., 2006; Nadaï, 2007); energy price reduction (Deepchand, 2002); or environmental compensation (Cowell, 2007). Some studies have shown that local economic involvement favoured a better acceptance of RE projects (Jobert et al., 2007; Maruyama et al., 2007). 


\section{Box 11.12 | Lessons from Denmark: The value of a comprehensive approach and individual and community ownership.}

Since the 1970s, wind power has developed into a mainstream technology in the Danish energy system, generating $20 \%$ of Denmark's electricity by 2009. In 2009, the Danish wind industry was the country's largest manufacturing industry, employing some 24,000 people (Danish Wind Industry Association, 2010) and accounting for 20\% of the global market (BTM Consult ApS, 2010).

The first oil crisis brought concern about energy security, and energy efficiency and RE became top political priorities. In the 1980s and beyond, energy security, creation of domestic jobs and export markets were the major drivers for transformation of the Danish energy sector (Danish Ministry of Energy, 1981).

A combination of policy mechanisms, guided by national energy plans with long-term targets, has facilitated RE development. A publicly funded R\&D programme began in 1976 with the goal of designing and testing megawatt-scale turbines. A small turbine test station was established at Risø National Laboratory; interaction between the test station and small enterprises in the industry helped feed experience back into the field to improve basic knowledge about turbine design (Sawin, 2001; Madsen, 2009).

In 1979, the government introduced its first and most important policy to stimulate the market, based on a $30 \%$ investment grant to purchasers of 'system-approved' wind turbines. This 10-year programme saw regular reductions in the grant level as technology improvements and economies of scale reduced costs. The investment grants to end users (private investors) created a small but strong industry by the early 1980s (Madsen, 2009). In 1985, the government enacted a per-kilowatt hour subsidy for all wind power fed into the grid, funded in part through a tax on $\mathrm{CO}_{2}$. A voluntary feed-in tariff (equivalent to $85 \%$ of the retail rate) paid by utilities to wind producers was fixed by law in 1992 (Sawin, 2001; Madsen, 2009).

Private investors, often organized in small cooperatives, owned more than $80 \%$ of total installed capacity through the 1990 s. This was largely due to a number of government policies, from special tax breaks to ownership limitations, to encourage local individual and cooperative ownership (Madsen, 2009). During the pioneering period, incentives for individuals and cooperatives encouraged municipalities to set aside specific areas for turbines. In 1992, the Danish Planning Agency launched guidelines that accelerated the permitting process and established capacity targets for all Danish counties, thereby eliminating uncertainty about siting while giving communities control over where projects were located (Danish Ministry of the Environment, 1993; Sawin, 2001).

Also important were Ministry of Energy 'contract policies', which required utilities to participate in wind power development. Under the first such contract, initiated in 1985, utilities were required to construct $100 \mathrm{MW}$ of wind capacity over five years. The utility mandate was extended twice, and the first requirement for offshore capacity was issued in 1990 (Sawin, 2001).

Nearly three decades of consistent policy were interrupted in the early 2000s when leadership changed, the per-kilowatt hour subsidy was significantly reduced, and deregulation of the electricity sector created uncertainty (see Figure 11.10). Little new capacity was added until 2008 because most projects were not economically feasible, and changes in planning structure delayed siting and installation of larger turbines (Madsen, 2009).

The government has since changed its position, announcing a political target of a '100\% fossil-free' energy system by 2050 . As of 2009 , Denmark aimed to get nearly $20 \%$ of total energy from RE sources by 2012 and $30 \%$ by 2020 , with wind power playing a major role (European Union, 2009). As a result, development has picked up again.

Consistent support for public R\&D in Denmark played a critical role in the advancement of wind power technology, education of technical experts and development of a manufacturing base. Market stimulation in the form of direct grants and later fixed feed-in tariffs, which reduced risk to investors, was essential for increasing deployment, reducing costs and creating broad-based support and a strong domestic industry, but significant policy changes and uncertainty stalled development for several years. Finally, Denmark's experience demonstrates that local ownership of wind power plants can facilitate market development. 


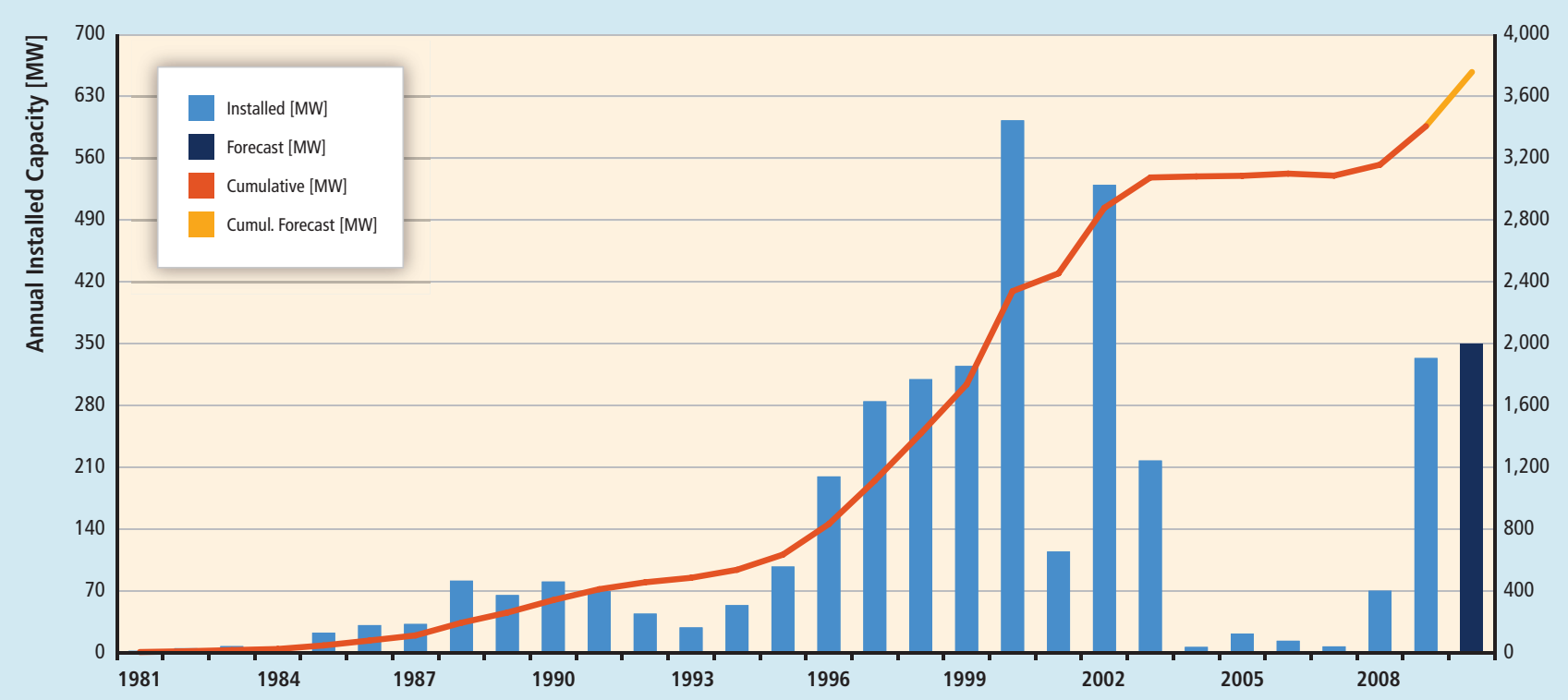

Figure 11.10 | Denmark's annual and cumulative installed wind capacity, 1995 to 2010 (BTM Consult ApS, 2010).

\subsubsection{Timing: pro-active national and local government}

Clear procedural rules (e.g., requirements for permitting, ground for court appeal, allocation of responsibilities and timing of the process) are important to reduce risks for the developer and to ensure legal security for other stakeholders.

National planning policies sometimes lag behind initiatives of those deploying innovative technologies, and therefore may hamper these innovations. Legislative changes or case-by-case approaches that account for technology- and scale-specific challenges might be required. For example, ocean energy projects at an early commercial stage occasionally face a 'catch-22' situation in which the existing permitting regime requires project impact data that could be produced only if they were granted temporary authorization (IEA, 2009a). In such cases, project license leases, pilot development zones, or specific site agreements have been used as tailored solutions.

Local governments are also often caught by surprise when a project developer presents a RE project proposal (Breukers and Wolsink, 2007a; Nadaï and Labussière, 2010). Organizing local participation in the development of comprehensive plans and identifying main siting areas before any projects are planned makes it easier to create an open and nonpolarized discussion, as seen in Denmark (Sussman, 2008).

Finally, explicit political support for RE at the national level can reduce local polarization by encouraging the perception of RE and associated impacts as public rather than private issues (Bergek and Jacobsson, 2010).

\subsubsection{Building collaborative networks}

If relevant stakeholders are brought into the RE project process and become part of the agreement for RE deployment, their long-term acceptance and lasting commitment toward a project are more likely to come about than if this does not occur. Further, networks that result can be important 'vehicles' for exchanging experience and knowledge; this in turn supports learning processes that stimulate change, such as policies or institutions that further help RE development (Breukers and Wolsink, 2007b; Mallett, 2007; Negro et al., 2007; Dinica, 2008; Heiskanen et al., 2008b; Suurs and Hekkert, 2009). Or, collaboration could bring about radical innovation in 'ways of doing', such as finding innovative ways to renew landscape values or protect birds in relation to wind power (e.g., Ellis et al., 2007; Nadaï and Labussière, 2009, 2010).

\subsubsection{Mechanisms for articulating conflict and negotiation}

The deployment of a RE project will rarely serve the interests of all stakeholders. Yet, existing formal avenues to voice opposition usually offer only the opportunity to object to ready-made project proposals (Wolsink, 2000). This can lead to polarization and be counterproductive (Healey, 1997). It is useful to enable the articulation of differing perspectives to allow parties to reach subsequent solutions or compromises through constructive deliberation (Cuppen et al., 2010). For example, following enactment of the Energy Policy Act of 2005, the US Departments of Energy and the Interior identified 24 tracts of land for large-scale solar energy development in six Western states, and then encouraged public participation in the studies of those areas through 
public scoping meetings, public comment on the draft programmatic environmental impact statement, and via a comprehensive project website (US Department of the Interior, 2008; ANL, 2010).

\subsubsection{Providing infrastructures, networks and markets for renewable energy}

After a RE project receives planning permission, investment to build it is only forthcoming once its economic connection to a network is agreed; when it has a contract for the 'off-take' of its production into the network; and when its sale of energy, usually via a market, is assured. The ability, ease and cost of fulfilling these requirements is central to the feasibility of a RE project. Moreover, the methods by which RE is integrated into the energy system will have an effect on the total system cost of RE integration (see Chapter 8) and the cost of different scenario pathways (see Chapter 10). This section discusses integration as it relates to enabling policies and available solutions. It is heavily weighted towards electricity because most experience has been in this sector; electricity is also relevant to both RE electric water and space heating and cooling, and to RE electric transportation. (See Section 8.2.1 for details related to technical integration.)

The economic regulation overseeing these areas is often technology- and fuel- 'blind', meaning that there is no differentiation made between technologies or fuels. Even so, however, it is possible for policies to be implemented to facilitate RE connection to networks and access to markets and to ensure that infrastructure requirements specific to RE are made in a timely and costeffective fashion.

\subsubsection{Infrastructure building and connection to networks}

Planning and investment in network infrastructure present challenges due to the large economies of scale in network investments (or the 'lumpiness' of transmission) and the broad impacts and beneficiaries of network expansion (Keller and Wild, 2004). These issues are particularly challenging in countries and regions where vertical separation exists between the generation, transmission and distribution of electricity to electrical customers. Significant debate and diverse policies regarding network investment exist throughout North America and Europe, for example; both regions where generation is largely vertically separated from transmission (see Joskow, 2005; Buijs et al., 2010).

One of the key policy debates regarding network infrastructure investments is that of cost allocation. Most policies generally fall between the two extremes of 1) socialized cost allocation, in which all network users share the burden of covering the cost of any network expansion, and 2) 'beneficiaries pay', where only those network users that benefit from specific network upgrades are responsible for paying the network investment costs (Krapels, 2010).

The connection of RE to networks and the expansion of the network to accommodate increased power flow between RE generation and demand will occur within this broader framework and may, due to the unique characteristics of RE, exacerbate some of the challenges. RE resources, for example, are often concentrated in areas where existing electricity networks have limited extra capacity for transporting additional electricity. These areas also may be a long way from centres of energy demand (see Section 8.2.1.2). With regard to RE, proponents of a 'beneficiary pays' type of mechanism argue that socialized network expansion costs may lead to inefficient siting of RE projects if individual projects do not bear any of the costs of network expansion. RE projects may locate in areas with the highest quality resources but, due to the additional network costs, these areas may not always be as economically efficient as RE resources in lower-quality regions that are closer to demand centres or existing network capacity (e.g., Hoppcock and Patiño-Echeverri, 2010).

Proponents of socialized cost-type mechanisms point out that network investments are long-term infrastructure investments and that they benefit a broad range of network users that may change as the system evolves. Furthermore, the large economies of scale involved with network expansion and the large size of RE resources relative to individual RE projects often leads to the most cost-effective network expansion, far exceeding the size required by an individual RE project. Policies that require individual RE projects to finance network expansion may therefore stifle efficient development of properly sized transmission investment (Puga and Lesser, 2009). Moreover, if the individual RE project must bear all of the costs of the larger, more efficiently sized network expansion, a project that otherwise may be economically efficient may become economically infeasible (Access Reform Options Development Group, 2006).

A further challenge is that the time it takes to plan, site and build transmission infrastructure sometimes well exceeds the time it takes to plan, site and build certain RE facilities. This difficulty can be exacerbated because most economic regulation of networks is based on the principle of 'ex-ante' cost regulation (Baldwin and Black, 2010). This means that network operators often must have regulatory approval in advance of undertaking the strengthening of the network. Before approving individual network reinforcements, however, regulators may require a clear financial commitment from generators or customers of their intention to connect to the network and utilize network assets. However, potential RE generators are unlikely to be able to commit financially to network reinforcement without planning consent; and they may be loathe to spend money on achieving planning consent without knowing the costs of connection. This presents a 'catch-22' situation, which is often further complicated by the disparity between RE project and network reinforcement commissioning time scales (Locke Lord Bissell \& Liddell, 2007).

In order to ensure the timely expansion and reinforcement of infrastructure and connection of RE projects, economic regulators may need to allow 'anticipatory' or 'proactive' network investment and/or allow projects to connect in advance of full infrastructure reinforcement (Araneda et al., 2010) (see Section 8.2.1.3 for examples of these policies being applied in practice). Traditionally within economic regulation, allowing anticipatory investment is thought to increase the risk of stranded 
assets. Policies that provide incentives could be allowed to the network operators to account for the extra risk of such investment decisions, for example by allowing enhanced rates of return on investments (Ofgem, 2008), or otherwise end-use customers could be asked to front the cost of the necessary transmission upgrades.

\subsubsection{Access to and injection of renewable energy into the network}

The rules and costs of how energy is injected into the network, whether a system operator has the right to refuse the RE, and whether the RE project is paid if it is refused access to the network all have major implications for the economics of electricity power plants and their ability to obtain investment (Strbac, 2007).

RE-specific policies can sometimes bypass these complex negotiations. In the EU, the Directive 2001/77/EC on the promotion of electricity produced from RE sources states that EU member states must ensure that transmission and distribution system operators guarantee network access for electricity generated by RE (European Commission, 2009a). This is both connection and off-take (i.e., injection into the grid). In general, but not always, a fundamental design feature of a FIT is a project's connection to the network, and the off-take of the electricity, according to a defined process and remuneration. As a result of the EU Directive, some European countries, particularly those which have FITs, have implemented interconnecting regulations that guarantee access to the network.

In other regions, access may be granted to new RE generation, but electricity generated by RE can be curtailed for economic or reliability reasons. Recent experience with curtailment of wind demonstrates that there are many different policies in place that restrict the injection of wind into networks under constrained conditions and many different policies to compensate wind generation during times where curtailment occurs (Fink et al., 2009).

\subsubsection{Network standards}

Historically, network design standards identify the reinforcement requirements triggered by an energy plant connecting to them to reach a particular level of network security. Alteration of network standards, ahead of time, that take account of RE technical characteristics and that maintain system security can avoid connection and system operation concerns. The UK, for example, has had a series of Work Groups since 2001 whose role is to highlight and recommend how to overcome potential concerns ahead of time (see DTI/Ofgem Embedded Generation Working Group, 2001; National Grid, 2008). In addition to standards for network reinforcements, network operators may also impose minimum performance or equipment requirements on generators in order to allow the plant to be connected. These requirements are often called 'grid codes' or 'interconnection standards' (see Sections 7.5.2.2 and 8.2.1.1).

\subsubsection{Increasing resilience of the system}

One of the significant challenges for integrating RE into the electricity sector in particular is dealing with the variability and uncertainty of some RE resources. As the percentage of RE increases there is an increasing requirement for resilience within the energy system (P. Baker et al., 2009), which is determined by a system's capacity to integrate variable energy output while matching energy demand. Policies can be put in place to facilitate such integration.

Policies might first recognize the variability smoothing effects of diversity for RE production (i.e., aggregation reduces forecasting and integration challenges (IEA, 2008a)). Similarly, policies might ensure the incorporation of aggregate RE production data (actual and forecasted) into electricity market operations by creating new mechanisms or altering rules. Spain, for example, has chosen to encourage RE by requiring the mandatory aggregation of all wind power plant data in Delegated Control Centres, which involves online communication with the National Renewable Energy Control Centre (Morales et al., 2008; Rodriguez, et al., 2008).

Similarly, since variable output RE such as wind cannot be forecast as accurately as far in advance as other energy resources, RE can be accommodated by 'balancing' the electricity as near to real time as possible, such as an hour ahead rather than three hours ahead or a day ahead. Flexible electricity trading rules can reduce the impact of forecast errors on electricity market operations (IEA, 2008a). There are also several changes to the power system that can increase the ability of the system to manage variable and uncertain RE generation. These changes will often require revisions to existing policies. In addition to the already-mentioned examples, increasing interconnection capacity within systems, adopting demand-side management measures that include real-time pricing (e.g., Sioshansi and Short, 2010), increasing storage capacity, using more flexible thermal generation, and improving planning methods are all examples of the measures that would also help to integrate variable RE (Alonso et al., 2008) (see Section 8.2.1.3 for further details).

\subsubsection{Technology transfer and capacity building}

Barriers to technology transfer in RE and other low-carbon technologies have been identified as being institutional, economic, informational, technological and social (UNFCCC, 1998; IPCC, 2000; Wilkins, 2002; Kline et al., 2004). It has been argued that many developing nations are unlikely to 'leapfrog' pollution-intensive stages of industrial development without access to clean technologies that have been developed in more advanced economies (Gallagher, 2006; Sauter and Watson, 2008). The reality is that most low-carbon technologies, including RE technologies, are developed and concentrated in a few countries. A recent study (UNEP et al., 2010) of patenting in selected RE technologies finds that six countries-Japan, the USA, Germany, the Republic of Korea, the UK and France-account for almost $80 \%$ of all patent applications. Accessing, 
adapting and diffusing these technologies to developing (and other developed) countries could greatly facilitate their ability to contribute to the mitigation of climate change.

Technology transfer is not the exclusive domain of any one actor, and technologies can be transferred from developed countries to other developed or even developing countries, not just from the developed to developing world. Also important is that clean technologies typically do not flow across borders unless environmental policies in the recipient country provide incentives for their adoption (e.g., Jha, 2009; Lovely and Popp, 2011).

An important insight in the evolution of technology and innovation (Mytelka, 2007; Roffe and Tesfachew, undated) in the past thirty years is the recognition that technology transfer is not just an end in itself, but a means to achieving a greater strategy of technological capacity building. Technology transfer is a process, not a one-off transaction. It occurs primarily between firms via the market, through the consumption of products or services that incorporate a specific technology; through licensing the capability to produce such products, either by an indigenous firm or through a joint venture arrangement or foreign direct investment (Kim, 1991, 1997; UNCTAD, 2010c).

Nor should technology transfer be considered only the transfer of hardware from one country to another (Dosi, 1982). Technology transfer can take place within countries (e.g., from urban to rural areas), between industries, academia and nongovernmental organizations. And in most cases it also includes transfer of skills and know-how, as well as knowledge and expertise embedded in the technology (M. Bell, 1990, 2007; IPCC, 2000; Ockwell et al., 2010)-in other words, a combination of 'hardware, software and orgware' (Fodella, 1989). Figure 11.11 illustrates the different types of technological content of technology transfer between countries.

\subsubsection{Technology transfer and intellectual property rights}

The role of intellectual property rights (IPRs) in the technology transfer process has been the source of much debate and controversy in the context of international climate change negotiations. Some empirical studies (Ockwell et al., 2010) suggest that intellectual property protection is a necessary but insufficient condition for the success of low-carbon technology transfer. The most recent empirical study (UNEP et al., 2010), carried out by UNEP, the International Centre for Trade and Sustainable Development (ICTSD) and the European Patent Office, finds that firms attach slightly more importance to scientific infrastructure, human capital, favourable market conditions and investment climates than IPR in their licensing decisions. The same study also revealed that $70 \%$ of the respondents were prepared to offer flexible licensing agreements to poor developing countries. However, there is evidence that technology transfer is inhibited in countries with high tariffs and lax intellectual property rights.

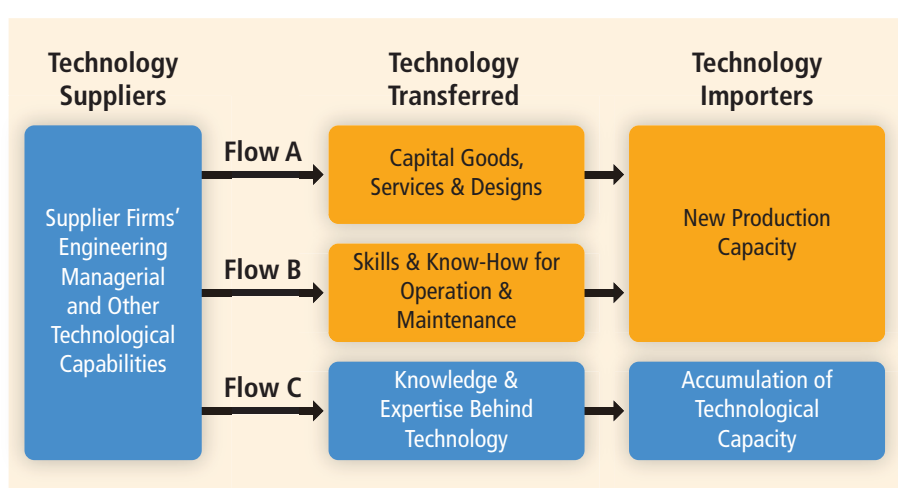

Figure 11.11 | The different types of technological content in technology transfer between countries (Ockwell et al., 2010; based on M. Bell,1990).

\subsubsection{Technology transfer and international institutions}

Development cooperation plays a major role in driving the adoption of RE in developing countries, many of which are undergoing considerable economic and infrastructure development that could result in lock-in to fossil fuel technologies without easy access to low-carbon technologies (IPCC, 2007). Mechanisms established within the UN Framework Convention on Climate Change (UNFCCC) process to facilitate development and transfer of clean technologies include an Expert Group on Technology Transfer (EGTT), the Global Environment Facility (GEF), the Clean Development Mechanism (CDM) and Joint Implementation (JI) (UNFCCC, 2007b). Development agencies and financing institutions demonstrate innovative technologies, provide soft loans for sector investment plans and pave the road for market introduction or promote technology deployment by means of international carbon finance, all of which is conducive for investment.

Incentives for technology transfer are currently included in mechanisms under the Kyoto Protocol, including the CDM. The CDM allows developed countries to meet their Kyoto Protocol commitments by financing emission reduction projects in developing countries. Even though the first projects were not registered until 2004, an analysis of international transfer of wind power technologies, covering 100 countries during the period 1988 to 2007, found that the CDM had a significant impact (Haščič and Johnstone, 2009).

Several studies have analyzed technology transfer associated with CDM projects (Haites et al., 2006; de Coninck et al., 2007; UNFCCC, 2007a, 2008, 2010; Dechezleprêtre et al., 2008; Schneider et al., 2008; Seres et al., 2009), and determined that roughly $40 \%$ of projects, which accounted for about $60 \%$ of the emission reductions up to 2009 , involved technology transfer. The decline in the rate of technology transfer for CDM projects over time suggests that mitigation technologies are being developed in, or transferred to, host countries through conventional channels such as trade, foreign direct investment and licensing (Hoekman et al., 2004; UNFCCC, 2010). 


\subsubsection{Technology transfer and energy access}

Looking at the sub-national level, the rural poor in developing countries who lack access to modern energy services are increasingly left out of the technology transfer debate. The type of innovative capabilities required tend to involve the adoption and adaptation of technologies to suit local conditions and needs, or supply chain management, rather than innovating at the technological frontier as technology producers. In order to have the capacity to adapt, install, maintain, repair and improve on RE technologies in remote and rural communities, investment in technology transfer must be complemented by investment in community-based extension services that provide expertise, advice and training regarding installation, technology adaptation, repair and maintenance (Ockwell et al., 2009; UNCTAD, 2010a) (see Box 11.13).

The United Nations Commission on Science and Technology (CSTD) (UNCTAD, 2010b) suggests that new, international collaborative approaches to low-carbon technology research and development are needed to facilitate North-South and South-South technology transfer. It calls on the UN Conference on Trade and Development (UNCTAD) as well as other UN entities to explore the structure of internationally collaborative R\&D mechanisms that might be effective in facilitating low-carbon technology transfer and learning with and from actors beyond national governments.

\subsubsection{Institutional learning}

In addition to technology transfer, institutional learning plays an important role in advancing deployment of RE. Institutional learning is conducive to institutional change, which provides space for institutions to improve the choice and design of RE policies. It also encourages a stronger institutional capacity at the deeper, often more local, level where numerous decisions on siting and investments in RE projects need to be made (Thelen, 1999; Breukers and Wolsink, 2007a). Private actors and civil society (e.g., regional energy distributors, small wind power entrepreneurs, local mayors, researchers) develop new social skills such as management styles and informal contacts through collaboration. They also rely on existing social conditions (e.g., trust or social coherence) in order to move through the prevailing institutional structure-including electricity regulation, nature conservation norms and planning procedures - in order to get RE projects developed (Agterbosch et al., 2009). Their insights can inform and influence policies to improve RE deployment. Institutional learning can occur if policymakers are able draw on these nongovernmental actors for collaborative approaches in policymaking. Others emphasize the gain in being flexible and reflexive because policymakers can learn from what happens, experiment, look for best practice, re-evaluate and so on (Smith et al., 2005; Stirling, 2009)

\subsubsection{A role for cities and communities}

Cities, towns, local authorities and communities, which often incorporate RE into their policies, have the potential to play an important role in climate change mitigation (Droege, 2009; IEA, 2009a) (see Box 11.14). Droege (2009) argues that whether and how cities and communities are able to implement climate change and RE policies both depend on their spatial, environmental, social and economic capacities to implement RE. Nearly $20 \%$ of city and local governments surveyed for a REN21 study have some sort of building code or permitting policy that incorporates RE. Mandates for solar water heating in new construction are in place in many countries, states and cities worldwide. Other mandates include designing buildings to include features that ease future installations of renewable energy technologies (REN21, 2010).

Both Droege (2009) and the IEA (2009a) conclude that local initiatives occur in places where there are people who understand the technical aspects of RE (i.e., technically literate) and that positive local experiences reinforce other local experiences. Local policymakers have support groups (for example, Local Governments for Sustainability (ICLEI), an association of 1,200 local government members).

\subsubsection{Community and individual links}

Communities provide the social experiences that individuals encounter beyond their own households. A growing body of research has found that social norms influence energy-related behaviour and that 'social visibility' of energy underlies social norms (Nolan et al., 2008; Wilson, 2008). Social visibility describes the extent to which people's attitudes and behaviour towards RE is communicated through social networks (Schultz, 2002). This type of social communication is central to the diffusion process for innovations, including many examples of distributed RE (Archer et al., 1987; E. Rogers, 2003; Jager,W, 2006). The physical visibility of residential wind or solar may help RE become a day-to-day talking point, and so enhance its 'social visibility' (Hanson et al., 2006) and the converse is true of poorly visible technologies such as micro-CHP or energy efficiency. Demonstration projects help promote 'social visibility' and allow potential adopters to observe, learn and communicate about, and test RE technologies vicariously. With solar PV for example, demonstration projects helped breed familiarity and reduce perceived risks for Dutch homeowners and US utility managers alike (Kaplan, 1999; Jager, 2006).

\subsubsection{A role for individuals as part of civil society}

The influence of supportive social norms may also be limited. In a household context, RE technologies have been described as limited by ritual and lifestyle (Sovacool, 2009a). Past experiences and habits are a key 


\section{Box 11.13 | Lessons from Nepal: Importance of upfront public investments in capacity building.}

The National Micro-Hydropower Programme in Nepal aims to enhance rural livelihoods and human development by accelerating the achievement of the Millennium Development Goals, primarily through the delivery of community-managed micro-hydropower systems (MHS). The Programme is coordinated by the Alternative Energy Promotion Centre (AEPC), a centre established under the Ministry of Environment to serve as a national agency for coordinating and monitoring alternative energy development programmes in Nepal (UNDP and AEPC, 2010).

Field experiences from the programme between 1996 and 2006 revealed that capacity development is central to successfully scaling up decentralized energy access programmes and attracting private financing. Capacity development efforts went far beyond training and management to include: planning, oversight, and monitoring; situational analysis; facilitation of stakeholder dialogue, communications and community mobilization; training; setting up and/or strengthening institutions, implementation capacities and management support; and the provision of policy advice (UNDP and AEPC, 2010).

Given the considerable planning, situational analysis and institution set-up efforts, especially at the national level, more than $90 \%$ of the early programme costs went to capacity development. As such, the upfront, publicly-funded investment (from government and donors) was essential to developing the functional capacities needed to scale up the rural energy programme (UNDP and AEPC, 2010).

However, when capacity development is created by systematic interventions, programme successes and maturation over time, it can enable market transformation to occur. Indeed, the study found that the share of public financing for the micro-hydro programme gradually declined to about $50 \%$, attracting substantial private sector funding in later stages of the programme. This indicates the important role of public investment in capacity development for attracting private financing sources, particularly decentralized sources among a project's many users/beneficiaries. Communities provided cash, acquired bank loans and supplied in-kind labour contributions-by digging channels for the MHS, for example—making up a significant portion of the overall financing needs (UNDP and AEPC, 2010).

Productive uses of the resulting energy services fuelled rural economies and increased the possibility for attracting further private investments, including through micro-finance. Fostering ownership also proved to be a necessary sustainability component, providing an incentive for users to use and maintain the technology properly (UNDP and AEPC, 2010).

Local action on the ground, which resulted from training and community mobilization, informed local and district institutions, which were created as a result of capacity development in the form of institutional set-up and strengthening. That, in turn, informed institutions at the national level, which used the knowledge gained to provide the functional capacity of 'policy development and advice'. Although this functional capacity makes up only a small proportion of the total capacity development cost, policy development and advice plays a major role in informing policy and regulation development, supporting overall programme success and sustainability, such as the enactment of a Rural Energy Policy in 2006 (UNDP and AEPC, 2010).

Knowledge gained through the positive experiences of alternative energy development programmes was used to develop Nepal's Rural Energy Policy, which aims to motivate and mobilize local institutions, rural energy users groups, nongovernmental organizations, cooperatives and private sector organizations for the development and expansion of rural energy resources for the purposes of providing energy access and furthering rural economic development and job creation (Government of Nepal, 2006).

In summary, the Nepal programme found that capacity building, broadly defined, was critical for successful scale-up. Further, involving stakeholders in the local community and promoting a sense of ownership was important for sustainability of the projects. It concluded that considerable upfront public investment is needed to develop local and national capacities through systematic interventions and to inform policy development to scale-up rural energy service delivery; however, once these upfront investments are made, they can attract substantial financing from private sources at later stages of the programme, and subsequently reap significant economic, social and environmental benefits (UNDP and AEPC, 2010). 


\section{Box 11.14 | Lessons from Güssing, Austria: Potential for rapid transition in a community's energy production and use.}

Güssing in Austria was the first town in the EU to reduce its carbon emissions by $90 \%$ (below 1992 levels) and today is a model for environmentally friendly energy production based on energy saving, self-sufficiency and environmental protection. Thirty RE plants-solid biomass, biodiesel, biogas and PV facilities—operate within $10 \mathrm{~km}$ of Güssing and meet the town's fuel demands for transportation, residential heating and electricity. Electricity produced locally and sold into the grid has increased local revenue, with profits reinvested into the community and its RE projects. By 2009, Güssing's renewable profile had attracted 60 companies wanting to run on clean energy, creating at least 1,000 new jobs (Droege, 2009).

The town's transformation began in the late 1980s when a massive fuel debt prompted the local mayor to enforce energy-saving measures and begin phasing out fossil fuel use in all sectors, replacing it with locally supplied RE (Droege, 2009). The municipal government initiated and supported financially the construction of local RE plants, which were locally managed and provided the town and greater region with energy services (BMVIT, 2007). It also implemented policies to manage and sustain local farms and forests to produce raw material for generating bioenergy (Droege, 2009). Several local and regional public and private research institutions provided technological assistance, while grants from regional authorities, the Austrian government and the European Commission helped with construction of new infrastructure, such as the district heating system (Droege, 2009).

A municipal marketing program promoted RE through the internet, brochures, exhibitions and conferences as a means to attract companies to the area. But the municipality is also working to export its model, and Güssing's specialized centre on RE has helped to raise public awareness about clean energy and climate protection goals (Droege, 2009).

Within two years of embarking on this path, Güssing's energy expenditures were reduced drastically. By 2001, Güssing was $100 \%$ selfsufficient and meeting all power and heat needs with RE (Droege, 2009).

element of an individual's behavioural context (Brennan, 2007). RE has to be seen as part of a social and technical system of energy provision and use, characterized by deeply embedded routines, social practices, patterns of time use, lifestyles and so on (Shove, 2003). These contextual factors point to the importance of collective action as a more effective, albeit more complex medium for change than individual action. This supports coordinated, systemic policies that go beyond narrow 'attitude-behaviour-change' policies if a policymaker wishes to involve individuals in the RE transition.

Information and education are often emphasized as key policy tools for influencing energy-related behaviours. They are relatively low-cost, uncontroversial and potentially empowering instruments of autonomous choice, favoured over coercion from an individual standpoint (Attari et al., 2009). However, impacts on behaviour are diffuse, long-term and hard to measure because values concerning the environment do not have a strong correlation with behaviour (Gatersleben et al., 2002; Poortinga et al., 2004). This cautions against an over-reliance on information- and education-based policies alone.

Individuals as part of civil society can play an important part in moving to a low-carbon economy, as seen in the Austrian town of Güssing (Box 11.14), as well as in many of the scenarios reviewed in Chapter 10. There is no universal model or understanding of what motivates such behaviours. Rather, a host of factors and constraints influences energy-related behaviours, but these factors do not necessarily exert influence directly. Some sources of influence are intentional. These include information policy, public education or policy signals (such as energy prices, financial incentives). Other influences are part of an individual's everyday environment. These include household routines and relationships, social practices and the inter-personal networks through which individuals communicate (Poortinga, 2004).

\subsection{A structural shift}

There is now substantial evidence that RE policies have had an impact on technology development and RE deployment in many countries, and that some policies or specific elements of policies have been more effective and efficient in advancing RE. However, RE's share of energy production is still limited in most countries. On a global basis, RE accounted for an estimated $12.9 \%$ of primary energy supply in 2008 (Section 1.3; IEA, 2010d). And although some countries can now look back on two to three decades of national experience with and lessons from RE policy, a shorter time series of data is available in most countries. Therefore, trying to assess what is needed for achieving a high share of RE is subject to substantial uncertainties. Further research is also needed to fully understand the effectiveness and efficiency of combinations of policy instruments designed to achieve a very high share of $\mathrm{RE}$ in the long term. 


\subsubsection{The link between scenarios and policies}

The scenarios presented in Chapter 10 demonstrate that a wide range of energy futures is possible, differing in their shares of RE up to $77 \%$ of primary energy by 2050. Conceptually, the scenarios can be distinguished into the four quadrants of potential energy futures, as seen in Table 11.5.

Table 11.5 | Conceptual placement of Chapter 10 scenarios against RE and energy efficiency levels.

\begin{tabular}{l|l}
\hline (3) High energy efficiency; low shares of RE & (4) High energy efficiency; high shares of RE \\
\hline (1) Low energy efficiency; low shares of RE & (2) Low energy efficiency; high shares of RE \\
\hline
\end{tabular}

When comparing these quadrants, a few policy differences become apparent. First, those scenarios that fall into quadrant (Q) 2 seem to bear a higher risk of overshooting global carbon targets than do scenarios in Q4. Second, given the need to create energy systems at a larger scale in a world characterized by high energy demand, scenarios in Q2 are more capital intensive on the supply side, although the necessary investment for RE and attendant infrastructure depends on the absolute contribution of RE. Thirdly, there are different societal risks involved in the two kinds of high RE scenarios (Q2 and Q4). Those scenarios that combine high RE with high energy efficiency rely on either active energy efficiency policies (which may create barriers to political acceptance) or they assume significant fuel (oil and gas) price shocks and an appropriate reaction from the consumer side and policy (for instance supporting structures or quick substitutions of fossil fuel and/or nuclear power technologies with low energy efficiency). On the other hand, the high RE, low energy efficiency scenarios rely on greater levels of deployment of RE supply infrastructure, which in turn could become an issue of social acceptance in many countries.

\subsubsection{Structural shifts result from a combination of technology and behaviour change}

An important, yet often implicit dimension of energy scenarios is whether the scenarios assume changes to be mainly driven by technological development, or whether they assume changes in behaviour as a driver for future development of energy systems. Scenarios that assume changes through technological development can also be differentiated between futures characterized by incremental technological changes and those based on disruptive technological change (Christensen, 1997). Similarly, the scenarios that assume changes in behaviour can also be differentiated between those that are incremental and those that are disruptive. 'Disruptive' refers to a new, low-cost, often simpler technology that displaces an existing technology and, in doing so, radically transforms or destroys existing markets in order to make way for new technologies or systems (Christensen, 1997). It implies the opposite of gradual or incremental changes.
Most 'business-as-usual' scenarios are based on the assumption that both technological development and behaviour change remain incremental. As a consequence, a high share of RE is relatively unlikely in these scenarios. However, in the disruptive, technology-optimistic world (Friedrichs, 2010), the scenarios reflect a leap in the competitiveness of $\mathrm{RE}$, leading to higher market penetration (for similar arguments related to other examples of low-carbon technologies, see Von Weizsäcker et al. (1998); Lovins et al. (2004)). However, behaviours and lifestyles in these scenarios resemble the business-as-usual world, and hence levels of energy consumption remain high.

In order to achieve a future energy mix based on a high share of RE and high energy efficiency, or to be in Q4, it is likely that disruptive changes will need to occur in both technology and behaviour.

\subsubsection{Addressing the challenges of governing long-term energy transitions}

Given that many RE technologies still have to reap considerable learning economies, there is the potential that short term-oriented policy assessment will undervalue the longer-term benefits that could accrue from supporting technology development today. If we are to achieve a structural shift towards high shares of RE, however, what sort of policy framework might that require?

Long-term policymaking was popular between the mid-1940s and into the 1970s. At that time, it was mostly implemented in the form of government-centred, hierarchical planning processes (Hiller and Healey, 2008). The demise of this approach was due to its low ability to predict major societal transformations (e.g., the oil crisis) and its incapability to provide solutions for the ever-increasing societal and environmental problems.

However, this concept of policymaking has experienced a revival in political sciences (Voß et al., 2009; for an example, see Box 11.15). In an effort to overcome the limitations of the earlier approach, today it is framed as 'long-term policy design', an interactive process of constructing and shaping socioeconomic transformation processes (Schneider and Ingram, 1997) that look two to three decades into the future, extending well beyond the attention spans that are generally prevalent in political processes (electoral cycles, standard government programs, hiring spans of civil servants etc.). In order to support long-term structural shifts, policies have to interact with many transformative changes as they unfold. Long-term policy design thus needs to be flexible, adaptive and reflexive (Voß et al., 2009).

This new generation of approaches to governance aims at navigating and spurring the complex processes of socio-technical change by means of deliberation, probing and learning. Emphasis is put on the 


\section{Box 11.15 | The Dutch technology and innovation frameworks.}

A notable example of recent innovation and technology policy frameworks aiming at a substantial increase of RE technologies is the Dutch Transition Management framework (Kemp and Rotmans, 2009). Since 2001, the Dutch ministry of economic affairs has been committed to a long-term sustainability program under the label of 'Transition Management'. It encompasses the elaboration of longterm transformation goals and associated policy mixes in sectors like energy, transport, food or housing (Loorbach, 2007). The particular approach to policy design in transition management comprises five main components: (1) Establishing a transition arena (i.e., a broad constituency of representatives from industry, politics and society that accompany the ongoing planning and implementation process); (2) developing a vision of a future sustainable sector structure; (3) identifying pathways towards these future states by means of backcasting methods; (4) setting up experiments for particularly interesting development options; and (5) monitoring, evaluation and revisions (Loorbach, 2007).

These experiences have gained considerable attention from researchers and policymakers alike. Still, many important conceptual and implementation problems remain unresolved (Kern and Howlett, 2009), and it is fair to say that the current state of Transition Management theory and praxis does not represent a readily available recipe that other countries could easily copy. Nevertheless, the issue of long-term policy design deserves considerable attention in future policy research and implementation, if policymakers decide to pursue ambitious goals of high RE shares (Meadowcroft, 2007).

interaction among different segments in society (government, civil society, industry etc.). Explorative scenarios, experimentation and learning therefore constitute important elements in specific policy mixes.

\subsubsection{Co-evolution of 'bricolage' versus 'breakthrough'}

As noted earlier, disruptive change for both technologies and behaviour is likely to be required to reach the high RE-high energy efficiency scenarios of quadrant 4 (Table 11.5). When developing a long-term policy framework for how to achieve such change, policymakers can choose amongst policies that attempt a technological 'bricolage' (aimed at change through resourcefulness and improvization on the part of involved actors, and more incremental) and/or policies that attempt technological 'breakthrough' (which is taken to evoke an image of actors attempting to generate dramatic and more disruptive outcomes (Garud and Karnøe, 2003)). Counter-intuitively, achieving disruptive technological or behavioural change is more likely to occur if bricolage and breakthrough policies are pursued together. O'Reilly and Tushman (2004) refer to ambidextrous organizations as those that master the art of simultaneously pursuing incremental and disruptive innovation ( $0^{\prime}$ Reilly and Tushman, 2004). Similarly, if achieving the sustainable transformation of an industry requires a fine-tuned mix of disruptive and incremental innovation, then this implies a balanced development of emerging technologies and greening existing technologies rather than single-mindedly focusing on only one of these paths (Hockerts and Wüstenhagen, 2010).

\subsubsection{Specific policy options for an accelerated transition to a high renewable energy world}

Facilitating disruptive change that enables a structural shift to a lowcarbon energy future, particularly one that relies heavily on $\mathrm{RE}$, will require more active policy approaches for the following reasons:

- Substantial new investment is needed. In the absence of stable and predictable policy frameworks and clearly communicated long-term targets (SRU, 2010; Teske et al., 2010), investors will shy away from such investment due to perceived policy risk (IEA, 2007a; Bürer and Wüstenhagen, 2009).

- The necessary infrastructure investment may require some level of public funding or public-private partnerships (for example grid connection for offshore wind power, intercontinental trading of concentrating solar power, new storage facilities) (IEA, 2010a).

- While low levels of RE penetration can be achieved with a relatively limited number of technologies, a high-RE world is likely to rely on a broader portfolio of RE sources with differing levels of maturity. Sustained efforts of research, development and deployment at significantly higher levels than today will be required to bring these different technologies to market over time (Sanden and Azar, 2005; Neuhoff et al., 2009; IEA, 2010a). 
- Technology R\&D alone is not likely sufficient to ensure commercialization of new energy technologies, and there is a general consensus that both R\&D and RE deployment policies are needed (Grubler et al., 1999b; Norberg-Bohm, 1999; Requate, 2005; Horbach, 2007). RE R\&D investments are most effective at advancing technology and reducing costs when complemented by policies that simultaneously enhance demand for new RE technologies, thereby stimulating private sector investment in $R \& D$.

- Strategic frameworks and long-term commitments and planning, along with flexibility to learn from experience will be critical for bringing about a structural shift. Countries like the Netherlands have implemented specific deployment policies to create protected spaces for experimentation with new energy technologies, and subsequent scaleup of promising concepts (Sanden and Azar, 2005; Voß et al., 2009).

- Two of the currently fastest growing renewable technologies, wind and solar, differ in their generation profile from current power generation technologies. A further sustained growth of these variable resources will require adaptation of electricity market rules if inefficiencies are to be avoided (Teske et al., 2010).

- Most high-RE scenarios simultaneously assume a substantial increase in energy efficiency. While some scenarios assume high shares of renewable sources at relatively high levels of energy consumption, and technical potential is high for many renewable sources, a high $\mathrm{RE}$ and high energy consumption scenario (quadrant 2) tends to face tighter constraints when it comes to capital requirements and social acceptance issues than does a high RE scenario that simultaneously increases energy efficiency (see Section 11.7.2). Such energy efficiency increases may be driven by market forces (e.g., fuel price shocks) or by active policies (e.g., carbon pricing, energy taxes, efficiency standards, labelling) (Teske et al., 2010).

- Both the level of energy consumption and the share of fossil and/or nuclear energy in the mix depend on strategic choices made today that are heavily interconnected to other policy areas, notably urban planning and transportation policies (Dowall, 1980; Hankey and Marshall, 2010). Achieving a high-RE world will depend on early policy integration.

- The magnitude of changes needed will require public consent to a variety of policies, which in turn implies increased efforts to raise public awareness of renewable energy (IEA, 2010a; SRU, 2010; West et al., 2010).

\section{Synthesis}

Significant investments will be required to make the transition to a low carbon future, whatever technologies are pursued (Section 10.5). Such a shift will require additional policies to attract large increases in private investment into technologies and infrastructure. From an investor's perspective, further deployment of RE technologies will result in new market opportunities.

The literature indicates that long-term objectives for RE and flexibility to learn from experience would be critical to achieve cost-effective and high penetrations of RE. To achieve GHG concentration stabilization levels with high shares of RE, a structural shift in today's energy systems will be required over the next few decades. This would require systematic development of policy frameworks that reduce risks and enable attractive returns that provide stability over a timeframe relevant to the RE and related infrastructure investments (Sections 11.6 and 11.7). The appropriate and reliable mix of instruments is even more important where energy infrastructure is still developing and energy demand is expected to increase in the future. 


\section{References}

Access Reform Options Development Group (2006). A Framework for Considering Reforms to how Generators gain Access to the GB Electricity Transmission System. A report by the Access Reform Options Development Group, UK.

Acemoglu, D., P. Aghion, L. Bursztyn, and D. Hemous (2009). The Environment and Directed Technical Change. NBER Working Paper 15451, National Bureau of Economic Research. Cambridge, MA, USA.

Adelaja, A., Y.Jailu, C. Mckeown, and A. Tekle (2010). Effects of renewable energy policies on wind industry development in the U.S. Journal of Natural Resources Policy Research, 2(3), pp. 245-262.

Agnolucci, P. (2007). The effect of financial constraints, technological progress and long-term contracts on tradable green certificates. Energy Policy, 35(6), pp. 3347-3359.

Agterbosch, S., and S. Breukers (2008). Socio-political embedding of onshore wind power in the Netherlands and North Rhine-Westphalia. Technology Analysis \& Strategic Management, 20(5), pp. 633-648.

Agterbosch, S., R.M. Meertens, and W.J.V. Vermeulen (2009). The relative importance of social and institutional conditions in the planning of wind power projects. Renewable and Sustainable Energy Reviews, 13(2), pp. 393-405.

Aitken, M. (2010). Wind power and community benefits: Challenges and opportunities. Energy Policy, 38(10), pp. 6066-6075.

Aldy, J.E., S. Barrett, and R.N. Stavins (2003). 13+1: A Comparison of Global Climate Change Policy Architectures. Climate Policy, 3(2003), pp. 373-397.

Alonso, O., J. Revuelta, M. de la Torre, and L. Coronado (2008). Spanish experience in wind energy integration. In: Power-Gen Conference and Exhibition, Milan, Italy, 3-5 June 2008.

Altenburg, T., H. Schmitz, and A. Stamm (2008). Breakthrough? China's and India's transition from production to innovation. World Development, 36(2), pp. 325-344.

Amranand, P. (2008). Alternative Energy, Cogeneration and Distributed Generation: Crucial Strategy for Sustainability of Thailand's Energy Sector. Energy Policy and Planning Office (EPPO), Ministry of Energy, Bangkok, Thailand.

Amranand, P. (2009). Keynote Address: The role of renewable energy, cogeneration and distributed generation in sustainable energy development in Thailand. In: World Renewable Energy Congress 2009 Asia, BITEC, Bangkok, Thailand, 19-22 May 2009

Amundsen, E.S. and J.B. Mortensen. (2001). The Danish Green Certificate Scheme: Some simple analytical results. Energy Economics, 23(5), pp. 489-509.

ANL (2010). Solar Energy Development Programmatic Environmental Impact Statement Web site. Argonne National Laboratory (ANL), U.S. Department of Energy, Argonne, IL, USA. Available at: solareis.anl.gov/.

Araneda, J.C., S. Mocarquer, R. Moreno, and H. Rudnick (2010). Challenges on integrating renewables into the Chilean grid. In: International Conference on Power System Technology, 2010, Hangzhou, China, 24-28 October 2010.

Archer, D., T. Pettigrew, M. Constanzo, B. Iritani, I. Walker, and L. White (1987). Energy conservation and public policy: The mediation of individual behavior. In: Energy Efficiency: Perspectives on Individual Behavior. W. Kempton and M. Neiman (eds.). American Council for an Energy Efficient Economy, Washington, DC, USA, pp. 69-92.

Argote, L., S.L. Beckman, and D. Epple (1990). The Persistence and Transfer of Learning in Industrial Settings. Management Science, 36(2), pp. 140-154.
ADB (2007). Investing in Clean Energy and Low Carbon Alternatives in Asia. Asian Development Bank (ADB), Manila, the Philippines. Available at: aequero.com/ docs/Publications_Presentations/Investing_in_Clean_Energy_and_Low_ Carbon_Alternatives_in_Asia_-_November_2007.pdf.

ASIF (2009). Informe anual 2009. Hacia la consolidación de la energía Fotovoltaica en España. Asociación de la industria Fotovoltaica (ASIF), Madrid, Spain.

Attari, S., M. Schoen, C. Davidson, M. DeKay, W. Bruine de Bruin, R. Dawes, and M. Small (2009). Preferences for change: Do individuals prefer voluntary actions, soft regulations, or hard regulations to decrease fossil fuel consumption? Ecological Economics, 68(6), pp. 1701-1710.

Austrian Energy Agency (2011). Energy in Central \& Eastern Europe. Online database, Vienna, Austria. Available at: http://www.enercee.net/.

AWEA (2010). Windpower Outlook 2010. American Wind Energy Association (AWEA), Washington, DC, USA

AWEA (2011). Fourth Quarter 2010 Market Report. American Wind Energy Association (AWEA), Washington, DC, USA.

Azevedo, J. M. and F. D. Galiana (2009). The sugarcane ethanol power industry in Brazil: Obstacles, success and perspectives. In: IEEE Electrical Power \& Energy Conference, Montreal, Canada, 22-23 October 2009.

Baker, E., L. Clarke, and J. Weyant (2003). R\&D as a Hedge against Climate Damages. University of Massachusetts, Amherst, MA, USA.

Baker, P. (2010). Electricity market design for a sustainable future. UKERC Working Paper Draft, UK Energy Research Centre, London, UK. Available at: geography. exeter.ac.uk/PhilBaker/marketdesignproject2.pdf.

Baker, P., C. Mitchell, and B. Woodman (2009). The Extent to which Economic Regulation Enables the Transition to a Sustainable Electricity System. UKERC/WP/ ESM/2009/013, UK Energy Research Centre, London, UK.

Baldwin, R., and J. Black (2010). Really responsive risk-based regulation. Law and Policy, 32(2), pp. 181-213.

Bansal, R. (2009). Identifying 'Key Value Drivers' and 'Determinants for Backward Integration' in Biofuel Industry. Imperial College London, Business School, London, UK.

Barry, M., and R. Chapman (2009). Distributed small-scale wind in New Zealand: Advantages, barriers and policy support instruments. Energy Policy, 37(9), pp. 3358-3369.

BC Hydro (2006-2008). Annual Report. BC Hydro, Vancouver, Canada.

BC Hydro (2007-2010). Annual Report. BC Hydro Regeneration,Vancouver, Canada. Beck, F., and E. Martinot (2004). Renewable energy barriers and policies. In: Encyclopedia of Energy. C. Cleveland (ed.), Academic Press/Elsevier Science, San Diego, CA, USA, pp. 365-383.

Bell, D., T. Gray, and C. Haggett (2005). The 'Social Gap' in wind farm citing decisions: explanations and policy responses. Environmental Politics, 14, pp. 460-477.

Bell, M. (1990). Continuing Industrialisation, Climate Change and International Technology Transfer. SPRU, University of Sussex, Brighton, UK.

Bell, M. (2007). Technological Learning and the Development of Production and Innovative Capacities in the Industry and Infrastructure Sectors of the Least Developed Countries: What Roles for ODA? University of Sussex: SPRU - Science and Technology Policy Research, Brighton, UK.

Bennear, L.S. and R.N. Stavins. (2007). Second-best theory and the use of multiple policy instruments. Environmental and Resource Economics, 37(1), pp. 111-129.

Bergek, A., and S. Jacobsson (2010). Are tradable green certificates a cost-efficient policy driving technical change or a rent-generating machine? Lessons from Sweden 2003-2008. Energy Policy, 38(3), pp. 1227-1606. 
BERR (2008). Low Carbon Buildings Programme. Department for Business, Enterprise and Regulatory Reform (BERR), Department of Energy and Climate Change (DECC). London, UK. Available at: www.lowcarbonbuildings.org.uk/.

BERR/NERA (2008). Qualitative Evaluation of Financial Instruments for Renewable Heat. Department for Business, Enterprise and Regulatory Reform (BERR) and National Economic Research Associates (NERA), London, UK.

Bird, J., and Institute for Public Policy Research (2009). A fair wind for a Green Economy. Institute for Public Policy Research, London, UK.

Bird, L., M. Bolinger, T. Gagliano, R. Wiser, M. Brown, and B. Parsons (2005). Policies and market factors driving wind power development in the United States. Energy Policy, 33, pp. 1397-1407.

Bird, L., and E. Lokey (2007). Interaction of Compliance and Voluntary Renewable Energy Markets. NREL/TP-670-42096, National Renewable Energy Laboratory, Golden, CO, USA.

Bird, L., and J. Sumner (2010). Green Power Marketing in the United States: A Status Report (2009 Data). NREL/TP-6A20-49403, National Renewable Energy Laboratory, Golden, CO, USA.

Blanford, G.J. (2009). R\&D investment strategy for climate change. Energy Economics, 31(Supplement 1), pp. S27-S36.

Blyth, W., D. Bunn, J. Kettunen, and T. Wilson (2009). Policy interactions, risk and price formation in carbon markets. Energy Policy, 37(12), pp. 5192-5207.

BMU (2006). Renewable Energy Sources Act (EEG), Development of electricity generation from renewable energies up to 2020 and financial impacts. Bundesministerium fur Umwelt, Naturschultz und Reaktorsicherheit (BMU), Berlin, Germany.

BMU (2009). Renewable Energy Sources in Figures: States, National and International Development, German Federal Ministry for the Environment, Nature Conservation and Nuclear Safety (BMU), Berlin, Germany, 80 pp.

BMU (2010). Zeutreihen zur Entwicklung der erneuerbaren Energien in Deutschland [Development of Renewable Energy Sources in Germany]. Bundesministerium fur Umwelt, Naturschultz und Reaktorsicherheit (BMU), Berlin, Germany.

BMVIT (2007). Model Region Güssing: Self-sufficient energy supply based on regionally available renewable resources and sustainable regional development. Bundesministerium für Verkehr, Innovation und Technologie (BMVIT: Austrian Federal Ministry for Transport, Innovation and Technology), Vienna, Austria.

Boardman, B. (2009). Fixing Fuel Poverty: Challenges and Solutions. Earthscan Ltd., Oxford, UK, $270 \mathrm{pp}$

Bohm, P., and C.S. Russell (1985). Comparative analysis of alternative policy instruments. In: Handbook of Natural Resource and Energy Economics. A.V. Kneese and J. Sweeney (eds.), Elsevier Science Publishers, pp. 395-460.

Bohringer, C. and K. E. Rosendahl (2010). Green promotes the dirtiest: On the interaction between black and green quotas in energy markets. Journal of Regulatory Economics, 37(3), pp. 316-325.

Bomb, C., K. McCormick, E. Deurwaarder, and T. Kaberger (2007). Biofuels for transport in Europe: lessons from Germany and the UK. Energy Policy, 35(2007), pp. 2256-2267.

Bouille, A. (2010). Financing Renewable Energy in the European Energy Market. Project No. PECPNL084659, A study led by Ecofys funded by the European Commission, DG Energy, Brussels, Belgium. Available at: ec.europa.eu/energy/ renewables/studies/doc/renewables/2011_financing_renewable.pdf.
Breitschopf, B., M. Klobasa, F. Sensfuß, J. Steinbach, M. Ragwitz, U. Lehr, J. Horst, U. Leprich, J. Diekmann, F. Braun, and M. Horn (2010). Einzel- und gesamtwirtschaftliche Analyse von Kosten- und Nutzenwirkungen des Ausbaus Erneuerbarer Energien im deutschen Strom- und Wärmemarkt (in German). Interim report of a study led by Fraunhofer ISI done on behalf of the German Federal Environment Ministry, Bonn, Germany.

Brennan, T.J. (2007). Consumer preference not to choose: methodological and policy implications. Energy Policy, 35(3), pp. 1616-1627.

Breukers, S., and M. Wolsink (2007a). Wind energy policies in the Netherlands: Institutional capacity-building for ecological modernisation. Environmental Politics, 16(1), pp. 92-112.

Breukers, S., and M. Wolsink (2007). Wind power implementation in changing institutional landscapes: An international comparison. Energy Policy, 35, pp. 2737-2750.

BTM Consult ApS (2010). World Market Update 2009. BTM Consult ApS, Ringkøbing, Denmark.

Buckman, G., and M. Diesendorf (2010). Design limitations in Australian renewable electricity policies. Energy Policy, 38(7), pp. 3365-3376.

Buen, J. (2005). Danish and Norwegian wind industry: the relationship between policy instruments, innovation and diffusion. Energy Policy, 34(18), pp. 3887-3897.

Buijs, P., D. Bekaert, and R. Belmans (2010). Seams issues in European transmission investments. The Electricity Journal 23(10), pp. 18-26.

Bürer, M.J., and R. Wüstenhagen (2009). Which renewable energy policy is a venture capitalist's best friend? Empirical evidence from a survey of international cleantech investors. Energy Policy, 37(12), pp. 4997-5006.

Bürger, V., S. Klinski, U. Lehr, U. Leprich, M. Nast, and M. Ragwitz (2008). Policies to support renewable energies in the heat market. Energy Policy, 36(8), pp. 3150-3159.

Büsgen, U., and W. Dürrschmidt (2009). The expansion of electricity generation from renewable energies in Germany: A review based on the Renewable Energy Sources Act Progress Report 2007 and the new German feed-in legislation. Energy Policy, 1(2009), pp. 2536-2545.

Butler, L., and K. Neuhoff (2008). Comparison of feed-in tariff, quota and auction mechanisms to support wind power development. Renewable Energy, 33(8), pp. 1854-1867.

BWE (2011). Windjahr in Prozent zum langährigen Mittel. Statistics, Bundesverband Windenergie e.V. (BWE), Berlin, Germany. Available at: www.wind-energie.de/ de/statistiken/.

CEC and CPUC (2008). Final Opinion and Recommendations on Greenhouse Gas Regulatory Strategies. California Energy Commission (CEC) and California Public Utilities Commission (CPUC), Sacramento, CA, USA, 297 pp.

Canadian Food Grains Bank (2008). Can A Hungry World Afford Biofuels? Canadian Food Grains Bank, Winnipeg, Canada.

Carlsson, B., S. Jacobsson, M. Holmén, and A. Rickne (2002). Innovation systems: analytical and methodological issues. Research Policy, 31(2), pp. 233-245.

Casillas, C., and D.M. Kammen (2010). The energy-poverty-climate nexus. Science, 330(6008), pp. 1181-1182

CCC (2009). Reducing Emissions in Buildings and Industry. Chapter 5 in: Meeting Carbon Budgets - The Need for a Step Change. Progress Report to Parliament, London, October 2009. Committee on Climate Change (CCC), London, UK, pp. 151-188. Available at: downloads.theccc.org.uk/21667\%20CCC\%20Report\%20 AW\%20WEB.pdf. 
CCC (2010). Meeting carbon budgets: Ensuring a Low-Carbon Recovery. Committee on Climate Change (CCC), London, UK.

Cerri, C.E.P., M. Easter, K. Paustian, K. Killian, K. Coleman, M. Bemoux, P. Falloon, D.S. Powlson, N.H. Batjes, E.Milne, and C.C. Cerri (2007). Predicted soil organic carbon stocks and changes in the Brazilian Amazon between 2000 and 2030. Agriculture, Ecosystems and Environment, 122, pp. 58-72.

Changliang, X., and S. Zhanfeng (2009). Wind energy in China: Current scenario and future perspectives. Renewable and Sustainable Energy Reviews, 13, pp. 1966-1974.

Christensen, C. (1997). The Innovator's Dilemma: When New Technologies Cause Great Firms to Fail. Harvard Business School Press, Cambridge, MA, USA.

CIPORE (2011). Caribbean Information Platform on Renewable Energy (CIPORE). Online database, Caribbean Information Platform on Renewable Energy (CIPORE), Kingston, Jamaica. Available at: www.cipore.org/.

CITI (2010). Europe Utilities (Citigroup Global Markets), September 2010. Citi Investment Research \& Analysis, London, UK.

City of Miami (2008). MiPlan: City of Miami Climate Action Plan. City of Miami, Miami, FL, USA, 48 pp.

Cohen, G.E., D.W. Kearney, and G.J. Kolb (1999). Final Report on the Operation and Maintenance Improvement Program for Concentrating Solar Power Plants. Sandia National Laboratories, Oak Ridge, TN, USA.

Cohen, L.R., and R.G. Noll (1991). The Technology Pork Barrel. Brookings, Washington, DC, USA.

Commission of the European Communities (2008). Commission Staff Working Document: The Support of Electricity from Renewable Energy Sources. Commission of the European Communities, Brussels, Belgium, 38 pp.

Connor, P., V. Bürger, L. Beurskens, K. Ericsson, and C. Egger (2009). Overview of RES-H/RES-C Support Options. D4 of WP2 from the RES-H Policy project. University of Exeter, Exeter, UK. Available at: www.res-h-policy.eu/downloads/ RES-H_Policy-Options_(D4)_final.pdf.

Cory, K., T. Couture, and C. Kreycik (2009). Feed-in Tariff Policy: Design, Implementation and RPS Policy Interactions. NREL/TP-6A2-45549, National Renewable Energy Laboratory (NREL), Golden, CO, USA, 17 pp.

Couture, T. (2009). State Clean Energy Policy Analysis: Renewable Energy Feed-in Tariffs. SCEPA Webinar. National Renewable Energy Laboratory, Golden, CO, USA, $23 \mathrm{pp}$.

Couture, T., and Y. Gagnon (2009). An Analysis of Feed-in Tariff Policy Design Options for Renewable Energy Sources. Universite de Moncton, Moncton, Canada.

Couture, T.D., K. Cory, C. Kreycik, and E. Williams (2010). A Policymaker's Guide to Feed In Tariff Policy Design. NREL/TP-6A2-44849, National Renewable Energy Laboratory (NREL) Golden, CO, USA.

Cowell, R. (2007). Wind power and 'the planning problem': the experience of Wales. European Environment, 17(5), pp. 291-306.

Cowell, R. (2010). Wind power, landscape and strategic, spatial planning - The construction of 'acceptable locations' in Wales. Land Use Policy, 27(2), pp. 222-232.

Creutzig, F., and D. He (2009). Climate change mitigation and co-benefits of feasible transport demand policies in Beijing. Transportation Research D, 14, pp. 120-131.

Cruetzig, F.S. and D.M. Kammen (2010). Getting the carbon out of transportation fuels. In: Global Sustainability: A Nobel Cause. H.-J. Schellenhuber, M. Molina, N. Stern, V. Huber and S. Kadner (eds), Cambridge University Press, pp. 307-318.
Creutzig, F., E. McGlynn, J. Minx, and O. Edenhofer (2010). Climate Policies for Road Transport Revisited: Evaluation of the Current Framework, Working Papers 1. Department of Climate Change Economics, TU Berlin, Berlin, Germany.

Cropper, M.L. and W.E. Oates (1992). Environmental economics: A survey. Journal of Economic Literature, 30, pp. 675-740.

CTED (2009). Washington State's Green Economy: A Strategic Framework. Discussion Draft. Washington State Department of Community, Trade and Economic Development (CTED), Olympia, WA, USA, 100 pp.

Cuppen, E., S. Breukersb, M. Hisschemöllera, and E. Bergsmaa (2010). Q methodology to select participants for a stakeholder dialogue on energy options from biomass in the Netherlands. Ecological Economics, 69(3), pp. 579-591.

Damborg, S., and S. Krohn (1998). Public Attitudes towards Wind Power. Danish Wind Turbine Manufacturers Association, Copenhagen, Denmark.

Danish Ministry of Energy (1981). Energiplan 81. Energiministeriet, Copenhagen, Denmark.

Danish Ministry of the Environment (1993). Cirkulære om primærkommuners planlægning for vindmøller (til alle kommunalbestyrelser). Miljøiministeriet, Copenhagen, Denmark.

Danish Wind Industry Association (2010). Danish Wind Industry Maintains High Export Figures In 2009 Despite Financial Crisis. Danish Wind Industry Association (Vindmølleindustrien), Frederiksberg, Denmark, Available at: www.windpower. org/en/news/news.html.

David, P.A. (1985). Clio and the Economics of QWERTY. American Economic Review, 75, pp. 332-337.

David, P.A., B.H. Hall, and A.A. Toole (2000). Is public R\&D a complement or substitute for private R\&D? A review of the econometric evidence. Research Policy, 29(4-5), pp. 497-529.

Davis, G.A., and B. Owens (2003). Optimizing the level of renewable electric R\&D Expenditures using real options analysis. Energy Policy, 31, pp. 1589-1608.

DBCCA (2009). Infrastructure Investments in Renewable Energy. Deutsche Bank Climate Change Advisors (DBCCA), Deutsche Bank, New York, NY, USA.

DBCCA (2010). Investing in Climate Change 2010: A Strategic Asset Allocation Perspective. Deutsche Bank Climate Change Advisors (DBCCA), Deutsche Bank, New York, NY, USA.

de Coninck, H.C., F. Haake, and N. van der Linden (2007). Technology transfer in the Clean Development Mechanism. Climate Policy, 7(5), pp. 444-456.

de Gorter, H., and D.R. Just (2010). The Social costs and benefits of biofuels: The intersection of environmental, energy and agricultural policy. Applied Economic Perspectives and Policy, 32(1), pp. 4-32.

de Jager, D., and M. Rathmann (2008). Policy Instrument Design to Reduce Financing Costs in Renewable Energy Technology Projects. Ecofys, Utrecht, The Netherlands, 142 pp.

de Jager, D., C. Klessman, E. Stricker, T. Winkel, E. de Visser, M. Koper, M. Ragwitz, A. Held, G. Resch, S. Busch, C. Panzer, A. Gazzo, T. Roulleau, P. Gousseland, M. Henriet, and A. Bouille (2010). Financing Renewable Energy in the European Energy Market. Project No. PECPNL084659, A study led by Ecofys funded by the European Commission, DG Energy, Brussels, Belgium.

de Jonghe, C., E. Delarue, R. Belmans, and W. D'haeseleer (2009). Interactions between measures for the support of electricity from renewable energy sources and $\mathrm{CO}_{2}$ mitigation. Energy Policy, 37(11), pp. 4743-4752. 
de Miera, G.S., P. del Río González, and I. Vizcaíno (2008). Analysing the impact of renewable electricity support schemes on power prices: the case of wind electricity in Spain. Energy Policy, 36(9), pp. 3345-3359.

de Saravia, C.F., and A. Diego Rosell (2011). Coup de Grâce: A New Royal Decree Slashes Tariffs and Opens the Door to Retroactive Changes for Spanish PV. Photon International, pp. 66-68.

DECC (2009). The UK Renewable Energy Strategy. Department of Energy and Climate Change (DECC). HM Government, London, UK.

Dechezleprêtre, A., M. Glachant, and Y. Ménière (2008). The Clean Development Mechanism and the international diffusion of technologies: An empirical study. Energy Policy, 36, pp.1273-1283.

Deepchand, K. (2002). Promoting equity in large-scale renewable energy development: the case of Mauritius. Energy Policy, 30(11-12), pp. 1129-1142.

DEFRA/BERR (2007). Renewable Heat Support Mechanisms. Department for Environment, Food and Rural Affairs (DEFRA) and Department for Business, Enterprise and Regulatory Reform (BERR), London, UK.

del Río González, P., F. Hernández, and M. Gual (2005). The implications of the Kyoto project mechanisms for the deployment of renewable electricity in Europe. Energy Policy, 33(15), pp. 2010-2022.

Department of Minerals and Energy (2003). White Paper on Renewable Energy. Department of Minerals and Energy, Pretoria, Republic of South Africa.

Derrick, A. (1998). Financing mechanism for renewable energy. Renewable Energy, 15(1998), pp. 211-214.

Devine-Wright, P. (2005). Beyond Nimbyism: Towards an integrated framework for understanding public perceptions of wind energy. Wind Energy, 8(2), pp. 125-139.

DG TREN (2007). Heating and Cooling from Renewable Energies: Costs of National Policies and Administrative Barriers. Contract TREN/D1/2006-7/S07.67170, MVV Consulting. Brussels, Belgium.

Dias de Moraes, M. A. F., and L. Rodrigues (2006). Brazil Alcohol National Program. Relatório de pesquisa. Piracicaba, Brazil: 54.

Dillon, H. S., T. Laan, and H.S. Dillon (2008). Biofuels - At What cost? Government Support For Ethanol and Biodiesel in Indonesia. Global Subsidies Initiative, Geneva, Switzerland. Available at: http://www.globalsubsidies.org/files/assets/ Indonesia_biofuels.pdf.

Dinica, V. (2008). Initiating a sustained diffusion of wind power: The role of publicprivate partnerships in Spain. Energy Policy, 36(9), pp. 3562-3571.

Domac, J., K. Richards, and S. Risovic (2005). Socio-economic drivers in implementing bioenergy projects. Biomass and Bioenergy, 28(2), pp. 97-106.

Dosi, G. (1982). Technological paradigms and technological trajectories: A suggested interpretation of the determinants and directions of technical change. Research Policy, 11, pp. 147-162.

Dosi, G. (1988). Sources, procedures, and microeconomic effects of innovation. Journal of Economic Literature, 26(3), pp. 1120-1171.

Dowall, D.E. (1980). US land use and energy policy - assessing potential conflicts. Energy Policy, 8(1), pp. 50-60.

Droege, P. (2009). 100\% Renewable: Energy Autonomy in Action. Earthscan, London, UK.

DSIRE (2011). US Database of State Incentives for Renewables and Efficiency. Online database, US Database of State Incentives for Renewables and Efficiency (DSIRE), North Carolina State University, Raleigh, NC, USA. Available at: www.dsireusa. org/.
DTI (2007). Meeting the Energy Challenge: A White Paper on Energy. Department of Trade and Industry (DTI), The Stationery Office, London, UK.

DTI/Ofgem Embedded Generation Working Group (2001). Report into Network Access Issues, Department of Trade and Industry (DTI) and Ofgem, London, UK.

DUKES (2009). Digest of United Kingdom Energy Statistics (DUKES). Department of Energy and Climate Change, London, UK. Available at: www.decc.gov.uk/en/content/cms/statistics/publications/dukes/dukes.aspx.

ECLAC (2009). Contribution of Energy Services to the Millennium Development Goals and to Poverty Alleviation in Latin America and the Caribbean. LC/W.281-P/I, Economic Commission for Latin America and the Caribbean (ECLAC), Club de Madrid, GTZ and UNDP, United Nations, Santiago, Chile. Available at: www.eclac. org/publicaciones/xml/0/38790/lcw281 i.pdf.

Edenhofer, O. and M. Kalkuhl (2011). When do increasing carbon taxes accelerate global warming? A note on the green paradox. Energy Policy, 39(4), pp. 2208-2212.

Edenhofer, O., N. Bauer, and E. Kriegler (2005). The impact of technological change on climate protection and welfare: insights from the model MIND. Ecological Economics, 54(2-3), pp. 277-292.

EGWG (2001). The Embedded Generation Working Group Report into Network Access Issues. Embedded Generation Working Group (EGWG), UK. Available at: www.dti.gov.uk/energy/domestic_markets/network_access_elec/egwp_report/.

Ellis, G., J. Barry, and C. Robinson (2007). Many ways to say 'no', different ways to say 'yes': applying Q-methodology to understanding public acceptance of wind farm proposals. Journal of Environmental Planning and Management, 50(4), pp. 517-555.

Ellis, G., R. Cowell, C. Warren, P. Strachan, and J. Szarka (2009). Wind Power and the 'Planning Problem'. Journal of Planning Theory and Practice, 10(4), pp. 521-547.

Energy Skills Queensland (2009). Research report: Sustainable Energy Skills Formation Strategy. Energy Skills Queensland. Rocklea, Queensland, Australia.

EPPO (2007a). VSPP (As of April 2007). Energy Policy and Planning Office (EPPO), Ministry of Energy, Thailand. Bangkok, Thailand.

EPPO (2007b). สรุปการรับซือไฟฟ้าจากผู้ผลิตไฟฟ้ารายเล็ก (สถานภาพ ณ เดือนกุมภาพันธ์ 2549 . Summary of electricity purchased from SPPs (as of February 2007). Energy Policy and Planning Office (EPPO), Ministry of Energy, Thailand. Bangkok, Thailand.

EPPO (2010a). Thailand Power Development Plan. Energy Policy and Planning Office (EPPO), Ministry of Energy, Thailand. Bangkok, Thailand.

EPPO (2010b). สถานภาพการรับซือไฟฟ้จาก SPP จำแนกตามประเภทเชือเพลิง (ณ วันท 24 มีนาคม 2553. (Electricity purchased from SPPs by fuel type - as of 24 March 2010). Energy Policy and Planning Office (EPPO), Ministry of Energy, Thailand. Bangkok, Thailand.

EPPO (2010c). สถานภาพการรับซือไฟฟ้าจาก VSPP จำแนกตามประเภทเชื้อเพลิง (ณ วันที24 มีนาคม 2553. (Electricity purchased from VSPP by fuel type as of 24 March, 2010). Energy Policy and Planning Office (EPPO), Ministry of Energy, Thailand. Bangkok, Thailand.

ERCOT (2010). Texas Posts Record Increase in Voluntary Renewable Energy Credits: State Exceeds Legislature's 2025 Goal 15 Years Early. Press release, Electric Reliability Council of Texas (ERCOT), Austin, TX, USA. Available at: www.ercot. com/news/press_releases/2010/nr-05-14-10.

Ericsson, K., and P. Svenningsson (2009). Introduction and Development of the Swedish District Heating Systems: Critical Factors and Lessons Learned. Lund University, Lund, Sweden. 
Ernst \& Young (2008). Renewable Energy Country Attractiveness Indices: Global Highlights. Ernst \& Young, London, UK, 24 pp.

Espey, S. (2001). Renewables portfolio standard: a means for trade with electricity from renewable energy sources? Energy Policy, 29(7), pp. 557-566.

European Centre for Development of Vocational Training (2010). Skills for Green Jobs: European Synthesis Report. European Centre for Development of Vocational Training, Publications Office of the European Union, Luxembourg. Available at: www.cedefop.europa.eu/EN/Files/3057_en.pdf.

European Commission (2005). The Support of Renewable Energy Sources. European Commission, Brussels, Belgium.

European Commission (2009a). Directive 2009/28/EC of the European Parliament and of the Council of 23 April 2009 on the promotion of the use of energy from renewable sources and amending and subsequently repealing Directives 2001/77/EC and 2003/30/EC (2009). Official Journal of the European Union, pp. 16-61.

European Commission (2009b). Investing in the Development of Low Carbon Technologies: A Technology Roadmap. Commission to the European Parliament, the Council, the European Economic and Social Committee and the Committee of the Regions, Brussels, Belgium.

European Commission (2010). Covenant of Mayors: Cities take the Lead to Tackle Climate Change. News release, EP President Press Service, Available at: www. eumayors.eu/IMG/pdf/EP_PR.pdf.

European Commission (2011). Commission staff working document: Recent progress in developing renewable energy sources and technical evaluation of the use of biofuels and other renewable fuels in transport in accordance with Article 3 of Directive 2001/77/EC and Article 4(2) of Directive 2003/30/EC. Accompanying document to the Communication from the Commission to the European Parliament and the Council: Renewable Energy: Progressing towards the 2020 target; $\operatorname{COM(2011)~} 31$ final. European Commission, Brussels, Belgium.

European Parliament and of the Council (2009). Directive 2009/28/EC of the European Parliament and of the Council of 23 April 2009 on the promotion of the use of energy from renewable sources and amending and subsequently repealing Directives 2001/77/EC and 2003/30/EC. Official Journal of the European Union.

European Union (2009). Annex I of Directive 2009/28/EC of the European Parliament and of the Council of 23 April 2009 on the Promotion and Use of Energy from Renewable Sources and Amending and Subsequently Repealing Directives 2001/77/EC and 2003/30/EC. European Union, Brussels, Belgium.

Eurostat (2010). Supply, transformation, consumption - renewables (biofuels) annual data (nrg_1073a). European Commission, Brussels, Belgium. Available at: appsso.eurostat.ec.europa.eu/nui/show.do?dataset=nrg_1073a\&lang=en.

Fankhauser, S., C. Hepburn, and J. Park (2010). Combining multiple climate policy instruments: How not to do it. Climate Change Economics, 1, pp. 209-225

FAO/GBEP (2007). A Review of the Current State of Biofuel Development in G8+5 Countries. Food and Agriculture Organization (FAO) and Global Bioenergy Partnership (GBEP), Rome, Italy.

Farrell, J. (2009). Feed-in tariffs in America: Driving the Economy with Renewable Energy Policy that Works. The New Rules Project, Minneapolis, MN, USA, 30 pp.

Faulin, J., F. Lera, J.M. Pintor, and J. Garcia (2006). The outlook for renewable energy in Navarre: An economic profile. Energy Policy, 34, pp. 2201-2216.

Felix-Saul, R. (2008). Assessing the impact of Mexico's Biofuels Law. Baker \& McKenzie Biomass Magazine. Available at: biomassmagazine.com/articles/1678/ assessing-the-impact-of-mexico's-biofuels-law/.
Fink, S., C. Mudd, K. Porter, and B. Morgenstern (2009). Wind Energy Curtailment Case Studies. National Renewable Energy Laboratory, Golden, CO, USA.

Fischer, C. (2008). Emissions pricing, spillovers, and public investment in environmentally friendly technologies. Energy Economics, 30(2), pp. 487-502.

Fischer, C. and R.G. Newell (2008). Environmental and technology policies for climate mitigation. Journal of Environmental Economics and Management, 55, pp. 142-162.

Fischer, C., and L. Preonas (2010). Combining policies for renewable energy: Is the whole less than the sum of its parts? International Review of Environmental and Resource Economics, 4(1), pp. 51-92.

Fischlein, M., J. Larson, D. Hall, R. Chaudhry, T.R. Peterson, J. Stephens, and E. Wilson (2010). Policy stakeholders and deployment of wind power in the sub-national context: A comparison of four U.S. states. Energy Policy, 38(8), pp. 4429-4439.

Flach, B., S. Lieberz, K. Bendz, B. Dahlbacka and D. Achilles (2009). EU-27 Biofuels Annual Report 2009. United States Department of Agriculture Foreign Agricultural Service, Washington, DC, USA.

Fodella, G. (1989) Orgware: the key of Japanese success. Rivista Internazionale di Scienze Economiche Ecommerciali, 36(12), pp. 1057-1062.

Ford, A., K. Vogstad, and H. Flynn (2007). Simulating price patterns for tradable green certificates to promote electricity generation from wind. Energy Policy, 35(1), pp. 91-111.

Forsyth, T.L., M. Pedden, and T. Gagliano (2002). The Effects of Net Metering on the Use of Small-Scale Wind Systems in the United States. NREL/TP-500-32471, NREL, Golden, CO, USA, 20 pp.

Fouquet, D., and T.B. Johansson (2008). European renewable energy policy at crossroads - Focus on electricity support mechanisms. Energy Policy, 36(11), pp. 4079-4092.

Fouquet, D., C. Grotz, J.L. Sawin, and N. Vassilakos (2005). Reflections on a Possible Unified EU-Financial Support Scheme for Renewable Energy Systems (RES): A Comparison of Minimum-Price and Quota Systems and an Analysis of Market Conditions. European Renewable Energies Federation and Worldwatch Institute, Brussels, Belgium and Washington, DC, USA.

Fouquet, R. (2008). Heat, Power And Light: Revolutions in Energy Services. Edward Elgar Publishing Ltd., Cheltenham, UK.

Fox, J. (2010). Renewable Energy in Thailand: Green Policies Take Off. Thailand Law Forum. Available at: www.thailawforum.com/green-policies-take-off.html.

Foxon, T., and P. Pearson (2008). Overcoming barriers to innovation and diffusion of cleaner technologies: some features of a sustainable innovation policy regime. Journal of Cleaner Production, 16(S1), pp. S148-S161.

Freeman, C. (1974). The Economics of Industrial Innovation. The MIT Press, Cambridge, MAUSA.

Freeman, C., and C. Perez (1988). Structural crises of adjustment, business cycles, and investment behavior. In: Technical Change and Economic Theory. G. Dosi, C. Freeman, R. Nelson, G. Silverberg and L. Soete (eds.), Pinter, London, UK and New York, NY, USA, pp. 38-66.

Frenken, K., M. Hekkert, and P. Godfroij (2004). R\&D portfolios in environmentally friendly automotive propulsion: Variety, competition and policy implications. Technological Forecasting and Social Change, 71(5), pp. 485-507.

Fri, R.W. (2003). The role of knowledge: Technological innovation in the energy system. The Energy Journal, 24(4), pp. 51-74. 
Friedrichs, J. (2010). Global energy crunch: how different parts of the world would react to a peak oil scenario. Energy Policy, 38(8), pp. 4562-4569.

Frondel, M., N. Ritter, C.M. Schmidt, and C. Vance (2010). Economic impacts from the promotion of renewable energy technologies: The German experience. Energy Policy, 38(2010), pp. 4048-4056

Fuller, M.C., C. Kunkel, and D.M. Kammen (2009a). Guide to Energy Efficiency and Renewable Energy Financing Districts for Local Governments, prepared for the city of Berkeley, California. Renewable and Appropriate Energy Laboratory, University of California, Berkeley, CA, USA.

Fuller, M.C., S. Portis, and D.M. Kammen (2009b). Towards a low-carbon economy: municipal financing for energy efficiency and solar power. Environment Magazine, 51(2), pp. 22-32.

Gallagher, K.S. (2006). Limits to leapfrogging in energy technologies? Evidence from the Chinese automobile industry. Energy Policy, 34, pp. 383-394.

Gan, Z. and Yu, L. (2008). Bioenergy transition in rural China: Policy options and co-benefits. Energy Policy, 36(2), pp: 531-540.

Garud, R., and P. Karnøe (2003). Bricolage versus breakthrough: distributed and embedded agency in technology entrepreneurship. Research Policy, 32, pp. 277-300.

Gatautis, R., I. Konstantinaviciute, D. Tarvydas, and V. Bobinaite (2009). Current State of Heating and Cooling Markets in Lithuania Kaunas. Lithuanian Energy Institute, Kaunas, Lithuania.

Gatersleben, B., L. Steg, and C. Vlek (2002). Measurement and determinants of environmentally significant consumer behavior. Environment and Behavior, 34(3), pp. 335-362.

GBC (2010). Clean Energy Act, Statutes of British Columbia, 2010. Bill 17. Government of British Columbia (GBC), Victoria, Canada. Available at: www.leg. bc.ca/39th2nd/1st_read/gov17-1.htm.

Geels, F.W. (2004). From sectoral systems of innovation to sociotechnical systems: insights about dynamics and change from sociology and institutional theory. Research Policy, 33 (6-7), pp. 897-920.

Geels, F.W. (2005). The dynamics of transitions in socio-technical systems: A multi-level analysis of the transition pathway from horse-drawn carriages to automobiles (1860-1930). Technology Analysis \& Strategic Management, 17(4), pp. 445-476.

Gerlagh, R. (2010). Too much oil. CESifo Economic Studies.

Gillenwater, M. (2008). Redefining RECs (Part 1): Untangling attributes and offsets. Energy Policy, 36(6), pp. 2109-2119.

Gillingham, K. (2009). Economic efficiency of solar hot water policy in New Zealand. Energy Policy, 37(9), pp. 3336-3347.

Girardet, H., and M. Mendonca (2009). A Renewable World: Energy, Ecology, Equality. Green Books, Devon, UK.

Goldemberg, J. (2006). The ethanol program in Brazil. Environmental Research Letters, 1, 014008.

Goldemberg, J. (2009). The Brazilian experience with Biofuels. Innovations, 4(4), pp. $91-107$.

Goldemberg, J., S.T. Coelho, P.M. Nastari, and O. Lucon (2004). Ethanol learning curve - the Brazilian experience. Biomass and Bioenergy, 26(3), pp. 301-304.

Goldemberg, J., S.T. Coelho, and P.M. Guardabassi (2008). The sustainability of ethanol production from sugarcane. Energy Policy, 36(6), pp. 2086-2097.

Goolsbee, A. (1998). Does government R\&D policy mainly benefit scientists and engineers? American Economic Review, 88(2), pp. 298-302.
Government of Jamaica (2006). Green Paper: The Jamaica Energy Policy 20062020. Government of Jamaica, Kingston, Jamaica.

Government of Nepal (2006). Rural Energy Policy. Government of Nepal, Ministry of Environment, Kathmandu, Nepal.

Government of Pakistan (2006). Policy for Development of Renewable Energy for Power Generation: Employing Small Hydro, Wind, and Solar Technologies. Government of Pakistan, Islamabad, Pakistan.

Government of the Kingdom of Tonga (2010). Tonga Energy Roadmap (TERM) 2010-2020: A Ten Year Road Map to Reduce Tonga's Vulnerability to Oil Price Shocks \& Achieve an Increase in Quality Access to Modern Energy Services in an Environmentally Sustainable Manner. HM Government of the Kingdom of Tonga, Nuku'aLofa, Tonga.

Grafton, R.Q., T. Kompas, and N. Van Long (2010). Biofuels Subsidies and the Green Paradox. CESifo Working Paper Series 2960, CESifo Group, Munich, Germany.

Greacen, C. (2007). An emerging light: Thailand gives the go-ahead to distributed energy. Cogeneration \& On-Site Power Production Magazine, pp. 65-73.

Greacen, C., and C. Greacen (2004). Thailand's electricity reforms: privatization of benefits and socialization of costs and risks. Pacific Affairs, 77(4), 517-541.

Greacen, C., C. Greacen, and R. Plevin (2003). Thai power: Net metering comes to Thailand. ReFocus, 4(6), pp. 34-37. Available at: netmeter.org/en/docs/ NetMeteringRefocusNov2003.pdf.

Griliches, Z. (1992). The search for R\&D spillovers. Scandinavian Journal of Economics, 94, pp. S29-S47.

Grimaud, A., and G. Lafforgue (2008). Climate change mitigation policies: are $R \& D$ subsidies preferable to a carbon tax? University of Toulouse, Toulouse, France.

Gross, C. (2007). Community perspectives of wind energy in Australia: The application of a justice and community fairness framework to increase social acceptance. Energy Policy, 35, pp. 2727-2736.

Grubb, M. (2004). Technology innovation and climate change policy: An overview of issues and options. Keio Economic Studies, 41(2), pp. 103-132.

Grubler, A. (1998). Technology and Global Change. Cambridge University Press.

Grubler, A., N. Nakicenovic, and D.G. Victor (1999a). Dynamics of energy technologies and global change. Energy Policy, 27(5), pp. 247-280.

Grubler, A., N. Nakicenovic, and D.G. Victor (1999b). Modeling technological change: Implications for the global environment. Annual Review of Energy and the Environment, 24, pp. 545-569.

Gupta, S., D.A. Tirpak, N. Burger, J. Gupta, N. Höhne, A.I. Boncheva, G.M. Kanoan, C. Kolstad, J.A. Kruger, A. Michaelowa, S. Murase, J. Pershing, T. Saijo, and A. Sari (2007). Policies, Instruments and Co-operative Arrangements. Cambridge University Press.

GWEC (2008). Global Wind 2007 Report. Global Wind Energy Council (GWEC), Brussels, Belgium.

GWEC (2010). Global Wind 2009 Report. Global Wind Energy Council (GWEC), Brussels, Belgium.

Haanyika, C.M. (2008). Rural electrification in Zambia: A policy and institutional analysis. Energy Policy, 36(3), pp. 1044-1058.

Haas, R., W. Eichhammer, C. Huber, O. Langniss, A. Lorenzoni, R. Madlener, P. Menanteau, P.-E. Morthorst, A. Martins, A. Oniiszk, J. Schleich, A. Smith, Z. Vass, and A. Verbruggen (2004). How to promote renewable energy systems successfully and effectively. Energy Policy, 32(6), pp. 833-839. 
Haas, R., C. Panzer, G. Resch, M. Ragwitz, G. Reece, and A. Held (2011). A historical review of promotion strategies for electricity from renewable energy sources in EU countries. Renewable and Sustainable Energy Reviews, 15, pp. 1003-1034.

Haites, E., M. Duan, and S. Seres (2006). Technology transfer by CDM projects. Climate Policy, 6(3), pp. 327-344.

Han, J., A. Mol, Y. Lu, and L. Zhang (2009). Onshore wind power development in China: Challenges behind a successful story. Energy Policy, 37(8), pp. 2941-2951.

Han, J., A.P.J. Mol, and Y. Lu (2010). Solar water heaters in China: A new day dawning. Energy Policy, 38, pp. 383-391.

Hankey, S., and J.D. Marshall (2010). Impacts of urban form on future US passenger-vehicle greenhouse gas emissions. Energy Policy, 38(9), pp. 4880-4887.

Hanley, N., J.F. Shogren, and B. White (1997). Environmental Economics. In Theory and Practice. MacMillan, $464 \mathrm{pp}$.

Hanley, N., A. Bergmann, and R. Wright (2004). Valuing the Environmental and Employment Impacts of Renewable Energy Investments in Scotland. Scottish Economic Policy Network.

Hanson, M., M. Bernstein, and R. Hammon (2006). The role of energy efficiency in homebuying decisions: Results of initial focus group discussions. In: ACEEE Summer Study on Energy Efficiency in Buildings, Asilomar, CA, 13-18 August 2006, American Council for an Energy Efficient Economy.

Haščič, I., and N. Johnstone (2009). The Clean Development Mechanism and International Technology Transfer: Empirical Evidence on Wind Power using Patent Data. Organisation for Economic Co-operation and Development, Paris, France.

Healey, P. (1997). Collaborative Planning. Shaping Places in Fragmented Societies. MacMillan Press, London, UK.

Heiskanen, E., M. Hodson, R.M. Mourik, R.P. J.M. C.F.J. Feenstra, T. Alcantud Torrent, B. Brohmann, A. Daniels, M. Difiore, B. Farkas, U.R. Fritsche, J. Fucskó, E. Jolivet, M.H. Maack, K. Matschoss, A. Oniszk-Poplawska, B.M. Poti, G. Prasad, R. Willemse, B. Schaefer, and K. Hünecke (2008a). Factors Influencing the Societal Acceptance of New Energy Technologies: MetaAnalysis of Recent European Projects. D3-D4 Create Acceptance. ECN-E-07-058 Project co-funded by the European Commission within the Sixth Framework Programme (2002-2006), Energy Research Centre of the Netherlands, Petten, The Netherlands.

Heiskanen, E., K. Jarvela, A. Pulliainen, M. Saastamoinen, and P. Timonen (2008b). Qualitative research and consumer policy: Focus group discussions as a form of consumer participation. The Qualitative Report, 13(2), pp. 152-172.

Hekkert, M., R.A.A. Suurs, S. Negro, S. Kuhlmann, and R. Smits (2007). Functions of innovation systems: A new approach for analysing technological change. Technological Forecasting and Social Change, 74(4), pp. 413-432.

Held, A., M. Ragwitz, C. Huber, G. Resch, T. Faber, and K. Vertin (2007). Feed-in Systems in Germany, Spain and Slovenia: A Comparison. Fraunhofer Institute Systems and Innovation Research, Karlsruhe, Germany.

Held, A., M. Ragwitz, E. Merkel, M. Rathmann, and C. Klessmann (2010). Indicators Assessing the Performance of Renewable Energy Support Policies in 27 Member States. RE-Shaping project report to the European Commission under the Intelligent Energy for Europe Program (Grant agreement no. ElE/08/517/ SI2.529243). Fraunhofer ISI and Ecofys, Karlsruhe, Germany and Utrecht, The Netherlands.

Helm, D. (2010). Government failure, rent-seeking, and capture: the design of climate change policy. Oxford Review of Economic Policy, 26(2), pp. 182-196.
Hertel, T.W., A.A. Golub, A.D. Jones, M. O'Hare, R.J. Plevin, and D.M. Kammen (2010). Effects of US maize ethanol on global land use and greenhouse gas emissions: Estimating market-mediated responses. BioScience, 60, pp. 223-231.

Heyward, M. (2007). Equity and international climate change negotiations: a matter of perspective. Climate Policy, 7, pp. 518-534.

Hiller, J., and P. Healey (2008). Contemporary Movements in Planning Theory. Critical Essays in Planning Theory. Ashgate, Aldershot, UK.

Hiremath, R.B., B. Kumar, P. Balachandra, N.H. Ravindranath, and B.N. Raghunandan (2009). Decentralised renewable energy: Scope, relevance and applications in the Indian context. Energy for Sustainable Development, 13(1), pp. 4-10.

Hockerts, K., and R. Wüstenhagen (2010). Greening Goliaths versus emerging Davids -Theorizing about the role of incumbents and new entrants in sustainable entrepreneurship. Journal of Business Venturing, 25, pp. 481-492.

Hoekman, B.M., K.E. Maskus, and K. Saggi (2004). Transfer of Technology to Developing Countries: Unilateral and Multilateral Policy Options. World Bank, Washington, DC, USA.

Hoel, M. (2010). Is there a Green Paradox? CESifo Working Paper Series 3168. CESifo Group, Munich, Germany.

Hogan, M. (2007). German tax hits Europe's biggest biodiesel market. Reuters, 2 Feb 2007. Available at: uk.reuters.com/article/2007/02/02/biofuels-germanyidUKL0231973020070202.

Hogan, M. (2009). German biodiesel firms say U.S. imports escape duty. Reuters, 30 Nov 2009. Available at: www.reuters.com/article/2009/11/30/ us-germany-biodiesel-us-idUSTRE5AT3QG20091130.

Holdren, J.P., and S.F. Baldwin (2001). The PCAST energy studies: Toward a national consensus on energy research, development, demonstration, and deployment policy. Annual Review of Energy and Environment, 26, pp. 391-434.

Hoppock, D.C., and D. Patiño-Echeverri (2010). Cost of wind energy: Comparing distant wind resources to local resources in the midwestern United States. Environmental Science \& Technology, 44(22), pp. 8758-8765.

Horbach, J. (2007). Determinants of environmental innovation - New evidence from German panel data sources. Research Policy, 37(1), pp. 163-173.

House of Commons (2008). Renewable Electricity - Generation Technologies. Innovation, Universities, Science and Skills Committee, The Stationery Office Limited, London, UK.

Houser, T., S. Mohan, and I. Hoffman (2010). Assessing the American Power Act: The Economic, Employment, Energy Security, and Environmental Impact of Senator Kerry and Senator Lieberman's Discussion Draft. No PB10-12, Policy Briefs from Peterson Institute for International Economics, Washington, DC, USA.

Huber, C., T. Faber, R. Haas, G. Resch, J. Green, S. Olz, S. White, H. Cleijne, W. Ruijgrok, P.E. Morthorst, K. Skytte, M. Gual, P. Del Rio, F. Hernandez, A. Tacsir, M. Ragwitz, J. Schleich, W. Orasch, M. Bokermann, and C. Lins (2004). Green-X: Deriving Optimal Promotion Strategies for Increasing the Share of RES-E in a Dynamic European Electricity Market. TU Wien, Energy Economics Group, Technical University of Denmark (DTU), Riso National Laboratory for Sustainable Energy, Consejo Superior de Investigaciones Cientificas (CSIC), Madrid, Fraunhofer-Institut fur Systemtechnik und Innovationsforschung (ISI), Karlsruhe, Vienna, Austria.

Hughes, T. (1986). The Seamless Web: Technology, Science, Etcetera, Etcetera. Social Studies of Science, 16(2), pp. 281-292. 
Hughes, T.P. (1987). The Evolution of large technological systems. In: The Social Construction of Technological Systems. W.E. Bijker, T.P. Hughes, and T. Pinch (eds.), MIT Press, Cambridge, MA, USA, pp. 51-82.

Hvelplund, F. (2001). Political prices or political quantities? A comparison of renewable support systems. New Energy, 5, pp. 18-23.

Hvelplund, F. (2006). Renewable energy and the need for local energy markets. Energy, 31(13), pp. 2293-2302.

ICCEPT (2003). Innovation in Long Term Renewables Options in the UK - Overcoming Barriers and 'Systems Failures'. ICCEPT report for the DTI Renewable Innovation Review, Centre for Energy Policy and Technology (ICCEPT), Imperial College, London, UK. Available at: webarchive.nationalarchives.gov.uk/+/http://www. berr.gov.uk/files/file22072.pdf.

IDAE (2006). Plan de energias renovables 2005-2010, description de medidas, actuaciones $y$ requisitos. Institute for the Saving and Diversification of Energy (IDEA), Madrid, Spain.

IDAE (2008). Seguimiento del Plan de Energías Renovables en España (PER) 20052010. Memoria 2008. Institute for the Saving and Diversification of Energy (IDAE), Ministerio de Industria, Turismo y Comercio Madrid, Spain.

IDAE (2009). La biomasa en el marco de los Planes de las Energías Renovables de España. Aspectos económicos y sociales de la agroenergética. Institute for the Saving and Diversification of Energy (IDAE), Ministerio de Industria, Turismo y Comercio, Madrid, Spain.

IDAE (2010). La industria fotovoltaica española en el contexto europeo. Institute for the Saving and Diversification of Energy (IDAE), Ministerio de Industria, Turismo y Comercio, Madrid, Spain.

IEA (2003a). National Survey Report of PV Power Applications in Japan 2002, prepared by Kiyoshi Shino. International Energy Agency, Paris, France, 34 pp.

IEA (2003b). Renewables for Power Generation: Status \& Prospects. International Energy Agency, Paris, France.

IEA (2004a). Renewable Energy - Market and Policy Trends in IEA Countries. International Energy Agency and Organisation for Economic Co-operation and Development, Paris, France.

IEA (2004b). World Energy Outlook 2004. International Energy Agency, Paris, France.

IEA (2006). Barriers, Challenges and Opportunities. International Energy Agency, Paris, France.

IEA (2007a). Climate Policy Uncertainty and Investment Risk. In Support of the G8 Plan of Action. International Energy Agency, Paris, France.

IEA (2007b). Renewables for Heating and Cooling: Untapped Potential. Renewable Energy Technology Deployment, International Energy Agency and Organisation for Economic Co-operation and Development, Paris, France.

IEA (2008a). Deploying Renewables: Principles for Effective Policies. International Energy Agency, Paris, France, 200 pp.

IEA (2008b). Energy Technology Perspectives 2008. Scenarios and Strategies to 2050. International Energy Agency, Paris, France, 646 pp.

IEA (2008c). World Energy Outlook 2008. International Energy Agency, Paris, France, $578 \mathrm{pp}$.

IEA (2009a). Cities, Towns and Renewable Energy - Yes In My Front Yard. International Energy Agency, Paris, France

IEA (2009b). Cogeneration and District Energy: Sustainable Energy Technologies for Today and Tomorrow. International Energy Agency and Organisation for Economic Co-operation and Development, Paris, France, 24 pp.

IEA (2009c). Statistics \& Balances. International Energy Agency, Paris, France, 2009.
IEA (2009d). World Energy Outlook 2009. International Energy Agency, Paris, France, $696 \mathrm{pp}$.

IEA (2010a). Energy Technology Perspectives 2010. Scenarios and Strategies to 2050. International Energy Agency, Paris, France, 708 pp.

IEA (2010b). Energy Technology R\&D Statistics. International Energy Agency, Paris, France.

IEA (2010c). Global Renewable Energy Policies and Measures Database. International Energy Agency, Paris, France

IEA (2010d). World Energy Outlook 2010. International Energy Agency, Paris, France, $736 \mathrm{pp}$.

IEA (2011). Global Renewable Energy Policies and Measures Database, March 2011. International Energy Agency, Paris, France.

IEA, OECD, and World Bank (2010). The Scope of Fossil Fuel Subsidies in 2009 and a Roadmap for Phasing Out Fossil-Fuel Subsidies. International Energy Agency, Organisation for Economic Co-operation and Development, and the World Bank, Paris, France and New York, NY, USA.

IEA RETD (2010). Best Practices for the Deployment of RE for Heating and Cooling in the Residential Sector. International Energy Agency Renewable Energy Technology Development (IEA RETD), Paris, France.

IEEE PES (2009). Preparing the US Foundation for Future Electric Energy Systems: A Strong Power and Energy Engineering Workforce. IEEE US Power and Energy Engineering Workforce Collaborative, Piscataway, NJ, USA. Available at: www. ieee-pes.org/images/pdf/US_Power_\&_Energy_Collaborative_Action_Plan_ April_2009_Adobe72.pdf.

IISD (2008). Biofuels - At what Cost? Government Support for Ethanol and Biodiesel in China, Global Subsidies Initiative, International Institute for Sustainable Development (IISD), Geneva, Switzerland. Available at: www.iisd.org/pdf/2008/ biofuels_subsidies_aus.pdf.

IJHD (2009). Annual Directory, Years 2004 to 2009. International Journal of Hydropower and Dams, Surrey, UK.

IMEC (2009a). SCHOTT Solar joins IMEC research program on silicon photovoltaics. Available at: www2.imec.be/be_en/press/imec-news/archive-2009/schott-solarjoins-imec-research-program-on-silicon-photovoltaics.html.

IMEC (2009b). Total, GDF SUEZ, and Photovoltech join IMEC's silicon solar cell research program. Press release, IMEC, Leuven, Belgium. Available at: www2. imec.be/be_en/press/imec-news/archive-2009/total-gdf-suez-and-photovoltechjoin-imec-08217-s-silicon-solar-cell-research.html.

Inhaber, H. (2004). Water use in renewable and conventional electricity production. Energy Sources, 26, pp. 309-322.

International Center for Trade and Sustainable Development (2010). US, EU Join Japan in Row over Canadian Green Energy Incentives. International Center for Trade and Sustainable Development, Geneva, Switzerland. Available at: ictsd. org/i/news/bridgesweekly/86146/.

IPCC (2000). Methodological and Technological Issues in Technology Transfer. B. Metz, O.R. Davidson, J.-W. Martens, S.N.M. van Rooijen, and L. Van Wie McGrory (eds.). Cambridge University Press, $432 \mathrm{pp}$.

IPCC (2002). Climate Change and Biodiversity. H. Gitay, A. Suárez, RT. Watson, and D.J. Dokken (eds.), IPCC Technical Paper V, IPCC, Geneva, Switzerland, 85 pp.

IPCC (2007). Climate Change 2007: Mitigation of Climate Change. Contribution of Working Group III to the Fourth Assessment Report of the Intergovernmental Panel on Climate Change. B. Metz, O.R. Davidson, P.R. Bosch, R. Dave, and L.A. Meyer (eds.), Cambridge University Press, 851 pp. 
IREC (2010). 2010 Updates and Trends. Interstate Renewable Energy Council (IREC), Latham, NY, USA, $38 \mathrm{pp}$

Ito, H. (2003). Japan's New and Renewable Energy Policies. Ministry of Economy, Trade and Industry, Tokyo, Japan. Available at: www.asiapacificpartnership.org/ pdf/REDGTF/1st_meeting/Japan1-country_report.pdf.

Jaccard, M., N. Melton, and J. Nyboer (2011). Institutions and processes for scaling up renewables: Run-of-river hydropower in British Columbia. Energy Policy, doi:10.1016/j.enpol.2011.02.035.

Jacobsson, S., and A. Johnson (2000). The diffusion of renewable energy technology: an analytical framework and key issues for research. Energy Policy, 28(9), pp. 625-640.

Jacobsson, S., and A. Bergek (2004). Transforming the energy sector: the evolution of technological systems in renewable energy technology. Industrial and Corporate Change, 13(5), pp. 815-849.

Jacobsson, S., and V. Lauber (2006). The politics and policy of energy system transformation - explaining the German diffusion of renewable energy technology. Energy Policy, 34(3), pp. 256-276.

Jacobsson, S., A. Bergek, D. Finon, V. Lauber, C. Mitchell, D. Toke, and A. Verbruggen (2009). EU renewable energy support policy: Faith or facts? Energy Policy, 37(6), pp. 2143-2146.

Jaffe, A.B. (1986). Technological opportunity and spillover of R\&D: evidence from firms' patents, profits, and market value. American Economic Review, 76, pp. 984-1001.

Jaffe, A.B., R.G. Newell, and R.N. Stavins (2003). Technological change and the environment. In: Handbook of Environmental Economics. K.-G. Mäler and J. Vincent (eds.), Elsevier Science, Amsterdam, The Netherlands, pp. 461- 516.

Jaffe, A.B., R.G. Newell, and R.N. Stavins (2005). A tale of two market failures: Technology and environmental policy. Ecological Economics, 54(2-3), pp. 164-174.

Jager, W. (2006). Stimulating the diffusion of photovoltaic systems: A behavioural perspective." Energy Policy 34(14): 1935-1943.

Jänicke, M. (2010). Das Innovationstempo in der Klimapolitik forcieren! In: Jahrbuch Ökologie 2011, S. Hirzel, Stuttgart, Germany, pp. 138-147. Available at: www. jahrbuch-oekologie.de/Jaenicke2011.pdf.

Jayanthi, S., E.C. Witt, and V. Singh (2009). Evaluation of potential of innovations: A DEA-based application to US photovoltaic industry. IEEE Transactions on Engineering Management, 56(3), pp. 478-493.

Jenvanitpanjakul, P., and P. Bhandhubanyong (2009). Rice and sugar energy complex model. In: 6th Biomass-Asia Workshop, Hiroshima, Japan, 18-20 November 2009. Available at: http://www.biomass-asia-workshop.jp/ biomassws/06workshop/presentation/18_Peesamai.pdf.

Jha, V. (2009). Trade Flows, Barriers and Market Drivers in Renewable Energy Supply Goods: The Need to Level the Playing Field. International Centre for Trade and Sustainable Development, Geneva, Switzerland.

JNNSM (2009). Towards Building SOLAR INDIA. Jawaharlal Nehru National Solar Mission (JNNSM), Ministry of New and Renewable Energy, Government of India, New Delhi, India. Available at: mnre.gov.in/pdf/mission-document-JNNSM.pdf.

Jobert, A., P. Laborgne, and S. Mimler (2007). Local acceptance of wind energy: Factors of success identified in French and German case studies. Energy Policy, 35, pp. 2751-2760.
Johansson, T.B., U.R. Fritsche, C. Flavin, J. Sawin, D. Aßmann, and T.C. Herberg (2004). Policy recommendations for renewable energies. Prepared for the International Conference for Renewable Energies under the guidance of the Conveners of the Conference. Bonn, Germany, 1-4 June 2004. Available at: www. oei.es/salactsi/recommendations_final.pdf.

Johnstone, N., I. Haščič, and D. Popp (2010). Renewable energy policies and technological innovation: Evidence based on patent counts. Environmental and Resource Economics, 45(1), pp. 133-155.

Jordan, A.J., and A. Lenschow (2000). Greening' the European Union: What can be learned from the leaders of EU environmental policy? European Environment, 10(3), pp. 109-120.

Joskow, P.L. (2005). Transmission policy in the United States. Utilities Policy 13(2), pp. 95-115.

Junginger, M., W. van Sark, and A. Faaij (eds.) (2010). Technological Learning in the Energy Sector: Lessons from Policy, Industry and Science. Edward Elgar, Cheltenham, UK, $352 \mathrm{pp}$.

Junginger, M., J. van Dam, S. Zarrilli, F. Ali Mohamed, D. Marchal, and A. Faaij (2011). Opportunities and barriers for global bioenergy trade. Energy Policy, 39(4), pp. 2028-2042.

Kahn, J. (2003). Wind Power planning in three Swedish municipalities. Journal of Environmental Planning and Management, 46(4), pp. 563-581.

Kammen, D.M. (2009). Financing energy efficiency with taxes. Scientific American, 21(Earth 3.0), March 2009.

Kaplan, A.W. (1999). From passive to active about solar electricity: innovation decision process and photovoltaic interest generation. Technovation, 19(8). pp. 467-481.

Karnoe, P. (1990). Technological innovation and industrial organization in the Danish wind industry. Entrepreneurship \& Regional Development, 2(2), pp. 105-124.

Keller, K., and J. Wild (2004). Long-term investment in electricity: a trade-off between co-ordination and competition? Utilities Policy 12(4), pp. 243-251.

Kemp, R., and J. Rotmans (2009). Transitioning policy: Co-production of a new strategic framework for energy innovation policy in the Netherlands. Policy Sciences, 42(4), pp. 303-322.

Kenney, M. (2010). Venture capital investment in the greentech industries: a provocative essay. In: Handbook of Research on Energy Entrepreneurship. R. Wustenhagen and R. Wuebker (eds.), Edward Elgar, Cheltenham, UK.

Kern, F., and F. Howlett (2009). Implementing transition management as policy reforms: A case study of the Dutch energy sector. Policy Sciences, 42(4), pp. 391-408.

Kim, L. (1991). Pros and cons of international technology transfer: A developing country view. In: Technology Transfer in International Business. T. Agmon and M.A. Von Glinow (eds.), Oxford University Press.

Kim, L. (1997). Imitation to Innovation: The Dynamics of Korea's Technological Learning. Harvard Business School Press, Cambridge, MA, USA.

Klein, A., A. Held, M. Ragwitz, G. Resch, and T. Faber (2008a). Evaluation of Different Feed-in Tariff Design Options - Best Practice Paper for the International Feed-in Cooperation. Fraunhofer Institute Systems and Innovation Research and Energy Economics Group, Karlsruhe, Germany and Vienna, Austria. 
Klein, A., B. Pfluger, A. Held, M. Ragwitz, G. Resch and T. Faber (2008b). Evaluation of Different Feed-in Tariff Design Options - Best Practice Paper for the International Feed-In Cooperation, 2nd edition. Energy Economics Group and Fraunhofer Institute Systems and Innovation Research, Vienna, Austria and Karlsruhe, Germany.

Klein, A., E. Merkel, B. Pfluger, A. Held, M. Ragwitz, G. Resch, and S. Busch (2010). Evaluation of Different Feed-in Tariff Design Options - Best Practice Paper for the International Feed-In Cooperation, 3rd edition. Energy Economics Group and Fraunhofer Institute Systems and Innovation Research, Vienna, Austria and Karlsruhe, Germany.

Klessmann, C., C. Nabe, and K. Burges (2008). Pros and cons of exposing renewables to electricity market risks - A comparison of the market integration approaches in Germany, Spain, and the UK. Energy Policy, 36, pp. 3646-3661.

Kline, D.M., L. Vimmerstedt, and R. Benioff (2004). Clean energy technology transfer: A review of programs under the UNFCCC. Mitigation and Adaptation Strategies for Global Change, 9, pp. 1-35.

Kobayashi, T. (2003). Vision of the future of the photovoltaic industry in Japan. In: Proceedings of 3rd World Conference on Photovoltaic Energy Conversion, Osaka, Japan, 18-18 May 2003, pp. 2538-2543.

Krapels, E.N. (2010). The terrible trio impeding transmission development: Siting, cost allocation, and interconnection animus. The Electricity Journal, 23(1), pp. 34-38.

Ku, J., E.I. Baring-Gould, and K. Stroup (2005). Renewable Energy Applications for Rural Development in China. NREL/CP-710-37605, National Renewable Energy Laboratory, Golden, CO, USA, 5 pp.

Laffont, J.J. and Tirole, J. (1988). The dynamics of incentive contracts. Econometrica, 56, pp. 1153-1176.

Laird, F.M., and C. Stefes (2009). The diverging paths of German and United States policies for renewable energy: Sources of difference. Energy Policy, 37(2009), pp. 2619-2629.

Lamers, P., C. Hamelinck, M. Junginger, and A. Faaij (2011). International bioenergy trade - a review of past developments in the liquid biofuels market. Renewable \& Sustainable Energy Reviews, 15(6), pp. 2655-2676.

Langniß, 0., and L. Neij (2004). National and international learning with wind power. Energy \& Environment, 15(2), pp. 175-185.

Langniß, 0., J. Diekmann, and U. Lehr (2009). Advanced mechanisms for the promotion of renewable energy. Models for the future evolution of the German Renewable Energy Act. Energy Policy, 37(2009), pp. 1289-1297.

Lantz, E., and E. Doris (2009). State Clean Energy Practices: Renewable Energy Rebates. NREL/TP-6A2-45039, National Renewable Energy Laboratory, Golden, CO, USA, $38 \mathrm{pp}$.

Lapola, D.M. R. Schaldach, J. Alcamo, A. Bondeau, J. Koch, C. Koelking, and J.A. Priess (2010). Indirect land use changes can overcome carbon savings from biofuels in Brazil. Proceedings of the National Academy of Sciences, 107(8), pp. 3388-3393.

Lauber, V. (2004). REFIT and RPS: options for a harmonised Community framework. Energy Policy, 32(12), pp. 1405-1414.

Lauber, V., and L. Mez (2004). Three decades of renewable electricity policies in Germany. Energy and Environment, 15(4), pp. 599-623.

Lehr, U., J. Nitsch, M. Kratzat, C. Lutz, and D. Edler (2008). Renewable energy and employment in Germany. Energy Policy, 36(1), pp. 108-117.

Lenschow, A. (2002). Environmental Policy Integration: Greening Sectoral Policies in Europe. Earthscan, London, UK.
Lewis, J.I. (2007). Technology acquisition and innovation in the developing world: Wind turbine development in China and India. Studies in Comparative International Development, 42, pp. 208-232.

Lewis, J. (2010). The evolving role of carbon finance in promoting renewable energy development in China. Energy Policy, 38(6). pp. 2875-2886.

Lewis, J., and R. Wiser (2005). Fostering a Renewable Energy Technology Industry: An International Comparison of Wind Industry Policy Support Mechanisms. LBNL-59116, Ernest Orlando Lawrence Berkeley National Laboratory, Berkeley, CA, USA, $30 \mathrm{pp}$.

Liao, C., E. Jochem, Y. Zhang, and N.R. Farid (2010). Wind power development and policies in China. Renewable Energy, 35, pp. 1879-1886.

Lipp, J. (2007). Lessons for effective renewable electricity policy from Denmark, Germany and the United Kingdom. Energy Policy, 35(11), pp. 5481-5495.

Liu,Y. and A. Kokko (2010). Wind power in China: Policy and development challenges. Energy Policy, 38, pp. 5520-5529.

Liu, L.-q., Z.-x. Wanga, H.-q. Zhang, and Y.-c. Xue (2010). Solar energy development in China-A review. Renewable and Sustainable Energy Reviews, 14, pp. 301-311.

Locke Lord Bissell \& Liddell (2007). Transmission Access Challenges for Wind Generation. Locke Lord Bissell \& Liddell, Chicago, IL, USA.

London School of Economics (2009). Meeting the Climate Challenge: Using Public Funds to Leverage Private Investment in Developing Countries. London School of Economics, London, UK.

Loorbach, D. (2007). Transition Management. New Mode of Governance for Sustainable Development. International Books, Utrecht, The Netherlands.

Lotker, M. (1991). Barriers to Commercialization of Large-Scale Solar Electricity: Lessons Learned from the LUZ Experience. Contractor Report, Sandia National Laboratories, Oak Ridge, TN, USA.

Lovely, M., and D. Popp (2011). Trade, technology and the environment: Does access to technology promote environmental regulation? Journal of Environmental Economics and Management, 61(1), pp. 16-35.

Lovins, A.B., K. Datta, O.-E. Bustnes, J. Koomey, and N. Glasgow (2004). Winning the Oil Endgame: Innovation for Profits, Jobs and Security. Rocky Mountain Institute, Snowmass, CO, USA.

Lucena, A.F.P., A.S. Szklo, R. Schaeffer, R.R. Souza, B.S.M.C. Borba, and I.V.L. Costa (2009). The vulnerability of renewable energy to climate change in Brazil. Energy Policy, 37, pp. 879-889.

Lund, J.W., and D.H. Freeston (2001). World-wide direct uses of geothermal energy 2000. Geothermics, 30(1), pp. 29-68.

Lund, P.D. (2008). Effects of energy policies on industry expansion in renewable energy. Renewable Energy, 34(1), pp. 53-64.

Madlener, R. (2007). Innovation diffusion, public policy and local initiative: the case of wood-fuelled district heating systems in Austria. Energy Policy, 35, pp. 1992-2008.

Madsen, B.T. (2009). Public initiatives and industrial development after 1979. In: The Danish Way: From Poul La Cour to Modern Wind Turbines. Poul La Cour Foundation, Askov, Denmark.

Mahapatra, S., H.N. Chanakya, and S. Dasappa (2009). Evaluation of various energy devices for domestic lighting in India: Technology, economics and $\mathrm{CO}_{2}$ emissions. Energy for Sustainable Development, 13(4), pp. 271-279.

Mallett, A. (2007). Social acceptance of renewable energy innovations: The role of technology cooperation in urban Mexico. Energy Policy, 35(5), pp. 2790-2798. 
Markard, J., and B. Truffer (2008). Technological innovation systems and the multilevel perspective: towards an integrated framework. Research Policy, 37(4), pp. 596-615.

Martinot, E., and L. Junfeng (2007). Powering China's Development - The Role of Renewable Energy. Worldwatch Institute, Washington, DC, USA.

Martinot, E., A. Chaurey, D. Lew, J.R. Moreira, and N. Wamukonya (2002). Renewable energy markets in developing countries. Annual Review of Energy and Environment, 27, pp. 309-48.

Maruyama, Y., M. Nishikido, and T. lido (2007). The rise of community wind power in Japan: Enhanced acceptance through social innovation. Energy Policy, 35, pp. 2761-2769.

Meadowcroft, J. (2007). National sustainable development strategies: Features, challenges, and reflexivity. European Environment, 17(3), pp. 152-163.

Meijer, I.S.M., M.P. Hekkert, and J.F.M. Koppenjan (2007a). How perceived uncertainties influence transitions; the case of micro-CHP in the Netherlands. Technological Forecasting and Social Change, 74(4), pp. 519-537.

Meijer, I.S.M., M.P. Hekkert, and J.F.M. Koppenjan (2007b). The influence of perceived uncertainty on entrepreneurial action in emerging renewable energy technology; biomass gasification projects in the Netherlands. Energy Policy, 35(11), pp. 5836-5854.

Mendis, M.S., and W.J. van Nes (1999). The Nepal Biogas Support Programme, Elements for Success in Rural Household Energy Supply, Policy and Best Practice Document 4. Ministry of Foreign Affairs, The Netherlands.

Mendonça, M. (2007). Feed-In Tariffs: Accelerating the Deployment of Renewable Energy. Earthscan, London, UK.

Mendonça, M., S. Lacey, and F. Hvelplund (2009). Stability, participation and transparency in renewable energy policy: Lessons from Denmark and the United States. Policy and Society, 27, pp. 379-398.

Menz, F.C., and S. Vachon (2006). The effectiveness of different policy regimes for promoting wind power: experiences from the States. Energy Policy, 34(14), pp. 1786-1796.

MERC Partners (2009). Staffing the Energy Industry: A survey on current and future skills needs. MERC Partners, Dublin, Ireland

Metcalf, G.E. (2008). Tax Policy for Financing Alternative Energy Equipment. Tufts University Economics Department Working Paper series, Tufts University, Medford, MA, USA.

METI (2009). About New Buyback System of PV. The 35th meeting (2009). Reference Material 1. New Energy Committee, Ministry of Economy, Trade and Industry (METI), Japan.

Meyer, N.I. (2003). European schemes for promoting renewables in liberalised markets. Energy Policy, 31(7), pp. 665-676.

Meyer, N.I. (2007). Learning from wind energy policy in the EU: lessons from Denmark, Sweden and Spain. European Environment, 17(5), pp. 347-362.

Milbrandt, A. and R.P. Overend (2008). Survey of Biomass Resource Assessments and Assessment Capabilities in APEC Economies. NREL/TP-6A2-43710; APEC\#208-RE-01.9, Asia-Pacific Economic Cooperation and National Renewable Energy Laboratory, Singapore and Golden, CO, USA, 155 pp. Available at: www. nrel.gov/docs/fy09osti/43710.pdf.

Ministerio de Economía (2004). Real Decreto 436/2004, de 12 de marzo, por el que se establece la metodología para la sistematización y actualización del régimen jurídico y económico de la actividad de producción de energía eléctrica en régimen especial. Boletín Oficial del Estado, Madrid, Spain.
Mitchell, C. (1995). The Renewable NFFO - A review. Energy Policy, 23(12), pp. 1077-1091.

Mitchell, C. (2000). The Non-Fossil Fuel Obligation and its future. Annual Review of Energy and Environment, 25, pp. 285-312.

Mitchell, C. (2008). The Political Economy of Sustainable Energy. Palgrave MacMillan, Hampshire, UK.

Mitchell, C. (2010). Forging European responses to the challenge of climate change and energy resource supply. In: International Science and Technology Cooperation in a Globalised World: the External Dimension of the European Research Area. H. Prange-Gstohl (ed.), Edward Elgar Publishers, Cheltenham, UK.

Mitchell, C., and P. Connor (2004). Renewable energy policy in the UK 1990-2003. Energy Policy, 32(17), pp. 1935-1947.

Mitchell, C., D. Bauknecht, and P.M. Connor (2006). Effectiveness through risk reduction: a comparison of the renewable obligation in England and Wales and the feed-in system in Germany. Energy Policy, 34(3), pp. 297-305.

Mitchell, R.L., C.E. Witt, R. King, and D. Ruby (2002). PVMaT advances in the photovoltaic industry and the focus of future PV manufacturing R\&D. In: Conference Record of the 29th IEEE Photovoltaic Specialists Conference, New Orleans, LA, USA, 19-24 May 2002, pp. 1444-1447.

MITyC (2007). Real Decreto 661/2007, de 25 de mayo, por el que se regula la actividad de producción de energía eléctrica en régimen especial. Boletín Oficial del Estado, Madrid, Spain.

MITyC (2008). Real Decreto 1578/2008, de 26 de septiembre, de retribución de la actividad de producción de energía eléctrica mediante tecnología solar fotovoltaica para instalaciones posteriores a la fecha límite de mantenimiento de la retribución del Real Decreto 661/2007, de 25 de mayo, para dicha tecnología. Boletín Oficial del Estado, Madrid, Spain (in Spanish). Available at: www.boe.es/ aeboe/consultas/bases_datos/doc.php?id=BOE-A-2008-15595.

MITyC (2009). La Energía en España 2008; Ministerio de Industria Turismo y Comercio, Madrid, Spain. Available at: www.mityc.es/energia/balances/Balances/ LibrosEnergia/ENERGIA_2008.pdf.

MlyE (1998). Real Decreto 2818/1998, de 23 de diciembre, sobre producción de energía eléctrica por instalaciones de abastecidas por recursos o fuentes de energías renovables, residuos y cogeneración, Boletín Oficial del Estado núm. 312, de 30 de diciembre de 1998. Ministerio de industria y Energía, Madrid, Spain.

MNRE (2010). Annual Report 2009-10. Ministry of New and Renewable Energy, Government of India, New Delhi, India.

Mondal, M.A.H., L.M. Kamp, and N.I. Pachova (2010). Drivers, barriers, and strategies for implementation of renewable energy technologies in rural areas in Bangladesh - An innovation system analysis. Energy Policy, 38(8), pp. 4626-4634.

Moore, B., and R. Wüstenhagen (2004). Innovative and sustainable energy technologies: The role of venture capital. Business Strategy and the Environment, 13, pp. 235-245.

Moore, M.C., D.J. Arent, and D. Norland (2007). R\&D advancement, technology diffusion, and impact on evaluation of public R\&D. Energy Policy, 35(3), pp. 1464-1473.

Morales, A., X. Robe, M. Sala, P. Prats, C. Aguerri, and E. Torres (2008). Advanced grid requirements for the integration of wind farms into the Spanish transmission system. let Renewable Power Generation, 2(1), pp. 47-59.

Moreira, J.R., and J. Goldemberg (1999). The alcohol program. Energy Policy, 27(4), pp. 229-245. 
Mowery, D., and N. Rosenberg (1979). The influence of market demand upon innovation: a critical review of some recent empirical studies. Research Policy, 8(2), pp. 102-153.

Mowery, D.C., R.R. Nelson, and B.R. Martin (2010). Technology policy and global warming: Why new policy models are needed (or why putting new wine in old bottles won't work). Research Policy, 39(8), pp. 1011-1023.

Müller, B. (2010). The Reformed Financial Mechanism of the UNFCCC Part II: The Question of Oversight Post Copenhagen Synthesis. Report EV52, Oxford Institute for Energy Studies, Oxford, UK.

Murphy, L.M., and P.L. Edwards (2003). Bridging the Valley of Death: Transitioning from Public to Private Sector Financing. National Renewable Energy Laboratory, Golden, CO, USA.

Mytelka, L. (2007). Technology Transfer Issues in Environmental Goods and Services: An Illustrative Analysis of Sectors Relevant to Air-pollution and Renewable Energy. International Centre for Trade and Sustainable Development, Geneva, Switzerland

Nadaï, A. (2007). "Planning", "siting" and the local acceptance of wind power: some lessons from the French case. Energy Policy, 35(5), pp. 2715-2726.

Nadaï, A., and O. Labussière (2009). Wind power planning in France (Aveyron), from state regulation to local planning. Land Use Policy, 26(3), pp. 744-754.

Nadaï, A., and O. Labussière (2010). Birds, wind, and the making of wind power landscapes in Aude, Southern France. Landscape Research, 35(2), pp. 209-233.

Nast, M. (2010). Renewable energies heat act and government grants in Germany. Renewable Energy, 35(8), pp. 1852-1856.

Nast, M., O. Langniss, and U. Leprich (2007). Instruments to promote renewable energy in the German heat market - Renewable Heat Sources Act. Renewable Energy, 32, pp. 1127-1135.

National Energy Policy Committee (2008). The Bahamas National Energy Policy. National Energy Policy Committee, Jamaica. Available at: cipore.org/ bahamas-national-energy-policy/.

National Greenhouse Strategy (1998). Strategic Framework for Advancing Australia's Greenhouse Response. Australian Government, Canberra, Australia.

National Grid (2008). GB SQSS Consultation Document - Review of Onshore Intermittent Generation. National Grid, UK. Available at: www.nationalgrid.com/ uk/Electricity/Codes/gbsqsscode/reviews/.

NEDO (2009). The Roadmap PV 2030+. New Energy and Industrial Technology Development Organization (NEDO), Kawasaki, Japan.

Negro, S.O., M.P. Hekkert, and R.E.H.M. Smits (2007). Explaining the failure of the Dutch innovation system for biomass digestion - A functional analysis. Energy Policy, 35(2), pp. 925-938.

Neij, L. (2008). Cost development of future technologies for power generation - A study based on experience curves and complementary bottom-up assessments. Energy Policy, 36(6), 2200-2211.

Nelson, R.R. (1959). The simple economics of basic scientific research. Journal of Political Economy, 67(3), pp. 297-306.

Nelson, R.R., and S.G. Winter (1982). An Evolutionary Theory of Economic Change. Belknap Press, Cambridge, MA, USA and London, UK.

Nemet, G. (2006). Beyond the learning curve: factors influencing cost reductions in photovoltaics. Energy Policy, 34(2006), pp. 3218-3232.

Nemet, G.F. (2009). Demand-pull, technology-push, and government-led incentives for non-incremental technical change. Research Policy, 38(5), pp. 700-709.
Nemet, G. (2010a). Benefit cost analysis of R\&D as a solution to climate change. In: Smart Solutions to Climate Change: Comparing Costs and Benefits. B. Lomborg (ed.), Cambridge University Press, pp. 349-359.

Nemet, G.F. (2010b). Robust incentives and the design of a climate change governance regime. Energy Policy, 38(11), pp. 7216-7225.

Nemet, G.F., and D.M. Kammen (2007). U.S. energy research and development: Declining investment, increasing need, and the feasibility of expansion. Energy Policy, 35(1), pp. 746-755.

NEPC (2009). Status of introduction of PV System by fiscal year and by prefecture (Nendobetu todofukenbetu jutakuyou taiyouko-hatsuden-sisutemu donyu-jokyou). New Energy Promotion Council (NEPC), Tokyo, Japan (in Japanese). Available at: nepc.or.jp/topics/pdf/090605_1.pdf.

Neuhoff, K. (2004). Large Scale Deployment of Renewables for Electricity Generation. Organisation for Economic Co-operation and Development, Paris, France, 40 pp.

Neuhoff, K. (2005). Large-scale deployment of renewables for electricity generation Oxford Review of Economic Policy, 21(1), pp. 88-110.

Neuhoff, K., S. Dröge, O. Edenhofer, C. Flachsland, H. Held, M. Ragwitz, J. Strohschein, A. Türk, and A. Michaelowa (2009). Translating Model Results to Economic Policies. RECIPE Background Paper, Potsdam Institute for Climate Impact Research (PIK), Potsdam, Germany.

New Energy Finance Limited (2007). RECS, ROCS, Feed-in Tariffs: What is the Best Incentive Scheme for Wind Power Investors? Bloomberg New Energy Finance.

Newig, J., and 0. Fritsch (2009). Environmental governance: participatory, multilevel - and effective? Environmental Policy and Governance, 19, pp. 197-214.

Nilkuha, K. (2009). National Biofuels Policy, Deployment and Plans - Thailand. In: Bangkok Biofuels 2009. Sustainable development of biofuels, 7-8 September 2009, Bangkok, Thailand

Nolan, J.M., P.W. Schultz, R.B. Cialdini, V. Griskevicius, and N.J. Goldstein (2008). Normative social influence is underdetected. Personality \& Social Psychology Bulletin, 34(7), pp. 913-923.

Norberg-Bohm, V. (1999). Stimulating green technological innovation: An analysis of alternative policy mechanisms. Policy Sciences, 32(1), pp. 13-38.

Nordhaus, W. (2010). Designing a friendly space for technological change to slow global warming. Energy Economics, doi:10.1016/j.eneco.2010.08.005. Abstract available at: nordhaus.econ.yale.edu/documents/sm_052610.pdf.

NRC (2001). Energy Research at DOE: Was It Worth It? Energy Efficiency and Fossil Energy Research 1978 to 2000. National Research Council (NRC), National Academies Press, Washington, DC, USA.

NRC (2007). Prospective Evaluation of Applied Energy Research and Development at DOE (Phase Two). National Research Council (NRC), The National Academies Press, Washington, DC, USA.

NREL (2004). Renewable Energy in China: Township Electrification Program. NREL/ FS-710-35788, National Renewable Energy Laboratory (NREL), Golden, CO, USA. NSB (2010). Science and Engineering Indicators 2010. National Science Board (NSB), National Science Foundation, Arlington, VA, USA.

O'Reilly, C.A.I., and M.L. Tushman (2004). The ambidextrous organization. Harvard Business Review, April, pp. 74-81.

Ockwell, D., A. Ely, A. Mallett, O. Johnson, and J. Watson (2009). Low Carbon Development: The Role of Local Innovative Capabilities: Paper 31. STEPS Centre and Sussex Energy Group, SPRU, University of Sussex, Brighton, UK. Available at: www.sussex.ac.uk/sussexenergygroup/documents/ockwell-et-al-paper-31.pdf. 
Ockwell, D.G., R. Hauma, A. Mallett, and J. Watson (2010). Intellectual property rights and low carbon technology transfer: Conflicting discourses of diffusion and development. Global Environmental Change, 20, pp. 729-738.

OECD (2008). The Paris Declaration on Aid Effectiveness and the Accra Agenda for Action. Organisation for Economic Co-operation and Development (OECD), Paris, France. Available at: www.oecd.org/dataoecd/11/41/34428351.pdf.

Ofgem (2008). Transmission Access Review - Initial Consultation on Enhanced Investment Incentives. Ofgem, London, UK. Available at: www.ofgem.gov.uk/ Networks/Trans/ElecTransPolicy/tar/Documents1/081219_TOincentives_consultation_FINAL.pdf.

Otto, V.M., A. Löschel, and J. Reilly (2008). Directed technical change and differentiation of climate policy. Energy Economics, 30(6), pp. 2855-2878.

Owens, S., and L. Driffill (2008). How to change attitudes and behaviours in the context of energy. Energy Policy, 36(12), pp. 4412-4418.

Parzen, J. (2009). Lessons Learned: Creating the Chicago Climate Action Plan. Prepared for the City of Chicago Department of the Environment, Chicago, IL, USA, 38 pp.

Peidong, Z., Y. Yanli, T. Yongsheng, Y. Xutong, Z. Yongkai, Z. Yonghong, and W. Lisheng (2009). Bioenergy industries development in China: Dilemma and solution. Renewable and Sustainable Energy Reviews, 13, pp. 2571-2579.

PEMM (2009). Proceedings of the Pacific Energy Ministers' Meeting (PEMM): A CROP Energy Working Group Report, 20-24 April 2009, Nuku'alofa, Tonga. Available at: dev.sopac.org.fj/VirLib/JC0200.pdf.

Peretz, N., and Z. Acs (2011). Driving energy innovation through ex ante incentive prizes. In: Handbook on Research in Energy Entrepreneurship. R. Wüstenhagen and R. Wuebker (eds.), Edward Elgar Publishing, Cheltenham, UK.

Persson, A. (2004). Environmental Policy Integration: an Introduction, PINTS Background Paper. Stockholm Environment Institute, Stockholm, Sweden.

Peters, G.B. (1998). Managing Horizontal Government. Research Paper 21. Canadian Centre for Management Development, Ottawa, Canada.

PIFS (2009a). Final Communique of 40th Pacific Islands Forum, Fortieth Pacific Islands Forum, Cairns, Australia, 5-6 August 2009.

PIFS (2009b). Summary of Decisions. Eighteenth Smaller Island States Leaders' Meeting. In: Pacific Islands Forum Secretariat, Cairns, Australia, 4 August 2009, pp. 7.

PIFS (2010). Pacific Islands Forum Secretariat. In: Forum Communiqué, Forty-first Pacific Islands Forum, Port Vila, Vanuatu, 4-5 August 2010, pp. 15.

Pigou, A.C. (1920). The Economics of Welfare. Macmillan, London, UK.

Pimentel, D., A. Marklein, M.A. Toth, M.N. Karpoff, G.S. Paul, R. McCormack, J. Kyriazis and T. Krueger (2009). Food versus Biofuels: Environmental and Economic Costs. Human Ecology, 37, pp. 1-12.

Plevin, R.J., M. O'Hare, A.D. Jones, M.S. Torn, and H.K. Gibbs (2010). Greenhouse gas emissions from biofuels' indirect land use change are uncertain but may be much greater than previously estimated. Environmental Science \& Technology, 44(21), pp. 8015-8021.

Poortinga, W., L. Steg, and C. Vlek (2004). Values, environmental concern, and environmental behavior: a study into household energy use. Environment and Behavior, 36(1), pp. 70-93.

Popp, D. (2006a). Comparison of climate policies in the ENTICE-BR model. Energy Journal (Special Issue), pp. 163-174.
Popp, D. (2006b). ENTICE-BR: The effects of backstop technology R\&D on climate policy models. Energy Economics, 28, pp. 188-222.

Popp, D. (2010). Innovation and climate policy. Annual Review of Resource Economics, 2(1), pp. 275-298.

Popp, D., and R.G. Newell (2009). Where Does Energy R\&D Come From? Examining Crowding Out from Environmentally-Friendly R\&D. NBER Working Paper No. 15423, National Bureau of Economic Research, Cambridge, MA, USA.

Pousa, G.P.A.G., A.L.F. Santos, and A.Z. Suarez (2007). History and policy of biodiesel in Brazil. Energy Policy, 35(11), pp. 5393-5398.

Prommin Lertsuriyadej (2003). Energy Strategy for Competitiveness Workshop. In: Energy Strategy for Competitiveness Workshop. Chaired by Prime Minister Thaksin Shinawatra, Bangkok, Thailand, 28 August 2003.

Prud'homme, R., and J.P. Bocajero (2005). The London congestion charge: a tentative economic appraisal. Transport Policy, 12(3), pp. 279-287.

Puga, J.N., and J.A. Lesser (2009). Public policy and private interests: Why transmission planning and cost-allocation methods continue to stifle renewable energy policy goals. The Electricity Journal, 22(10), pp. 7-19.

Puig, J. (2008). Barcelona and the power of solar ordinances: Political will, capacity building and people's participation. In: Urban Energy Transition: From Fossil Fuels to Renewable Power. P. Droege (ed.), Elsevier, London, UK, pp. 433-450.

Radov, D., P. Klevnas, and S. Carter (2008). Qualitative Evaluation of Financial Instruments for Renewable Heat. National Economic Research Associates, London, UK.

Ragwitz, M., A. Held, G. Resch, T. Faber, C. Huber, and R. Haas (2005). Final Report: Monitoring and Evaluation of Policy Instruments to Support Renewable Electricity in EU Member States. Fraunhofer Institute Systems and Innovation Research and Energy Economics Group, Karlsruhe, Germany and Vienna, Austria.

Ragwitz, M. A. Held, F. Sensfuss, C. Huber, G. Resch, T. Faber, R. Haas, R. Coenraads, A. Morotz, S.G. Jensen, P.E. Morthorst, I. Konstantinaviciute, and B. Heyder (2006). OPTRES - Assessment and Optimisation of Renewable Support Schemes in the European Electricity Market. Intelligent Energy Europe. Available at: www.optres.fhg.de/OPTRES_FINAL_REPORT.pdf.

Ragwitz, M., W. Schade, B. Breitschopf, R. Walz, N. Helfrich, M. Rathmann, G. Resch, C. Panzer, T. Faber, R. Haas, C. Nathani, M. Holzhey, I. Konstantinaviciute, P. Zagamé, A. Fougeyrollas, and B.L. Le Hir (2009). The Impact of Renewable Energy Policy on Economic Growth and Employment in the European Union. EMployRES Final report, Contract No. TREN/D1/474/2006, 27 April, European Commission DG Energy and Transport, Brussels, Belgium. Available at: ec.europa. eu/energy/renewables/studies/doc/renewables/2009_employ_res_report.pdf.

Ragwitz, M., A. Held, E. Stricker, A. Krechting, G. Resch, and C. Panzer (2010). Recent Experiences with Feed-in Tariff Systems in the EU - A research paper for the International Feed-In Cooperation. A report commissioned by the Ministry for the Environment, Nature Conservation and Nuclear Safety (BMU), Bonn, Germany.

Ragwitz, M., A. Held, B. Breitschopf, M. Rathman, C. Klessmann, G. Reche, C. Panzer, S. Busch, K. Neuhoff, M. Junginger, R. Hoefinagels, N. Cusumano, A. Lorenzoni, J. Burgers, M. Boots, I. Konstantinaviciute, and B. Weores (2011). D8 Report Review on Support Schemes for Renewable Electricity and heating in Europe.A Report compiled for RE-Shaping, No. EIE/08/517/512.529243, Intelligent Energy Europe. Available at: www.reshaping-res-policy.eu/downloads/D8\%20Review\%20Report_final\%20(RE-Shaping).pdf. 
Raven, R., E. Heiskanen, R. Lovio, M. Hodson, and B. Brohmann (2008). The contribution of local experiments and negotiation processes to field-level learning in emerging (niche) technologies: Meta-analysis of 27 new energy projects in Europe. Bulletin of Science, Technology and Society, 28, pp. 464-477.

RECIPES (2005). Country Reports, 2005-2006. Developing Renewables, 'Renewable Energy in developing countries: Current situation, market Potential and recommendations for a win-win-win for EU industry, the Environment and local Socio-economic development' (RECIPES).

Reed, D., A. Kutter, A. Ballesteros, E. Fendley, M. del Socorro Flores Liera, J. Harnisch, S. Huq, and H.-0. Ibrekk (2009). The Institutional Architecture for Financing a Global Climate Deal: An Options Paper. Technical Working Group on the Institutional Architecture for Climate Finance. Available at: www.usclimatenetwork.org/resource-database/Options\%20Paper\%20Final\%20May\%2028.pdf.

REEGLE (2011). Clean Energy Information Portal (REEGLE). Online database. Available at: www.reegle.info/.

REN21 (2005). Renewables 2005 Global Status Report: Notes and References Companion Document. Worldwatch Institute and Renewable Energy Policy Network for the 21st Century (REN21) Secretariat, Washington, DC, USA and Paris, France.

REN21 (2006). Changing Climates: The Role of Renewable Energy in a CarbonConstrained World. Renewable Energy Policy Network for the 21st Century (REN21) Secretariat, Paris, France.

REN21 (2007). Renewables 2007: Global Status Report. Renewable Energy Policy Network for the 21st Century (REN21), Paris, France.

REN21 (2009a). Recommendations for Improving Effectiveness of Renewable Energy Policies in China. Renewable Energy Policy Network for the 21st Century (REN21), Paris, France.

REN21 (2009b). Renewables Global Status Report: 2009 Update. Renewable Energy Policy Network for the 21st Century Secretariat, Paris, France, $42 \mathrm{pp}$.

REN21 (2010). Renewables 2010: Global Status Report. Renewable Energy Policy Network for the 21st Century Secretariat, Paris, France, 80 pp.

REN21 (2011). Renewables Interactive Map. Renewable Energy Policy Network for the 21st Century (REN21). Paris, France. Available at: www.ren21.net/ REN21Activities/InteractiveTools/RenewablesMap/tabid/5444/Default.aspx.

Renewables (2004). Conference Report: Outcomes \& Documentation - Political Declaration / International Action Programme/Policy Recommendations for Renewable Energies. In: Renewables 2004 - International Conference for Renewable Energies, Bonn, Germany, 1- 4 June 2004.

Requate, T. (2005). Dynamic incentives by environmental policy instruments - a survey. Ecological Economics, 54(2-3), pp. 175-195.

Resch, G., C. Panzer, M. Ragwitz, T. Faber, C. Huber, M. Rathmann, G. Reece, A. Held, R. Haas, P.E. Morthorst, S. Grenna, L. Jawowski, I. Konstantinaviciute, R. Pasinetti, and K. Vertin (2009). futures-e - deriving a future European policy for renewable electricity. Final Report of the Research Project futures-e, with support from the European Commission. Contract No. EIE/06/143/S12.444285, DG TREN, EACl under the Intelligent Energy for Europe Programme, Vienna, Austria.

Resources and Logistics (2010). Identification Mission for the Mediterranean Solar Plan, Final Report. Funded by the European Union, Resources and Logistics. available at: ec.europa.eu/energy/international/international_cooperation/ doc/2010_01_solar_plan_report.pdf.

Rhodes, R.A.W. (1996). The new governance: Governing without government. Political Studies, 44(4), pp. 652-667.
Richels, R.G., and G.J. Blanford (2008). The value of technological advance in decarbonizing the U.S. economy. Energy Economics, 30(6), pp. 2930-2946.

Rickerson, W.H., J.L. Sawin, and R.C. Grace (2007). If the shoe FITs: Using feed-in tariffs to meet U.S. renewable electricity targets. The Electricity Journal, 20(4), pp. 73-86.

Rickerson, W.H., F. Bennhold, and J. Bradbury (2008). Feed-in Tariffs and Renewable Energy in the USA - a Policy Update. North Carolina Solar Center, Heinrich Boll Foundation, and World Future Council, Raleigh, NC, USA, Berlin, Germany, and Washington, DC, USA.

Rickerson, W.H., T. Halfpenny, and S. Cohan (2009). The emergence of renewable heating and cooling policy in the United States. Policy and Society, 27(4), pp. 365-377.

Ritz, R. (2009). Carbon Leakage under Incomplete Environmental Regulation: An Industry Level Approach. Discussion Paper 461, Oxford University Department of Economics, Oxford, UK.

Rivers, N. and M. Jaccard (2006). Choice of environmental policy in the presence of learning by doing. Energy Economics, 28(2), pp. 223-242.

Rodriguez, J.M., O. Alonso, M. Duvison, and T. Domingez (2008). The integration of renewable energy and the system operation: The Special Regime Control Centre (CECRE) in Spain. In: Power and Energy Society General Meeting Conversion and Delivery of Electrical Energy in the 21st Century, IEEE, Pittsburgh, PA, USA, 20-24 July 2008, pp. 1-6, 20-24

Roffe, P., and T. Tesfachew (2002). Revisiting the technology transfer debate: lessons for the new WTO Working Group. Bridges, 6(2), February 2002, International Centre for Trade and Sustainable Development.

Rogers, E.M. (2003). Diffusion of Innovations. Free Press, New York, NY, USA.

Rogers, J., E. Simmons, I. Convery, and A. Weatherall (2008). Public perceptions of opportunities for community-based renewable energy projects. Energy Policy, pp. 4217-4226.

Rose, J., E. Webber, A. Browning, S. Chapman, G. Rose, C. Eyzaguirre, J. Keyes, K. Fox, R. Haynes, K. McAllister, M. Quinlan, and C. Murchie (2008). Freeing the Grid: Best and Worst Practices in State Net Metering Policies and Interconnection Standards. Network for New Energy Choices, New York, NY, USA.

Rosenau, J.N., and E.O. Czempiel (eds.) (1992). Governance without Government: Order and Change in World Politics. Cambridge University Press.

Rosendahl, K.E. (2004). Cost-effective environmental policy: implications of induced technological change. Journal of Environmental Economics and Management 48(3), pp. 1099-1121.

Rotmans, J., R. Kemp, and M. Van Asselt (2001). More evolution than revolution: Transition management in public policy. Foresight, 3(1), pp.15-31.

Roulleau, T., and C.R. Lloyd (2008). International policy issues regarding solar water heating, with a focus on New Zealand. Energy Policy, 36(6), pp. 1843-1857.

Sanden, B.A., and C. Azar (2005). Near-term technology policies for long-term climate targets--economy wide versus technology specific approaches. Energy Policy, 33(12), pp. 1557-1576.

Sauter, R., and J. Watson (2008). Technology Leapfrogging: A Review of the Evidence: $A$ Report for DFID. Sussex Energy Group - Science \& Technology Policy Research (SRPU), University of Sussex, Brighton, UK.

Sawin, J.L. (2001). The Role of Government in the Development and Diffusion of Renewable Energy Technologies: Wind Power in the United States, California, Denmark and Germany, 1970-2000. PhD Thesis, Fletcher School of Law and Diplomacy, Tufts University, Medford, MA, USA, 672 pp. 
Sawin, J.L. (2004). National Policy Instruments: Policy Lessons for the Advancement and Diffusion of Renewable Energy Technologies Around the World - Thematic Background Paper. International Conference for Renewable Energies. Secretariat of the International Conference for Renewable Energies. Bonn, Germany.

Sawin, J.L., and W.R. Moomaw (2009). An enduring energy future. In: State of the World 2009: Into a Warming World. W.W. Norton \& Company, Inc., Washington, DC, USA.

SCB (2009). Electricity Supply, District Heating and Supply of Natural and Gasworks Gas 2008. EN 11 SM 1002 (and older reports in that publishing series), Statistics Sweden (SCB), Örebro, Sweden.

Schaeffer, G.J., E. Alsema, A. Seebregt, L. Beurskens, H. de Moor, W. van Sark, M. Durstewitz, M. Perrin, P. Boulanger, H. Laukamp, and C. Zuccaro (2004). Learning from the Sun: Analysis of the Use of Experience Curves for Energy Policy Purposes: The Case of Photovoltaic Power. ECN-C--04-035, Energy Research Centre of the Netherlands, Petten, The Netherlands.

Schmidt, R.C., and R. Marschinski (2009). A model of technological breakthrough in the renewable energy sector. Ecological Economics, 69, 2: 435-444

Schneider, A.L., and H. Ingram (1997). Policy design for democracy. University of Kansas Press, Lawrence, KS, USA.

Schneider, M., A. Holzer, and Volker H. Hoffmann (2008). Understanding the CDM's contribution to technology transfer. Energy Policy, 36, pp. 2920- 2928.

Schock, R.N., W. Fulkerson, M.L. Brown, R.L.S. Martin, D.L. Greene, and J. Edmonds (1999). How much is energy research and development worth as insurance? Annual Review of Energy and Environment, 24, pp. 487-512.

Schultz, P.W. (2002). Knowledge, information, and household recycling: Examining the knowledge-deficit model of behavior change. In: New Tools for Environmental Protection: Education, Information, and Voluntary Measures. T. Dietz and P.C. Stern (eds.), National Academy Press, Washington, DC, pp. 67-82.

Searchinger, T., R. Heimlich, and R.A. Houghton (2008). Use of U.S. croplands for biofuels increases greenhouse gases through emissions from land use change. Science, 319, pp. 1238-1240.

SEF Alliance (2008). Public Venture Capital Study. Bloomberg New Energy Finance. Available at: www.sefalliance.org/fileadmin/media/sefalliance/docs/specialised_ research/NEF_Public_VC_Study_Final.pdf.

SEI (2009). Bilateral Finance Institutions and Climate Change - A Mapping of Climate Portfolios, Working Paper. Stockholm Environment Institute, Stockholm, Sweden.

Sensfuß, F., M. Ragwitz, and M. Genoese (2008). The merit-order effect: A detailed analysis of the price effect of renewable electricity generation on spot market prices in Germany. Energy Policy, 36, pp. 3086-3094.

Seres, S., E. Haites, and K. Murphy (2009). Analysis of technology transfer in CDM projects: An update. Energy Policy, 37, pp. 4919-4926.

SERIS (2009). Annual Report. National University of Singapore and Singapore Economic Development Board, Singapore.

Seyboth, K., L. Beurskens, O. Langniss, and R.E.H. Sims (2008). Recognising the potential for renewable energy heating and cooling. Energy Policy, 36(7), pp. 2460-2463.

Sherwood, L. (2010). U.S. Solar Market Trends 2009. Interstate Renewable Energy Council, Latham, NY, USA, 24 pp. Available at: irecusa.org/wp-content/ uploads/2010/07/IREC-Solar-Market-Trends-Report-2010_7-27-10_web1.pdf.

Shove, E. (2003). Comfort, Cleanliness, and Convenience: The Social Organisation of Normality. Berg Publishers, Oxford, UK.
Siddiqui, A.S., C. Marnay, and R.H. Wiser (2007). Real options valuation of US federal renewable energy research, development, demonstration, and deployment. Energy Policy, 35(1), pp. 265-279.

Sims, R.E.H., R.N. Schock, A. Adegbululgbe, J. Fenhann, I. Konstantinaviciute, W. Moomaw, H.B. Nimir, B. Schlamadinger, J. Torres-Martinez, C. Turner, U. Y., S.J.V. Vuori, N. Wamukonya, and X. Zhang (2007). Energy Supply. In: Climate Change 2007: Mitigation of Climate Change. Contribution of Working Group III to the Fourth Assessment Report of the Intergovernmental Panel on Climate Change. B. Metz, O.R. Davidson, P.R. Bosch, R. Dave, L.A. Meyer (eds.), Cambridge University Press, pp. 251-322.

Sinn, H.-W. (2008). Public policies against global warming: a supply-side approach. International Tax and Public Finance, 15, pp. 360-394.

Sioshansi, R and W. Short (2009). Evaluating the impacts of real-time pricing on the usage of wind generation. IEEE Transactions on Power Systems, 24(2), pp. 516-524.

SIS (2009). Renewable energy and energy efficiency in the SIS. In: SIS Leaders' Summit, Cairns, Australia, 4 August 2009, Pacific Islands Forum Smaller Island States (SIS).

Sjögren, T. (2009). Optimal Taxation and Environmental Policy in a Decentralized Economic Federation with Environmental and Labor Market Externalities. Department of Economics, Umeå University, Umeå, Sweden.

Smith, A., A. Stirling, and F. Berkhout (2005). The governance of sustainable sociotechnical transitions. Research Policy, 34(10), pp. 1491-1510.

Smitherman, G. (2009). An Act to enact the Green Energy Act, 2009 and to build a green economy, to repeal the Energy Conservation Leadership Act, 2006 and the Energy Efficiency Act and to amend other statutes. Ministry of Energy and Infrastructure, Legislative Assembly of Ontario, Canada.

Söderholm, P., K. Ek, and M. Pettersson (2007). Wind power development in Sweden: Global policies and local obstacles. Renewable and Sustainable Energy Reviews, 11(3), pp. 365-400.

Sonntag-O'Brien, V., and E. Usher (2004). Mobilising Finance for Renewable Energies. Thematic Background Paper for the International Conference for Renewable Energies. Secretariat of the International Conference for Renewable Energies, Bonn, Germany.

Sorrell, S. and J. Sijm (2003). Carbon trading in the policy mix. Oxford Review of Economic Policy, 19(3), pp. 420-437.

Sovacool, B.K. (2009a). The importance of comprehensiveness in renewable electricity and energy-efficiency policy. Energy Policy, 37(4), pp. 1529-1541.

Sovacool, B.K. (2009b). Resolving the impasse in American energy policy: The case for a transformational R\&D strategy at the U.S. Department of Energy. Renewable and Sustainable Energy Reviews, 13(2), pp. 346-361.

SOU (2005). Fjärrvärme och kraftvärme i framtiden. Statens offentliga utredningar (SOU), Betänkande av Fjärrvärmeutredningen, Stockholm, Sweden.

SPC (2010). Towards an Energy Secure Pacific: A Framework for Action on Energy Security in the Pacific. Secretariat of the Pacific Community (SPC), Noumea, New Caledonia. Available at: www.sprep.org/att/irc/ecopies/pacific_region/686.pdf.

Sperling, D., and S. Yeh (2009). Low carbon fuel standards. Issues in Science and Technology, 2, pp. 57-66.

SRU (2010). Climate-Friendly, Reliable, Affordable: 100\% Renewable Electricity Supply by 2050. German Advisory Council on the Environment (SRU), Berlin, Germany. 
St. Denis, G., and P. Parker (2009). Community energy planning in Canada: The role of renewable energy. Renewable and Sustainable Energy Reviews, 13(8), pp. 2088-2095.

Standing Committee of the National People's Congress (2005). The Renewable Energy Law of the People's Republic of China. Standing Committee of the National People's Congress (NPC) of the People's Republic of China in the 14th Session.

Stern, N. (2007). The Economics of Climate Change. Cambridge University Press, 712 pp. Available at: webarchive.nationalarchives.gov.uk/+/http://www.hm-treasury. gov.uk/sternreview_index.htm.

Stirling, A. (1994). Diversity and ignorance in electricity supply investment: Addressing the solution rather than the problem. Energy Policy, 22(3), pp. 195-216.

Scrase, I., A. Stirling, F.W. Geels, A. Smith, and P. Van Zwanenberg (2009). Transformative Innovation. A report to the Department for Environment, Food and Rural Affairs, SPRU - Science and Technology Policy Research, University of Sussex, Brighton, UK.

Stokes, D.E. (1997). Pasteur's Quadrant: Basic Science and Technological Innovation. Brookings Institution Press, Washington, DC, USA, $180 \mathrm{pp}$.

Strategic Energy Technology Plan (2007). A European Strategic Energy Technology Plan - Towards a Low Carbon Future. European Commission, Brussels, Belgium.

Strbac, P.C. (2007). Transmission Investment, Access and Pricing in Systems with Wind Generation. DTI Centre for Distributed Generation and Sustainable Electrical Energy Draft Summary Report. Centre for Sustainable Electricity \& Distributed Generation, UK.

Sugiyama, K. (2008). Recall of the first oil shock (Daiitiji oil-shock wo kaiko suru). Quarterly Review of International Trade and Investment (Kikan Kokusai-boeki to toshi), No. 71. Institute for International Trade and Investment (in Japanese). Available at: www.iti.or.jp/kikan71/71echo.pdf.

Sussman, E. (2008). Reshaping municipal and county laws to foster green building, energy efficiency, and renewable energy, N.Y.U. Environmental Law Journal, 15(1) pp. 1-44.

Suurs, R.A.A., and M.P. Hekkert (2009). Cumulative causation in the formation of a technological innovation system: The case of biofuels in the Netherlands. Technological Forecasting \& Social Change, 76(8), pp. 1003-1020.

Swedish District Heating Association (2001). Fjärrvärme 2000; fakta och statistik. Swedish District Heating Association, Stockholm, Sweden.

Swedish Energy Agency (2009a). Energy statistics for dwellings and non-residential premises 2008. ES 2009:10, Swedish Energy Agency, Eskilstuna, Sweden.

Swedish Energy Agency (2009b). Facts and figures - Energy in Sweden 2009. ET2009:29, Swedish Energy Agency, Eskilstuna, Sweden.

Swedish Energy Agency (2010a). The Electricity Certificate System 2010 (in Swedish). ET2010:25, Swedish Energy Agency, Eskilstuna, Sweden.

Swedish Energy Agency (2010b). Facts and figures - Energy in Sweden 2010. ET2010:46, Swedish Energy Agency, Eskilstuna, Sweden.

Takahashi, K. (1989). Sunshine Project in Japan - Solar photovoltaic program. Solar Cells, 26, pp. 87-96.

Teske, S., T. Pregger, S. Simon, T. Naegler, W. Graus, and C. Lins (2010). Energy [R]evolution 2010-a sustainable world energy outlook. Energy Efficiency, doi:10.1007/s12053-010-9098-y.

Thai Ministry of Energy (2003). Energy Strategy for Competitiveness. Thai Ministry of Energy. Bangkok, Thailand.
Thelen, K. (1999). Historical institutionalism in comparative politics. Annual Review of Political Science, 2, pp. 369-404.

Toke, D. (2007). Renewable financial support systems and cost-effectiveness. Journal of Cleaner Production, 15(3), pp. 280-287.

Toke, D., S. Breukers, and M. Wolsink (2008). Wind power deployment outcomes: How can we count for the differences? Renewable and Sustainable Energy Reviews, 12(4), pp. 1129-1147.

Tol, R.S.J. (2009). The economic effects of climate change. Journal of Economic Perspectives, 23(2), pp. 29-51.

Tongsopit, J. (2010). Thailand's VSPP Program. Technical Visit of the Delegation from the United Republic of Tanzania to Thailand regarding Thailand's Very Small Power Producer (VSPP) program. Bankgok, Thailand.

Tsoutsos, T., E. Papadopoulou, A. Katsiri, and A.M. Papadopoulos (2008). Supporting schemes for renewable energy sources and their impact on reducing the emissions of greenhouse gases in Greece. Renewable and Sustainable Energy Reviews, 12, pp. 1767-1788.

Twiddell, J., and T. Weir (2006). Renewable Energy Resources. 2nd ed. Taylor \& Francis, Oxford, UK and New York, NY, USA.

Ulph, A., and D. Ulph (2009). Optimal Climate Change Policies When Governments Cannot Commit. Discussion Paper Series, Department of Economics, University of St. Andrews, Fife, Scotland. Available at: www.st-andrews.ac.uk/academic/economics/papers/dp0909.pdf.

UNCTAD (2010a). Report of the Expert Meeting on Green and Renewable Technologies as Energy Solutions for Rural Development. TD/B/C.I/EM.3/3. United Nations Conference on Trade and Development, Geneva, Switzerland.

UNCTAD (2010b). Report of the Secretary general on New and emerging technologies: renewable energy for development. E/CN.16/2010/4. United Nations Conference on Trade and Development, Geneva, Switzerland.

UNCTAD (2010c). World Investment Report. United Nations Conference on Trade and Development, Geneva, Switzerland.

UNDP and AEPC (2010). Capacity development in Scaling up Decentralized Energy Access Programmes. Lessons from Nepal on its role, costs and financing. Alternative Energy Promotion Centre (AEPC), United Nations Development Programme (UNDP), New York, NY, USA.

UNEP (2005). Public Finance Mechanisms to Catalyse Sustainable Energy Sector Growth. United Nations Environment Programme (UNEP), Paris, France. Available at: www.uneptie.org/energy/activities/sefi/pdf/SEFI_PublicFinanceReport.pdf.

UNEP (2008). Public Finance Mechanisms to Mobilise Investment in Climate Change Mitigation: An overview of mechanisms being used today to help scale up the climate mitigation markets, with a particular focus on the clean energy sector. United Nations Environment Programme (UNEP), Paris, France. Available at: www.unep.fr/energy/finance/documents/pdf/UNEP_PFM\%20_Advance_Draft. pdf.

UNEP and BNEF (2010) Global Trends in Sustainable Energy Investment 2010: Analysis of Trends and Issues in the Financing of Renewable Energy and Energy Efficiency. United Nations Environment Programme (UNEP), Paris, France and Bloomberg New Energy Finance (BNEF). Available at: bnef.com/WhitePapers/ download/30.

UNEP, EPO, and ICTSD (2010). Patent and Clean Energy, Bridging the Gap between Evidence and Policy. United Nations Environment Programme (UNEP), Paris, France, European Patent Office and International Centre for Trade and Sustainable Development, Geneva, Switzerland. 
UNEP and NEF (2008). Global Trends in Sustainable Energy Investment 2008: Analysis of Trends and Issues in the Financing of Renewable Energy and Energy Efficiency. Division of Technology, Industry and Economics, United Nations Environment Programme (UNEP) Sustainable Energy Finance Initiative and New Energy Finance (NEF) Limited, Paris, France.

UNEP and NEF (2009). Global Trends in Sustainable Energy Investment 2009: Analysis of Trends and Issues in the Financing of Renewable Energy and Energy Efficiency. Division of Technology, Industry and Economics, United Nations Environment Programme (UNEP) Sustainable Energy Finance Initiative and New Energy Finance (NEF) Limited, Paris, France.

UNEP Finance Initiative (2009). Financing a Global Deal on Climate Change: $A$ Green Paper produced by the UNEP Finance Initiative Climate Change Working Group. United Nations Environment Programme (UNEP), Geneva, Switzerland.

UNFCCC (1998). Technical Paper on Terms of Transfer of Technology and know-how. FCCC/TP/1998/1. United Nations Framework Convention on Climate Change (UNFCCC), Bonn, Germany. Available at: unfccc.int/resource/docs/tp/tp0198.pdf.

UNFCCC (2007a). Analysis of technology transfer in CDM projects. United Nations Framework Convention on Climate Change (UNFCCC), Bonn, Germany.

UNFCCC (2007b). Investment and financial flows relevant to the development of an effective and appropriate international response to Climate Change. United Nations Framework Convention on Climate Change (UNFCCC), Bonn, Germany.

UNFCCC (2008). A summary of submissions to the Ad hoc Working Group on Longterm Cooperative Action. FCCC/AWGLCA/2008/16, United Nations Framework Convention on Climate Change (UNFCCC), Bonn, Germany.

UNFCCC (2010). Analysis of the contribution of the clean development mechanism to technology. United Nations Framework Convention on Climate Change (UNFCCC), Bonn, Germany.

Unger, T., and E.O. Ahlgren (2005). Impacts of a common green certificate market on electricity and $\mathrm{CO}_{2}$-emission markets in the Nordic countries. Energy Policy, 33(16), pp. 2152-2163.

UNICA (2010). Quotes and Stats. Ethanol production. Brazilian Sugarcane Industry Association (UNICA), Sao Paulo, Brazil. Available at: english.unica.com.br/ dadosCotacao/estatistica/.

Unruh, G.C. (2000). Understanding carbon lock-in. Energy Policy, 28(12), pp. 817-830.

Upreti, B.R., and D. Van Der Horst (2004). National renewable energy policy and local opposition in the UK: The failed development of a biomass electricity plant. Biomass and Bioenergy, 26(1), pp. 61-69.

Urmee, T., D. Harries, and A. Schlapfer (2009). Issues related to rural electrification using renewable energy in developing countries of Asia and Pacific. Renewable Energy, 34(2), pp. 354-357.

US Congress (2004). American Jobs Creation Act of 2004. Congress, (2004). In: GovTrack.us (database of federal legislation). Available at: www.govtrack.us/ congress/bill.xpd?bill=h108-4520

US Department of the Interior (2008). Energy Corridors Designated in Eleven Western States. Press Release, U.S. Department of the Interior. Washington, DC, USA.

US DOE (2008a). Green Power Markets: Net Metering Policies. Office of Energy Efficiency and Renewable Energy, U.S. Department of Energy, Washington, DC, USA.

US DOE (2008b). Renewable Energy Requirement Guidance for EPACT 2005 and Executive Order 13423. Office of Energy Efficiency and Renewable Energy Federal Energy Management Program, U.S. Department of Energy, Washington, DC, USA.
US DOE (2009). Technology Pathway Partnerships. U.S. Department of Energy, Washington, DC, USA. Available at: www1.eere.energy.gov/solar/technology pathway_partnerships.html.

USDA/FAS (2009a). Guatemala Biofuels Annual. U.S. Department of Agriculture Foreign Agricultural Service, Washington, DC, USA. Available at: gain.fas. usda.gov/Recent\%20GAIN\%20Publications/General\%20Report_Guatemala_ Guatemala_5-26-2009.pdf.

USDA/FAS (2009b). Peru Biofuels Annual. Lima, Peru. U.S. Department of Agriculture Foreign Agricultural Service, Washington, DC, USA. Available at: gain.fas.usda. gov/Recent\%20GAIN\%20Publications/Biofuels\%20Annual_Lima_Peru_8-31. 2010.pdf.

USEPA (2010a). Green Power Partnership. U.S. Environmental Protection Agency. Washington, DC

USEPA (2010b). Regulatory Announcement - EPA Finalizes Regulations for the National Renewable Fuel Standard Program for 2010 and Beyond. EPA420-F-10-007, U.S. Environmental Protection Agency, Washington, DC, USA. Available at: www.epa.gov/oms/renewablefuels/420f10007.pdf.

van Alphen, K., H.S. Kunz, and M.P. Hekkert (2008). Policy measures to promote the widespread utilization of renewable energy technologies for electricity generation in the Maldives. Renewable and Sustainable Energy Reviews, 12(7), pp. 1959-1973.

van den Bergh, J.C.J.M., and F.R. Bruinsma (2008). Managing the Transition to Renewable Energy: Theory and Practice from Local, Regional and Macro Perspectives. Edward Elgar Publishing Limited, Cheltenham, UK.

van der Linden, N.H., M.A. Uyterlinde, C. Vrolijk, L.J. Nilsson, J. Khan, K. Astrand, K. Ericsson, and R. Wiser (2005). Review of International Experience with Renewable Energy Obligation Support Mechanisms. ECN-C-05-025, Energy Research Centre of the Netherlands. Petten, The Netherlands.

van der Ploeg, F. and C.A.Withagen. (2010). Is There Really a Green Paradox? CESifo Working Paper 2963

van Dijk, A.L., L.W.M. Beurskens, M.G. Boots, M.B.T. Kaal, T.J. de Lange, E.J.W. van Sambeek and M.A. Uyterlinde (2003). Renewable Energy Policies and Market Developments. ECN, Amsterdam, the Netherlands.

Verbong, G., and F. Geels (2007). The ongoing energy transition: Lessons from a socio-technical, multi-level analysis of the Dutch electricity system (1960-2004). Energy Policy, 35 (2), 1025-1037

Verbruggen, A. (2009). Performance evaluation of renewable energy support policies, applied on Flanders' tradable certificates system. Energy Policy, 37(4), pp. 1385-1394.

Verbruggen, A. (2010). Preparing the design of robust policy architectures. International Environmental Agreements: Politics, Law and Economics, doi:10.1007/s10784-010-9130-x.

Verbruggen, A., and V. Lauber (2009). Basic concepts for designing renewable electricity support aiming at a full-scale transition by 2050. Energy Policy, 37(12), pp. 5732-5743.

Vitousek, P.M. H.A. Mooney, J. Lubchenco, and J.M. Melillo (1997). Human domination of Earth's ecosystems. Science, 277(5325), pp. 494-499.

Von Weizsäcker, E., A.B. Lovins, and L.H. Lovins (1998). Factor Four: Doubling Wealth, Halving Resource Use. Earthscan, London, UK.

Voß, J.-P., A. Smith, and J. Grin (2009). Designing long-term policy: rethinking transition management. Policy Sciences, 42, pp. 275-302. 
Vrolijk, C., J. Green, V. Bürger, C. Timpe, N. van der Linden, J. Jansen, M. Uyterlinde, C. García Barquero, P. Yerro, and F. Rivero (2004). Renewable Energy Guarantees of Origin: implementation, interaction and utilisation: Summary of the RE-GO project. IT Power, Madrid, Spain.

Wagner, A. (1999). Wind power on "Liberalised Markets": Maximum Market Penetration with Minimum Regulation. In: European Wind Energy Conference, Nice, France, 1-5 March 1999. Available at: www.oregon.gov/ENERGY/RENEW/ Wind/OWWG/docs/FGWWagnerWindpoweronLiberalisedMarkets 1999. pdf?ga=t.

Walker, G. (2008). What are the barriers and incentives for community-owned means of energy production and use? Energy Policy, 36(12), pp. 4401-4405.

Wallace, W.L., L. Jingming, and G. Shangbin (1998). The Use of Photovoltaics for Rural Electrification in Northwestern China. NREL/CP-520-23920, National Renewable Energy Laboratory and Chinese Ministry of Agriculture, Golden, $\mathrm{CO}$, USA and Beijing, China.

Walter, A. (2006). Is Brazilian Biofuels Experience a Model for Other Developing Countries? Entwicklung \& Ländlicher Raum, 40, pp. 22-24.

Wang, B. (2010). Can CDM bring technology transfer to China? An empirical study of technology transfer in China's CDM projects. Energy Policy, 38, pp. 2572-2585.

Wang, F. and S. HaitaoYin (2010). China's renewable energy policy: Commitments and challenges. Energy Policy, 38, pp. 1872-1878.

Wang, Q. (2010). Effective policies for renewable energy - the example of China's wind power-lessons for China's photovoltaic power. Renewable and Sustainable Energy Reviews, 14, pp. 702-712.

Wårell, L. and T. Sundqvist (2009). Market Opening in Local District Heating Networks. Lund University, Lund, Sweden.

Warren, C.R., and M. McFadyen (2010). Does community ownership affect public attitudes to wind energy? A case study from south-west Scotland. Land Use Policy, 27(2), pp. 204-213.

Watanabe, C., K. Wakabayashi, and T. Miyazawa (2000). Industrial dynamism and the creation of a 'Virtuous cycle' between R\&D, market growth and price reduction: The case of photovoltaic power generation (PV) development in Japan. Technovation, 20(6), pp. 299-312.

Watanabe, C., M. Kishioka, and A. Nagamatsu (2004). Effect and limit of the government role in spurring technology spillover - a case of R\&D consortia by the Japanese government. Technovation, 24(5), pp. 403-420.

Weiss, C., and W.B. Bonvillian (2009). Stimulating a revolution in sustainable energy technology. Environment, 51(4), pp. 10-20.

West, J., I. Bailey, and M. Winter (2010). Renewable energy policy and public perceptions of renewable energy: A cultural theory approach. Energy Policy, 38(10), pp. 5739-5748.

Weyant, J.P. (2010). Accelerating the development and diffusion of new energy technologies: Beyond the "valley of death". Energy Economics, doi:10.1016/j. eneco.2010.08.008.

Wiesenthal, T., G. Leduc, P. Christidis, B. Schade, L. Pelkmans, L. Govaerts, and P. Georgopoulos (2009). Biofuel support policies in Europe: Lessons learnt for the long way ahead. Renewable and Sustainable Energy Reviews, 13(4), pp. 789-800.

Wilkins, G. (2002). Technology Transfer for Renewable Energy - Overcoming Barriers in Developing Countries. Royal Institute of International Affairs/Chatham House, London, UK.

Wilson, C. (2008). Social norms and policies to promote energy efficiency in the home. Environmental Law Reporter, 38, pp. 10882-10888.
Wiser, R., and G. Barbose (2008). Renewables Portfolio Standards in the United States: A Status Report with Data Through 2007. LBNL-154E, Lawrence Berkeley National Laboratory, Berkeley, CA, USA.

Wiser, R., and M. Bolinger (2009). 2008 Wind Technologies Market Report. U.S. Department of Energy, Washington, DC, USA. Available at: eetd.Ibl.gov/ea/emp/ reports/2008-wind-technologies.pdf.

Wiser, R. and M. Bolinger (2010). 2009 Wind Technologies Market Report. LBNL3716E. U.S. Department of Energy, Washington, DC, USA. Available at: eetd.Ibl. gov/ea/emp/reports/lbnl-3716e.pdf.

Wiser, R., and S. Pickle (1997). Financing Investments in Renewable Energy: The Role of Policy Design and Restructuring. LBNL-39826, Lawrence Berkeley National Laboratory, Berkeley, CA, USA.

Wiser, R., and S. Pickle (2000). Renewable Energy Policy Options for China: Feed In Laws and Renewable Portfolio Standards Compared. Center for Resource Solutions, San Francisco, CA, USA.

Wiser, R., K. Porter, and R. Grace (2005). Evaluating experience with renewables portfolio standards in the United States. Mitigation and Adaptation Strategies for Global Change, 10, pp. 237-263.

Wiser, R., M. Bolinger and G. Barbose (2007). Using the Federal Production Tax Credit to build a durable market for wind power in the United States, The Electricity Journal, 20(9), pp. 77-88.

Wiser, R., G. Barbose, and E. Holt (2010). Supporting Solar Power in Renewables Portfolio Standards: Experience from the United States. Lawrence Berkeley National Laboratory, Berkeley, CA, USA.

Wolsink, M. (2000). Wind power and the NIMBY-myth: institutional capacity and the limited significance of public support. Renewable Energy, 21(1), pp. 49-64.

Worrell, E., and W. Graus (2005). Tax and Fiscal Policies for Promotion of Industrial Energy Efficiency: A Survey of International Experience. Ernest Orlando Lawrence Berkeley National Laboratory, Berkeley, CA, USA.

Wüstenhagen, R., and M. Bilharz (2006). Green energy market development in Germany: effective public policy and emerging customer demand. Energy Policy, 34(13), pp. 1681-1696.

Xiao, C., H. Luo, R. Tang, and H. Zhong (2004). Solar thermal utilization in China. Renewable Energy, 29(9), pp. 1549-1556.

Yang, M., W. Blyth, R. Bradley, D. Bunn, C. Clarke, and T. Wilson (2008). Evaluating the power investment options with uncertainty in climate policy. Energy Economics, 30(4), pp. 1933-1950.

Yoohoon, A. (2010). Low Carbon Development Path for Asia and the Pacific: Challenges and Opportunities to the Energy Sector. ESCAP Energy Resources Development Series ST/ESCAP/2589, Beijing, China.

Yu, J., F. Ji, L. Zhang, and Y. Chen (2009). An over painted oriental arts: Evaluation of the development of Chinese renewable energy market using wind power market as model. Energy Policy, 37, pp. 5221-5225.

Zahnd, A., and H.M. Kimber (2009). Benefits from a renewable energy village electrification system. Renewable Energy, 34(2), pp. 362-368.

Zhang, X., W. Ruoshui, H. Molin, and E. Martinot (2010). A study of the role played by renewable energies in China's sustainable energy supply. Energy \& Environment, 35(11), pp. 4392-4399.

Zhao, Z., J. Zuo, L.-L. Fan, and G. Zillante (2011). Impacts of renewable energy regulations on the structure of power generation in China - A critical analysis. Renewable Energy, 36, pp. 24-30. 